MAGALY MARÇULA

\title{
Avaliação prognóstica em pacientes com insuficiência cardíaca com o emprego de redes neurais artificiais
}

Tese apresentada à Faculdade de Medicina da Universidade de São Paulo para obtenção do título de Doutor em Ciências

Programa de Cardiologia

Orientador Prof. Dr. Alfredo Jose Mansur

São Paulo

2018 


\section{Dados Internacionais de Catalogação na Publicação (CIP)}

Preparada pela Biblioteca da

Faculdade de Medicina da Universidade de São Paulo

Creprodução autorizada pelo autor

Marçula, Magaly

Avaliação prognóstica em pacientes com

insuficiência cardíaca com o emprego de redes

neurais artificiais / Magaly Marçula. -- São Paulo, 2018 .

Tese (doutorado)--Faculdade de Medicina da

Universidade de São Paulo.

Programa de Cardiologia.

Orientador: Alfredo José Mansur.

Descritores: 1.Insuficiência cardíaca

2. Cardiomiopatias 3.Assistência ambulatorial

4.Análise de sobrevivência 5.Rede neural

6. Prognóstico

$\mathrm{USP} / \mathrm{FM} / \mathrm{DBD}-496 / 18$

Responsável: Erinalva da Conceição Batista, CRB-8 6755 
Dedicatória 
À minha irmã Adriana e ao meu irmão Arnaldo gratidão e reconhecimento que excelem a fraternidade 
Agradecimentos 
Ao Prof. Dr. Antonio Carlos Pereira Barretto que nos iniciou para a investigação clínica de modo inspirador estimulando-nos incessantemente no desenvolvimento do presente trabalho.

À Comissão de Pós-Graduação da Disciplina de Cardiologia que amparou a iniciativa para a conclusão de um trabalho desenvolvido no decorrer de, pelo menos, treze anos, ora apresentado na forma de tese.

Ao orientador Prof. Dr. Alfredo José Mansur, pela orientação nas diferentes etapas do trabalho e nas produtivas interações interdisciplinares no decorrer da investigação.

Ao Centro de Estatística Aplicada do Instituto de Matemática e Estatística da Universidade de São Paulo, nas pessoas do Prof. Dr. Antonio Carlos Pedroso de Lima, Profa. Dra. Lucia Pereira Barroso, Profa. Dra. Gisela Tunes da Silva, pelo convívio competente, dedicado e edificante durante todas as etapas deste trabalho. Agradecimento especial ao Dr. Tiago Mendonça dos Santos, pelo auxílio no cômputo da função de perda.

À Fundação Sistema Estadual de Análise de Dados (SEADE) nas pessoas da Dra. Bernadette Cunha Waldvogel, Monica La Porte Teixeira e Lilian Cristina Correia Morais, pelo inestimável auxílio no estudo de sobrevida;

À empresa Arion Tecnologia Ltda, na pessoa de seu Diretor de Pesquisa e Desenvolvimento Arnaldo Marçula Jr. e da Diretora Administrativa Adriana Marçula, mestre em Físico-química pelo Instituto de Química da Universidade de São Paulo, pelo apoio logístico e liberação de horas de trabalho dedicadas à presente pesquisa.

Ao Prof. Dr. Marco Antonio Gutierrez, Diretor da Divisão de Informática do Instituto do Coração, pelas contribuições metodológicas que auxiliaram a consolidar a aplicação da rede neural. 
Aos médicos da Unidade Clínica de Ambulatório Geral do Instituto do Coração do HC FMUSP, pelo convívio em ambiente cientificamente estimulante, voltado para o cultivo das dimensões de ensino e pesquisa a partir da responsabilidade institucional de assistência aos pacientes.

À biomédica Sra. Marcia Nunes Figueira e ao engenheiro eletrotécnico Marcelo Marçula, pela revisão e edição dos gráficos apresentados neste trabalho.

Ao Serviço de Arquivo Médico e Estatístico, na pessoa do Sr. Wallace Fernandes, colegas e colaboradores, pelo dedicado e competente auxílio na consulta a dados de arquivo.

À Secretaria da Comissão de Pós-Graduação na pessoa da Sra. Neusa Rodrigues Dini e sua equipe de assessoras, pelo empenho receptivo nos encaminhamentos necessários a um projeto desta natureza.

À Profa. Marise Cukier, pela revisão e correção gramatical deste trabalho.

À Sra. Sandra Miranda Souza, assistente administrativa da Unidade Clínica de Ambulatório Geral do Instituto do Coração do HC FMUSP, pela devotada, eficiente e cordial contribuição cotidiana durante o desenvolvimento do trabalho. 
Epígrafe 


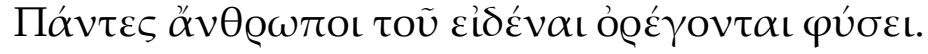

Todos os homens aspiram por natureza ao conhecimento.

(Aristóteles, Metafísica)

Alles Interesse meiner Vernunft (das spekulative sowohl, als das praktische) vereinigt sich in folgenden drei Fragen:

1. Was kann ich wissen? 2. Was soll ich tun? 3. Was darf ich hoffen?

Todo o interesse da minha razão (tanto especulativa como prática) concentrase nas seguintes três interrogações

1. Que posso saber? 2. Que devo fazer? 3. Que me é permitido esperar? (Emanuel Kant, Crítica da Razão Pura)

This warp seemed necessity; and here, thought I, with my own hand I ply my own shuttle and weave my own destiny into these unalterable threads.

A urdidura parecia a Necessidade; e aqui, pensei, com as minhas próprias mãos guio a lançadeira e teço meu próprio destino nestes fios inalteráveis. 
Normatização adotada 
Esta tese está de acordo com as seguintes normas, em vigor no momento de sua publicação:

Referências: adaptado de International Committee of Medical Journals Editors (Vancouver).

Universidade de São Paulo. Faculdade de Medicina. Divisão de Biblioteca e Documentação. Guia de apresentação de dissertações, teses e monografias. Elaborado por Anneliese Carneiro da Cunha, Maria Julia de A.L.Freddi, Maria F.Crestana, Marinalva de Souza Aragão, Suely Campos Cardoso, Valéria Vilhena. $3^{\underline{a}}$ ed. São Paulo: Divisão de Biblioteca e Documentação; 2011.

Abreviatura dos títulos e periódicos de acordo com List of Journals Indexed in Index Medicus. 
Sumário 


\section{Lista de figuras}

\section{Lista de tabelas}

\section{Resumo}

\section{Abstract}

Objetivos primários.

\section{8}

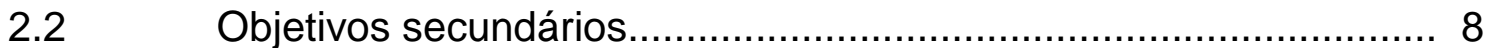

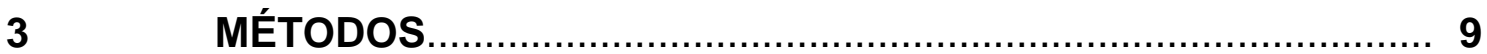

3.1 Delineamento do estudo.......................................................... 10

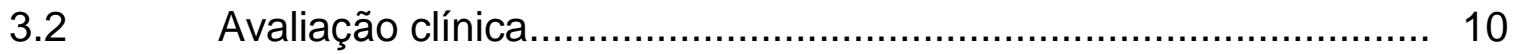

3.3 Critérios diagnósticos............................................................ 11

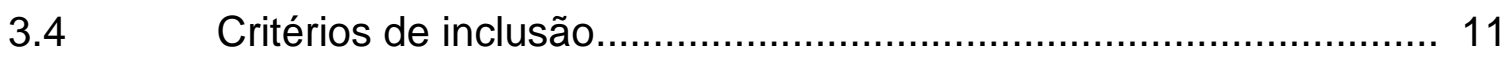

3.5 Critérios de exclusão............................................................. 12

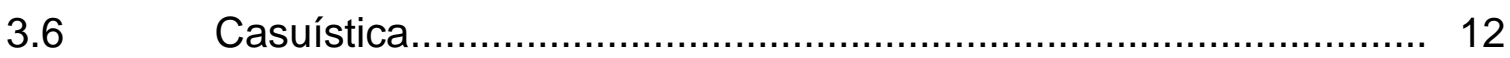

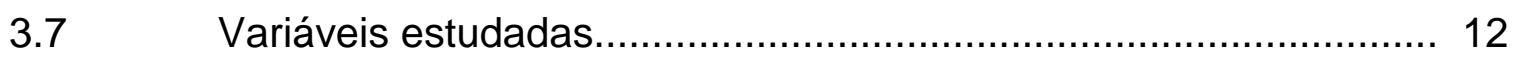

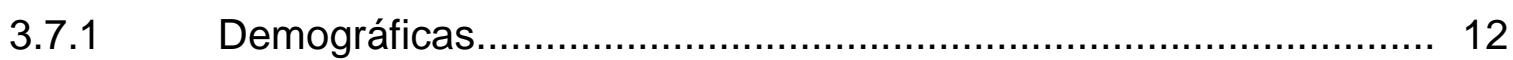

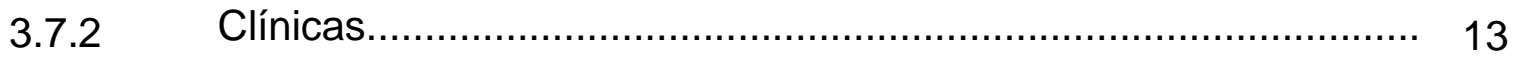

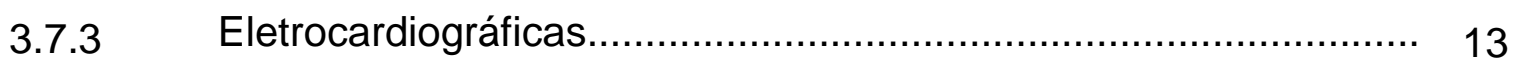

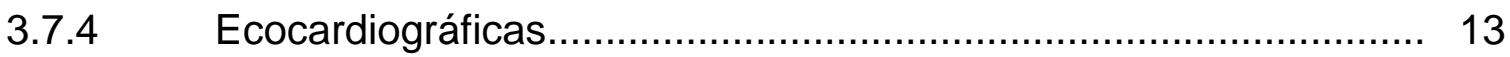

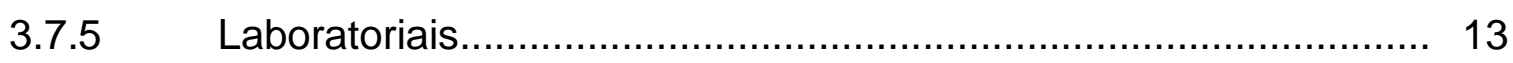

3.7.6 Medicamentos em uso na consulta inicial..................................... 14

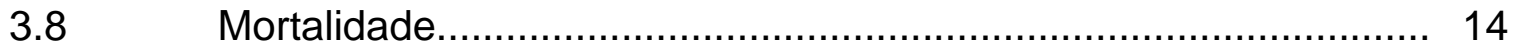

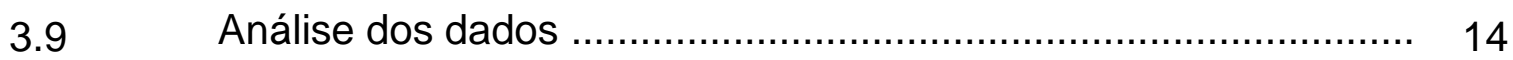

3.9.1 Análise estatística...................................................................... 15

3.9.1.1 Análise descritiva e exploratória................................................ 15

3.9.1.2 Análise inferencial.......................................................... 15

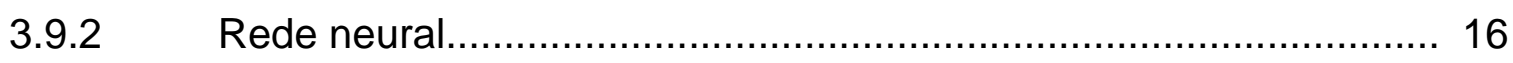

3.9.2.1 Escolha da arquitetura da rede neural ...................................... 17

3.9.2.2 Aprendizado-treinamento da rede neural .................................... 19

3.9.2.3 Avaliação dos melhores modelos de rede neural.......................... 21

3.10 Aspectos éticos............................................................. 22

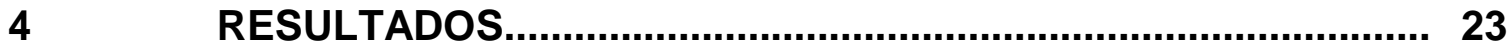

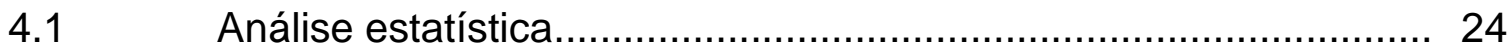

4.1.1 Análise descritiva e exploratória.............................................. 24

4.1.2 Análise inferencial .......................................................... 27

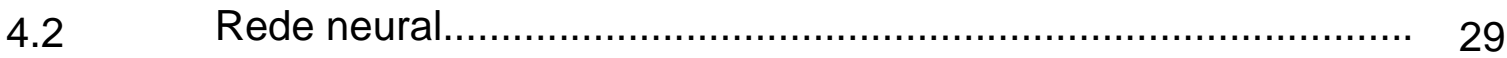


4.2.1 Escolha da arquitetura da rede neural........................................ 29

4.2.2 Aprendizado-treinamento da rede neural .................................... 29

4.2.2.1 Amostragem aleatória......................................................... 30

4.2.2.2 Fases do estudo da casuística................................................. 30

4.2.2.2.1 Primeira fase - aprendizado-treinamento da rede neural............. 30

4.2.2.2.2 Segunda fase - avaliação e aplicação da rede neural para estimar a sobrevida

4.2.2.2.3 Terceira fase - comparação dos modelos de dados da rede neural.

4.2.2.2.4 Quarta fase - reensaios dos modelos de dados da rede neural.. 35

4.2.2.2.5 Quinta fase - comparação dos modelos de previsão da rede neural.

4.3 Avaliação dos melhores modelos da rede neural

4.3.1 Sensibilidade, especificidade, acurácia, valor preditivo positivo, valor preditivo negativo da rede neural.

4.3.2 Função de perda da rede neural.

DISCUSSÃO

Considerações sobre as características clínicas dos pacientes....

Sexo.

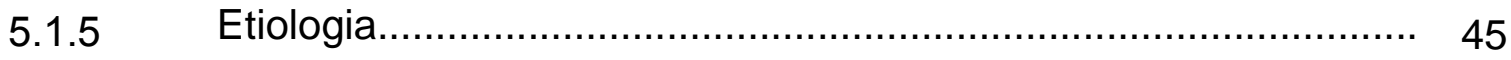

5.1.6 Índice de massa corpórea................................................... 46

5.1.7 Frequência cardíaca............................................................ 46

5.1.8 Pressão arterial sistólica e diastólica......................................... 46

5.1.9 Classe funcional............................................................... 47

5.1.10 Tempo decorrido até o desfecho............................................... 47

5.1.11 Variáveis ecocardiográficas.................................................... 48

5.1.12 Variáveis laboratoriais.......................................................... 49

5.1.13 Medicamentos em uso....................................................... 50

5.1.14 Mortalidade.................................................................... 51

5.2 Considerações sobre a análise estatística................................... 51

5.3 Considerações sobre as estimativas feitas pelo emprego da rede neural. 
5.3.1 Amostras aleatórias 56

5.3.2 Data do início dos sintomas............................................... 57

5.3.3 Tempos de evolução.................................................. 58

5.3.4 Variáveis faltantes............................................................. 60

5.3.5 Variáveis selecionadas pelo modelo de Cox versus variáveis em geral.

5.3.6 Funções de transferência

5.3.7 Treinamento excessivo (overfitting)

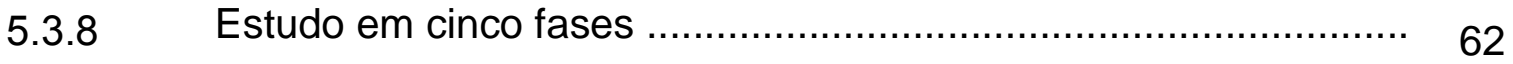

5.4 Avaliação dos melhores modelos de rede neural........................ 62

5.4.1 Sensibilidade, especificidade, valor preditivo positivo e valor preditivo negativo.

5.4.2 Função de perda......................................................... 64

5.4.3 Sensibilidade e especificidade versus função de perda............... 65

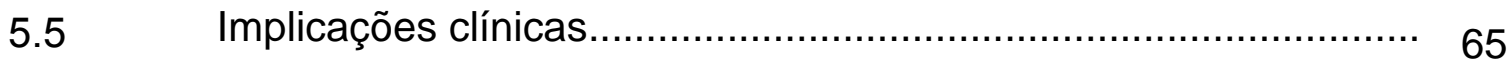

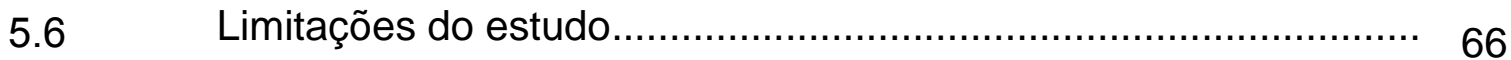

$6 \quad$ CONCLUSÔES.................................................................... 67

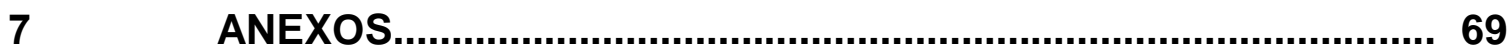

$8 \quad$ REFERÊNCIAS BIBLIOGRÁFICAS........................................ 153 
Listas 
Figura 1 Representação esquemática do delineamento do estudo....... 70

Figura 2 Arquitetura da rede neural perceptron múltiplas camadas...... 71

Figura 2a Representação do modelo não linear de um neurônio artificial...................................................................... 72

Figura 2b llustração das direções de propagação do sinal e do erro da informação.

Figura 3 Representação gráfica da função tangente hiperbólica e da função zero based log sigmoid.

Figura 4 Representação esquemática das fases da rede neural........... 74

Figura 5 Probabilidade de sobrevida estimada (Kaplan-Meier) geral

Figura 6 Probabilidade de sobrevida estimada (Kaplan-Meier) quanto à etiologia da insuficiência cardíaca.

Figura 7 Probabilidade de sobrevida estimada (Kaplan-Meier) quanto à idade.

Figura 8 Probabilidade de sobrevida estimada (Kaplan-Meier) quanto ao sexo.

Figura 9 Probabilidade de sobrevida estimada (Kaplan-Meier) quanto à etnia.

Figura 10 Probabilidade de sobrevida estimada (Kaplan-Meier) quanto ao peso.

Figura 11 Probabilidade de sobrevida estimada (Kaplan-Meier) quanto à altura.

Figura 12 Probabilidade de sobrevida estimada (Kaplan-Meier) quanto ao índice de massa corpórea.

Figura 13 Probabilidade de sobrevida estimada (Kaplan-Meier) quanto à pressão arterial sistólica.

Figura 14 Probabilidade de sobrevida estimada (Kaplan-Meier) quanto à pressão arterial diastólica.

Figura 15 Probabilidade de sobrevida estimada (Kaplan-Meier) quanto à classe funcional

Figura 16 Probabilidade de sobrevida estimada (Kaplan-Meier) quanto 
à frequência cardíaca.

Figura 17 Probabilidade de sobrevida estimada (Kaplan-Meier) quanto ao início dos sintomas.

Figura 18 Probabilidade de sobrevida estimada (Kaplan-Meier) quanto ao antecedente de hipertensão arterial.

Figura 19 Probabilidade de sobrevida estimada (Kaplan-Meier) quanto ao antecedente de tabagismo.

Figura 20 Probabilidade de sobrevida estimada (Kaplan-Meier) quanto ao antecedente de diabetes

Figura 21 Probabilidade de sobrevida estimada (Kaplan-Meier) quanto ao antecedente de etilismo.

Figura 22 Probabilidade de sobrevida estimada (Kaplan-Meier) quanto ao diâmetro do átrio esquerdo no ecocardiograma.

Figura 23 Probabilidade de sobrevida estimada (Kaplan-Meier) quanto ao diâmetro diastólico do ventrículo esquerdo no ecocardiograma.

Figura 24 Probabilidade de sobrevida estimada (Kaplan-Meier) quanto ao diâmetro sistólico do ventrículo esquerdo no ecocardiograma.

Figura 25 Probabilidade de sobrevida estimada (Kaplan-Meier) quanto à fração de ejeção do ventrículo esquerdo no ecocardiograma

Figura 26 Probabilidade de sobrevida estimada (Kaplan-Meier) quanto à espessura diastólica do septo interventricular no ecocardiograma

Figura 27 Probabilidade de sobrevida estimada (Kaplan-Meier) quanto à espessura diastólica da parede posterior do ventrículo esquerdo no ecocardiograma.

Figura 28 Probabilidade de sobrevida estimada (Kaplan-Meier) quanto ao ritmo cardíaco.

Figura 29 Probabilidade de sobrevida estimada (Kaplan-Meier) quanto a taxa de hemoglobina.

Figura 30 Probabilidade de sobrevida estimada (Kaplan-Meier) quanto à glicemia de jejum 
Figura 31 Probabilidade de sobrevida estimada (Kaplan-Meier) quanto à taxa de creatinina sérica.

Figura 32 Probabilidade de sobrevida estimada (Kaplan-Meier) quanto à taxa de sódio sérico.

Figura 33 Probabilidade de sobrevida estimada (Kaplan-Meier) quanto à taxa de potássio sérico.

Figura 34 Probabilidade de sobrevida estimada (Kaplan-Meier) quanto à taxa de colesterol total.

Figura 35 Probabilidade de sobrevida estimada (Kaplan-Meier) quanto à taxa de HDL- colesterol.

Figura 36 Probabilidade de sobrevida estimada (Kaplan-Meier) quanto à taxa de LDL-colesterol.

Figura 37 Probabilidade de sobrevida estimada (Kaplan-Meier) quanto à taxa de triglicérides.

Figura 38 Probabilidade de sobrevida estimada (Kaplan-Meier) quanto à taxa de leucócitos.

Figura 39 Probabilidade de sobrevida estimada (Kaplan-Meier) quanto à taxa de linfócitos.

Figura 40 Probabilidade de sobrevida estimada (Kaplan-Meier) quanto ao uso dos inibidores da enzima conversora da angiotensina e bloqueadores dos receptores da angiotensina II.

Figura 41 Probabilidade de sobrevida estimada (Kaplan-Meier) quanto ao uso de bloqueadores adrenérgicos.

Figura 42 Probabilidade de sobrevida estimada (Kaplan-Meier) quanto ao uso de diuréticos.

Figura 43 Probabilidade de sobrevida estimada (Kaplan-Meier) quanto ao uso de espironolactona.

Figura 44 Probabilidade de sobrevida estimada (Kaplan-Meier) quanto ao uso de digoxina.

Figura 45 Probabilidade de sobrevida estimada (Kaplan-Meier) quanto ao uso de antiagregante plaquetário.

Figura 46 Probabilidade de sobrevida estimada (Kaplan-Meier) quanto 
ao uso de anticoagulante.

Figura 47 Probabilidade de sobrevida estimada (Kaplan-Meier) quanto ao uso de sinvastatina.

Figura 48 Probabilidade de sobrevida estimada (Kaplan-Meier) quanto ao uso de vasodilatador direto

Figura 49 Probabilidade de sobrevida estimada (Kaplan-Meier) quanto ao uso de bloqueador do canal de cálcio.

Figura 50 Probabilidade de sobrevida estimada (Kaplan-Meier) quanto ao uso de amiodarona.

Figura 51 Probabilidade de sobrevida estimada (Kaplan-Meier) quanto ao número de medicamentos em uso. 
Tabela 1 Características demográficas e clínicas dos pacientes.

Tabela 2 Variáveis estudadas quanto à probabilidade de sobrevida (etapa 1)

Tabela 3 Uso de tratamento medicamentoso

Tabela 4 Número de medicamentos em uso.

Tabela 5 Variáveis retiradas do modelo de Cox (etapa 2)....

Tabela 6 Reavaliação das variáveis excluídas da etapa 2 do modelo de Cox (etapa 3)

Tabela 7 Variáveis do modelo final de Cox selecionadas para a rede neural

Tabela 8 Valores de referência para as variáveis com dados faltantes..

Tabela 9 Testes para definição do modelo da rede neural (A) (fase 1)..

Tabela 9.1 Testes para definição do modelo da rede neural (B) (fase 1)..

Tabela 10 Comparação das redes neurais categorizadas pelo tempo de sobrevida observado: seleção dos melhores modelos de rede neural.

Tabela 11 Modelos de redes neurais para previsão da sobrevida dos pacientes vivos até 2012 (fase 2).

Tabela 12 Modelos de redes neurais comparáveis: erro hipotético de previsão da rede versus erro real observado (fase 3 )

Tabela 13 Modelo de rede neural 13 individual e comparável: erro hipotético de previsão da rede versus erro real observado (fase 3)

Tabela 14 Modelo de rede neural 20 individual e comparável: erro hipotético de previsão da rede versus erro real observado (fase 3)

Tabela 15 Modelo de rede neural 22 individual e comparável: erro hipotético de previsão da rede versus erro real observado (fase 3).

Tabela 16 Modelo de rede neural 24 individual e comparável: erro hipotético de previsão da rede versus erro real observado (fase 3)

Tabela 17 Modelo de rede neural 26 individual e comparável: erro 
hipotético de previsão da rede versus erro real observado (fase 3)

Tabela 18 Reensaio da rede neural com pacientes que vieram a falecer em 2013 (reensaio 1) - fase 4

Tabela 19 Reensaio da rede neural com pacientes que vieram a falecer em 2014 (reensaio 2) - fase 4.

Tabela 20 Comparação da previsão da sobrevida entre o modelo inicial da rede neural 24 e reensaio 1 (fase 4).

Tabela 21 Comparação da previsão da sobrevida entre o modelo inicial da rede neural 26 e reensaio 1 (fase 4)

Tabela 22 Comparação da previsão da sobrevida entre o modelo inicial da rede neural 24, reensaio 1 e reensaio 2 (fase 5 ).

Tabela 23 Comparação da previsão da sobrevida entre o modelo inicial da rede neural 26 , reensaio 1 e reensaio 2 (fase 5 ).

Tabela 24 Sensibilidade, especificidade, acurácia, valor preditivo positivo, valor preditivo negativo dos melhores modelos de rede neural.

Tabela 25 Avaliação dos melhores modelos de rede neural com o emprego da função de perda 
Marçula M. Avaliação prognóstica em pacientes com insuficiência cardíaca com o emprego de redes neurais artificiais [tese]. São Paulo: Faculdade de Medicina, Universidade de São Paulo; 2018.

Fundamentos - Identificar pacientes ambulatoriais que necessitam de recursos terciários de hospital de referência voltado para a prática cardiológica é inerente à responsabilidade assistencial. Compete reconhecer pacientes sob maior risco de prognóstico desfavorável, o que pode ser feito pelo emprego de métodos estatísticos tradicionais. Com o mesmo fito, as redes neurais têm sido objeto de interesse. Formulamos a hipótese de que as redes neurais, alimentadas a partir de variáveis selecionadas com o emprego de estatística tradicional, pudessem contribuir para a avaliação prognóstica de pacientes com insuficiência cardíaca.

Objetivos - Avaliar o prognóstico de pacientes com diagnóstico de insuficiência cardíaca com o emprego de métodos da estatística de sobrevivência associada com a rede neural artificial.

Delineamento - Estudo de coorte retrospectiva a partir de dados assistenciais de pacientes que receberam o diagnóstico de insuficiência cardíaca, identificação das variáveis associadas ao prognóstico com o emprego da estatística tradicional e alimentação da rede neural perceptron de múltiplas camadas (Neuro XL Predictor - OLSOFT Software Development) com essas variáveis.

Local - Ambulatório cardiológico com alto volume de atendimentos voltado para pacientes do Sistema Único de Saúde (SUS) em hospital acadêmico de referência terciário.

Participantes -2.128 pacientes consecutivos, que receberam o diagnóstico de insuficiência cardíaca de 2 de julho de 2003 a 2 de julho de 2007.

Desfecho - óbito por qualquer causa.

Análise de dados - À análise descritiva e exploratória, seguiu-se a avaliação da probabilidade de sobrevida pelo método de Kaplan Meier, seguida de análise inferencial com o emprego do teste de log-rank e do modelo de riscos proporcionais de Cox. Identificadas as variáveis associadas ao prognóstico de sobrevida, foi desenvolvida a rede neural nas diferentes fases de aprendizado- 
treinamento e com o recurso do algoritmo de treinamento backpropagation. A rede neural foi desenvolvida em cinco fases: fase 1 - aprendizado-treinamento ( $\mathrm{n}=968$ óbitos com informação completa); fase 2 - avaliação e aplicação (pacientes vivos até 2012); fase 3 - comparação da previsão de sobrevida com o emprego rede ( pacientes vivos até 2012) com a sobrevida observada; fase 4 - reensaios para aprendizados com novos desfechos (óbitos em 2013 e 2014); fase 5 - avaliação do aprendizado da rede na fase 4 (pacientes vivos e falecidos).

A acurácia, a sensibilidade, a especificidade, o valor preditivo positivo e o valor preditivo negativo dos melhores modelos na previsão da sobrevida obtidas com a rede neural foram avaliados, considerando as duas funções de ativação (tangente hiperbólica e zero-based log sigmoid). Para tanto, foi preciso determinar intervalos de corte definidos por critério clínico de razoabilidade de expectativa do tempo de sobrevida e acerto calculado pela rede. A estimativa da previsibilidade e do erro também foi avaliada com o emprego da função de perda.

Resultados - A análise estatística ( $n=2.128$ pacientes) revelou as seguintes variáveis associadas ao prognóstico: idade $(p<0,001)$, índice de massa corpórea $(p<0,001)$, pressão arterial diastólica $(p<0,001)$, etiologia da insuficiência cardíaca $(p<0,001)$, classe funcional $(p<0,001)$, espessura do septo interventricular $(p=0,037)$, diâmetro diastólico do ventrículo esquerdo $(p<0,001)$, diâmetro do átrio esquerdo $(p=0,025)$, potássio sérico $(p=0,015)$, colesterol total $(p<0,001)$, creatinina $(p<0,001)$ e a presença de diabetes melito $(p=0,034)$.

Os modelos de redes neurais com melhor previsibilidade foram obtidos pela categorização do tempo de sobrevida inferior a 2 anos, entre 2 anos e 6 anos, e superior a 6 anos.

Nos pacientes com tempo de sobrevida observado superior a 6 anos, a partir da consulta inicial, com intervalo de corte de 3 anos, a estimativa feita com o emprego da rede neural demonstrou sensibilidade 93,0\% (com ambas as funções de ativação), especificidade $76,4 \%$ ou $77,5 \%$ (dependendo da função de ativação), valor preditivo negativo $97,4 \%$ (com ambas as funções de 
ativação) e valor preditivo positivo $53,6 \%$ ou $54,7 \%$ (dependendo da função de ativação).

Nos pacientes com tempo de sobrevida observado entre 2 anos e 6 anos, a partir da data do início dos sintomas, com intervalo de corte de 2 anos, obtivemos sensibilidade $89,8 \%$ (com ambas as funções de ativação), especificidade $72,5 \%$ ou $76,5 \%$, valor preditivo positivo $86,3 \%$ ou $88,0 \%$ e valor preditivo negativo $78,7 \%$ ou $79,6 \%$ (dependendo da função de ativação).

Nos pacientes com tempo de sobrevida observado inferior a 2 anos, a partir da data do início dos sintomas, com intervalo de corte de 1 ano, a estimativa com o emprego da rede neural demonstrou sensibilidade $87,2 \%$ (com ambas as funções de ativação), especificidade de 62,5\% ou 66,7\% (dependendo da função de ativação), valor preditivo positivo 82,0\% ou 83,7\% (dependendo da função de ativação) e valor preditivo negativo $71,4 \%$ ou $72,7 \%$ (dependendo da função de ativação).

O erro da previsão de sobrevida com o emprego da rede neural, estimado com o auxílio da função de perda, variou de 4,4 meses até 1,1 anos.

Conclusões - O emprego da rede neural alimentada por variáveis selecionadas com o emprego de estatística de sobrevivência tradicional pode ser método profícuo na avaliação prognóstica de pacientes com insuficiência cardíaca.

A previsibilidade de estimativa de sobrevida alcançada com o uso de rede neural foi menor nos pacientes com quadros clínicos de menor tempo de evolução, comparativamente aos pacientes com maior tempo de evolução; no primeiro caso permitiria sugerir quadros mais instáveis em relação aos casos mais estáveis, isto é, aqueles com tempo de evolução maior.

Descritores:: insuficiência cardíaca, cardiomiopatia, assistência ambulatorial, análise de sobrevivência, rede neural, prognóstico. 
Abstract 
Marçula M. Prognostic evaluation of patients with heart failure with the use of artificial neural networks [thesis]. São Paulo: "Faculdade de Medicina, Universidade de São Paulo"; 2018.

Background - Identifying outpatients who need tertiary resources of a referral cardiology hospital includes recognizing those at higher risk of unfavorable prognosis. Studies aimed at this objective may be accomplished with traditional statistics. Neural networks have been studied as a promising tool in the assessment of patients' prognosis. We hypothesized that the neural networks developed with variables selected through traditional statistics might contribute to the prognostic evaluation of patients with heart failure.

Objectives - To evaluate the prognosis of patients with heart failure using methods of survival statistics combined with the resources of artificial neural networks.

Design - Retrospective cohort study from a database of patients previously diagnosed with heart failure, identification of variables associated with prognosis using traditional statistics, development of a neural network perceptron of multiple layers (Neuro XL Predictor - OLSOFT Software Development) with these variables.

Setting - outpatient clinic from an academic tertiary cardiology center

Participants - 2128 consecutive patients who received the diagnosis of heart failure between July 2, 2003 and July 2, 2007.

Outcomes - death for any cause.

Data analysis - Statistical evaluation was performed for descriptive and exploratory analysis and was followed by Kaplan Meier survival probability, and inferential analysis using the log-rank test and the Cox proportional hazards model to identify the variables associated with prognosis. Variables thus selected were then input for the neural network in the different stages of learning-training, with the backpropagation algorithm. The neural network was developed in 5 phases: phase 1 - learning / training $(n=968$ deaths with complete information); phase 2 - evaluation and application (patients alive until 2012); phase 3 - comparison of the predicted versus the observed survival 
using the network (patients alive until 2012); phase 4 - re-tests for learning with new outcomes (deaths in 2013 and 2014); phase 5 - assessment of network learning in phase 4 (living and deceased patients).

The accuracy, sensitivity, specificity, positive predictive value and negative predictive value of the best models in the prediction of survival obtained with the neural network were evaluated taking into account the two activation functions (hyperbolic tangent and zero-based log sigmoid) and the cut-off intervals defined by clinical criteria of reasonableness of expected survival time and the estimated estimate by the network. The estimation of predictability and error was also evaluated using the loss function.

Results - Statistical analysis ( $n=2128$ patients) revealed the following variables associated with prognosis: age $(p<0.001)$, body mass index ( $p$ $<0.001)$, diastolic blood pressure $(p<0.001)$, heart failure etiology $(P<0.001)$, functional class ( $p<0.001$ ), interventricular septum thickness $(p=0.037$ ), left ventricular diastolic diameter $(p<0.001)$, left atrial diameter $(p=0.025)$, serum potassium level, total cholesterol ( $p<0.001)$, serum creatinine level $(p<0.001)$ and the presence of diabetes mellitus ( $p=0.034)$.

The models of neural networks with better predictability were obtained with the categorization of the survival time of less than 2 years, between 2 and 6 years, and over 6 years.

In patients with a survival time of more than 6 years from the initial consultation, with a cut-off interval of 3 years (or 1095 days), the estimate using the neural network showed sensitivity $93.0 \%$ (with both activation functions), specificity of $76.4 \%$ or $77.5 \%$ (depending on the activation function), negative predictive value $97.4 \%$ (with both activation functions) and positive predictive value $53.6 \%$ or $54.7 \%$ (depending on the function of activation).

In patients with a survival time of 2 to 6 years from the onset of symptoms, with a cut-off interval of 2 years (or 730 days), we obtained $89.8 \%$ sensitivity (with both activation functions), specificity $72,5 \%$ or $76.5 \%$, positive predictive value $86.3 \%$ or $88.0 \%$ and negative predictive value $78.7 \%$ or $79.6 \%$ (depending on the activation function).

In patients with a survival time of less than 2 years from the onset of symptoms, with a cut-off interval of 1 year (or 365 days), the estimate using the neural 
network showed a sensitivity of $87.2 \%$ (with both activation functions), specificity of $62.5 \%$ or $66.7 \%$ (depending on the activation function), positive predictive value $82.0 \%$ or $83.7 \%$ (depending on the activation function) and negative predictive value $71.4 \%$ or $72.7 \%$ (depending on the activation function).

The error of survival prediction with the use of the estimated neural network with the aid of the function of absolute loss ranged from 4.4 months to 1.1 years.

Conclusions - The use of selected variables input in the neural network with the use aid of traditional survival statistics, may be a useful method for the prognostic evaluation of patients with heart failure. Estimates were less accurate in patients with a shorter duration of symptoms relative to those with symptoms for a long time; in the first case it would suggest more unstable disease relative to those with more stable disease, namely with symptoms for a long time.

Descriptors: heart failure, cardiomyopathy, ambulatory care, survival analysis, neural networks, prognosis. 
1. Introdução 
A atuação em ambulatório médico cardiológico com alto volume de atendimentos a pacientes do Sistema Único de Saúde (SUS), em hospital acadêmico de referência terciário (940.048 consultas de 1988 a 2017), traz à atividade cotidiana a responsabilidade de avaliar e distinguir pacientes com maior necessidade clínica de receber tratamento que utilize as competências e a tecnologia disponíveis em hospital de referência, recursos que têm, entre suas características, o fato de serem limitados.

Portanto, é necessário continuamente estudar e aprimorar a avaliação clínica para orientar a terapêutica no longo prazo, em recursos da comunidade ou em centros de atenção terciária. Esta responsabilidade diz respeito, também, aos pacientes com diagnóstico de insuficiência cardíaca atendidos em ambulatório cardiológico de hospital acadêmico de referência.

O conhecimento da probabilidade de sobrevida no longo prazo como método de avaliação do prognóstico é de interesse para essa orientação; a menor sobrevida seria indicador de maior gravidade da condição. A sobrevida pode ser avaliada por diferentes métodos (Oliveira et al., 2016). Decorre também a identificação de variáveis associadas com a sobrevida (Marçula et al., 2011).

A probabilidade de sobrevida foi avaliada previamente em casuística no próprio Serviço (Freitas et al, 2005), em 1.220 pacientes com diagnóstico de insuficiência cardíaca sintomática, tratados entre 1991 e 2000, e foi estimada, após um ano de acompanhamento, aproximadamente, em $60 \%$, o que revalida dados publicados de sobrevida estimada entre $40 \%$ e $70 \%$ (Mady et al., 1994; Pereira Barretto et al., 1998; Carlo et al., 2014; Bocchi et al., 2017).

A etiologia cardiopatia da doença de Chagas foi o fator mais relevante associado com a mortalidade (risco relativo 2,97), quando comparada com cardiomiopatia dilatada idiopática (risco relativo 2,27), cardiopatia isquêmica (risco relativo 2,53), cardiopatia hipertensiva (risco relativo 2,73), além de outras variáveis como diâmetro diastólico do ventrículo esquerdo no ecocardiograma (risco relativo 1,16 ) e fração de ejeção do ventrículo esquerdo (risco relativo 0,95$)$ na ventriculografia por radioisótopo (Freitas et al., 2005). A 
observação do pior prognóstico dos pacientes com insuficiência cardíaca por doença de Chagas se harmoniza com dados publicados em outras investigações (Espinosa et al., 1985; Mady et al., 1994; Bestetti et al., 1997; Bestetti; Daniel, 2016; Pereira-Barretto et al., 1998; Carlo et al., 2014; Rassi et al., 2010; Bocchi, 2012, 2013, 2017) que, nas formas mais severas da doença, revelaram mortalidade de $80 \%$ a $100 \%$ em um ano de seguimento (Mady et al., 1994; Theodoropoulos et al., 2008).

Uma questão intrincada nesse estudo (Freitas et al., 2005), realizado em condições que a literatura denomina "vida real" ("real life conditions" em oposição a "protocol conditions", situação de variáveis controladas), foi lidar com dados faltantes, e objeto de pesquisa específica (Paes, 2007).

Além do tratamento medicamentoso, os processos de transformação inerentes à prática clínica abrangem características dos pacientes, inclusive no acesso às oportunidades de tratamento, progresso na experiência clínica, seja em ferramentas diagnósticas, seja na terapêutica, com a natural consequência na sobrevida em longo prazo (Pitt et al., 1999, 2003; Bocchi et al., 2008; Issa et al., 2010; Bestetti et al., 2011; Carlo et al., 2014). Portanto, a necessidade de reavaliação periódica do prognóstico dos pacientes é inerente à prática médica.

Além dos recursos metodológicos da estatística de sobrevivência, a experiência prévia com pesquisadores de estatística estimulou a associação de métodos estatísticos pelo uso de redes neurais (Ogava, 2007). Além disso, uma experiência pioneira, em nosso meio, foi conduzida há duas décadas, com casuística pequena (95 pacientes) fora do ambiente do Sistema Único de Saúde (Ortiz et al., 1995a). De fato, o uso de redes neurais artificiais na análise de dados clínicos de pacientes com diagnóstico de insuficiência cardíaca foi apresentado como um método que deve ser investigado (Braunwald, 2008).

As redes neurais artificiais têm sido progressivamente utilizadas na prática clínica (Lisboa; Taktak, 2006), e a potencial contribuição da aplicação da rede neural, no diagnóstico e prognóstico de várias doenças, inclusive, tem se tornado objeto de interesse e investigação na área da Cardiologia (Lisboa, 2002).

Rede neural artificial foi conceituada como "estrutura de processamento de informação distribuída em paralelo e constituída por 
elementos de processamento, ligados por canais de sinal unidirecionais denominados conexões, em que cada elemento de processamento possui uma única conexão de saída que se ramifica em tantas quantas as conexões colaterais desejadas" (Hecht-Nielsen, 1989). Entre as características potenciais da rede neural, há o caráter adaptativo, treinável, capaz de armazenar e processar informações por associação e adquirir conhecimento pela experiência, por meio de exemplos ou da própria aplicação (Sanchez, 2009).

A arquitetura de rede neural mais utilizada e estudada é a do tipo perceptron de múltiplas camadas (Cross, Harrison e Kennedy, 1995) e o tipo de treinamento mais frequente utiliza o algoritmo de treinamento supervisionado ou de retropropagação do erro (backpropagation) (Scott, 1993; Cross et al., 1995; Papik et al., 1998). Estas redes neurais têm por característica a propagação positiva (feedforward) ou na mesma direção do erro, partindo da camada de entrada rumo à camada de saída e à retropropagação do erro (backward), partindo da camada de saída até a camada de entrada (Castro LN, 1998; Sanchez, 2009). O algoritmo backpropagation fundamenta-se numa regra de aprendizado que corrige os erros durante todo $\mathrm{o}$ aprendizado $\mathrm{e}$ treinamento da rede neural, em todas as camadas, partindo da saída até a entrada (Haykin, 1994).

O processo de aprendizado da rede neural é gradual, interativo e iterativo de ajuste dos pesos sinápticos, de forma a adequar a rede a um conjunto de exemplos, adaptar o seu comportamento ao longo do tempo e aperfeiçoar a resposta a ser obtida (Ambrosio, 2002; Castro FCC, 2016). Por sua característica de aprendizado e treinamento, a rede neural permite a melhoria contínua de seu desempenho a partir de exemplos e tem sido aplicada na área médica, no estudo de diferentes condições (Baxt, 1991, 1995, 1996; Astion; Wilding, 1992; Widing et al., 1994; Tourassi et al., 1995; Fogel et al., 1995; Ahmed, 2005; Sinha et al., 2007; Bartosch-Härlid et al., 2008; Silva et al, 2008; Das et al., 2008; Ogulata et al., 2009).

Estudos que integram análise estatística como fundamento para alimentação de rede neural são escassos (Ogava, 2007).

Em pacientes com insuficiência cardíaca, a comparação entre vários métodos computacionais, entre eles a rede neural, a partir de informações da 
etiologia, severidade e evolução da doença, evidenciou melhor desempenho dos sistemas de suporte (Guidi et al., 2014). Por outro lado, estudo de casuística nacional publicada há duas décadas avaliou o prognóstico de 95 pacientes com insuficiência cardíaca e fração de ejeção reduzida, em seguimento de doze meses; esta baseou-se em parâmetros ecocardiográficos e na idade, estimou a acurácia, sensibilidade, especificidade, valor preditivo positivo e valor negativo, respectivamente, $67 \%, 67 \%, 68 \%, 28 \%, 92 \%$, por análise discriminatória linear; enquanto pelos valores correspondentes à rede neural artificial, foram estimados em 90\%, 71\%, 93\%, 63\% e 95\% (Ortiz et al., 1995b).

Recentes publicações apontaram para o potencial uso da rede neural no universo da inteligência artificial (neurocomputing, machine learning, deep learning) (Krittanawrong et al., 2017; Miller e Brown, 2018), usando o algoritmo de aprendizado supervisionado (backpropagation) na análise de amplas bases de dados para melhor precisão cardiovascular (Krittanawong et al., 2017). Além disso, a rede neural foi utilizada na predição da mortalidade em pacientes submetidos a teste de esforço cardiopulmonar (Myers et al., 2014), como também em ampla metanálise que avaliou a eficácia do tratamento em pacientes com diagnóstico de insuficiência cardíaca, nos últimos trinta anos (Burnet et al., 2017).

Como método, a rede neural artificial tem vantagens e desvantagens, quando comparada aos sistemas de computação convencionais ou sistemas baseados em algoritmos (Papik et al., 1998).

Entre as vantagens foram citadas a efetividade do método na modelagem não linear de fenômenos biológicos com grande número de dados; precisão para inferência preditiva e ajuda na tomada de decisão médica; facilidade de disseminação do conhecimento pelo método (Lisboa et al., 2006); capacidade de utilizar informações incompletas; aprendizado por meio de exemplos e exposição de padrões à rede neural (Sanchez, 2009).

Tendo em vista a missão assistencial no atendimento de pacientes com diagnóstico de insuficiência cardíaca recebidos para avaliação, diagnóstico e orientação de tratamento em unidade ambulatorial de hospital de referência, voltado para pacientes do Sistema Único de Saúde, situação na qual se 
esmera a aplicação mais judiciosa possível dos recursos instalados, requer-se a atualização constante dos dados prognósticos para a melhor orientação. Estudos são necessários para reunir recursos de técnicas estatísticas tradicionais, como também para empregar redes neurais e sua potencial capacidade de aprendizado, possibilitando mudanças nas casuísticas brasileiras lastreadas no tempo.

Destarte, planejamos o presente estudo para avaliar o emprego da estatística tradicional como etapa de seleção de variáveis para a aplicação da rede neural artificial na avaliação prognóstica de pacientes para esmerar na distinção de pacientes de prognóstico menos favorável e com maior necessidade clínica de tratamentos que utilizem as competências e a tecnologia geralmente disponíveis apenas em serviços médicos de referência. 
2. Objetivos 


\subsection{Objetivos Primários}

Avaliar o prognóstico de pacientes com diagnóstico de insuficiência cardíaca pelo emprego de métodos da estatística de sobrevivência associada com a rede neural artificial.

\subsection{Objetivos Secundários}

Estimar a contribuição dos dados de exame clínico e laboratorial obtidos na avaliação inicial dos pacientes.

Estimar o impacto dos dados faltantes na análise. 
3. Métodos 


\subsection{Delineamento do estudo}

Estudo observacional tipo transversal (coorte retrospectiva) a partir de base de dados administrativa e assistencial que receberam o diagnóstico de insuficiência cardíaca na Unidade Clínica de Ambulatório Geral do Instituto do Coração e foram acompanhados até o desfecho (óbito por qualquer causa) ou até a data do último contato.

Dados da mortalidade foram obtidos por meio de consulta a registros hospitalares, contato telefônico, consulta ao Programa de Aprimoramento das Informações de Mortalidade no Município de São Paulo (PRO-AIM) ou à Fundação Sistema Estadual de Análise de Dados (SEADE) (Figura 1).

\subsection{Avaliação clínica}

O exame clínico e a avaliação laboratorial dos pacientes seguiram a rotina assistencial da Unidade. Os pacientes, cerca de $50 \%$, encaminhados ao sistema CROSS (Central de Regulação de Oferta de Serviços de Saúde, Secretaria de Estado da Saúde, São Paulo), foram avaliados por meio de exame clínico, incluindo a história clínica e o exame físico, eletrocardiograma em repouso e a radiografia de tórax, além de revisão de testes complementares, eventualmente trazidos pelos pacientes. A avaliação laboratorial complementar no Serviço foi indicada de acordo com a necessidade clínica dos pacientes dentro da rotina assistencial e a disponibilidade operacional institucional, incluindo avaliação metabólica laboratorial, ecocardiografia ou outros testes.

O tratamento foi recomendado de acordo com a rotina institucional, conforme necessidade clínica e tolerância dos pacientes, de acordo com a orientação do médico responsável pelo atendimento do paciente, além da 
disponibilidade na dispensação por farmácia do sistema público de atenção farmacêutica.

\subsection{Critérios diagnósticos}

O diagnóstico de insuficiência cardíaca foi feito com base nos critérios de Framingham, definido pela presença simultânea de, no mínimo, dois critérios maiores ou um critério maior e dois menores (McKee et al., 1971). São critérios maiores: dispneia paroxística noturna, turgência jugular, crepitações pulmonares, cardiomegalia na radiografia do tórax, edema agudo de pulmão, terceira bulha cardíaca, aumento da pressão venosa central $(>16 \mathrm{~cm}$ água no átrio direito), refluxo hepatojugular, perda de peso maior $4,5 \mathrm{~kg}$ em cinco dias, em resposta ao tratamento. Os critérios menores incluem: edema de tornozelo bilateral, tosse noturna, dispneia aos esforços habituais, hepatomegalia, derrame pleural, taquicardia (>120 batimentos por minuto), diminuição da capacidade funcional em um terço da máxima registrada previamente (Hunt et al., 2001, 2005).

O diagnóstico etiológico foi feito de acordo com critérios previamente publicados (Maron et al., 2006). Os diagnósticos etiológicos foram revisados individualmente para este estudo.

Os diagnósticos foram categorizados segundo a Classificação Internacional de Doenças, $10^{\text {a }}$. revisão (World Health Organization. 2010).

\subsection{Critérios de inclusão}

Foram incluídos no estudo portadores de insuficiência cardíaca em diferentes classes funcionais da New York Heart Association (New York Heart Association, 1964; Remme et al., 2001). 


\subsection{Critérios de exclusão}

Foram excluídos do estudo os pacientes com angina instável, infarto do miocárdio há menos de seis meses, doença valvar, história de cirurgia ou infecção aguda nos trinta dias anteriores à consulta médica.

\subsection{Casuística}

Foram estudados 2.128 pacientes consecutivos, de ambos os sexos, com idade acima de 18 anos que, depois do exame clínico, receberam o diagnóstico de insuficiência cardíaca de diferentes etiologias, no período de 2 de julho de 2003 a 2 de julho de 2007.

No Serviço foram realizadas 113.185 consultas ambulatoriais no período de estudo. Portanto, a casuística representa $1,8 \%$ do total de consultas atendidas que receberam o diagnóstico de insuficiência cardíaca.

\subsection{Variáveis estudadas}

\subsubsection{Demográficas}

Idade, sexo, etnia; 


\subsubsection{Clínicas}

Duração dos sintomas, etiologia da insuficiência cardíaca, classe funcional, peso, altura, índice de massa corpórea, frequência cardíaca, pressão arterial sistólica, pressão arterial diastólica e comorbidades (presença de hipertensão arterial, tabagismo, diabete melito, etilismo);

\subsubsection{Eletrocardiográficas}

Ritmo cardíaco;

\subsubsection{Ecocardiográficas}

Diâmetro do átrio esquerdo, diâmetro diastólico do ventrículo esquerdo, diâmetro sistólico do ventrículo esquerdo, fração de ejeção do ventrículo esquerdo, espessura diastólica do septo interventricular e espessura diastólica da parede posterior do ventrículo esquerdo;

\subsubsection{Laboratoriais}

Taxa de hemoglobina, taxa de leucócitos, taxa de linfócitos, taxa de glicose em jejum, creatinina sérica, sódio sérico, potássio sérico, colesterol total, lipoproteína de alta densidade (HDL-colesterol), lipoproteína de baixa densidade (LDL-colesterol) e triglicérides sérico. 


\subsubsection{Medicamentos em uso na consulta inicial}

Inibidores da enzima conversora da angiotensina (captopril, enalapril) e bloqueadores dos receptores da angiotensina II (losartana), bloqueadores adrenérgicos (carvedilol, metoprolol, propranolol e atenolol), diuréticos (furosemida, hidroclorotiazida, espironolactona), digital (digoxina), antiagregante plaquetário (ácido acetilsalicílico), anticoagulante oral (varfarina), estatina (sinvastatina), vasodilatadores (hidralazina e mononitrato de isossorbida), bloqueadores dos canais de cálcio (anlodipina); antiarrítmico (amiodarona); número de medicamentos em uso.

3.8 Mortalidade - foi considerado desfecho o óbito por qualquer causa.

\subsection{Análise dos dados}

Foi realizada em duas etapas: a) análise estatística ( $n=2.128$ pacientes) para identificar as variáveis associadas à sobrevida, cujo tempo de seguimento ou de sobrevida observado foi o intervalo entre a data da consulta inicial ou a data do início dos sintomas até o último contato com o paciente ou a data do óbito; b) aplicação da rede neural para estimar a sobrevida ( $n=968$ pacientes).

A escolha pela técnica da análise de sobrevida foi decorrente de sua característica para identificar e selecionar as variáveis mais importantes na sobrevida dos pacientes, como também pelo pressuposto que a presença de pacientes censurados ou com perda de seguimento, ao longo do tempo, representam todos os pacientes sujeitos ao risco de terem o evento de interesse naquele momento (Bustamante-Teixeira et al., 2002). 


\subsubsection{Análise estatística}

A análise estatística foi realizada nas seguintes etapas: análise descritiva, análise exploratória e estimativa da influência das variáveis na sobrevida.

\subsubsection{Análise descritiva e exploratória}

Foram avaliadas as frequências e distribuições das variáveis demográficas, clínicas, de exames complementares e de medicação (tabela 1).

A probabilidade de sobrevida foi avaliada para cada variável pelo método de Kaplan-Meier (Kaplan; Meier, 1958). As variáveis foram categorizadas de acordo com critérios clínicos ou com base nos valores de referência, quando pertinente. Dados faltantes foram reunidos em uma categoria. As curvas de probabilidade de sobrevida foram comparadas com o teste log-rank (Peto, 1972) e os valores-p, obtidos e informados. As variáveis com $\mathrm{p}<0,10$ foram selecionadas para a análise inferencial.

Foram selecionadas para a análise inferencial todas as variáveis com $p<0,10$ e algumas variáveis com $p>0,10$ pela relevância clínica evidenciada em estudos anteriores (Zugck et al., 2001; Acanfora et al., 2001; Anand et al., 2004; Huehnergarth et al., 2005; Maraldi et al., 2006; Nieminen et al., 2008; Marçula et al., 2015).

\subsubsection{Análise inferencial}

Foi adotado modelo de regressão semiparamétrico de riscos proporcionais de Cox (Cox, 1972) para estimar a influência de cada variável associada com a probabilidade de sobrevida. A comparação da qualidade dos 
ajustes do modelo foi feita pelo teste de razão de verossimilhança, nas seguintes fases:

a) ajuste de modelo univariado, tendo como variáveis independentes a idade e cada uma das variáveis demográficas e clínicas, separadamente. Foram selecionadas as variáveis com valores de $p<0,10$ para a sequência da análise;

b) as variáveis selecionadas e a idade foram submetidas ao ajuste do modelo multivariado. Nesta fase, para cada variável analisada e sem informação foi definida uma categoria de variável faltante. As variáveis com valor de $p>0,05$ foram retiradas sequencialmente do modelo. Também foi retirada do modelo a variável em que somente a categoria variável faltante apresentou valor de $p<0,05$. Sendo assim, permaneceram para a terceira fase do modelo as variáveis com valores de $p<0,05$ e a variável idade;

c) na terceira fase, para teste de segurança do modelo, com a finalidade de avaliar se as variáveis previamente retiradas do modelo contribuiriam ou não, de modo significativo, para a estimação da sobrevida, cada uma das variáveis previamente retiradas do modelo na fase inicial foi reintroduzida no modelo multivariado com as variáveis que, na segunda fase, alcançaram valor de $p<0,05$. Se fosse encontrado $p<0,05$, esta variável permaneceria no modelo;

d) as variáveis assim selecionadas foram as variáveis de entrada para a rede neural artificial.

\subsubsection{Rede neural}

Os testes da rede neural foram realizados pelo emprego do programa Neuro XL Predictor (OLSOFT Software Development) que utiliza a rede neural perceptron de múltiplas camadas.

A rede neural tipo perceptron de múltiplas camadas compreendeu uma camada de entrada, camadas intermediárias (ou ocultas) e uma camada de 
saída (figura 2). Cada neurônio de qualquer das camadas da rede se conectou a todos os neurônios da camada seguinte, e o fluxo da informação foi em uma única direção (rede feedforward), da esquerda para a direita ou da camada de entrada para a camada de saída (Figura 2a). $O$ treinamento da rede foi feito pelo emprego do algoritmo de treinamento supervisionado ou de retropropagação (backpropagation) que retropropaga o erro (backward) da informação da camada de saída para a camada de entrada (Figura 2b).

A função de ativação ou de transferência da rede neural foi uma função não linear (Figura 3). Entre as funções de não linearidade de ativação da rede neural foram testadas a função zero based log sigmoid (Buskard et al., 1994; Lundin et al., 1999; Grossi, 2006) e a função tangente hiperbólica (Buskard et al.,1994; Frize et al., 2000; Ennett et al., 2001, 2004; Grossi, 2006) a cada um dos neurônios da rede neural, camada a camada.

A aplicação da rede neural foi feita em três etapas: aprendizadotreinamento, previsão e agrupamento aleatório.

\subsubsection{Escolha da arquitetura da rede neural}

De início foi avaliada a arquitetura mais adequada para o aprendizadotreinamento da rede neural, mediante realização de testes com até 20 camadas intermediárias, de acordo com o ajuste de estimativas. Foram investigados:

a) número de ciclos - $\mathrm{A}$ definição do número máximo de ciclos ou iterações para o aprendizado-treinamento da rede neural foi ajustada após testes variando o parâmetro em 30.000, 20.000 e 10.000 ciclos, mantendo fixos todos os demais parâmetros da rede neural (Tabela 9.1);

b) erro delta - A definição do valor do erro delta para o aprendizadotreinamento da rede foi estipulado após testes, variando o parâmetro em $0.0001,0.0010$ e 0.0020 do erro delta, mantendo fixos todos os demais parâmetros envolvidos da rede neural, inclusive o número máximo de ciclos em 30.000 ciclos (tabela 9.1); 
O número máximo de ciclos definido para o aprendizado-treinamento da rede foi de 30.000 etapas ou o valor do erro delta de 0.0001 ;

c) os pesos sinápticos iniciais - A determinação dos pesos (ponderação da contribuição da variável na estimação) das conexões sinápticas foi definida pela própria rede na execução repetida do algoritmo de aprendizado-treinamento. A partir do peso sináptico inicial de 0.3 , previamente definido, foi modulado a cada conexão, seguindo regra de aprendizado pela aplicação do algoritmo de treinamento supervisionado (backpropagation) para ajustar o erro da variável de saída. De maneira iterativa, a variável de saída estimada na rede foi comparada com a variável de saída observada, resultando num sinal de erro, que foi retropropagado pela rede para permitir o ajuste dos pesos (Figura 2b). Esses ciclos foram repetidos até que a rede atribuiu para cada variável de entrada uma variável de saída com valores estimados de sobrevida consistentes com os valores observados;

d) taxa de aprendizado - O parâmetro denominado taxa de aprendizado influencia o aprendizado da rede (Sanchez, 2009) e foi fixado no valor limite de 0.3 para o ajuste limitado da curva de aprendizado-treinamento da rede neural;

e) termo de momentum - $\mathrm{O}$ parâmetro da rede neural denominado termo de momentum intervém no aprendizado, por aumentar a taxa de aprendizado (Sanchez, 2009) como moderador, e foi fixado no valor limite de 0,3 para o ajuste da curva de aprendizado-treinamento da rede neural.

Para definir a abordagem mais adequada para a imputação nos valores faltantes, foram adotados três critérios distintos para avaliar a mais apropriada previsão de sobrevida da rede neural:

a) valores de referência normais para as variáveis faltantes (Frize et al., 2001; Ennett et al., 2001) - índice de massa corpórea (World Health Organization, 1995), pressão arterial diastólica (James et al., 2014), espessura diastólica do septo intraventricular, diâmetro diastólico do ventrículo esquerdo, diâmetro do átrio esquerdo (Lang et al., 2005), potássio sérico, colesterol total e creatinina sérica (rotina laboratorial institucional) (Tabela 8);

b) valor superior da normalidade (rotina laboratorial institucional) para as taxas de colesterol total e creatinina sérica (Tabela 8); 
c) valor da mediana das variáveis disponíveis para imputação nos valores faltantes (Frize et al., 2001; Ennett et al., 2001) (Tabela 8);

\subsubsection{Aprendizado-treinamento da rede neural}

Para definir o mais apropriado tipo de treinamento para a previsão da sobrevida da rede neural duas técnicas foram avaliadas:

a) utilizando amostragem aleatória - três amostras aleatórias de um terço da casuística ( $\mathrm{n}=968$ ) foram constituídas para aprendizado-treinamento, validação e ajuste e aplicação.

b) utilizando a casuística do estudo ( $n=968)$ em cinco fases aprendizado- treinamento e definição da rede neural com base nos óbitos identificados até 2012, aplicação para estimativa de sobrevida até 2012, comparação de previsões com base nos óbitos verificados em 2013, reensaios com óbitos identificados até 2014, comparação da previsão para pacientes que faleceram em 2013 e 2014 (Figura 4).

$\mathrm{Na}$ primeira fase, com a finalidade de iniciar o aprendizado-treinamento da rede neural, foi avaliada a amostra dos pacientes com óbitos ocorridos até 2012 e informações completas (dados falantes imputados, segundo as abordagens mencionadas). Foram realizados testes com base nas variáveis indicadas, tanto pela análise estatística, quanto pela relevância clínica, tendo como função de ativação zero based log sigmoid e tangente hiperbólica (Figura $3)$.

O tempo de sobrevida observado até o desfecho óbito foi estimado a partir da data do início dos sintomas e a partir da data da primeira consulta no ambulatório do hospital. Com base no tempo médio de seguimento, o tempo de sobrevida observado foi explorado e categorizado com base na experiência clínica, nas variáveis prognósticas referidas na literatura (Cowie et al., 2000; Dries et al., 2000; Lewis et al., 2003; Rauchhaus et al., 2003; Freitas et al., 2005; Pocock et al., 2006; Rassi Jr et al., 2007; McManus et al., 2009) para identificar os pacientes com prognóstico menos favorável e obter a melhor 
estimativa da rede (Tabelas 9, 9.1). Variáveis de relevância clínica foram empregadas (Tabelas 9 e 9.1).

O erro da estimativa do tempo de sobrevida até o óbito, nesta fase, foi avaliado por meio do emprego da expressão:

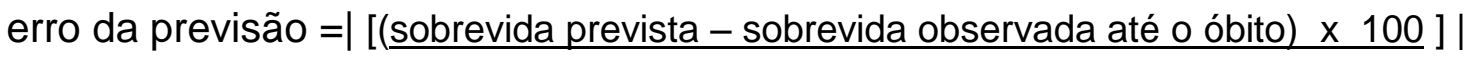

sobrevida observada até o óbito

em que:

erro da previsão (\%) - erro relativo da previsão da sobrevida com o emprego da rede;

sobrevida prevista - tempo de sobrevida previsto com o emprego da rede;

sobrevida observada até o óbito - tempo de sobrevida dos pacientes até 0 óbito.

Na segunda fase, com a finalidade de se obter a previsão da sobrevida para os sobreviventes até dezembro de 2012, foram realizados nove testes (Tabela 10). Esta fase avaliou os pacientes com variáveis completas e incompletas para os modelos de dados da rede neural com respostas inferiores a $36 \%$. Foi calculado o erro relativo da estimativa de óbito por meio do emprego da expressão:

erro hipotético de previsão $=\mid$ [( sobrevida prevista - sobrevida observada $) \times 100] \mid$

sobrevida observada

em que:

erro hipotético de previsão (\%) - erro de estimativa de previsão de sobrevida com o emprego da rede;

sobrevida prevista - tempo de sobrevida previsto com o emprego da rede; sobrevida observada - sobrevida observada com base na data do último contato dos sobreviventes.

$\mathrm{Na}$ terceira fase, foram comparadas as previsões com o emprego de modelos de redes neurais para os sobreviventes até 2012 e que faleceram em 
2013 (Tabela 11). Esta fase comparou o modelo de rede ou os modelos de dados da rede com respostas inferiores a $41 \%$ (Tabelas 12, 13, 14, 15, 16, 17). $\mathrm{Na}$ quarta fase, foram realizados novos testes de aprendizado-treinamento da rede neural, incorporando as atualizações de mortalidade de 2013 (reensaio 1 Tabela 18) e 2014 (reensaio 2 - Tabela 19). Esta fase de aprendizadotreinamento considerou os melhores modelos de rede neural para previsão da sobrevida.

$\mathrm{Na}$ quinta fase, foram comparados os resultados de previsão da sobrevida inicial da rede neural, a partir dos óbitos ocorridos até 2012, com os reensaios 1 (Tabelas 20, 21) e 2 (Tabelas 22, 23) atualizando mortalidade, respectivamente, de 2013 e 2014.

\subsubsection{Avaliação dos melhores modelos de rede neural}

A avaliação dos parâmetros de variabilidade entre os modelos de rede neural, bem como a sensibilidade, especificidade, acurácia, valor preditivo positivo, valor preditivo negativo (Tabela 24) e a função de perda (Tabela 25) dos modelos de dados da rede neural foram calculados:

a) Dispersão ou variabilidade dos modelos de rede neural - os desviospadrão em torno da média geral do erro de previsão da sobrevida dos modelos de rede neural foram calculados e comparadas as homogeneidades entre os modelos de rede neural no aprendizado (vivos até 2012) e na previsão (falecidos em 2013 e 2014) (Tabelas 12, 13, 14, 15, 16, 17, 20, 21, 22, 23).

b) Sensibilidade, especificidade, acurácia, valor preditivo positivo e valor preditivo negativo dos modelos de rede neural - a probabilidade de previsão para os melhores modelos da rede neural foi calculada para os intervalos de tempo ou de corte (Martinez et al., 2003) em 6 meses, 1 ano, 2 anos e 3 anos. As previsões obtidas a partir do emprego da rede neural foram categorizadas em (Tabela 24):

$b_{1}$ ) verdadeiro positivo (VP) - previsto o óbito que ocorreu;

$b_{2}$ ) verdadeiro negativo (VN) - prevista a sobrevivência que se confirmou; 
$b_{3}$ ) falso positivo (FP) - previsão de sobrevida e ocorreu o óbito;

$b_{4}$ ) falso negativo (FN) - previsão de óbito que não ocorreu;

$b_{5}$ ) sensibilidade - previsão acertada de óbito pela rede. $O$ cálculo foi feito por meio do emprego da expressão: VP / (VP + FN);

$b_{6}$ ) especificidade - previsão acertada de sobrevida pela rede. O cálculo foi feito por meio do emprego da expressão: VN / (VN + FP);

$b_{7}$ ) acurácia - precisão na estimativa de sobrevida. $O$ cálculo foi feito por meio do emprego da expressão: (VP + VN) / (VP + FP + VN + FN);

$b_{8}$ ) valor preditivo positivo - previsão de óbito estimado pela rede e que de fato ocorreu. O cálculo foi feito por meio do emprego da expressão: VP / (VP + FP);

b) valor preditivo negativo - previsão de sobrevida pela rede e que de fato ocorreu. O cálculo foi feito por meio do emprego da expressão: VN / (VN + FN).

c) Função de perda dos modelos de rede neural - o desempenho preditivo da rede neural foi avaliado por meio do emprego da função de perda aparente para a variável contínua tempo de sobrevida (Yuan, 2008) que leva em consideração a diferença entre a sobrevida prevista pelo emprego da rede neural e a sobrevida observada em cada caso. $O$ resultado foi demonstrado pela perda média estimada ou a média aritmética simples, em valores absolutos e expresso em dias (Santos, 2013) (Tabela 25).

\subsection{Aspectos éticos}

O protocolo do estudo foi aprovado pela Comissão de Ética para Análise de Projetos de Pesquisa do Hospital das Clínicas da Faculdade de Medicina da Universidade de São Paulo (CAAE 34706714.1.0000.0068). 
4. Resultados 


\subsection{Análise estatística}

Os resultados foram obtidos pela análise estatística descritiva e exploratória e pela análise inferencial para o ajuste do modelo estatístico.

\subsubsection{Análise descritiva e exploratória}

A idade dos pacientes variou de 18 anos a 94 anos (média 57,7, desvio- padrão 13,1), 1.362 (64\%) homens e 766 (36\%) mulheres; 1.325 (62\%) pacientes tinham idade entre 41 anos e 65 anos e 603 (28\%) pacientes tinham idade superior a 65 anos. A etnia branca foi observada em 343 (16\%) dos pacientes e o sobrepeso foi identificado em 697 (33\%) pacientes. A fração de ejeção do ventrículo esquerdo foi inferior a 45\% em 1.476 (69\%) pacientes. As etiologias predominantes foram as cardiopatias hipertensiva e isquêmica em $1.443(67,8 \%)$ pacientes e a doença de Chagas ocorreu em 333 (16\%) pacientes. A cardiopatia dilatada e a alcoólica ocorreram, respectivamente, em $206(10 \%)$ pacientes e $146(7 \%)$ pacientes. Na qualidade de pacientes que procuraram atendimento, a condição funcional era tal que permitia o acesso à consulta deambulando. Dos pacientes em tratamento, 967 (45\%) faziam uso da associação de três ou quatro medicamentos.

Outras características clínicas, laboratoriais, eletrocardiográficas e ecocardiográficas são apresentadas na tabela 1. A frequência de dados faltantes é apresentada nas tabelas 2,3 e 4, para cada variável.

Foram identificados 968 (45,5\%) óbitos até dezembro de 2012. Somaram-se 83 (3,9\%) óbitos verificados em 2013 e 50 (2,3\%) óbitos verificados em 2014. O total de óbitos foi 1.101 (51,7\%).

A curva da probabilidade de sobrevida geral da casuística é apresentada na figura 5. O tempo médio de acompanhamento dos pacientes foi 59,6 meses, desvio- padrão 41,8 meses (variação de um dia a 137 meses) e, 
aos cinco anos de evolução, 68\% dos pacientes da casuística estavam vivos. Tomando em consideração a etiologia da insuficiência cardíaca, no tempo médio de acompanhamento, $71 \%$ dos portadores de cardiopatia hipertensiva, $69 \%$ dos portadores de cardiopatia dilatada, $66 \%$ dos portadores de cardiopatia alcoólica, 55\% dos portadores de cardiopatia isquêmica e 50\% dos portadores de cardiopatia da doença de Chagas estavam vivos.

Nas curvas de probabilidade de sobrevida relativas a cada variável estudada, os valores faltantes foram agrupados em uma categoria. A comparação entre as curvas de sobrevida foi feita para as variáveis categorizadas em faixas de valores, de acordo com os valores de referência e com a categorização individual do dado faltante para cada variável avaliada (Figuras 6 a 51).

A comparação entre as curvas de sobrevida revelou diferença estatisticamente significante (valor $-p<0,05$ ) para as seguintes variáveis:

a) demográficas - idade ( $<<0,001$; figura 7$)$;

b) clínicas - etiologia da insuficiência cardíaca $(p<0,001$; figura 6$)$, peso ( $p<0,001$; figura 10), altura ( $p=0,048$; figura 11), índice de massa corpórea $(p<0,001$; figura 12$)$, pressão arterial sistólica $(p<0,001$; figura 13$)$, pressão arterial diastólica ( $p<0,001$; figura 14) classe funcional $(p<0,001$; figura 15);

c) ecocardiográficas - diâmetro do átrio esquerdo ( $p<0,001$; figura 22), diâmetro diastólico do ventrículo esquerdo ( $p<0,001$; figura 23$)$, diâmetro sistólico do ventrículo esquerdo ( $p<0,001$; figura 24), fração de ejeção do ventrículo esquerdo; ( $p<0,001$; figura 25), espessura diastólica do septo interventricular ( $p<0,001$; figura 26) e espessura diastólica da parede posterior do ventrículo esquerdo ( $p<0,001$; figura 27$)$;

d) laboratoriais - hemoglobina sérica ( $p<0,001$; figura 29), taxa de glicose sérica em jejum ( $p<0,001$; figura 30$)$, taxa de creatinina sérica $(p<0,001$; figura $31)$, taxa de sódio sérico ( $p<0,001$; figura 32), taxa de potássio sérico $(p<0,001$; figura 33), taxa de colesterol total ( $p<0,001$; figura 34), taxa de HDL-colesterol ( $p<0,001$; figura 35), taxa de LDL-colesterol $(p<0,001$; figura 36$)$ e taxa de triglicérides ( $p<0,001$; figura 37$)$; 
A comparação entre as curvas de sobrevida não revelou diferença estatisticamente significante (valor-p $>0,05$ ) para as seguintes variáveis:

a) demográficas - sexo ( $p=0,025$; figura 8 ), etnia ( $p=0,27$; figura 9 );

b) clínicas - frequência cardíaca ( $p=0,62$; figura 16$)$, duração dos sintomas ( $p=0,68$; figura 17) e o antecedente de hipertensão arterial ( $p=0,049$; figura 18), tabagismo ( $p=0,74$; figura 19$)$, diabetes melito $(p=0,024$; figura 20$)$ e etilismo $(p=0,024$; figura 21$)$;

c) eletrocardiográficas - ritmo cardíaco ( $p=0,0051$; figura 28);

d) laboratoriais - taxa de leucócitos ( $p<0,048$; figura 38), taxa de linfócitos $(p=0,011$; figura 39$)$;

e) medicamentos em uso na consulta inicial - inibidores da enzima conversora da angiotensina (captopril, enalapril) e bloqueadores dos receptores da angiotensina II (losartana) ( $p=0,91$; figura 40), bloqueadores adrenérgicos (carvedilol, metoprolol, propranolol e atenolol) ( $p=0,042$; figura 41), diuréticos (furosemida, hidroclorotiazida ( $p=0,0032$; figura 42$)$, espironolactona $(p=0,32$; figura 43), digoxina ( $p=0,077$; figura 44 ), antiagregante plaquetário (ácido acetilsalicílico) ( $p=0,55$; figura 45$), \quad$ anticoagulante oral (varfarina) $(p=0,43$; figura 46), estatina (sinvastatina) ( $p=0,07$; figura 47), vasodilatadores (hidralazina e mononitrato de isossorbida) ( $\mathrm{p}=0,58$; figura 48 ), bloqueador dos canais de cálcio (anlodipina) ( $\mathrm{p}=0,77$; figura 49 ), antiarrítmico (amiodarona) $(p=0,51$; figura 50$)$; número de medicamentos em uso ( $p=0,14$; figura 51 ).

De 33 variáveis reunidas inicialmente para a sequência de análise pelo emprego do modelo de riscos proporcionais de Cox, avaliamos os valores disponíveis de todas as variáveis clínicas, laboratoriais, ecocardiográficas (Tabela 2), bem como dos medicamentos agrupados por classe farmacológica (Tabela 3) e do número de medicamentos em uso na consulta inicial (Tabela 4). 


\subsubsection{Análise inferencial}

Para a etapa seguinte de análise inferencial, as variáveis foram selecionadas com base no valor $\mathrm{p}<0,10$ ou pela especial relevância clínica (Tabela 2) que discrimina as variáveis com $p \leq 0,001$ mais etnia, diabetes melito, frequência cardíaca, hipertensão arterial, etilismo, tabagismo, ritmo cardíaco, espessura diastólica do septo interventricular, espessura diastólica da parede posterior, glicemia de jejum, hemoglobina, potássio sérico, leucócitos, linfócitos, lipoproteína de alta (HDL-colesterol) e baixa (LDL-colesterol) densidade, triglicérides, número de medicamentos em uso na consulta inicial e data do início dos sintomas.

Nesta primeira etapa da análise, apenas as variáveis com dados válidos foram utilizadas no modelo, ou seja, a categoria individual de dado faltante para cada variável não foi utilizada (Tabela 2). Na segunda etapa, a categoria dados faltantes foi incluída na análise e foram retiradas as variáveis não associadas com o prognóstico (Tabela 5). Na terceira etapa, as variáveis não significativas foram reintroduzidas, testadas uma a uma no modelo e tiveram sua significância recalculada para confirmar que não estaríamos perdendo a relevância clínica (Tabela 6).

Os níveis descritivos (valor-p) para as 32 variáveis foram obtidos pelo teste de razão de verossimilhança para os modelos ajustados, com cada variável separadamente, controlando idade, definindo a influência de cada variável na probabilidade de sobrevivência (Tabela 2).

A variável início dos sintomas foi dicotomizada em um período inferior a doze meses e superior ou igual a doze meses, mas não se revelou significativa (valor $p=0,68$ ) para o prognóstico e foi retirada do modelo.

As variáveis com valor-p $<0,10$ ou relevância clínica foram selecionadas para a segunda etapa da análise inferencial (Tabela 2).

Após novo ajuste sequencial do modelo e considerando o valor-p > 0,05 , obtido do teste de razão de verossimilhança, as variáveis hipertensão 
arterial sistêmica, hemoglobina sérica, glicemia de jejum, fração de ejeção do ventrículo esquerdo, frequência cardíaca, sexo, sódio sérico, taxa de leucócitos, triglicérides, diâmetro sistólico do ventrículo esquerdo e taxa de linfócitos não revelaram diferença significativa para a sobrevida e foram retiradas do modelo (Tabela 5).

Entre as variáveis com valor- $\mathrm{p}<0,05$, a saber: idade, índice de massa corpórea, pressão arterial sistólica, pressão arterial diastólica, etiologia da insuficiência cardíaca, classe funcional, espessura do septo interventricular, diâmetro diastólico do ventrículo esquerdo, diâmetro do átrio esquerdo, potássio sérico, colesterol total e creatinina, observou-se que, para a variável pressão arterial sistêmica, somente a categoria de dados faltantes revelou significância para a sobrevida e, por este motivo, foi retirada do modelo.

Para reavaliar o ajuste do modelo as variáveis retiradas do primeiro ajuste do modelo multivariado em razão de valor- $p>0,05$ foram reintroduzidas, uma a uma, no modelo, e sua significância foi calculada com base no teste da razão de verossimilhança. A variável início dos sintomas foi dicotomizada em um período inferior a doze meses e superior ou igual a doze meses, mas não se revelou significativa (valor- $\mathrm{p}=0,78$ ) para o prognóstico e foi retirada do modelo. A variável antecedente pessoal de diabetes melito foi a única que se revelou com importância para a sobrevida (Tabela 6).

Assim, foram selecionadas as variáveis idade, índice de massa corpórea, pressão arterial diastólica, etiologia da insuficiência cardíaca, classe funcional, espessura do septo interventricular, diâmetro diastólico do ventrículo esquerdo, diâmetro do átrio esquerdo, potássio sérico, colesterol total, creatinina e a presença de diabetes melito como as variáveis relacionadas com a sobrevida (Tabela 7) e selecionadas para a alimentação da rede neural. 


\subsection{Rede neural}

\subsubsection{Escolha da arquitetura da rede neural}

Os resultados da rede neural sugeriram que a arquitetura da rede neural com cinco camadas intermediárias, 30.000 ciclos e erro delta de 0,0001 revelou-se a mais adequada (Tabela 9.1).

Os dados que observamos permitem sugerir que não houve diferença entre os dois tipos de função de ativação de não linearidade que foram utilizados - zero based log sigmoid e tangente hiperbólica - para a previsão da sobrevida pela rede neural (Tabela 9 e 9.1 ).

Entre as diferentes abordagens utilizadas para a imputação nos valores faltantes - valor da normalidade, valor superior da normalidade, valor da mediana - observamos que a rede neural não revelou resultado adequado na previsão da sobrevida (Tabela 9 e 9.1)

As 12 variáveis selecionadas para o aprendizado-treinamento da rede neural foram submetidas à interação mútua nas cinco camadas para o ajuste da rede.

\subsubsection{Aprendizado-treinamento da rede neural}

Os resultados que definiram o tipo de treinamento mais apropriado para a previsão da sobrevida da rede neural foram obtidos pela técnica da amostragem aleatória e pela técnica da utilização da casuística do estudo em cinco fases. 


\subsubsection{Amostragem aleatória}

Foram realizados testes para o aprendizado-treinamento da rede neural ( $n=968$ pacientes) em 322 pacientes selecionados aleatoriamente. No segundo terço de pacientes $(n=322)$, o erro relativo da previsão de sobrevida da rede neural foi de $336,85 \%$. Se comparada com a porcentagem de erro da previsão da rede neural sem agrupamento aleatório e sem categorização do tempo de sobrevida observado, para os mesmos 322 pacientes, o erro de previsão da rede foi de $363,88 \%$.

No teste realizado no terceiro terço $(n=324)$ dos pacientes agrupados aleatoriamente, o erro relativo da previsão de sobrevida da rede neural foi $544,19 \%$. Se comparado com a porcentagem de erro da previsão da rede neural sem agrupamento aleatório e sem categorização do tempo de sobrevida, o erro de previsão foi $618,80 \%$.

Em síntese, pelos testes da rede neural com agrupamento aleatório, o aprendizado-treinamento da rede neural não foi apropriado.

\subsubsection{Fases do estudo da casuística}

Foram realizados testes para o aprendizado-treinamento da rede neural ( $n=968$ pacientes) em cinco fases:

\subsubsection{Primeira fase - aprendizado-treinamento da rede neural}

Para efeito de teste, foi considerada a amostra dos pacientes com óbitos ocorridos até 2012, e a rede foi também alimentada com outras variáveis que não as 12 selecionadas pela análise estatística. 
As variáveis sexo, fração de ejeção do ventrículo esquerdo de $25 \%$ e $55 \%$, creatinina sérica nos valores de 1,3 e 2,6 mg/dL, colesterol total nos valores de $200 \mathrm{mg} / \mathrm{dL}$ e $239 \mathrm{mg} / \mathrm{dL}$, diâmetro diastólico do ventrículo esquerdo nos valores de $60 \mathrm{~mm}$ e $75 \mathrm{~mm}$ e a associação das variáveis colesterol total nos valores de $200 \mathrm{mg} / \mathrm{dL}$ e $239 \mathrm{mg} / \mathrm{dL}$ e diâmetro diastólico do ventrículo esquerdo nos valores de $60 \mathrm{~mm}$ e $75 \mathrm{~mm}$ foram consideradas para 0 aprendizado-treinamento da rede por serem variáveis significativas no prognóstico de alguns estudos (Gradman et al, 1989; Dries et al., 2000; Senni et al., 2001; Lee DS et al., 2003; Levy et al., 2006; Pocock et al., 2006; Abraham et al., 2008; Anand et al., 2008; Roger et al., 2013; Mahmood et al., 2014; Kenchaiah et al., 2015), portanto limitadoras para os testes da rede neural (Tabelas 9 e 9.1). Não houve melhora da capacidade de previsão da sobrevida pela rede (Tabelas 9 e 9.1).

O tempo de sobrevida observado foi trabalhado sem categorização e com a classificação em seis categorias do tempo de seguimento, tomando também como base o seu tempo médio: até 2 anos, entre 1 ano e 6 anos, entre 2 anos e 6 anos, entre 1,5 ano e 8,5 anos, acima de 2 anos e acima de 6 anos.

Os resultados da modelagem da rede neural tomando em consideração o tempo de sobrevida observado, estratégia para imputação no caso de dados faltantes, critérios para variáveis clínicas, função de transferência ou de ativação e informação da data inicial disponível para estimar a sobrevida (data do início dos sintomas ou a data primeira consulta) estão apresentados nas tabelas 9 e 9.1 .

Os resultados obtidos foram:

a) quando avaliadas diferentes estratégias - o erro de previsão da sobrevida variou entre $201 \%$ (rede neural 4) e 1.023,08\% (rede neural 12), dependendo da data disponível para estimar a sobrevida, da função de transferência, dos valores de imputação para os dados faltantes e das variáveis clinicamente relevantes (Tabelas 9 e 9.1). Portanto, os resultados foram inadequados para prever a sobrevida;

b) quando avaliadas diferentes categorizações do tempo de sobrevida observado - o erro de previsão da sobrevida variou entre 31,99\% (rede neural 13) e $880 \%$ (rede neural 14) para a estratégia um de imputação para os dados 
faltantes, função de transferência zero based log sigmoid, a partir da data da primeira consulta e diferentes variáveis clínicas significativas (Tabela 9). Os resultados foram inadequados para prever a sobrevida, exceto para a categorização do tempo de evolução entre 2 anos e 6 anos, sem nenhuma variável clínica (31,99\%; rede neural 13).

Pela categorização do tempo de sobrevida observado entre 1 ano e 6 anos, a inclusão de variáveis clínicas significativas com a função de transferência zero based log sigmoid, a partir da data da primeira consulta e valores de imputação para os dados faltantes baseados na estratégia 1 (Tabela 9), fez o erro de estimativa variar entre $51,85 \%$ (rede neural 15) e $70,68 \%$ (rede neural 17). Os resultados foram considerados inadequados para prever a sobrevida;

c) o resultado de previsão da sobrevida variou entre o limite máximo de $48,01 \%$ (rede neural 24) e mínimo de $11,37 \%$ (rede neural 26), quando as categorizações do tempo de sobrevida observado tomaram como referência o tempo médio de seguimento dos pacientes (4,9 anos), dependendo da data disponível para estimar a sobrevida e da função de transferência (Tabela 9). Os resultados foram considerados mais adequados para prever a sobrevida;

d) a inclusão da etiologia na categorização do tempo de sobrevida observado entre 2 anos e 6 anos resultou numa previsão da rede neural entre $21,91 \%$ (rede neural 42) a 29,52\% (rede neural 40) (Tabelas 9 e 9.1). $O$ resultado foi considerado mais adequado para prever a sobrevida para a cardiopatia da doença de Chagas $(21,91 \%$, rede neural 42$)$ e não acrescentou capacidade estimativa para as outras etiologias.

O teste com várias categorizações do tempo de sobrevida observado revelou que os melhores resultados de previsão da sobrevida foram obtidos pelo modelo de rede definida por tempo de sobrevida observado acima de 6 anos, a partir da data da primeira consulta com estimativa de sobrevida de 12,77\% (função de ativação - tangente hiperbólica; rede neural 24) ou 11,37\% (função de ativação - zero based log sigmoid, rede neural 26), e com tempo de sobrevida observado entre 2 anos e 6 anos, a partir da data do início dos sintomas com estimativa de sobrevida de $20,54 \%$ (função de ativação - 
tangente hiperbólica, rede neural 22) ou 22,60\% (função de ativação - zero based log sigmoid, rede neural 20) (Tabelas 9 e 9.1).

Os resultados dos testes que definiram os melhores modelos de dados da rede neural em estimar a sobrevida estão representados na tabela 10.

\subsection{Segunda fase - avaliação e aplicação da rede neural para estimar a sobrevida}

Nos pacientes sobreviventes até dezembro de 2012, os resultados de previsão da sobrevida são apresentados na tabela 11.

Os erros de previsão pelo emprego da rede neural foram superiores aos obtidos na previsão da primeira fase. Ainda assim, foram adequados para prever a sobrevida, principalmente no modelo de rede com tempo de sobrevida observada superior a 6 anos.

Os melhores modelos de previsão da sobrevida foram aqueles com tempo de sobrevida observado superior a 6 anos e que consideraram como data disponível para estimar a sobrevida a data da primeira consulta, tanto para tangente hiperbólica $(20,71 \%)$ quanto para função zero based log sigmoide $(21,50 \%)$.

Os melhores resultados da rede neural observados nesta fase coincidiram com os melhores resultados revelados pela rede neural na primeira fase do aprendizado da rede.

\subsection{Terceira fase - comparação dos modelos de dados da rede neural}

Os resultados da previsão de sobrevida sugeridos pela rede neural estão apresentados na tabela 12; o erro de estimativa da rede variou de acordo com o modelo de dados da rede neural. A comparação dos erros (previsto pela rede neural versus observado na evolução) para cada paciente está 
representada nas tabelas 13, 14, 15, 16 e 17 (estimativas individuais). Os resultados obtidos foram:

a) modelo com tempo de sobrevida observado entre 2 anos e 6 anos, a partir da data da primeira consulta e função zero based log sigmoid - a média dos erros de previsão ( $n=19$ sobreviventes) da rede, comparada com a média dos erros de previsão dos falecidos em 2013, aumentou de 35,62\% (desviopadrão 24,98) para 47,55\% (desvio-padrão 13,84), com homogeneidade dos erros de previsão maior (menor desvio-padrão).

Porém, individualmente, os erros de previsão da comparação com 0 real foram superiores a $44 \%$ em $73,68 \%$ (14 pacientes) do total de pacientes da amostra e inferiores a $40 \%$ em $26,32 \%$ (5 pacientes) do total de pacientes, para este modelo de dados da rede neural (Tabela 13);

b) modelo com tempo de sobrevida observado entre 2 anos e 6 anos, a partir da data de início dos sintomas e função zero based log sigmoid - a média dos erros de previsão ( $n=2$ sobreviventes), comparada com a média dos erros de previsão dos falecidos em 2013, aumentou de 11,55\% para $40,37 \%$, com discreta diferença na homogeneidade dos erros de previsão, respectivamente, desvios-padrão 12,49 e 13,65. Para os dois pacientes deste modelo de dados da rede neural, os resultados de 50,02\% e 30,72\% de sobrevida não permitiram avaliar da precisão da rede neural (Tabela 14);

c) modelo com tempo de sobrevida observado entre 2 anos e 6 anos, a partir da data do início dos sintomas e função tangente hiperbólica - a média dos erros de previsão ( $\mathrm{n}=2$ sobreviventes), comparada com a média dos erros de previsão dos falecidos em 2013, aumentou de 40,95\% (desvio-padrão 12,37) para 56,14\% (desvio-padrão 0,01), com homogeneidade dos erros de previsão maior (desvio-padrão menor). Para os dois pacientes deste modelo de dados da rede neural, os resultados de previsão da sobrevida de 56,15\% e $56,14 \%$ não permitiram avaliar a precisão da rede neural (Tabela 15);

d) modelo com tempo de sobrevida observado superior a 6 anos, a partir da data da primeira consulta e função tangente hiperbólica - a média dos erros de previsão ( $n=36$ sobreviventes), comparada com a média dos erros de previsão dos falecidos em 2013, diminuiu de 21,20\% (desvio-padrão 13,96) para $18,80 \%$ (desvio-padrão 12,39), com a dispersão em torno da média do 
erro de previsão mais homogêneo (desvio-padrão menor). Os resultados individuais, para este modelo de dados da rede neural, dos erros de previsão da comparação com o real variaram de $0,69 \%$ a $38,7 \%$. Os resultados superiores a $26 \%$ de erro previsão da sobrevida foram observados em 10 pacientes $(27,78 \%)$ do total de pacientes da amostra e foram inferiores a $25 \%$ em 26 pacientes (72,22\%). Em 13 pacientes (36,11\%), o erro de previsão da sobrevida da rede neural foi inferior a $11 \%$ (Tabela 16);

e) modelo com tempo de sobrevida observado superior a 6 anos, a partir da data da primeira consulta e função zero based log sigmoid - a média dos erros de previsão ( $\mathrm{n}=36$ sobreviventes), comparada com a média dos erros de previsão dos falecidos em 2013, aumentou de 18,48\% (desvio-padrão 13,54) para 19,48\% (desvio-padrão 11,67), com maior homogeneidade (menor desvio-padrão). Os resultados individuais dos erros de previsão da comparação com o real variaram de $0,95 \%$ a $45,88 \%$. Os resultados superiores a $26 \%$ de erro de previsão da sobrevida foram observados em 13 pacientes $(36,11 \%)$, e inferiores a $25 \%$ em 23 pacientes $(63,89 \%)$ do total de pacientes para este modelo de dados da rede. Em 13 pacientes (36,11\%), o erro de previsão da sobrevida da rede neural foi inferior a 13\% (Tabela 17).

A análise dos resultados de previsão da sobrevida pela rede neural sugere que os modelos de redes neurais com tempo de sobrevida observada superior a seis anos, considerando a data da primeira consulta tanto para a função tangente hiperbólica quanto para a função zero based log sigmoid, apresentaram maior precisão na estimativa da sobrevida.

\subsection{Quarta fase - reensaios dos modelos de dados da rede neural}

Foram incorporados para aprendizado-treinamento dos modelos de dados de rede neural 44 pacientes com dados completos dos 83 pacientes que vieram a falecer em 2013 (reensaio 1 - Tabela 18) e 30 pacientes com dados completos dos 50 pacientes que faleceram em 2014 (reensaio 2 - Tabela 19). Os resultados obtidos foram: 
a) reensaio incorporando os óbitos até 2013 - os testes de reensaio realizados em 145 pacientes com óbito e informações completas (101 falecidos em 2012 e 44, em 2013) e a estimativa de sobrevida da rede neural em 269 pacientes (186 falecidos em 2012 e 83 pacientes em 2013). Foi realizado o reensaio para os melhores modelos de dados da rede neural para previsão da sobrevida:

$a_{1}$ ) modelo com tempo de sobrevida observado superior a 6 anos, a partir da data da primeira consulta e função tangente hiperbólica - o erro de previsão de sobrevida ao incorporar os óbitos de 2013 ( $n=36$ pacientes) aumentou para $13,76 \%$, quando comparado com a previsão inicial sem esse dado (12,77\%) (Tabela 18). A média geral dos erros reais de previsão da sobrevida pela rede diminuiu de 21,20\% (desvio-padrão 13,96) para 8,48\% (desvio-padrão 9,61) após o reensaio 1 (Tabela 20). A homogeneidade dos erros de previsão foi maior (menor desvio-padrão);

$\mathrm{a}_{2}$ ) modelo com tempo de sobrevida observado superior a 6 anos, a partir da data da primeira consulta e função zero based log sigmoid - o erro de previsão da sobrevida ao incorporar os óbitos de 2013 ( $n=36$ pacientes) aumentou para $12,30 \%$, quando comparado com o resultado de previsão inicial sem esses dados (11,37\%) (Tabela 18) A média geral dos erros reais de previsão da sobrevida pela rede neural diminuiu de 18,48\% (desvio-padrão 14,10) para $11,24 \%$ (desvio-padrão 8,51) após o reensaio 1 (Tabela 21). A homogeneidade dos erros de previsão foi maior (menor desvio-padrão);

b) reensaio incorporando os óbitos até 2014 - Os testes de reensaio realizados em 175 pacientes com óbito identificado e informações completas (145 pacientes falecidos 2012 e 30, em 2014). A previsão da estimativa de sobrevida da rede neural foi realizada em 319 pacientes (269 pacientes falecidos em 2012 e 50, em 2013). Foi realizado o reensaio para os melhores modelos de dados da rede neural para previsão da sobrevida:

$b_{1}$ ) modelo com tempo de sobrevida observado superior a 6 anos, a partir da data da primeira consulta e função tangente hiperbólica - o erro de previsão da sobrevida ao incorporar os óbitos de 2014 ( $n=36$ pacientes) aumentou para $17,33 \%$, quando comparado com o resultado de previsão inicial sem esse dado 
$(12,77 \%)$ (Tabela 19). A média geral dos erros reais de previsão da sobrevida real pela rede diminuiu de $21,20 \%$ (desvio-padrão 13,96) para $9,10 \%$ (desviopadrão 9,61) após o reensaio 2 (Tabela 22). A homogeneidade dos erros de previsão foi maior (menor desvio-padrão);

$b_{2}$ ) modelo com tempo de sobrevida observado superior a 6 anos, a partir da data da primeira consulta e função zero based log sigmoid - o erro de previsão da sobrevida ao incorporar os óbitos de 2014 ( $n=36$ pacientes) aumentou para $14,88 \%$, quando comparado com o resultado de previsão inicial sem esse dado $(11,37 \%)$ (Tabela 19). A média geral dos erros reais de previsão da sobrevida real pela rede diminuiu de $18,48 \%$ (desvio-padrão 14,10 ) para 12,63\% (desviopadrão 11,27) após o reensaio 2 (Tabela 23). A homogeneidade dos erros de previsão foi maior (menor desvio-padrão).

\subsection{Quinta fase - comparação dos modelos de previsão da rede neural}

Foram comparadas as médias dos erros de previsão da sobrevida $(\mathrm{n}=$ 36 pacientes) pela rede neural, sem a incorporação dos óbitos de 2013 e 2014 com a incorporação dos óbitos de 2013 e 2014. Os resultados obtidos foram:

a) modelo de rede com tempo de sobrevida observado acima de 6 anos, a partir da data da primeira consulta e função tangente hiperbólica - a média geral ( $n=36$ pacientes) dos erros sem a incorporação dos óbitos de 2013 e 2014 de previsão da sobrevida pela rede, comparados com os resultados após os reensaios, incorporando os óbitos de 2013 e 2014, diminuiu, respectivamente, de $21,20 \%$ (desvio-padrão 13,96 ) para a $8,48 \%$ (desviopadrão 9,61) e 9,10\% (desvio-padrão 7,87). A homogeneidade dos erros de previsão para o modelo de dados do reensaio 2 foi maior (menor desviopadrão).

Os resultados individuais das médias dos erros de previsão da sobrevida foram inferiores a 10\% em $75 \%$ (27 pacientes) e superiores a 15\% em 25\% (9 pacientes) do total de pacientes para o reensaio 1 (Tabela 22). 
Para o reensaio 2, os erros de previsão da sobrevida pela rede neural foram inferiores a $10 \%$ em $72,22 \%$ ( 26 pacientes) e superiores ou iguais a $15 \%$ em $27,78 \%$ (10 pacientes) do total de pacientes (Tabela 22);

b) modelo de rede com tempo de sobrevida observado superior a 6 anos, a partir da data da primeira consulta e função zero based log sigmoid - a média geral ( $n=36$ pacientes) dos erros de previsão da sobrevida pela rede sem a incorporação dos óbitos de 2013 e 2014, comparados com os resultados após o reensaio 1, incorporando os óbitos, diminuiu de 18,48\% (desvio-padrão 14,10) para $11,24 \%$ (desvio-padrão 8,51 ) e aumentou para $12,63 \%$ (desviopadrão 11,27 ) após o reensaio 2 , com maior homogeneidade dos erros de previsão para o modelo de dados do reensaio 1 (menor desvio-padrão) (Tabela 23). Os resultados individuais das médias dos erros de previsão da sobrevida, incorporando os óbitos de 2013 e 2014, foram inferiores ou iguais a 10\% em $61,11 \%$ (22 pacientes) e superiores a $15 \%$ em $38,89 \%$ (14 pacientes) do total de pacientes para o reensaio 2 (Tabela 23).

Em síntese, os resultados obtidos pelos testes para os dois melhores modelos de dados da rede neural sugerem que:

a) houve aprendizado satisfatório da rede neural pela atualização dos dados de mortalidade de anos subsequentes;

b) a acurácia das médias dos erros de previsão da sobrevida após a incorporação dos óbitos ocorridos em 2013 e 2014 foi melhor, quando comparada com as médias de previsão da rede neural para os sobreviventes até 2012;

c) os resultados das médias gerais dos erros de previsão da sobrevida foram satisfatórios, mas inferiores a 13\% após a incorporação dos óbitos de 2013 e 2014;

d) o modelo de dados com limite de sobrevida superior a seis anos, a partir da data da primeira consulta e função tangente hiperbólica, teve a melhor precisão da rede neural na previsão da sobrevida com erro inferior a 10\%;

e) a precisão da previsão da sobrevida, quando avaliada caso a caso, após a incorporação dos óbitos ocorridos em 2013 permite resultados satisfatórios (erro de previsão $\leq 5 \%$ ) em 16 casos, mas também incorre em 
erros de previsão insatisfatórios (>30\%) em dois casos, num total de 36 casos para este modelo de rede;

f) a categorização do tempo de sobrevida observado é importante para o aprendizado-treinamento da rede neural na previsão da sobrevida.

\subsection{Avaliação dos melhores modelos da rede neural}

Os resultados do desempenho dos melhores modelos de rede neural para a previsão da sobrevida foram avaliados.

\subsubsection{Sensibilidade, especificidade, acurácia, valor preditivo positivo, valor preditivo negativo da rede neural.}

Para os seis melhores modelos de rede neural os resultados evidenciaram sensibilidade que variou entre 93,0\% e $87,2 \%$, especificidade entre $77,5 \%$ e $66,7 \%$, acurácia entre $85,2 \%$ e $78,9 \%$, valor preditivo positivo que variou entre $88,0 \%$ e $53,6 \%$ e valor preditivo negativo entre $97,4 \%$ e $71,4 \%$ (Tabela 23).

Os resultados obtidos pelos melhores modelos de dados avaliados permitem a seguinte síntese:

a) no modelo de rede neural com tempo de sobrevida observado superior a 6 anos, a partir da data da consulta inicial, com intervalo de corte de três anos (1.095 dias), a sensibilidade foi de 93\% (com ambas as funções de ativação), especificidade de 77,5\% (função tangente hiperbólica) e 76,4\% (função zero based log sigmoid), acurácia da rede foi satisfatória de $81 \%$ ou $80,2 \%$ (dependendo da função de ativação), valor preditivo negativo alto de $97,4 \%$ (com ambas as funções de ativação) e valor preditivo positivo baixo de $54,7 \%$ ou $53,6 \%$ \% (dependendo da função de ativação); 
b) no modelo de rede neural com tempo de sobrevida observado entre 2 anos e 6 anos, a partir da data do início dos sintomas, com intervalo de corte de dois anos (730 dias), a sensibilidade foi de $89,8 \%$ (com ambas as funções de ativação), especificidade de 76,5\% (função zero based log sigmoid) e 72,5\% (função tangente hiperbólica), acurácia da rede foi satisfatória de $83,9 \%$ e $85,2 \%$ (dependendo da função de ativação), valor preditivo positivo alto de $88 \%$ ou $86,3 \%$ (dependendo da função de ativação) e valor preditivo negativo alto de $79,6 \%$ ou $78,7 \%$ (dependendo da função de ativação);

c) no modelo de rede neural com tempo de sobrevida observado inferior a 2 anos, a partir da data do início dos sintomas, com intervalo de corte de um ano (365 dias), a sensibilidade foi razoável de $87,2 \%$ (com ambas as funções de ativação), especificidade inadequada de $66,7 \%$ e $62,5 \%$ (dependendo da função de ativação), acurácia satisfatória de $80,3 \%$ e 78,9\% (dependendo da função de ativação), valor preditivo positivo razoável de 83,7\% e $82,0 \%$ (dependendo da função de ativação) e valor preditivo negativo baixo de 72,75 e $71,4 \%$ (dependendo da função de ativação);

d) os resultados foram insatisfatórios nas estimativas por tempo de seguimento observado superior a 6 anos, a partir da data do início dos sintomas, com intervalo de corte de dois anos, independentemente da função de ativação bem como no tempo de sobrevida observado inferior a 2 anos, a partir da data do início dos sintomas, com intervalo de corte de seis meses, independentemente da função de ativação. Nos modelos com tempo de seguimento observado entre 2 anos e 6 anos, com intervalo de corte de um ano, independentemente da função de ativação, tanto para a data do início dos sintomas quanto para a data da consulta inicial, os resultados foram insatisfatórios (Tabela 24).

\subsubsection{Função de perda da rede neural}

O erro ou perda média estimada da sobrevida para os melhores modelos de rede neural (Tabela 25) revelou: 
a) o erro médio de previsão da sobrevida variou de 126,95 dias a 389,31 dias;

b) os menores erros de previsão (126,95 dias e 133,07 dias) foram obtidos pelo modelo de rede neural com tempo de sobrevida inferior a 2 anos e o tempo estimado desde a data de início dos sintomas;

c) os segundos menores erros de previsão (231,61 dias e 259,06 dias) foram alcançados pelo modelo de rede neural com tempo de sobrevida entre 2 anos e 6 anos, e o tempo estimado desde a data de início dos sintomas;

d) os piores erros de estimativa foram (293,88 dias, 332,55 dias e 389,31 dias) para tempo de sobrevida superior a 6 anos e tempo de sobrevida entre 2 anos e 6 anos, com informação da data da primeira consulta;

Os melhores resultados da função de perda foram obtidos pelos modelos de rede neural, com o menor número de pacientes (tamanho da amostra $=47$ ) e com informação da data do início dos sintomas.

A avaliação pelo emprego da função de perda revelou a estimativa da rede neural que pode alcançar erros de 4,4 meses até 1,1 anos para mais ou para menos. 
A casuística estudada tem características de interesse para a interpretação dos achados e potenciais implicações clínicas dos resultados obtidos.

\subsection{Considerações sobre as características clínicas dos pacientes}

Trata-se de casuística ambulatorial, diversa de casuísticas de publicações de nosso meio que avaliaram pacientes hospitalizados (Bestetti et al., 1997; Pereira Barretto et al., 1998; Carlo et al., 2014; Albuquerque et al., 2015). Também é digno de nota o fato de ser hospital acadêmico de referência terciária que integra a rede do Sistema Único de Saúde (SUS), incluindo, entre suas responsabilidades institucionais, identificar pacientes com insuficiência cardíaca de prognóstico mais reservado com necessidade de tratamentos complexos.

\subsubsection{Casuística}

A casuística $(n=2.128)$ pode ser estimada grande, comparada com outras que avaliaram incidência e fatores desencadeantes $(n=903)$ (Pereira Barretto et al., 1998), sobrevida ( $n=104)$ (Mady et al., 1994), prognóstico ( $n=1220$ - Freitas et al., 2004 ou n=944 - Nadruz et al., 2018), fatores preditores de mortalidade $(n=56)$ (Bestetti et al., 1994), modelo clínico de predição ambulatorial de sobrevida $(n=268)$ (Aaronson et al., 1997), impacto de comorbidades na estratificação prognóstica ambulatorial $(n=807)$ (Senni et al., 2006) de pacientes com insuficiência cardíaca. Porém, dada a natureza generalizada sob ponto de vista cardiológico, de certa forma aberta do Serviço, lidamos com pacientes que recebem o diagnóstico clínico sem restrições quanto a casuísticas apenas de homens (Mady et al., 1994), etiologia da doença de Chagas (Bestetti et al., 1994) ou isquêmica (Lewis et al., 2003), ou 
fração de ejeção do ventrículo esquerdo inferior ou igual a 40\% (Gradman et al.,1989).

\subsubsection{Idade}

A média da idade na casuística (57,7 anos; desvio-padrão 13,1$)$ foi de pacientes com idade inferior a 65 anos (71\%), à semelhança de outros estudos, que verificaram médias de idade entre 51,7 anos (desvio- padrão 8,3) e 59 anos (desvio- padrão 14 anos) (Bestetti et al., 1997; Freitas et al., 2005; Silva et al., 2007; Nadruz et al., 2018), embora haja casuísticas publicadas com média de idade superior a 61 anos (Roger et al., 2004; Rohde et al., 2005; Moutinho et al., 2008; Shah et al., 2017) e outra com média de idade de 48 anos desviopadrão 12 anos (Nunes et al., 2008).

Portanto, nossa casuística identificou, no período de estudo, pacientes adoecidos em fase potencialmente produtiva da vida, com suas eventuais implicações familiares, econômicas e sociais.

\subsubsection{Sexo}

A frequência de homens em relação a mulheres predominou (64\%) na casuística, assim como em outros estudos (Likoff et al., 1987; Bestetti et al., 1997; Lewis et al., 2003; Freitas et al., 2005; Rassi et al, 2006; Ahmed et al., 2006a; Theodoropoulos et al., 2007; Nunes et al., 2008; Marcula et al., 2011; Carlo et al., 2014; Gheorghiade et al., 2013; Abdul-Rahim et al., 2016; Nadruz et al., 2018).

Por outro lado, há estudos em que o sexo feminino foi mais frequente (Mahmood et al., 2014; Gradman et al., 1989; Maclntyre et al., 2000; Roger et al., 2004; Ahmed et al., 2006b; Fonarow et al., 2007b; Moutinho et al., 2008; Gerber et al., 2015; Albuquerque et al., 2015). 
Por conseguinte, ainda que a frequência de homens predomine na casuística, as mulheres compõem contingente relevante (Ponikowski et al., 2016).

\subsubsection{Antecedentes}

Na nossa casuística, a maioria dos pacientes foi de não diabéticos $(70 \%)$ e, entre aqueles com diagnóstico de diabete melito (23\%), houve $18 \%$ insulino - independentes. Pacientes com antecedentes de hipertensão arterial foram prevalentes (72\%) na casuística. Tais características reiteram a importância epidemiológica da hipertensão arterial em relação, também, à insuficiência cardíaca.

\subsubsection{Etiologia}

A distribuição da etiologia revisada em cada paciente tem características próprias quanto à frequência das cardiopatias hipertensiva (43\%), isquêmica (25\%), cardiopatia da doença de Chagas (16\%), cardiopatia dilatada idiopática (10\%) e alcoólica (7\%).

Em outras casuísticas brasileiras, houve predomínio de cardiomiopatia dilatada idiopática (28,2\% a 37,2\%) (Freitas et al., 2005; Silva et al., 2007) e isquêmica (21\% a 33\%) (Pereira Barretto et al., 1998; Albuquerque et al., 2015; Nadruz et al., 2018).

Em casuística de outros países, houve diferença na distribuição etiológica nas amostras estudadas com a maior frequência de cardiomiopatia dilatada idiopática (Keogh et al., 1990) ou a etiologia isquêmica (Senni et al., 1999; Levy et al., 2006; Abraham et al., 2008).

Por isso, esta casuística permite a interessante possibilidade de avaliação comparativa de diferentes etiologias da insuficiência cardíaca. 


\subsection{6 Índice de massa corpórea}

A média do índice de massa corpórea foi baixa $\left(26,9 \mathrm{~kg} / \mathrm{m}^{2}\right.$; desviopadrão 5,7 ), o valor inferior a $25 \mathrm{~kg} / \mathrm{m}^{2}$ e o superior a $30 \mathrm{~kg} / \mathrm{m}^{2}$ ocorreram, respectivamente, em $31 \%$ e $18 \%$ dos pacientes. Portanto, extremos de massa corpórea, que podem se associar ao prognóstico, não foram frequentes (Anker et al., 1997, 2003; Kenchaiah et al., 2002; Veloso et al., 2005; Okoshi et al., 2017).

\subsubsection{Frequência cardíaca}

A média da frequência cardíaca foi 80,78 (desvio-padrão 15,97) batimentos por minuto, e os extremos superior a cem batimentos por minuto e inferiores a 60 batimentos por minuto ocorreram, respectivamente, em 7\% e $3 \%$ dos pacientes com insuficiência cardíaca. Tais dados podem ser úteis, também, para o planejamento terapêutico (Swedberg et al., 2010), uma vez que a frequência cardíaca elevada é um fator de risco (Kannel 1987; Pocock et al., 2006; Böhm et al., 2010) e um preditor de mortalidade (Ariel et al., 2005).

\subsubsection{Pressão arterial sistólica e diastólica}

O valor médio da pressão arterial sistólica foi de $137,5 \mathrm{~mm} \mathrm{Hg}$ com desvio-padrão $28,8 \mathrm{~mm} \mathrm{Hg}$ e o valor médio da pressão arterial diastólica de 88 $\mathrm{mm} \mathrm{Hg}$ com desvio-padrão, $17,1 \mathrm{~mm} \mathrm{Hg}$, o que não deixa de ser digno de nota em relação ao antecedente de hipertensão arterial frequente. 
Pressão arterial sistólica superior a $130 \mathrm{~mm} \mathrm{Hg} \mathrm{(46 \%} \mathrm{dos} \mathrm{pacientes)} \mathrm{foi}$ frequente, e inferior a $100 \mathrm{~mm} \mathrm{Hg}$, mais rara (4\%); por outro lado, pressão arterial diastólica superior a $90 \mathrm{~mm} \mathrm{Hg}$ e inferior a $80 \mathrm{~mm} \mathrm{Hg}$ foram observadas, respectivamente, em $30 \%$ e $21 \%$ dos pacientes. Em amostra ambulatorial, os extremos de pressão arterial que podem ter significado prognóstico (Vasan et al., 2001; Lewis et al., 2003; Lee DS et al., 2003; Klein et al., 2005; Pocock et al., 2006) não foram frequentes.

\subsubsection{Classe funcional}

Como casuística ambulatorial, a maior parte dos pacientes (65\%) da casuística estava na classe funcional II ou III da New York Heart Association, enquanto $28 \%$, na classe funcional I e IV em igual porcentagem, demonstrando que a maioria dos pacientes se encontrava em condição estável, de modo a permitir a orientação terapêutica apropriada.

\subsubsection{Tempo decorrido até o desfecho}

Um singularidade desta casuística são as informações de desfechos no longo prazo, pois a casuística de 2003 a 2007 teve as informações de desfechos recuperadas até 2014, com tempo médio de seguimento de 59,6 meses (desvio-padrão 41,8 meses). O tempo de observação de outras casuísticas brasileiras publicadas variou de 1 ano a 6,4 anos (Bestetti et al., 1994; Mady et al., 1994; Pereira Barretto et al., 1998; Freitas et al., 2005; Carlo et al., 2014). 


\subsubsection{Variáveis ecocardiográficas}

Quanto às variáveis ecocardiográficas, identificamos o diâmetro do átrio esquerdo, o diâmetro diastólico do ventrículo esquerdo e a espessura do septo interventricular associados à mortalidade. Esse achado vai ao encontro de publicações anteriores que relacionaram a dimensão do átrio esquerdo (Hsiao; Chiou, 2013) e a dimensão diastólica do ventrículo esquerdo com prognóstico de mortalidade (Freitas et al., 2005).

Reiteramos o achado da não associação entre o diâmetro sistólico de ventrículo esquerdo e o prognóstico de sobrevida, o que vai de encontro a outros estudos que observaram fraca associação do diâmetro sistólico de ventrículo esquerdo com sobrevida em pacientes com diagnóstico de insuficiência cardíaca (Cowie et al., 2000). Por outro lado, a associação da espessura do septo interventricular com a mortalidade foi um achado curioso.

A distribuição da fração de ejeção do ventrículo esquerdo reflete as características de casuística ambulatorial e observamos que os valores observados não foram associados com o prognóstico, o que vai de encontro a outros estudos (Cohn et al., 1986, 1987,1988; Gradman et al., 1989; Lewis et al., 2003; Pfeffer et al., 2003; Freitas et al., 2005; Pocock et al., 2006; Rassi et al., 2007; Lupón et al., 2017).

Não deixa de ser de interesse a restrição ao uso da fração de ejeção do ventrículo esquerdo na estratificação da insuficiência cardíaca em algumas circunstâncias - no caso de idosos e hospitalizados - (Shah et al., 2017) e o conceito que a fração de ejeção não seja um marcador acurado de risco de pacientes após internação hospitalar (Steinberg; Fang, 2017). Talvez este fato esteja relacionado ao fato de que, nas formas mais avançadas da doença tanto os diâmetros ventriculares quanto a fração de ejeção do ventrículo esquerdo atenuem sua associação com a sobrevida (Veloso et al., 2005). Possivelmente nesta casuística o mesmo se aplique, uma vez que a variável fração de ejeção do ventrículo esquerdo não se revelou associada ao prognóstico de sobrevida. 


\subsubsection{Variáveis laboratoriais}

Entre as variáveis laboratoriais identificamos, à semelhança de outros estudos, a taxa de potássio sérico (Ahmed et al., 2007; Bielecka-Dabrowa et al., 2012), a taxa de creatinina sérica (Silverberg et al., 2000; Vardeny et al., 2012; Zanaad et al, 2013; Damman et al., 2014; Pimentel et al., 2014; Palazzuoli et al., 2016) e a taxa de colesterol (Volpato et al., 2001a; Horwich et al., 2002, 2008; Rauchhaus et al., 2003; Kalantar-Zadeh et al., 2004; Afsarmanesh et al., 2006) associadas ao prognóstico.

Por outro lado, verificamos que a dosagem sérica de sódio não foi associada ao prognóstico, o que vai de encontro a outros estudos que correlacionaram a concentração mais baixa de sódio sérico à severidade da insuficiência cardíaca (Klein et al., 2005) e como preditor de mortalidade (Lee WH; Packer, 1986; Lee DS et al., 2003; Milo-Cotter et al., 2008; Abraham et al., 2008; Waikar et al., 2009; Kajimoto et al., 2016).

Reproduzimos, neste estudo, a observação de não associação da dosagem sérica de hemoglobina com o prognóstico. Uma possível explicação estaria relacionada à baixa prevalência da anemia (11\% de pacientes com hemoglobina sérica inferior a $12 \mathrm{~g} / \mathrm{dl}$ ), quando comparada com a prevalência tanto em pacientes ambulatoriais de $42,6 \%$ (Go et al., 2006) a 55,6\% (Silverberg et al., 2000), quanto em pacientes hospitalizados de $17 \%$ (Ezekowitz et al., 2003) a 45\% (Maraldi et al., 2006). Entretanto, os resultados que observamos vão de encontro a outros autores (Ezekowitz et al., 2003; Anand et al., 2004; Maraldi et al., 2006; Levy et al., 2006; Tang; Katz ,2008; Kyriakou; Kiff ,2016) que associaram a anemia com prognóstico.

Talvez a explicação para nossa observação que vai ao encontro de estudos (Anand et al., 2005; Abebe et al., 2017) e da afirmação de Inder S. Anand seja a presença de anemia como marcador de risco, não como preditor de mortalidade (Anand, 2008). 
As taxas séricas de leucócitos e de linfócitos foram outras variáveis laboratoriais avaliadas em nossa casuística que não foram associadas com o prognóstico de sobrevida, o que vai de encontro a outros estudos que associaram valores baixos de linfócitos - mas não à dosagem sérica de leucócitos - com mortalidade (Acanfora et al., 2001; Huehnergarth et al., 2005; Charach et al., 2011; Uthamalingam et al., 2011; Marcula et al., 2015).

\subsubsection{Medicamentos em uso}

Verificamos a subutilização do tratamento medicamentoso recomendado (Bocchi et al., 2009, 2012; Ponikowski et al., 2016) para os pacientes com insuficiência cardíaca com fração de ejeção reduzida. Fatores de aderência ao tratamento medicamentoso recomendado têm sido reconhecidos como desafios no tratamento de pacientes (Chizzola et al., 1996; Pereira-Barretto et al., 2001). A preocupação com a subutilização do tratamento medicamentoso, por diferentes motivos, tem existido em nosso meio há vinte e dois anos. Porém, esperar-se-ia que fosse menor, hoje, do que a observada em nossa casuística. Tal verificação também foi feita em outros países, em duas grandes coortes com, respectivamente, 105.388 pacientes (53\% 55.856 pacientes em uso de inibidores da enzima de conversão da angiotensina ou bloqueadores do receptor da angiotensina e $48 \% 50.586$ pacientes em uso de betabloqueadores) do Registro ADHERE (Acute Descompensated Heart Failure National Registry) (Gheorghiade; Filippatos, 2005 ) e em 6.505 pacientes, (56\% 3.643 pacientes em uso de $50 \%$ da dose alvo de betabloqueador) do estudo SHIFT (Systolic Heart Failure tratment with the inhibitor Ivabradine Trial) (Swedberg et al., 2010).

Curiosamente, verificamos que o número de medicamentos em uso, da maneira como foi analisado, não foi associado ao prognóstico. 


\subsubsection{Mortalidade}

A mortalidade geral, por todas as causas, em nossa casuística foi alta (60\%) nos onze anos de seguimento ambulatorial; em consonância a outras experiências da literatura (Roger et al., 2004; Barker et al., 2006) foi superior nos pacientes do sexo masculino e nos idosos (acima de 65 anos) e comparável à casuística estrangeira, com média de oito anos de acompanhamento, cuja mortalidade foi similarmente alta $(67,8 \%)$ e mais frequente (54\%) nos pacientes acima de 80 anos (Gerber et al., 2015).

Os dados de evolução tardia são uma peculiaridade relevante desta casuística. De fato, observações dilatadas no tempo são úteis para divisar a evolução de doenças.

\subsection{Considerações sobre a análise estatística}

Estimamos a probabilidade de sobrevida em relação às características demográficas, clínicas e laboratoriais escolhidas dentre 45 variáveis, reduzidas para 33, em função de redundância de informação implícita na variável. É de interesse observar a influência de cada variável obtida no exame de rotina, no decorrer de quase uma década de acompanhamento.

É oportuno enfatizar o tratamento dos dados faltantes quase inerentes a este estudo da área de epidemiologia clínica em condições da vida real (real life conditions), sempre um desafio científico e estatístico, pois há os limites do controle possível na atividade cotidiana que dissipa controles estritos atinentes a protocolos (protocol conditions).

Em estudo anterior, foi submetida a teste a hipótese de ordenar os dados faltantes, para cada variável em uma categoria, atenuando a perda de participantes com informação na modelagem estatística e, consequentemente, com perda da estimativa também para os participantes com dado faltante (Paes, 2007; Assunção, 2012). Tivemos a oportunidade de nos apoiarmos 
nesse método, amenizando, assim, o escape de potenciais resultados relevantes pela perda da informação, sem comprometer a confiabilidade do resultado obtido (Nunes, 2009; Nunes, 2011; Kaambwa et al., 2012), pela necessidade de enfrentar a realidade prática de dados faltantes (Little et al., 2012; Ware et al., 2012).

Em relação às variáveis demográficas e clínicas, a idade se revelou significativa $(p<0,001)$ à similitude da observação de outros autores (Klein et al., 2005; Abraham et al., 2008) e a probabilidade de sobrevida foi significativamente menor em relação aos pacientes com mais de 65 anos de idade, observação condizente com estudos prévios (Maclntyre et al., 2000; Lewis et al., 2003; Roger et al., 2004, 2013; Barker et al., 2006; Pocock et al., 2006), nos pacientes com índice de massa corpórea inferior a $25 \mathrm{~kg} / \mathrm{m}^{2}$ acordes com outras experiências (Horwich et al., 2001; Davos et al., 2003; Pocock et al., 2006; Fonarrow et al., 2007a; Doehner, 2014), nos pacientes com doença de Chagas, concordante com observações feitas no decorrer de décadas (Freitas et al., 2002, 2005; Nunes et al., 2008, 2013; Issa et al., 2010; Rassi et al., 2010; Bocchi et al., 2017; Nadruz et al., 2018). Também foi menor a probabilidade de sobrevida para pacientes em classe funcional III e IV da New York Heart Association, de acordo com as observações em estudos prévios (Pocock et al.,2006; Theodoropoulos et al., 2008) e em pacientes com história de diabetes melito sem o uso de insulina ou com o uso de insulina, conforme estudos anteriores de outros pesquisadores (Pfeffer et al., 2003; Pocock et al., 2006).

Por outro lado, pacientes com pressão arterial diastólica superior a 90 $\mathrm{mm} \mathrm{Hg}$ demonstraram maior probabilidade de sobrevida, tendência também observada por outros autores (Poole-Wilson et al., 2003; Kalantar-Zadeh et al., 2004; Pocock et al., 2006).

Entre os dados de exames complementares, verificamos menor probabilidade de sobrevida nos doentes com espessura do septo interventricular superior a $12 \mathrm{~mm}$, no diâmetro diastólico do ventrículo esquerdo superior a $75 \mathrm{~mm}$, no diâmetro do átrio esquerdo (Hsiao; Chiou, 2013) superior ou igual a $40 \mathrm{~mm}$, na dosagem sérica do potássio superior a $5,0 \mathrm{mEq} / \mathrm{L}$, de 
acordo com observações de outros autores (Rossignol et al., 2011). $\mathrm{Na}$ dosagem sérica de colesterol total inferior a $200 \mathrm{mg} / \mathrm{dl}$, concorde com outros pesquisadores (Krumholz et al., 1994; Volpato et al., 2001b; Horwich et al., 2002, 2008; Rauchhaus et al., 2003; Kalantar-Zadeh et al., 2004; Afsarmanesh et al., 2006; Christ et al., 2006; Kjekshus et al., 2007) e na dosagem sérica da creatinina superior a $2.6 \mathrm{mg} / \mathrm{dL}$, achados em harmonia com outras experiências (Dries et al., 2000; Fonarow et al., 2005; Vardeny et al., 2012; Damman et al., 2014 ; Pimentel et al., 2014; Kang et al., 2018).

Reproduzimos, neste estudo, a observação da relação inversa entre a elevação de algumas variáveis clínicas e laboratoriais e a melhor probabilidade de sobrevida, significativamente maior, que confirmaram os resultados de outros estudos para a pressão arterial diastólica (Horwich et al, 2001; KalantarZadeh et al., 2004), índice de massa corpórea (Horwich et al., 2001; Davos et al., 2003; Pocock et al., 2006; Fonarrow et al., 2007a; Doehner, 2014) e dosagem de colesterol total (Krumholz et al., 1994; Volpato et al., 2001a; Horwich et al., 2002; Rauchhaus et al., 2003; Kalantar-Zadeh et al., 2004; Afsarmanesh et al., 2006; Christ et al., 2006; Kjekshus et al., 2007; Horwich et al., 2008).

$\mathrm{Na}$ maioria dos pacientes ( $86 \%$ dos pacientes), observamos que a dosagem de hemoglobina sérica foi superior a $12 \mathrm{mg} / \mathrm{dl}$ e estes evoluíram com melhor sobrevida ao longo do tempo, o que vai de encontro ao observado (Silverberg et al., 2000).

Reiteramos a relação inversa entre a fração de ejeção do ventrículo esquerdo e a mortalidade concordante com estudos prévios (Senni; Redfield, 2001), porém a fração de ejeção do ventrículo esquerdo foi associada com o prognóstico apenas na análise univariada, o que vai de encontro a observações prévias de outros estudos (Cohn et al., 1988; Gradman et al., 1989; Cintron et al., 1993; Lewis et al., 2003; Freitas et al., 2005; Pocock et al., 2006), mas não se manteve como variável significante na análise subsequente.

A nossa casuística caracterizou-se pela baixa utilização do tratamento medicamentoso recomendado, apesar dos avanços observados nos últimos 
trinta anos (Sacks et al., 2014; McMurray et al., 2014) que comprovaram a redução na fração de ejeção e de mortalidade (Burnett et al., 2017).

Reproduzimos que $14 \%$ e $49 \%$ dos pacientes, respectivamente, não fizeram uso dos inibidores da enzima de conversão da angiotensina ou do bloqueador do receptor da angiotensina e do antagonista da aldosterona, e mais da metade dos pacientes (55\%) não fizeram uso de betabloqueador, apesar da importância do seu uso contra o deletério efeito da ativação do sistema nervoso simpático (Khan, 2015), e da redução de 34\% na mortalidade nos pacientes com etiologia isquêmica (Hjalmarson et al., 2000), bem como a redução de $35 \%$ na mortalidade em pacientes com insuficiência cardíaca (Packer et al., 2001). Sendo assim, nossos resultados se aproximam das tendências observadas em estudos recentes em que 83\% dos pacientes fizeram uso de betabloqueador; 16\%, de inibidores da enzima de conversão; $56 \%$, de bloqueadores do receptor da angiotensina e $21 \%$, com antagonistas da aldosterona (Shah et al., 2017; Steinberg et al., 2017).

Verificamos mortalidade, em cinco anos, de $32 \%$ e, em onze anos, de $60 \%$, semelhante às observações de estudos nacionais (Godoy et al., 2011; Kaufman et al., 2015) e internacionais (Roger et al., 2004; Barker et al., 2006; McMurray et al., 2014; Sacks et al., 2014; Gerber et al., 2015). Ainda que elevada e necessitando de redução, foi menor do que o observado no Framingham Heart Study com mortalidade superior a 50\%, decorridos cinco anos do diagnóstico de insuficiência cardíaca (Kenchaiah; Vasan, 2015).

Selecionamos, assim, as variáveis para a avaliação prognóstica pelo modelo de riscos proporcionais de Cox.

Para a construção do modelo de riscos proporcionais de Cox, houve um cuidado adicional para identificar variáveis associadas com o prognóstico. $\mathrm{Na}$ primeira etapa, contribuíram apenas os dados válidos, cujo interesse foi comparar grupos e identificar diferenças. A partir da segunda etapa, a categoria dados faltantes foi incluída na análise e foram retiradas as variáveis não significativas.

A pressão arterial sistólica foi retirada do modelo pois, na avaliação da significância do seu efeito pelo teste de verossimilhança, somente a categoria 
dos "dados faltantes" foi relevante, portanto foi eliminada como fator prognóstico para a sobrevida.

Na terceira etapa, as variáveis não significativas foram reintroduzidas, testadas uma a uma no modelo, e tiveram sua significância recalculada para confirmar que não estaríamos perdendo a relevância clínica de alguma variável. O antecedente de diabetes revelou-se significante. Assim, identificamos cuidadosamente as variáveis associadas com o prognóstico.

Uma variável que se revelou importante durante o estudo foi o tempo decorrido desde o início dos sintomas, estimado a partir da anamnese dos pacientes individualmente, que informa, de certo modo, a evolução da doença. É digno de nota que tal informação, básica e fundamental estivesse ausente em alta percentagem de pacientes (76\%). Nossa observação reiterou a importância de um dado obtenível na anamnese, tanto na avaliação da probabilidade de sobrevida, quanto nas estimativas da rede neural, e que deve sempre ser pesquisado nos pacientes.

Apesar de estudos anteriores revelarem maior mortalidade associada à taxa de sódio sérico (Klein et al., 2005; Levy WC et al., 2006; Abraham et al., 2008), à concentração de hemoglobina sérica (Levy WC et al., 2006), à taxa de triglicérides (Freitas et al., 2009), à fração de lipoproteína de baixa densidade (Horwich et al., 2008), à fração de lipoproteína de alta densidade (Volpato et al., 2001b) e ao valor da fração de ejeção do ventrículo esquerdo (Levy WC et al., 2006), em nossa casuística, essas variáveis não foram selecionadas pela análise estatística como fatores prognósticos de sobrevida. Portanto, não foram eleitas como variáveis preditoras de sobrevida para a rede neural.

A associação sugerida entre a taxa de hemoglobina e o prognóstico (Anand et al., 2004; Ezekowitz et al., 2003; Maraldi et al., 2006; Tang et al., 2008; Kyriakow et al., 2016) como preditor de sobrevida (Levy WC et al., 2006) e como marcador de risco (Anand et al., 2005, 2008; Abebe et al., 2017) não foi reproduzida nos achados deste estudo. Por outro lado, diabetes melito influiu negativamente no prognóstico. Entre os dados ecocardiográficos também observamos a associação com o prognóstico do diâmetro do átrio 
esquerdo (Hsiao; Chiou, 2013), do diâmetro diastólico do ventrículo esquerdo (Merlo et al., 2011; Addetia et al., 2015) e da espessura do septo interventricular, variáveis selecionadas para a rede neural.

Nas 12 variáveis selecionadas como fator prognóstico na sobrevida, os dados faltantes foram inferiores a $31 \%$ : índice de massa corpórea 18\%; pressão arterial diastólica 6\%; classe funcional, segundo a New York Heart Association, diabetes melito $7 \%$; dosagem sérica de potássio $5 \%$; dosagem sérica de creatinina $3 \%$; dosagem sérica de colesterol total 30\%; espessura do septo interventricular do ventrículo esquerdo 37\%; diâmetro diastólico do ventrículo esquerdo $21 \%$; diâmetro do átrio esquerdo $22 \%$.

\subsection{Considerações sobre as estimativas feitas pelo emprego da rede neural}

Antes de avaliar os resultados obtidos pelo emprego da rede neural, cabem observações sobre questões metodológicas desenvolvidas na análise.

\subsubsection{Amostras aleatórias}

O emprego da rede neural pressupõe as etapas de aprendizadotreinamento e previsão, além de experimentar a melhor maneira de agrupar os dados para que a rede neural aprenda e reconheça padrões, a partir de exemplos, alcançando melhor estimativa da sobrevida.

O primeiro método de aprendizado-treinamento utilizado foi ordenar a casuística em três grupos aleatórios, de forma que o aprendizado seria feito no primeiro; o treinamento, no segundo, e a aplicação, no terceiro grupo. A acurácia da previsibilidade da rede nesta circunstância foi muito baixa. Tal 
ocorreu provavelmente, em razão de agrupar valores de tempos de sobrevida, tempo decorrido do início dos sintomas ou tempo decorrido da primeira consulta, tão díspares entre os pacientes. Portanto, ordenar a nossa casuística pelo método de amostras aleatórias não foi adequado para melhorar a previsão da sobrevida pela rede neural.

Também merece menção o fato de que este estudo não se dedicou à comparação entre a análise estatística tradicional e a rede neural, mas por utilizar o método estatístico como ferramenta para definição das variáveis associadas ao prognóstico viabilizando a imputação dessas variáveis para aprendizado e treinamento da rede neural.

\subsubsection{Data do início dos sintomas}

Com base na importância clínica da referência da data em que o paciente iniciou a percepção dos sintomas, a ser obtida na avaliação inicial, foi oportuno considerar a variável data do início dos sintomas que, independentemente de outras variáveis limitadoras, da função de ativação ou do tempo de sobrevida com ou sem categorização, sugeriu os melhores resultados de previsão da sobrevida pela rede neural.

Constatamos que a presença da data do início dos sintomas para o aprendizado-treinamento da rede revelou resultados adequados de previsão de sobrevida, entre $20,54 \%$ e $22,60 \%$ de erro de previsão. Porém, estes resultados foram piores quando se realizou a previsão da rede nos pacientes, em acompanhamento (vivos), com valores entre 33,23\% e 39,33\%. Sendo assim, estudos adicionais serão necessários com a data inicial da estimativa do início dos sintomas para melhor acurácia de previsão da sobrevida pela rede neural e avaliação prognóstica.

Em síntese, quando a informação data do início dos sintomas foi utilizada como momento inicial da estimativa de sobrevida, a acurácia da rede neural foi maior. A observação por tempo mais longo teria permitido apreciar a natureza do quadro clínico mais estável (período menos sintomático) em 
relação à data da primeira consulta (em geral associada à piora de sintomas e referência a hospital terciário). Tal achado permite sugerir que os pacientes com longa evolução da doença, portanto mais estáveis, foram propensos a uma previsão mais acurada da rede neural do que pacientes com menor tempo de evolução, entendidos como clinicamente mais instáveis.

\subsubsection{Tempos de evolução}

Em razão da disparidade de valores, considerados tanto por nossa prática clínica quanto por dados de estudos prévios (Likoff et al., 1987; Bestetti et al., 1994; Mady et al., 1994; Alla et al., 2000; Freitas et al., 2005; Franke et al., 2015), a verificação de acurácia da rede sugere que existam grupos de melhor prognóstico (tempo mais longo de evolução) e de prognóstico mais reservado (tempo mais curto de evolução), resultado clinicamente fundamentado, a nosso ver, pois categoriza os tempos de evolução dos pacientes da casuística.

A categorização da rede neural em três modelos de rede com faixas de tempos distintos revelou-se, em nossa casuística, como a mais apropriada para melhorar a estimativa da sobrevida. Tal observação é concordante com o resultado obtido na melhora da acurácia da rede neural após a categorização dos tempos de seguimento ou tempo de sobrevida observado. Esse cuidado preveniu que a rede neural dissipasse as estimativas em virtude da grande diferença entre os tempos de sobrevida.

Confirma-se, desse modo, que as doenças de mais longa evolução são mais estáveis e indicam quadro clínico mais benigno do que os quadros de curta evolução mais instáveis.

Os melhores resultados da rede neural foram revelados pelos três modelos de redes neurais categorizadas por tempo de sobrevida inferior a dois anos (até 729 dias), entre dois anos e seis anos (730 a 2.190 dias) e superior a seis anos (acima de 2.190 dias), que viabilizaram a mais satisfatória previsão da sobrevida pela rede neural. 
Para o aprendizado-treinamento da rede neural com sobrevida superior a 2 anos, a retirada do extremo inferior (menor do que dois anos) do tempo de sobrevida observado permitiu melhor previsão pela rede neural.

Se o paciente tiver longo tempo de história, poderá significar fase avançada de evolução, mas também indicará quadro clínico mais benigno e de melhor prognóstico - isto talvez se relacione ao achado de pacientes, embora aguardando muito tempo em fila de transplante, foram retirados dela. Estes pacientes com tempo de evolução mais curto, portanto mais instáveis clinicamente, talvez sejam os mais beneficiados da análise pelo emprego de marcadores adicionais, como parte da avaliação prognóstica. Para eles, as dosagens das catecolaminas plasmáticas, da função renal e do peptídeo natriurético atrial, bem como a inclusão dos medicamentos em uso contribuiriam para o estudo da acurácia ou da estimativa prognóstica.

Sendo assim, o modelo de rede neural com o melhor resultado de previsão da sobrevida - erro da rede inferior a 12,8\% - ocorreu com os pacientes com tempo de sobrevida observado superior a seis anos, a partir da data da primeira consulta, independentemente da função da ativação. Além disso, o segundo modelo de melhor acurácia - erro da rede neural inferior a $23 \%$ - ocorreu para o tempo de sobrevida observado entre dois anos e seis anos, a partir da data do início dos sintomas, independentemente da função de ativação utilizada pela rede neural.

Por outro lado, na fase de previsão da rede neural, o modelo com 0 melhor resultado de previsão da sobrevida - erro da rede inferior ou igual a $21,5 \%$ - ocorreu com os pacientes com tempo de sobrevida observado superior a seis anos, a partir da data da primeira consulta, independentemente da função da ativação, em concordância com o que sugeriu a rede neural na fase de aprendizado-treinamento.

Todavia, para o segundo modelo, a acurácia da rede foi menos adequada erro da rede neural inferior a $39,4 \%$ - para o tempo de sobrevida observado entre dois anos e seis anos, a partir da data do início dos sintomas, independentemente da função de ativação.

Também devemos tomar em consideração que, por razões metodológicas, a variação dos tempos de seguimento dos pacientes foi fixada 
e limitada até 2012 para a análise de sobrevida e atualizada até 2014 para a rede neural.

\subsubsection{Variáveis faltantes}

Seguimos orientação da literatura (Ennett et al., 2001; Frize et al., 2001) tanto para imputar valores normais para as informações faltantes, como pela necessidade deste pré-requisito para o aprendizado da rede neural (Ennett et al., 2001, 2008; Frize et al., 2001). Para melhor avaliação, exploramos para imputação os valores de referência da normalidade, os superiores da normalidade e os da mediana (Kaambwa et al., 2012). Em face dos resultados, optamos por assumir os valores de referência normais das variáveis faltantes.

Também devemos salientar que as variáveis faltantes podem, ou não, associar-se com menor probabilidade de sobrevida.

\subsubsection{Variáveis selecionadas pelo modelo de Cox versus variáveis em geral}

Por vezes, a pressuposta importância clínica reconhecida da variável submetida a teste não se traduziu em melhor previsibilidade da rede neural. A inclusão da variável fração de ejeção do ventrículo esquerdo não melhorou a previsão de sobrevida pela rede neural. Esta observação vai ao encontro do resultado do modelo de Cox que não considerou a fração de ejeção como variável prognóstica.

A categorização de variáveis como idade, sexo, creatinina, colesterol total, diâmetro diastólico do ventrículo esquerdo ou outras variáveis consideradas de importância clínica não melhoraram a previsão de sobrevida da rede neural. 
Portanto, o critério de limitar características clínicas, isoladamente, não foi bom previsor de prognóstico.

O teste de previsão do prognóstico com a rede neural, isoladamente, não revelou boa acurácia; a acurácia melhorou quando foram empregadas as variáveis selecionadas a partir do modelo de riscos proporcionais de Cox.

\subsubsection{Funções de transferência}

A acurácia da rede neural, sem a categorização do tempo de sobrevida, foi baixa, independentemente da função de transferência ou de ativação sugerida na literatura (Buskard et al., 1994; Lundin et al., 1999; Frize et al., 2000; Ennett e col., 2004, 2008; Grossi 2006). Por outro lado, quando o tempo de sobrevida foi categorizado e a função de transferência zero based log sigmoid foi adotada, o resultado na previsão da sobrevida melhorou.

\subsubsection{Treinamento excessivo (overfitting)}

Pode resultar em aumento do erro de previsão e menor acurácia da rede neural. Identificar o momento apropriado de finalizar o treinamento da rede neural é um dos detalhes metodológicos relevantes (Guimarães et al., 2008). Prevenimos o treinamento excessivo da rede neural ao limitar o número máximo de ciclos e o erro delta da rede neural, por meio de testes adicionais, variando o número de ciclos e o erro delta.

\subsubsection{Estudo em cinco fases}


O método que empregamos foi criterioso nas fases iniciais para categorizar e selecionar os melhores modelos de dados para a previsão da sobrevida pela rede neural. Destacamos a estimativa do erro hipotético (sobrevida prevista subtraída da sobrevida observada e multiplicada por cem, dividida pela sobrevida observada) utilizada na fase 2 do aprendizadotreinamento, em que a rede neural superestimou o erro verdadeiro de previsão da sobrevida. Nas fases 4 e 5, com novos dados de mortalidade, observamos a acurácia da rede e, dependendo do modelo, melhorou ou se manteve em valores menores que $13 \%$ de média do erro de previsão da sobrevida.

\subsection{Avaliação dos melhores modelos de rede neural}

\subsubsection{Sensibilidade, especificidade, valor preditivo positivo e valor preditivo negativo}

Observamos boa sensibilidade (93\%) para ambas as funções de ativação e razoável especificidade (superior a 76,3\%) - com valores de 76,4\% ou $77,5 \%$ - para o modelo com tempo de sobrevida observado superior a seis anos, a partir da data da consulta inicial, com o intervalo de corte de 1.095 dias ou três anos, dependendo da função de ativação utilizada pela rede neural. Da mesma forma, a acurácia da rede neural foi boa com valores de $80,2 \%$ e $81 \%$, dependendo da função de ativação utilizada pela rede neural. Para estes modelos de rede neural, o valor preditivo negativo foi adequado $(97,4 \%)$ já que, na previsão da rede neural em que o paciente estava vivo, no intervalo de tempo definido, existiram $97,4 \%$ de chance de acerto da rede no prognóstico de sobrevida e $2,6 \%$ de chance de o paciente ter morrido.

Também observamos boa sensibilidade $(89,8 \%)$ para ambas as funções de ativação e razoável especificidade (superior a 73\%) - com valores de $72,5 \%$ ou $76,5 \%$ - para o modelo com tempo de sobrevida observado entre 
dois anos a seis anos, a partir da data do início dos sintomas, para intervalo de corte de 730 dias ou dois anos, dependendo da função de ativação utilizada pela rede neural. Para estes modelos de rede, a acurácia foi boa com valores de $85,2 \%$ e $83,9 \%$, dependendo da função de ativação, e o valor preditivo positivo foi adequado e variou entre $88 \%$ e $86,3 \%$, dependendo da função de ativação, já que na previsão da rede neural em que o paciente morreu no intervalo de corte definido, existiram $88 \%$ ou $86,3 \%$ de chance de acerto da rede no prognóstico de sobrevida e, respectivamente, $12 \%$ ou $19,6 \%$ de chance de o paciente estar vivo, apesar de a rede ter sugerido o oposto.

Observamos razoável sensibilidade $(87,2 \%)$ para ambas as funções de ativação e inadequada especificidade (inferior a 66,7\%) - com valores de $66,5 \%$ ou $66,7 \%$ - para o modelo com tempo de sobrevida observado inferior a dois anos, a partir da data do início dos sintomas, com intervalo de corte de um ano (365 dias), dependendo da função de ativação. Para estes modelos, a acurácia foi satisfatória entre $80,3 \%$ e $78,9 \%$ (dependendo da função de ativação), valor preditivo positivo razoável entre 83,7\% e 82,0\% (dependendo da função de ativação) e valor preditivo negativo baixo entre 72,75 e $71,4 \%$ (dependendo da função de ativação).

Também observamos os resultados insatisfatórios nas estimativas com o tempo de seguimento observado superior a seis anos, a partir da data do início dos sintomas, com intervalo de corte de dois anos, independentemente da função de ativação, assim como no tempo de sobrevida observado inferior a dois anos, a partir da data do início dos sintomas, com intervalo de corte de seis meses, independentemente da função de ativação. Da mesma maneira, modelos com tempo de seguimento observado entre dois anos e seis anos, com intervalo de corte de um ano, independentemente da função de ativação; tanto para a data do início dos sintomas quanto para a data da consulta inicial, os resultados foram insatisfatórios.

Em síntese, os resultados dos melhores modelos de redes neurais evidenciaram:

a) boa sensibilidade, razoável especificidade, bom valor preditivo negativo e inadequado valor preditivo positivo para o modelo de rede com 
tempo de sobrevida observado e categorizado superior a seis anos, a partir da data da consulta inicial, independentemente da função de transferência;

b) boa sensibilidade, inadequada especificidade e razoável valor preditivo positivo e valor preditivo negativo para o modelo de rede com tempo de sobrevida observado e categorizado entre dois anos e seis anos, a partir da data do início dos sintomas, independentemente da função de transferência. Porém, se considerarmos o mesmo modelo com a data da primeira consulta, a sensibilidade e o valor preditivo positivo foram razoáveis, enquanto a especificidade e o valor preditivo negativo foram inadequados.

\subsubsection{Função de perda}

Para maior rigor metodológico e levando em consideração que os conceitos de sensibilidade e especificidade são aplicáveis, principalmente, para variáveis binárias e não para variáveis contínuas, o desempenho preditivo da rede neural foi avaliado pelo emprego da função de perda para a variável contínua, tempo de sobrevida (Yuan, 2008).

Observamos que os resultados de previsão da sobrevida obtidos pela função de perda foram satisfatórios e com variações de desempenho preditivo, que podem alcançar erros de 4,4 meses até 1,1 anos, para mais ou para menos, para os modelos de rede neurais avaliados. Tendo em vista o pressuposto de que, para a função de perda, quanto menor o erro da rede neural, melhor a previsão de sobrevida da rede neural, ou quanto maior o erro da rede neural, menor a previsão de sobrevida (Santos, 2013).

Cabe salientar que os quatro melhores resultados da função de perda foram obtidos para os modelos de rede neural com tempo de sobrevida observado, respectivamente, inferior a dois anos (126 dias, 95 dias e 133,07 dias) e entre dois anos e seis anos (231,61 dias e 259,06 dias), ambos com data do início dos sintomas, independentemente da função de ativação utilizada pelo modelo de rede neural. Na sequência, os melhores resultados 
foram obtidos para os modelos de rede neural com tempo de sobrevida observado acima de seis anos (293,88 dias e 332,55 dias), a partir da data da primeira consulta, independentemente da função de ativação, e entre dois anos e seis anos (389,31 dias), a partir da data da primeira consulta para a função zero based log sigmoid utilizada pela rede neural.

Os resultados permitem sugerir que a informação data do início dos sintomas seja importante para a estimativa dos modelos de rede neural com sobrevida inferior a seis anos, independentemente do tamanho da amostra.

\subsubsection{Sensibilidade e especificidade versus função de perda}

O desempenho preditivo oposto obtido entre os resultados da função de perda e os resultados da sensibilidade e especificidade para os modelos de redes neurais - os modelos de rede neural com as melhores estimativas pela função de perda foram os modelos de rede com as piores estimativas pela sensibilidade e especificidade. É de se destacar que a melhor estimativa de sobrevida, obtida pela função de perda para os modelos de rede neural, foi observada no modelo de rede com o menor número de pacientes $(n=47)$, porém com a informação data do início dos sintomas. Tal verificação reforça a importância da data do início dos sintomas para a acurácia da rede neural.

\subsection{Implicações clínicas}

Há na literatura médica corrente o empenho no desenvolvimento de ferramentas de inteligência artificial como método de avaliação clínica (Braunwald, 2008). Apesar disso, não identificamos, na literatura, trabalhos que conciliassem as duas técnicas - análise de sobrevida com rede neural - para a previsão da sobrevida em pacientes com insuficiência cardíaca, o que permitiria a hipótese de originalidade para as observações deste trabalho. 
É digno de ênfase termos identificado que a data do início dos sintomas obtida na anamnese é uma ferramenta de estimativa diagnóstica, principalmente associada a outras variáveis do exame clínico. Suscita-se a indagação de esta variável estar subvalorizada, por alguma razão, na medida em que está ausente dos registros clínicos como informação nuclear, até por sua compreensível "imprecisão" biológica. Apesar dessa potencial inexatidão, revelou-se variável relevante. Portanto, o empenho em obter, com a precisão possível, a data do início dos sintomas pode ser reiterado útil para a avaliação de pacientes.

Finalizando, nossos resultados sugeriram a possibilidade do uso da rede neural artificial como uma ferramenta suplementar para a orientação dos pacientes com insuficiência cardíaca, desde que a rede neural seja modelada pelo tempo de sobrevida observado entre dois anos e seis anos, inferior a dois anos e superior a seis anos e com base em variáveis preditivas de sobrevida estimadas por método estatístico tradicional.

Novos estudos em outras casuísticas e serviços podem adicionar experiência, ampliar e aprofundar os resultados ora apresentados.

\subsection{Limitações do estudo}

Entre as limitações deste trabalho citamos o caráter uni-institucional, retrospectivo, o número limitado de variáveis, a presença de dados faltantes, a ausência de controle da uniformidade de tratamento medicamentoso com suas particularidades, entre elas a aderência a tratamento, e a mortalidade avaliada no Estado de São Paulo. Por outro lado, atenuam-se as limitações por se tratar de estudo em real life conditions no contexto de um Serviço Médico com grande responsabilidade assistencial no âmbito de hospital acadêmico. 
6. Conclusões 
A probabilidade de sobrevida geral desta casuística de insuficiência cardíaca de diferentes etiologias no longo prazo foi $68 \%$ em cinco anos e $40 \%$ em onze anos.

A influência dos dados faltantes no prognóstico variou conforme a natureza das variáveis.

O emprego de redes neurais, categorizadas por tempo de sobrevida dos pacientes a partir de variáveis identificadas significantes em análise estatística tradicional, pode contribuir para identificar pacientes com insuficiência cardíaca com prognóstico potencialmente mais reservado, de modo a contribuir para melhor orientação da sequência do tratamento na rede de atenção médica primária ou secundária ou em hospital de referência; em nosso caso específico, seria identificar os pacientes que pela condição clínica mais grave demandariam recursos tecnológicos e intervenções complexas para seu tratamento. O tempo de evolução da insuficiência cardíaca, obtida pelo auxílio da história clínica, modulada pelas demais variáveis clínicas e laboratoriais, contribuiu para a avaliação prognóstica; quadros clínicos de evolução mais longa podem sugerir pacientes com doença mais estável, enquanto que tal avaliação torna-se mais limitada no caso de quadro clínico de evolução mais breve. 


\section{Anexos}




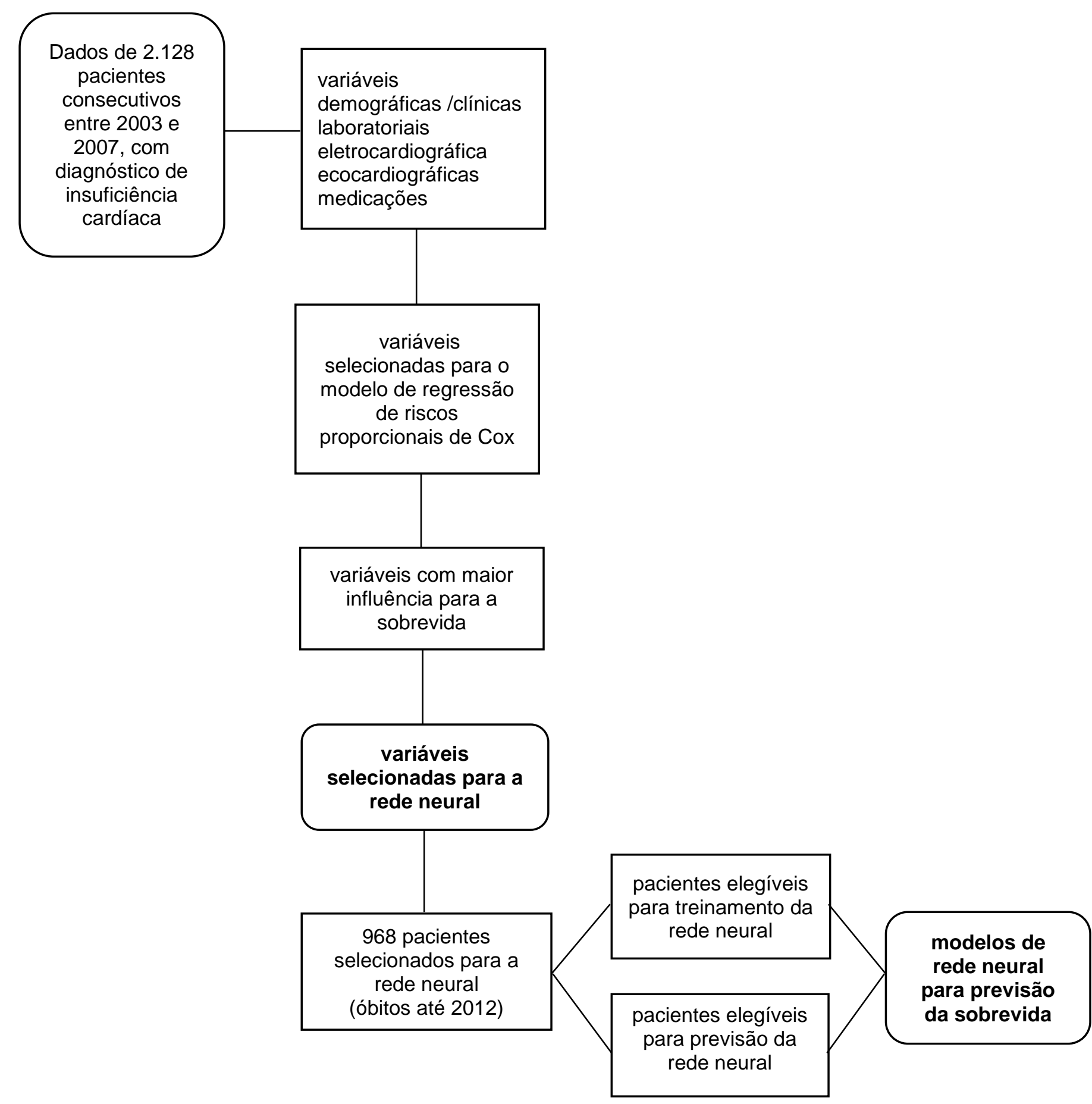

Figura 1 - Delineamento do estudo de 2.128 pacientes ambulatoriais com diagnóstico de insuficiência cardíaca. 


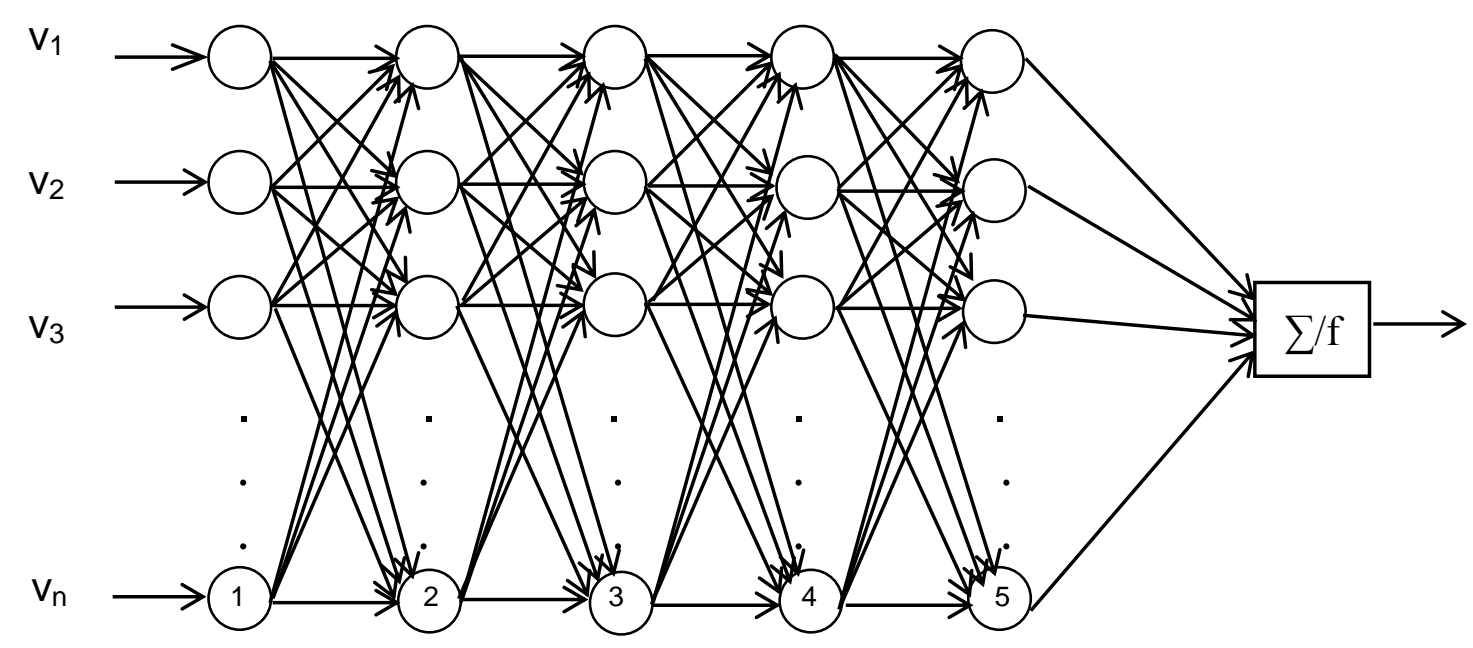

Variáveis

de

entrada
Cinco camadas intermediárias de neurônios ou unidades
Variável de saída

FONTE: adaptado de Fernando J. Von Zuben e Romis R. F. Attux. Disponível em: ftp://ftp.dca.fee.unicamp.br/pub/docs/vonzuben/ia.353_1s07/tópico5_07.pdf

Figura 2 - Arquitetura da rede neural Perceptron de Múltiplas Camadas em que f representa a função de ativação ou de transferência não linear definida para o aprendizado-treinamento da rede neural. 


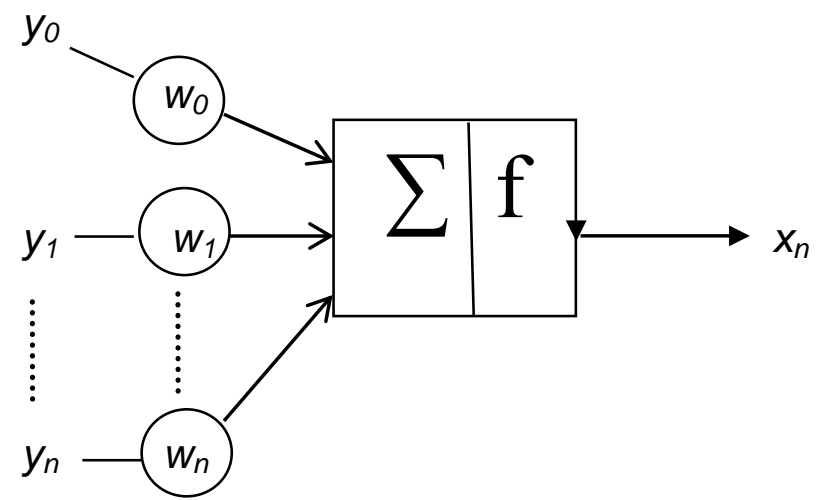

Em que:

\begin{tabular}{|c|c|}
\hline$n$ & $n$-ésima variável de entrada (iteração) \\
\hline$y_{0} y_{1}$ & variáveis de entrada \\
\hline$y_{n}$ & i-ésima variável de entrada \\
\hline$w_{0} \quad w_{1}$ & pesos sinápticos ajustáveis \\
\hline$w_{n}$ & peso sináptico ajustável conectando a entrada da unidade \\
\hline & à saída da unidade na iteração $n$ \\
\hline$x_{n}$ & i-ésima variável de saída da unidade na iteração $n$ \\
\hline$\Sigma$ & função de soma \\
\hline$f$ & função de transferência ou função de ativação \\
\hline
\end{tabular}

FONTE: adaptado de Neural Networks and Learning Machines por Simon Hayken 1999.

Figura 2a: Representação funcional de um neurônio da rede neural perceptron de múltiplas camadas. 


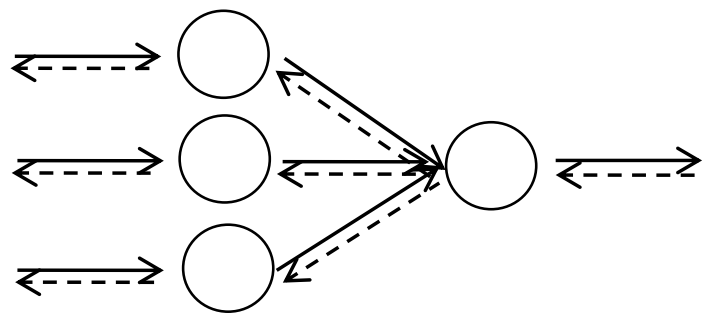

Em que: $\longrightarrow \quad$ propagação da informação

<--- - retro-propagação do erro da informação

FONTE: adaptado de Leandro Nunes de Castro Silva 1998. Disponível em: ftp://ftp.dca. fee.unicamp.br/pub/docs/vonzuben/theses/Inunes_mest/indice.pdf

Figura 2b: Representação das duas fases de direções de propagação da informação pelo algorítmo de aprendizado supervisionado ou de retropropagação do erro ou backpropagation da rede neural perceptron de multiplas camadas e permite o ajuste dos pesos sinápticos. 


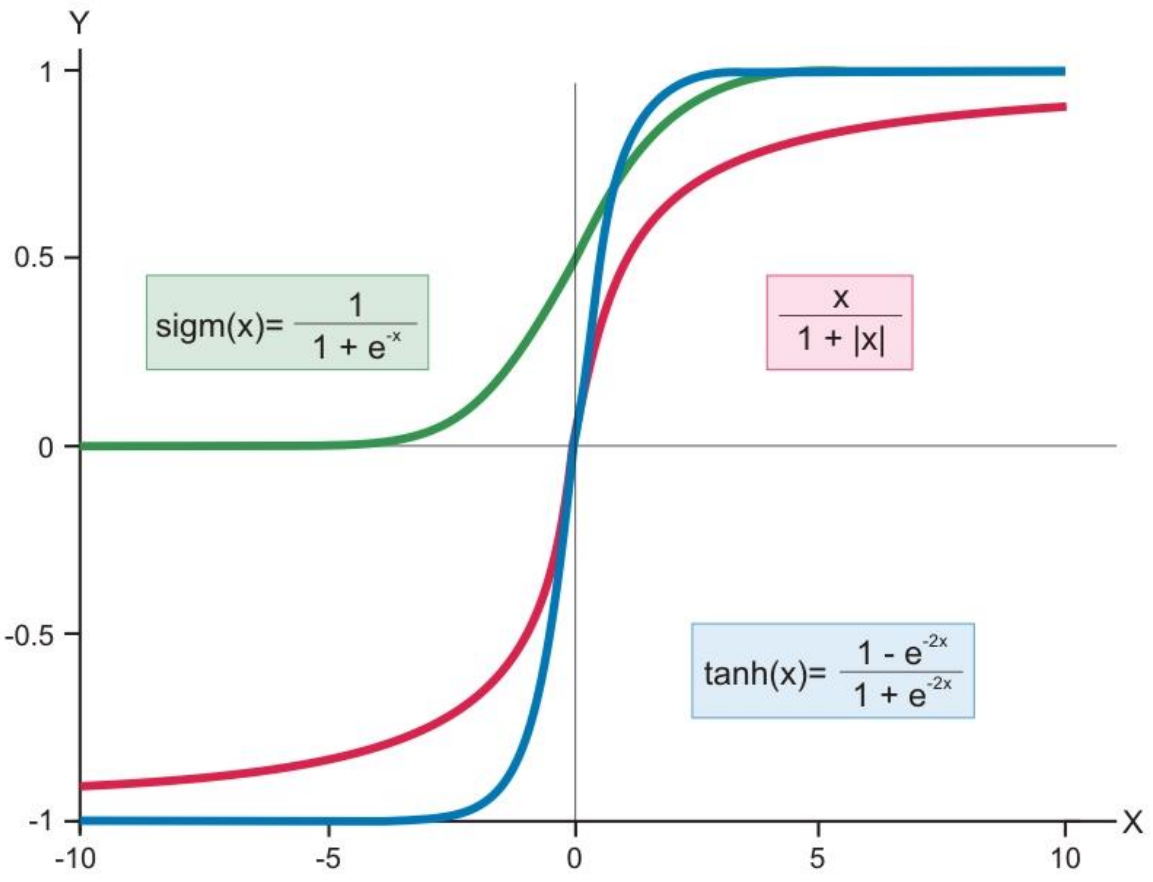

Figura 3 - Representação gráfica da função tangente hiperbólica e da função $\log$ sigmoid. Ambas são funções não lineares de transferência ou de ativação porém a função logística zero based log sigmoid assume o intervalo de variação entre 0 e 1, e a função tangente hiperbólica preserva a forma sigmoidal e assume valores positivos e negativos (intervalo de variação entre 1 e 1).

\begin{tabular}{|c|c|c|c|c|}
\hline $\begin{array}{l}\text { Aprendizado- } \\
\text { treinamentoe } \\
\text { escolhada } \\
\text { arquitetura da } \\
\text { rede neural } \\
\text { com base nos } \\
\text { dados de } \\
\text { mortalidade } \\
\text { até } 2012 \text {. }\end{array}$ & $\begin{array}{l}\text { Avaliação e } \\
\text { aplicação da } \\
\text { rede para } \\
\text { previsão da } \\
\text { sobrevida até } \\
2012 \text { e } \\
\text { geração dos } \\
\text { modelos de } \\
\text { dados ou de } \\
\text { rede. }\end{array}$ & $\begin{array}{l}\text { Comparação } \\
\text { entre os } \\
\text { modelos de } \\
\text { rede para } \\
\text { estimara } \\
\text { sobrevida até } \\
2012 \text { e os } \\
\text { óbitos de } \\
2013 \text {. }\end{array}$ & $\begin{array}{l}\text { Reensaios } \\
\text { para } \\
\text { aprendizado- } \\
\text { treinamento } \\
\text { da rede } \\
\text { neural com } \\
\text { base nos } \\
\text { óbitos de } \\
2013 \text { e } 2014 \text {. }\end{array}$ & $\begin{array}{l}\text { Comparação } \\
\text { entre } \\
\text { modelos de } \\
\text { previsão da } \\
\text { rede neural } \\
\text { iniciale os } \\
\text { melhores } \\
\text { modelos } \\
\text { reensaiados. }\end{array}$ \\
\hline
\end{tabular}

Figura 4 - Representação esquemática das cinco fases da rede neural que compreenderam o aprendizado/treinamento da rede, a previsão da rede neural, a comparação dos melhores modelos de previsão da rede neural, os reensaios da rede neural incorporando os pacientes que faleceram em 2013 e 2014 e nova comparação dos melhores modelos reensaiados. 


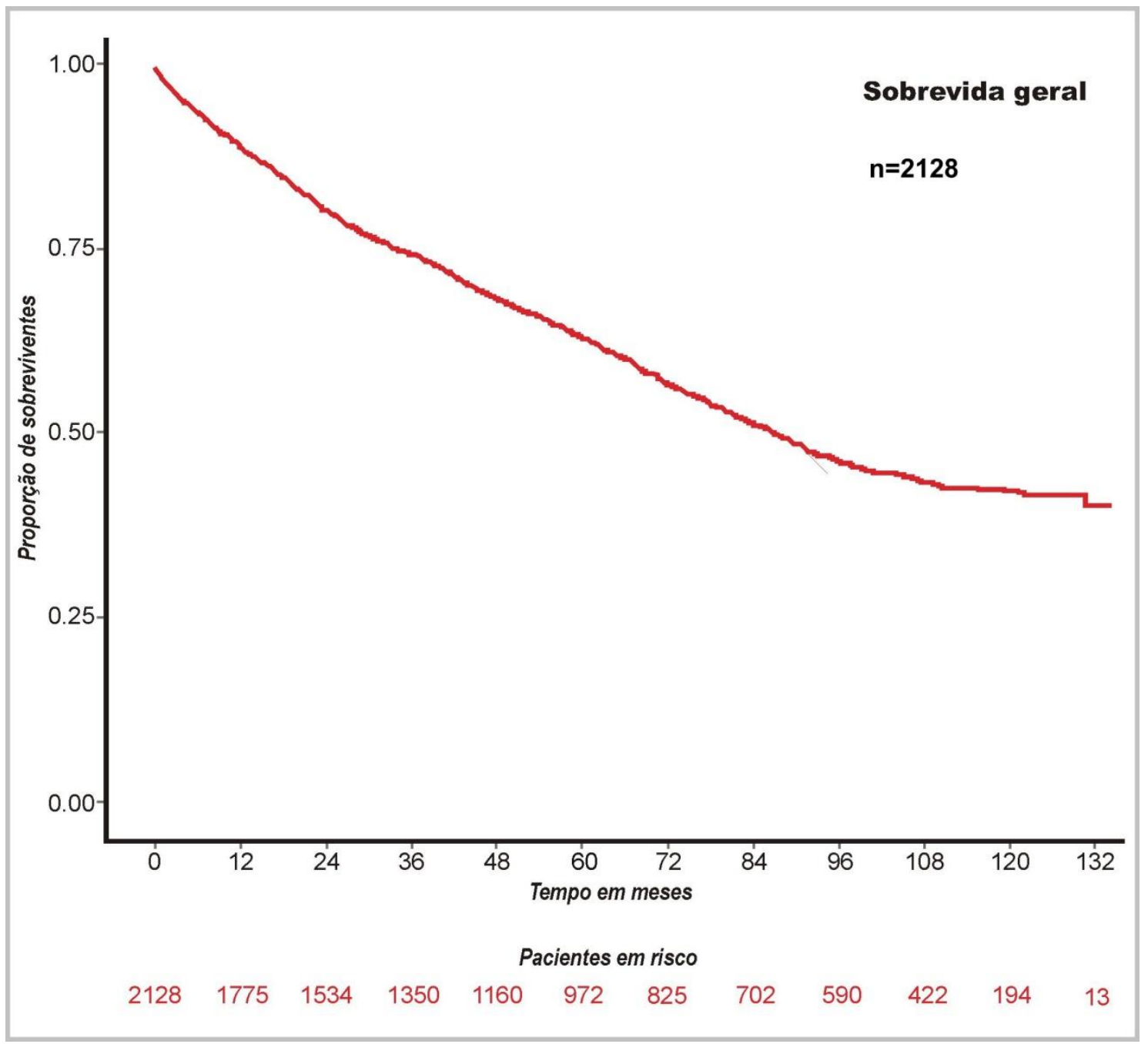

Figura 5 - Probabilidade de sobrevida estimada (Kaplan-Meier) dos pacientes com insuficiência cardíaca. Os números sob o eixo das abscissas indicam o número de pacientes em risco no decorrer do tempo de observação a partir da consulta inicial até a última informação obtida ou data do óbito. 


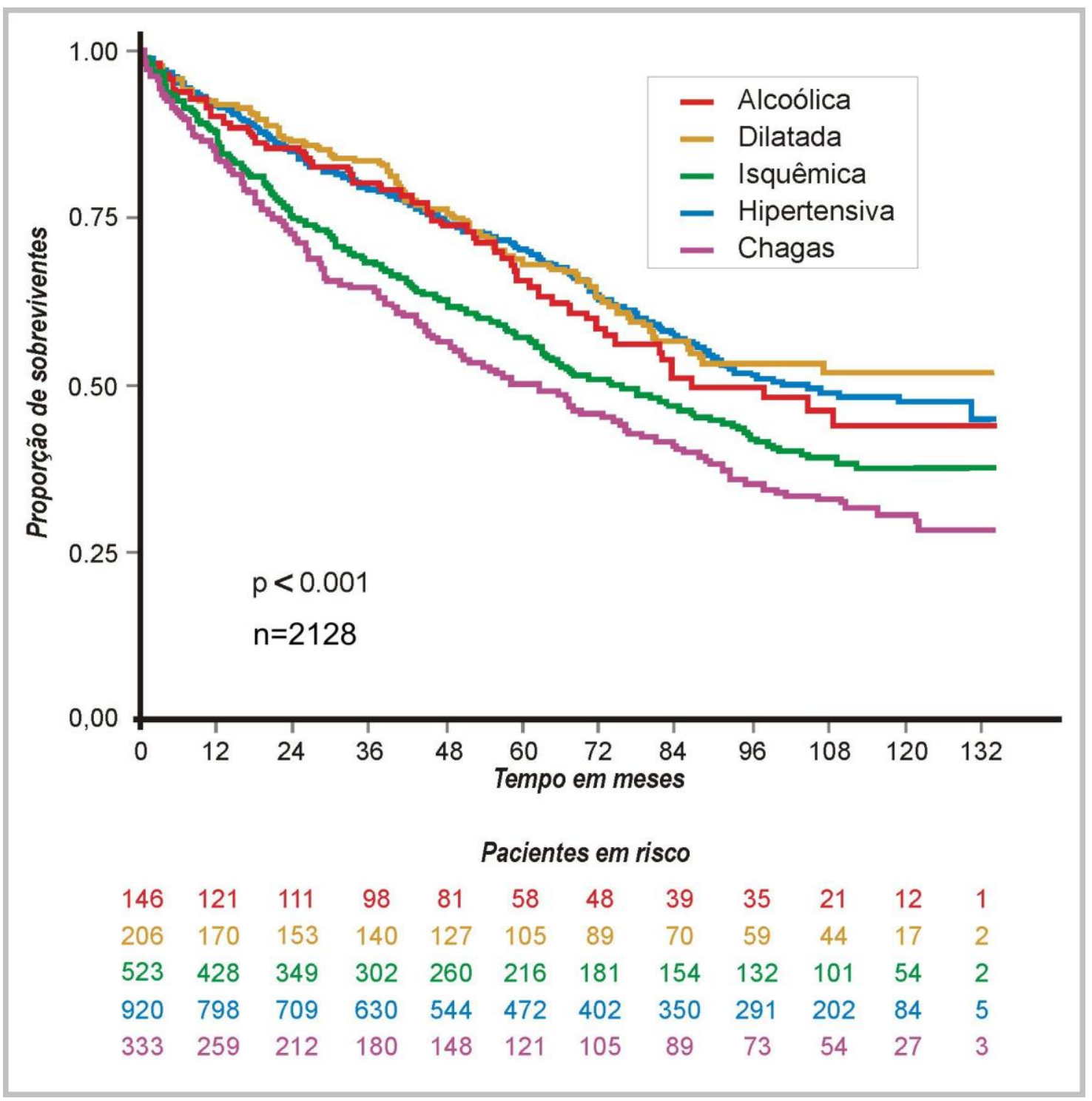

Figura 6 - Probabilidade de sobrevida estimada (Kaplan-Meier) dos pacientes de acordo com a etiologia da insuficiência cardíaca. Os números sob o eixo das abscissas indicam o número de pacientes em risco no decorrer do tempo de observação a partir da consulta inicial até a última informação obtida ou data do óbito. 


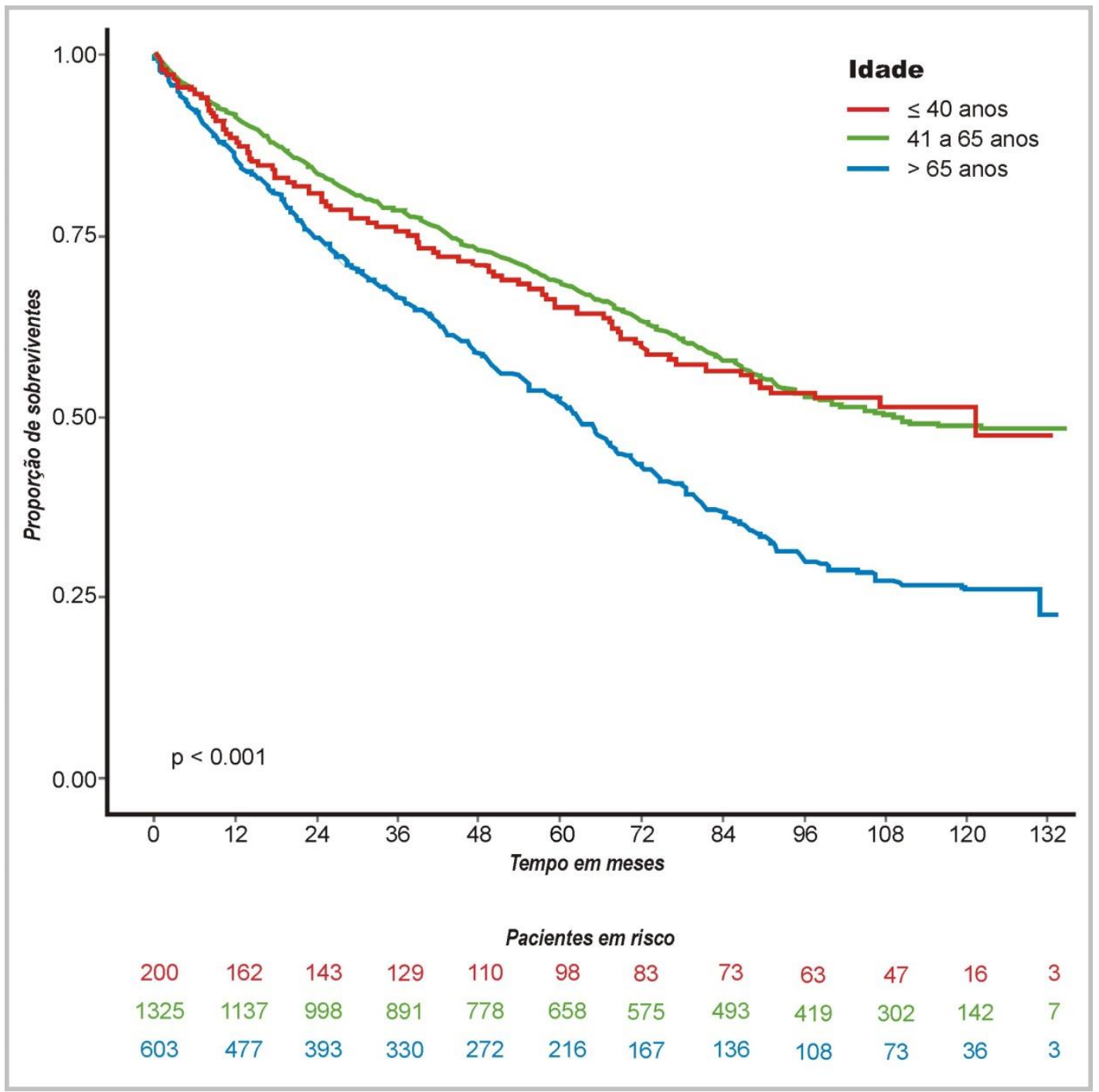

Figura 7 - Probabilidade de sobrevida estimada (Kaplan-Meier) para os 2.128 pacientes de acordo com sua idade. Os números sob o eixo das abscissas indicam o número de pacientes em risco no decorrer do tempo de observação decorrido da consulta inicial até a última informação obtida ou data do óbito. 


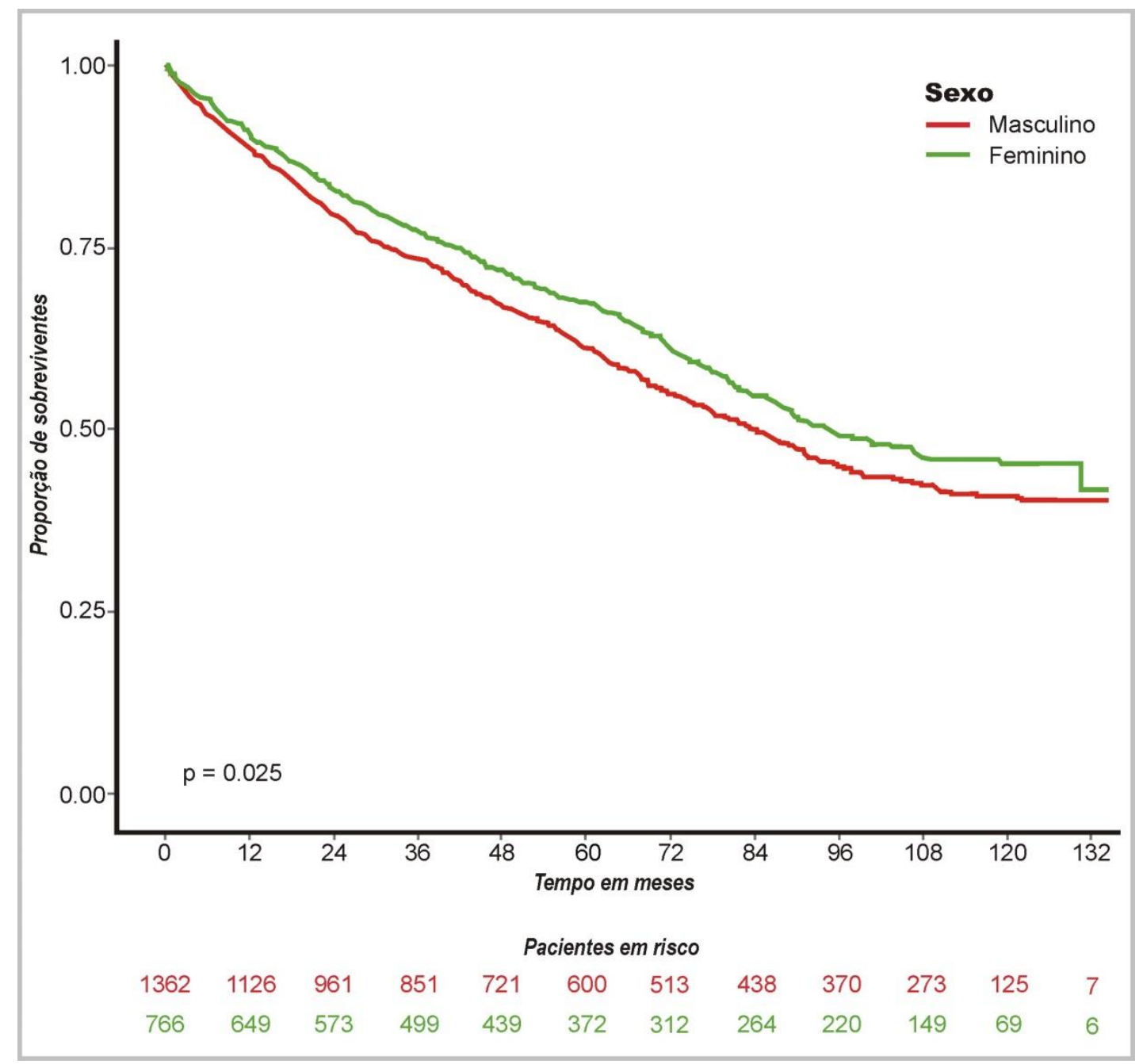

Figura 8 - Probabilidade de sobrevida estimada (Kaplan-Meier) para os 2.128 pacientes de acordo com o sexo. Os números sob o eixo das abscissas indicam o número de pacientes em risco no decorrer do tempo de observação decorrido da consulta inicial até a última informação obtida ou data do óbito. 


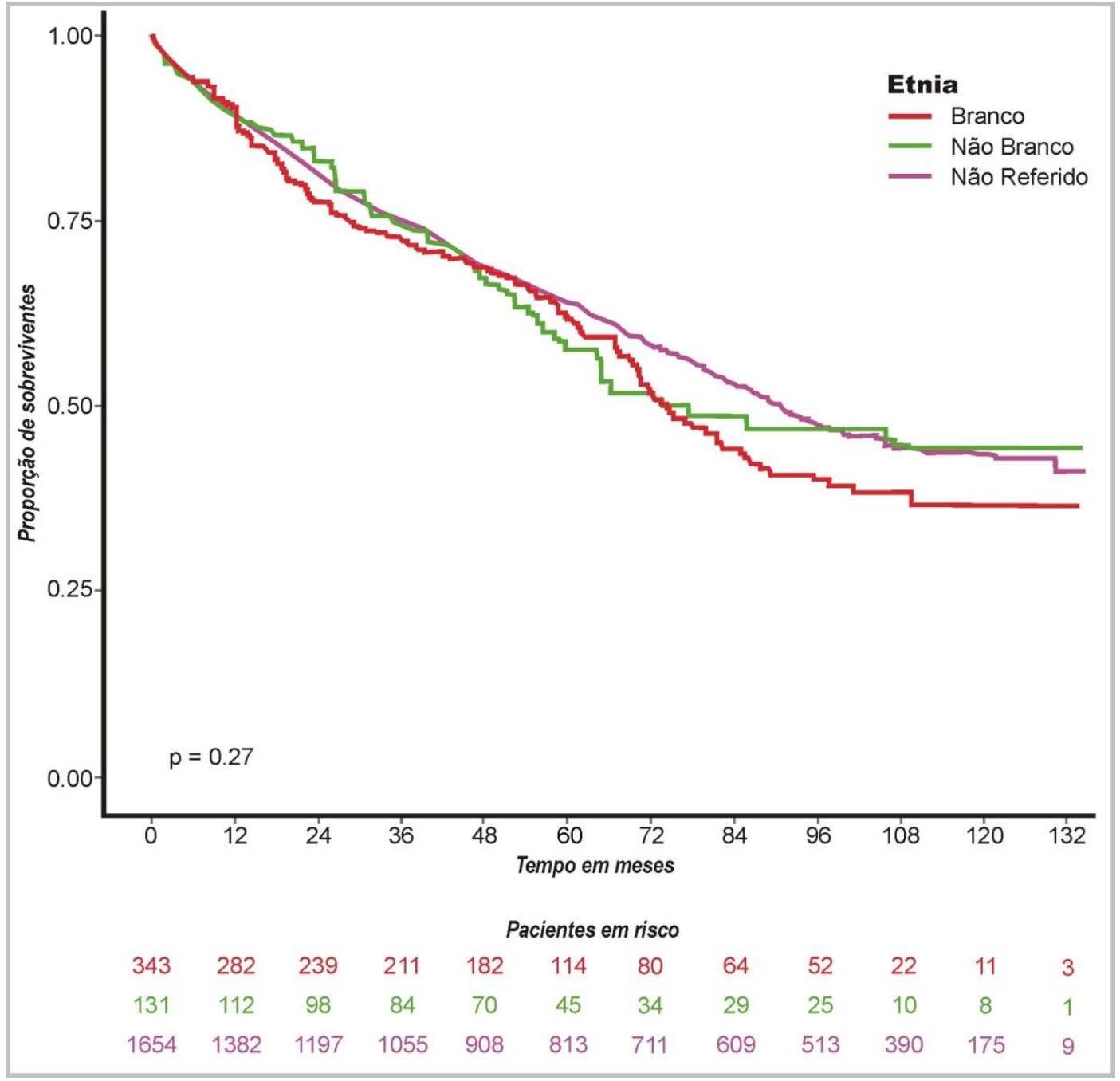

Figura 9 - Probabilidade de sobrevida estimada (Kaplan-Meier) dos 2.128 pacientes de acordo com a etnia. Os números sob o eixo das abscissas indicam o número de pacientes em risco no decorrer do tempo de observação a partir da consulta inicial até a última informação obtida ou data do óbito. 


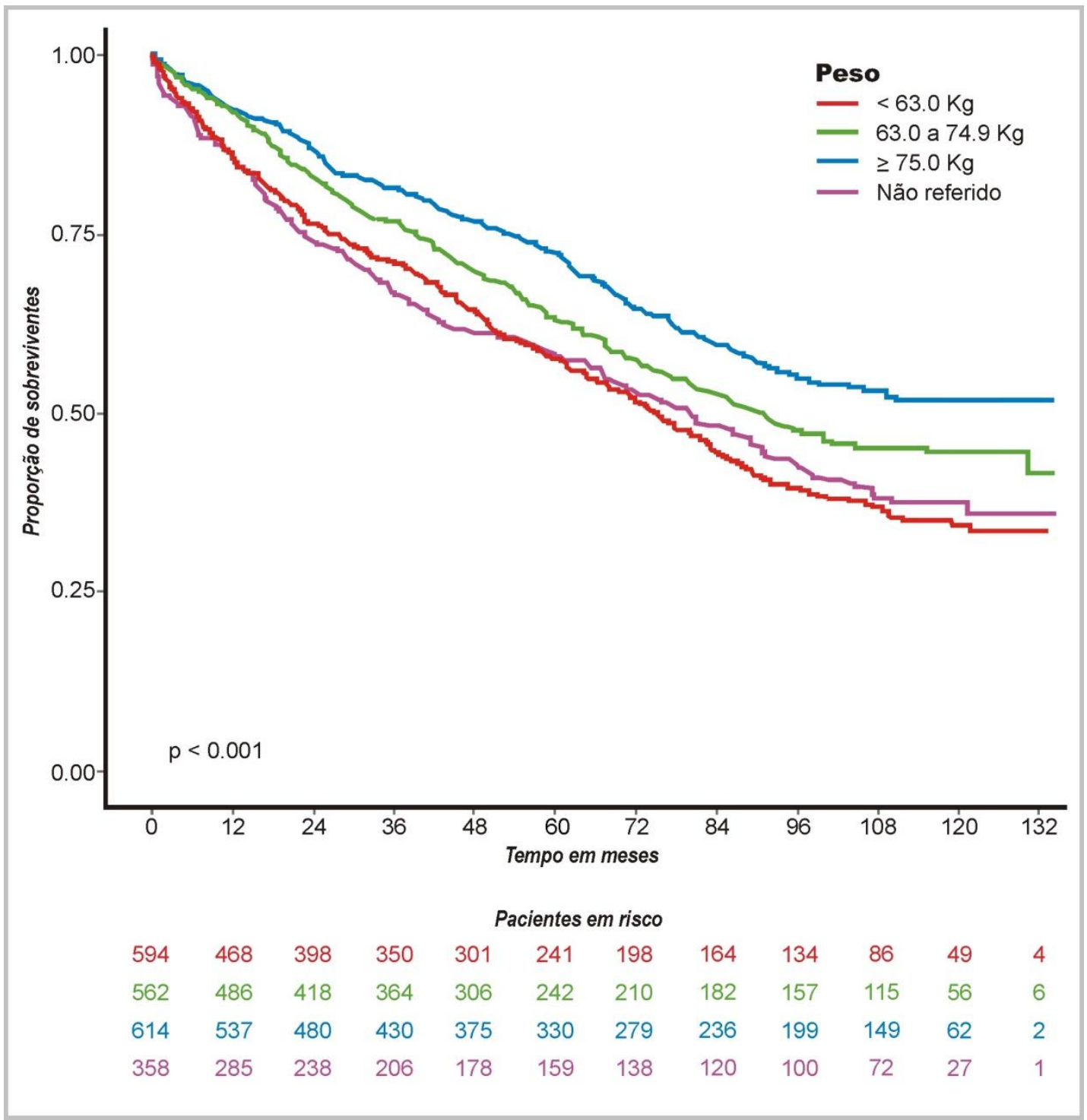

Figura 10 - Probabilidade de sobrevida estimada (Kaplan-Meier) dos 2.128 pacientes de acordo com o peso. Os números sob o eixo das abscissas indicam o número de pacientes em risco no decorrer do tempo de observação a partir da consulta inicial até a última informação obtida ou data do óbito. 


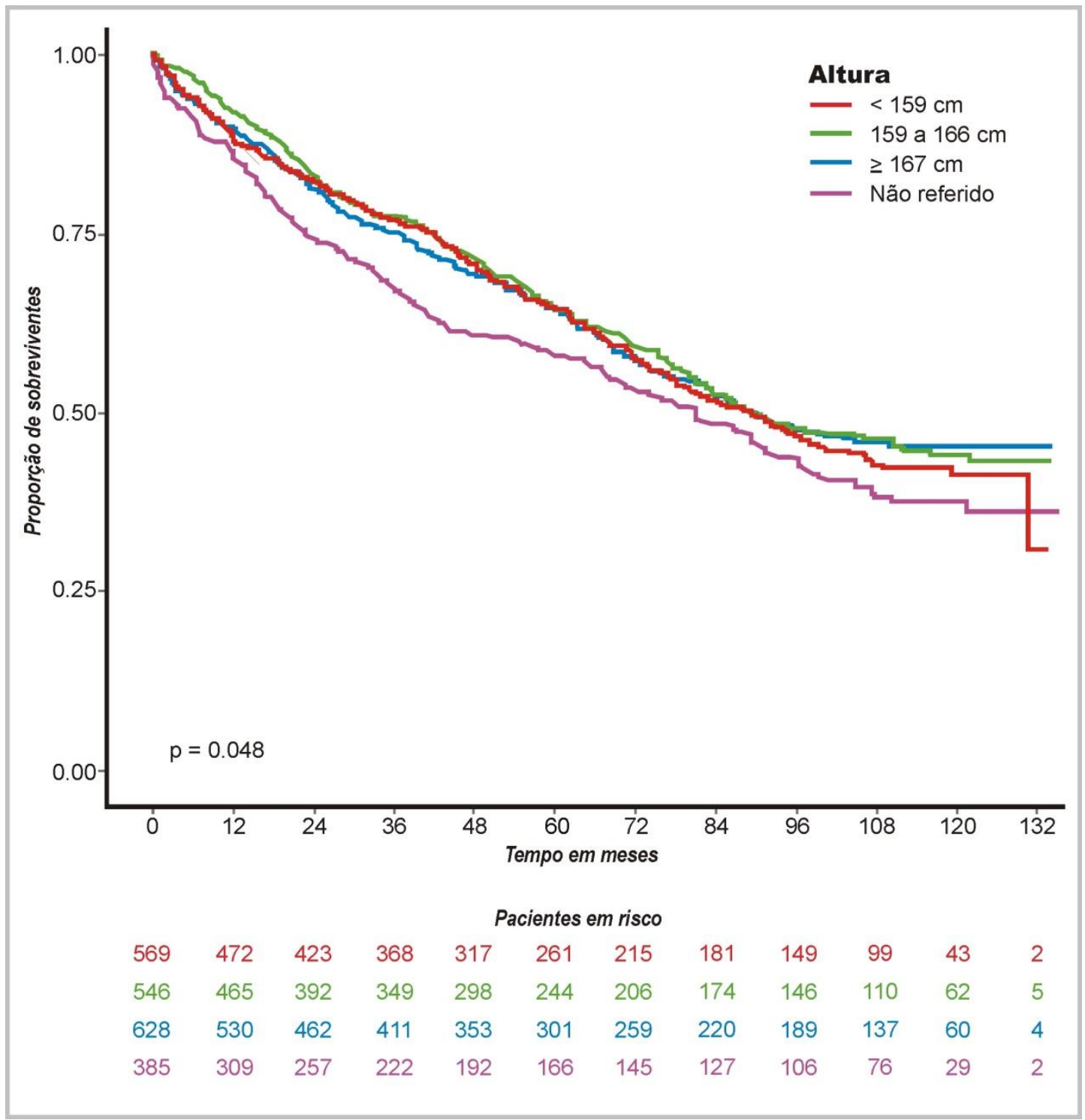

Figura 11 - Probabilidade de sobrevida estimada (Kaplan-Meier) dos 2.128 pacientes de acordo com a altura. Os números sob o eixo das abscissas indicam o número de pacientes em risco no decorrer do tempo de observação a partir da consulta inicial até a última informação obtida ou data do óbito. 


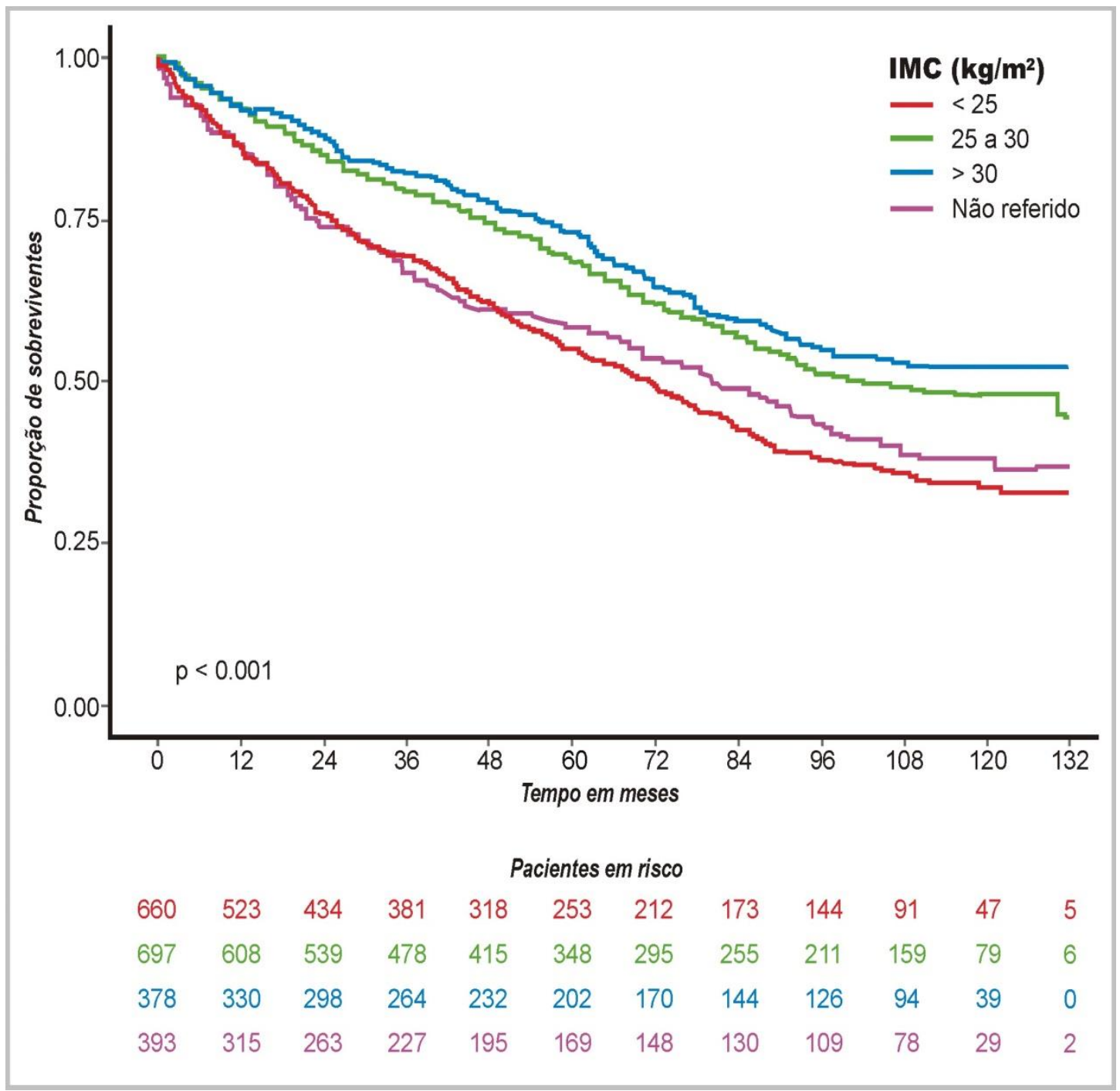

Figura 12 - Probabilidade de sobrevida estimada (Kaplan-Meier) dos 2.128 pacientes de acordo com o índice de massa corpórea (IMC). Os números sob o eixo das abscissas indicam o número de pacientes em risco no decorrer do tempo de observação a partir da consulta inicial até a última informação obtida ou data do óbito. 


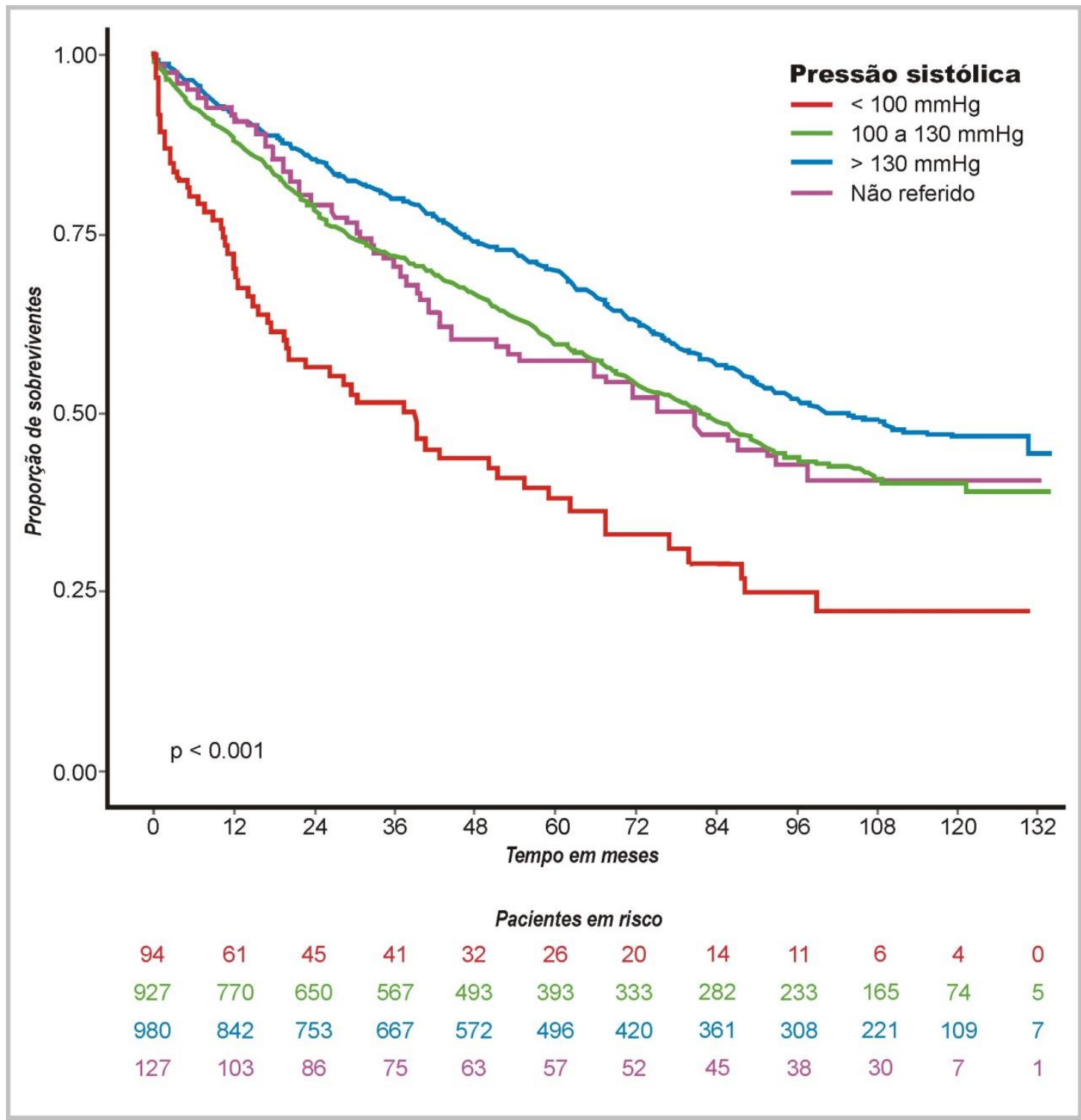

Figura 13 - Probabilidade de sobrevida estimada (Kaplan-Meier) dos 2.128 pacientes de acordo com a pressão arterial sistólica. Os números sob o eixo das abscissas indicam o número de pacientes em risco no decorrer do tempo de observação a partir da consulta inicial até a última informação obtida ou data do óbito. 


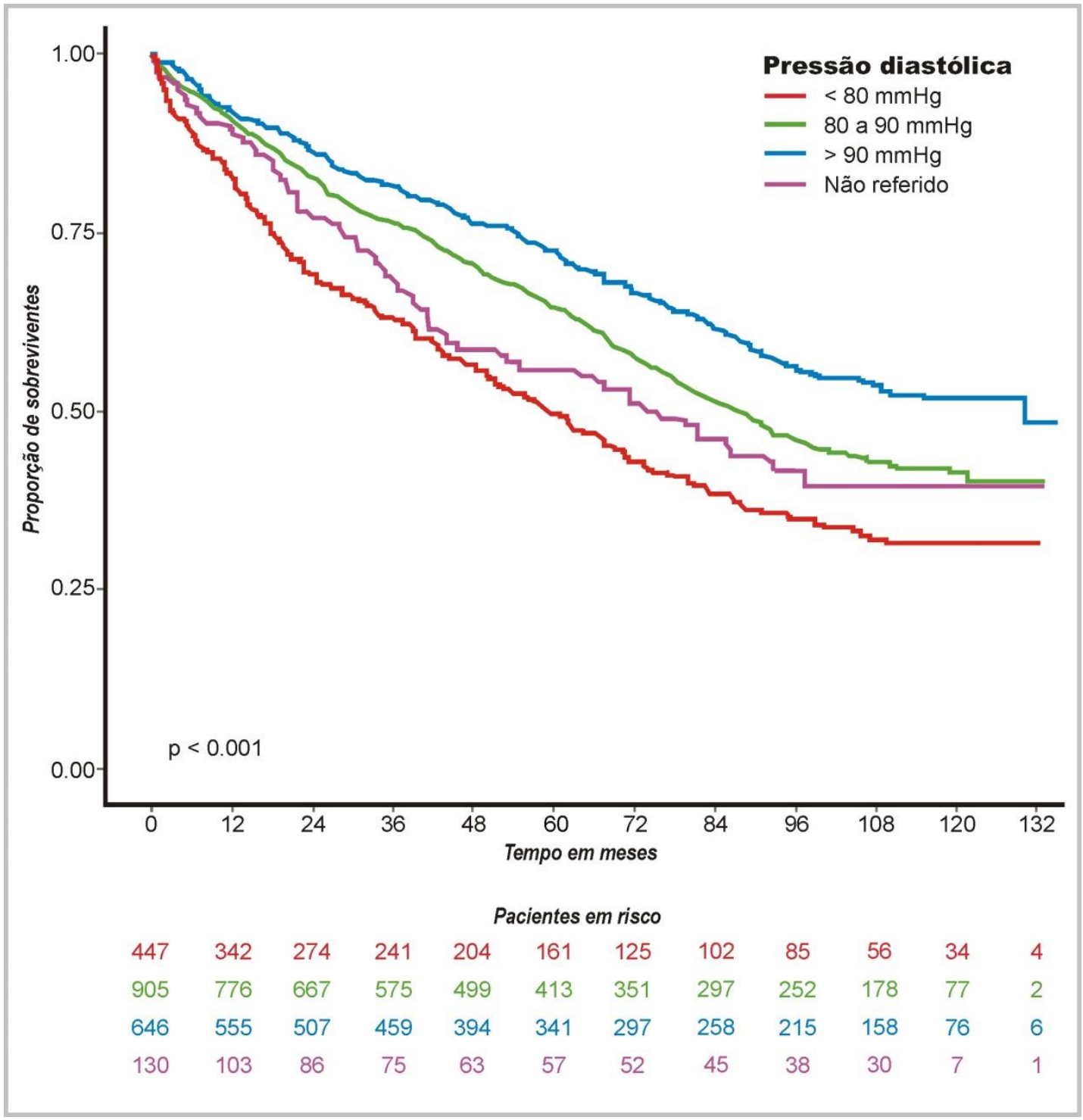

Figura 14 - Probabilidade de sobrevida estimada (Kaplan-Meier) dos 2.128 pacientes de acordo com a pressão arterial diastólica. Os números sob o eixo das abscissas indicam o número de pacientes em risco no decorrer do tempo de observação a partir da consulta inicial até a última informação obtida ou data do óbito. 


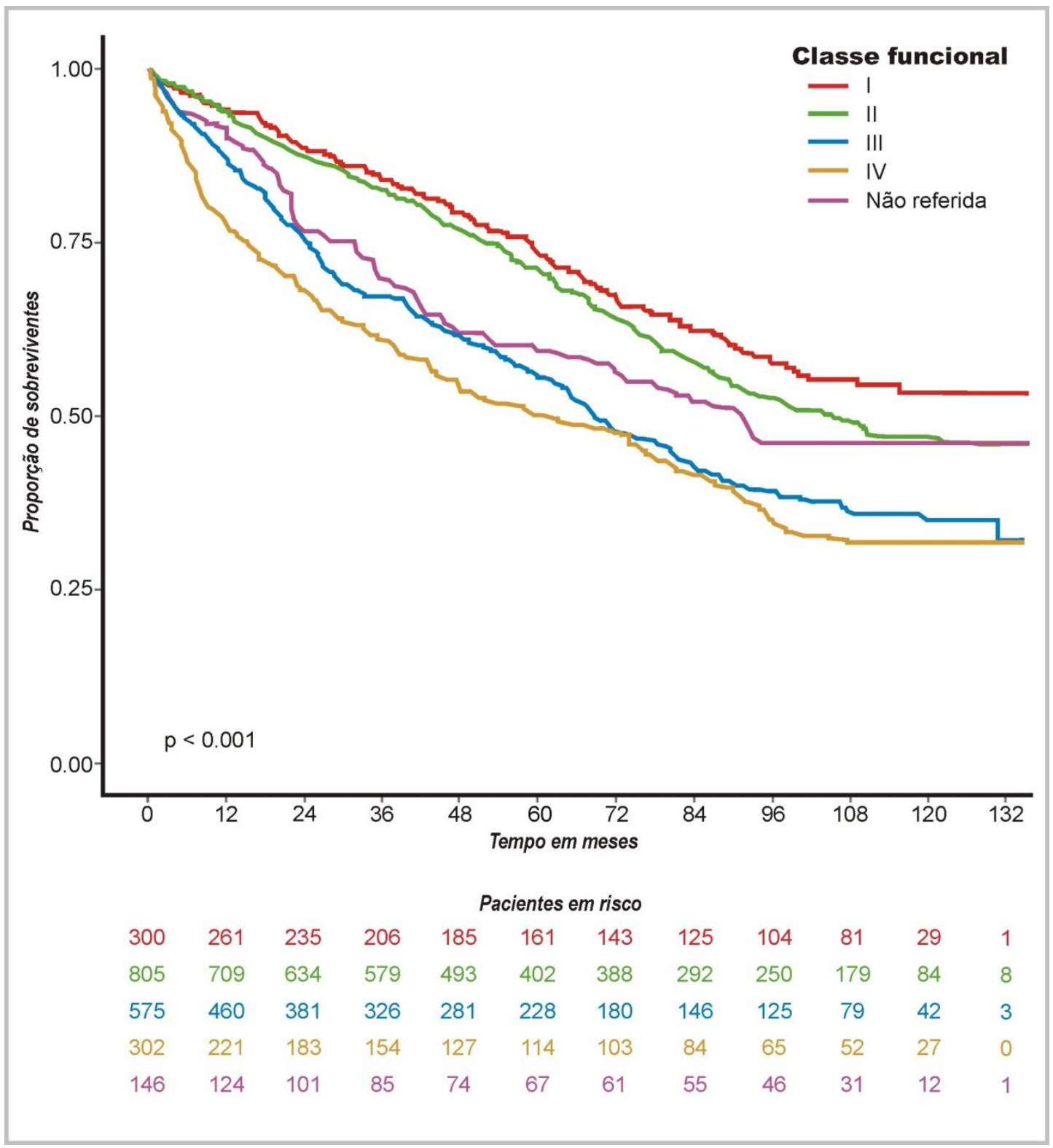

Figura 15 - Probabilidade de sobrevida estimada (Kaplan-Meier) dos 2.128 pacientes de acordo com a classe funcional da New York Heart Association. Os números sob o eixo das abscissas indicam o número de pacientes em risco no decorrer do tempo de observação a partir da consulta inicial até a última informação obtida ou data do óbito. 


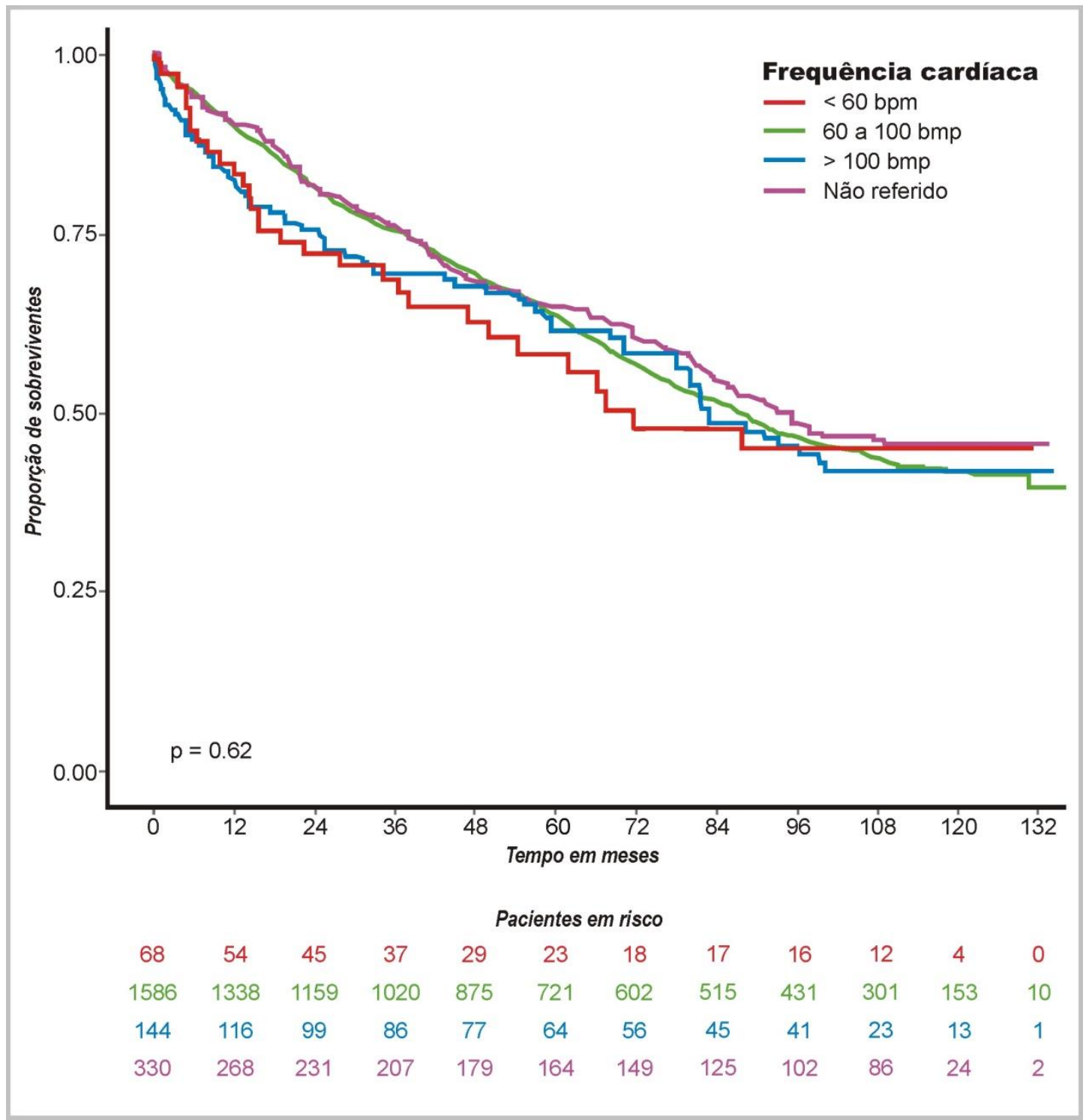

Figura 16 - Probabilidade de sobrevida estimada (Kaplan-Meier) dos 2.128 pacientes de acordo com a frequência cardíaca. Os números sob o eixo das abscissas indicam o número de pacientes em risco no decorrer do tempo de observação a partir da consulta inicial até a última informação obtida ou data do óbito. 


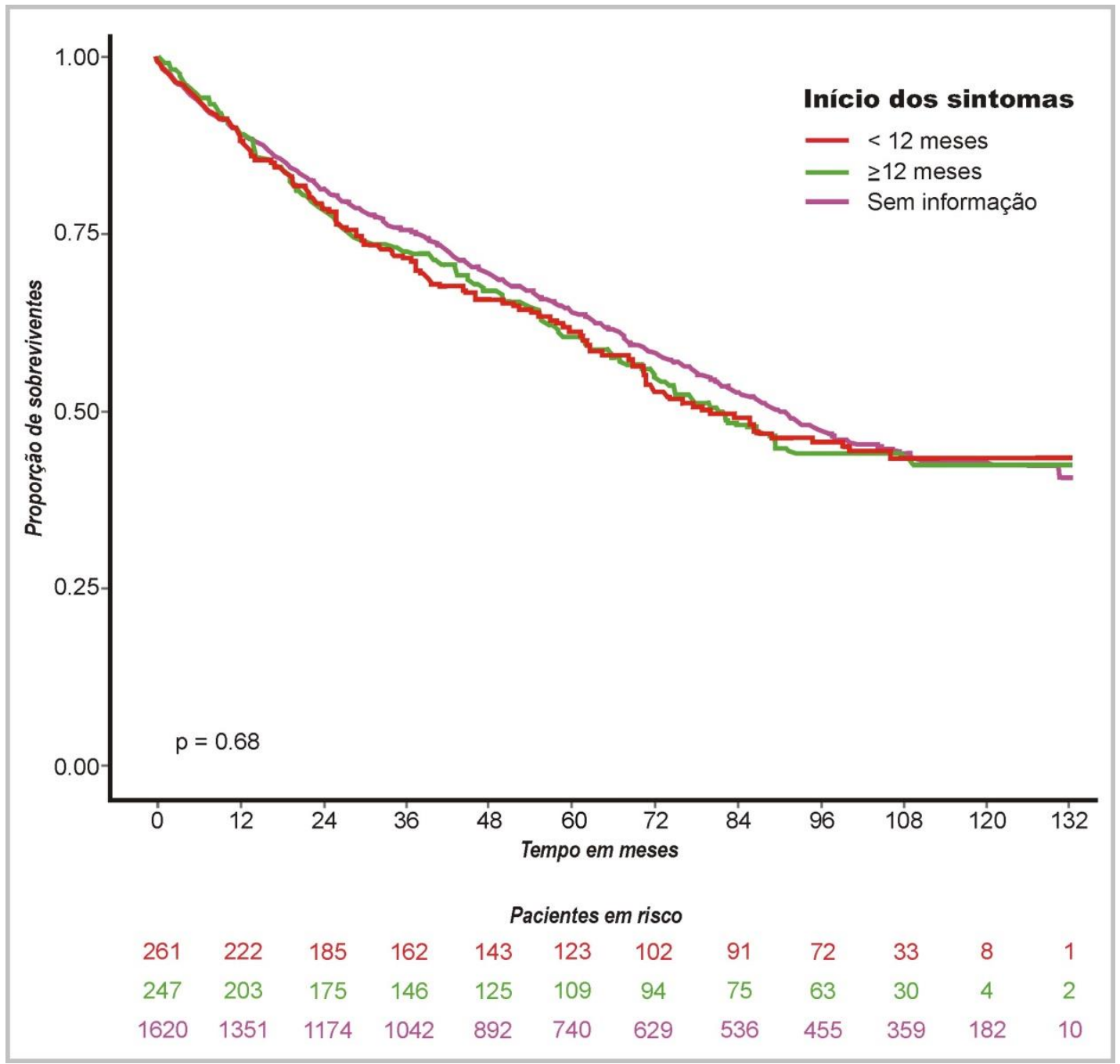

Figura 17 - Probabilidade de sobrevida estimada (Kaplan-Meier) para os 2.128 pacientes de acordo com a data do início dos sintomas. 


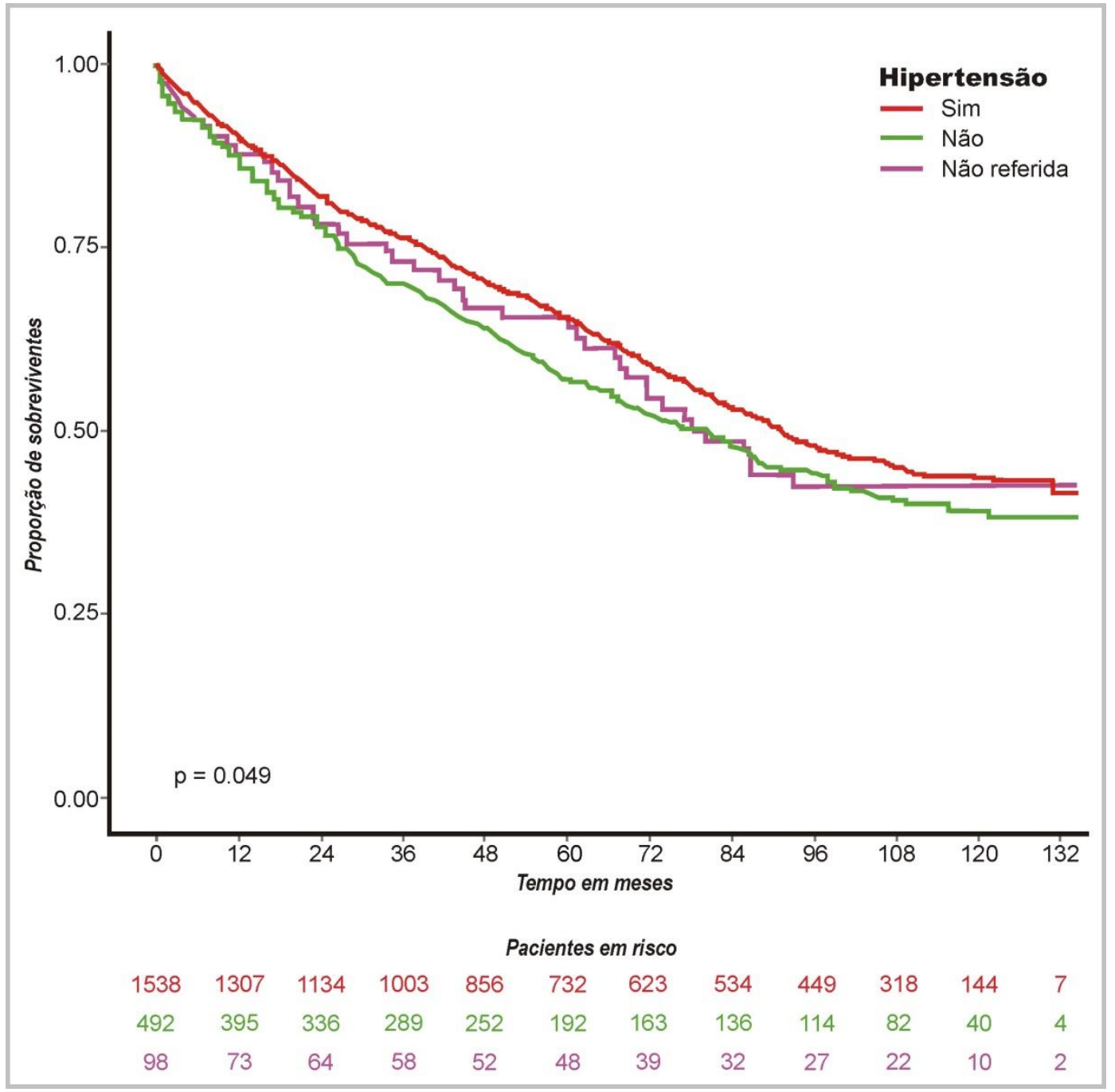

Figura 18 - Probabilidade de sobrevida estimada (Kaplan-Meier) dos 2.128 pacientes de acordo com antecedente de hipertensão arterial. Os números sob o eixo das abscissas indicam o número de pacientes em risco no decorrer do tempo de observação a partir da consulta inicial até a última informação obtida ou data do óbito. 


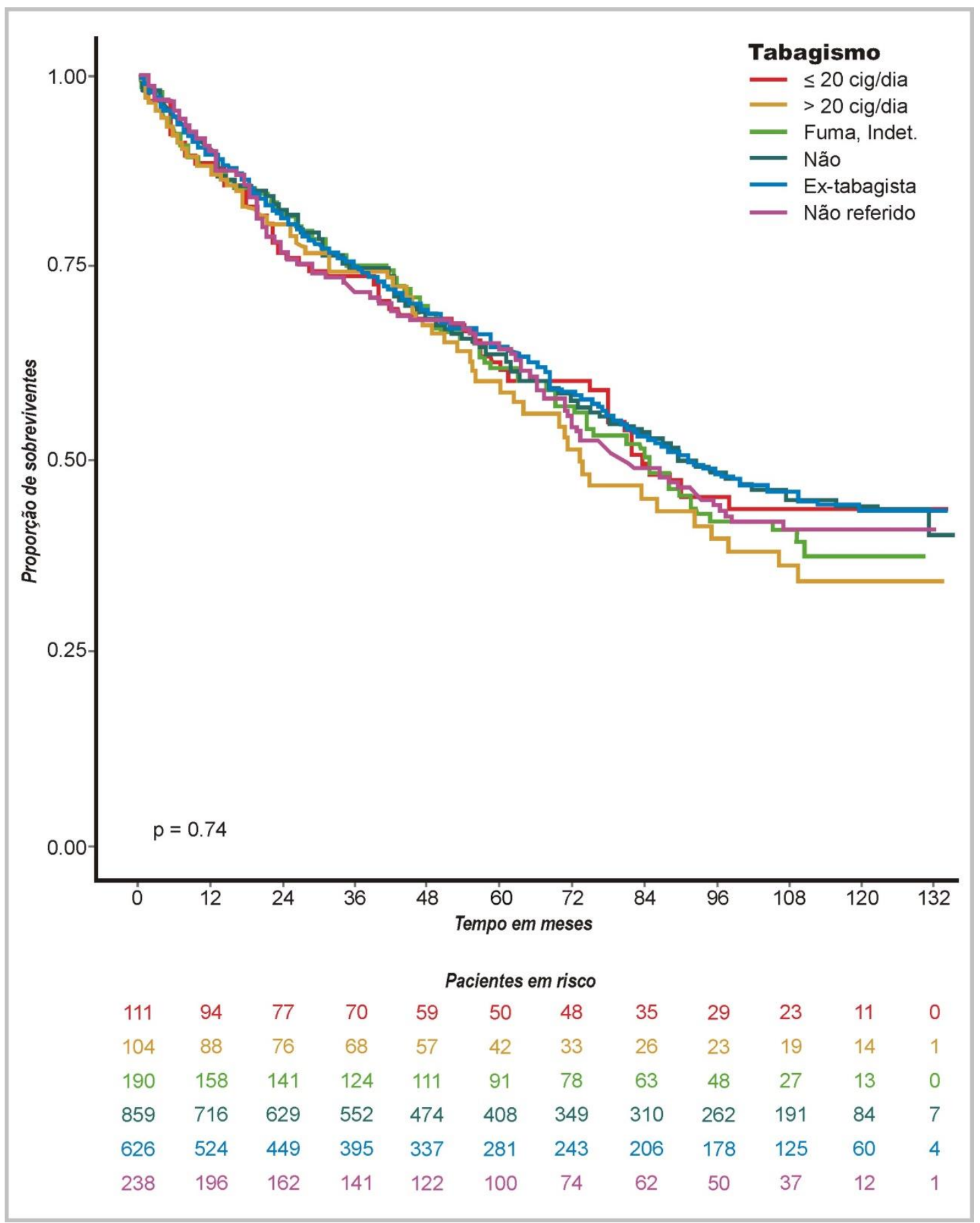

Figura 19 - Probabilidade de sobrevida estimada (Kaplan-Meier) dos 2.128 pacientes de acordo com o antecedente de tabagismo. Os números sob o eixo das abscissas indicam o número de pacientes em risco no decorrer do tempo de observação a partir da consulta inicial até a última informação obtida ou data do óbito. 


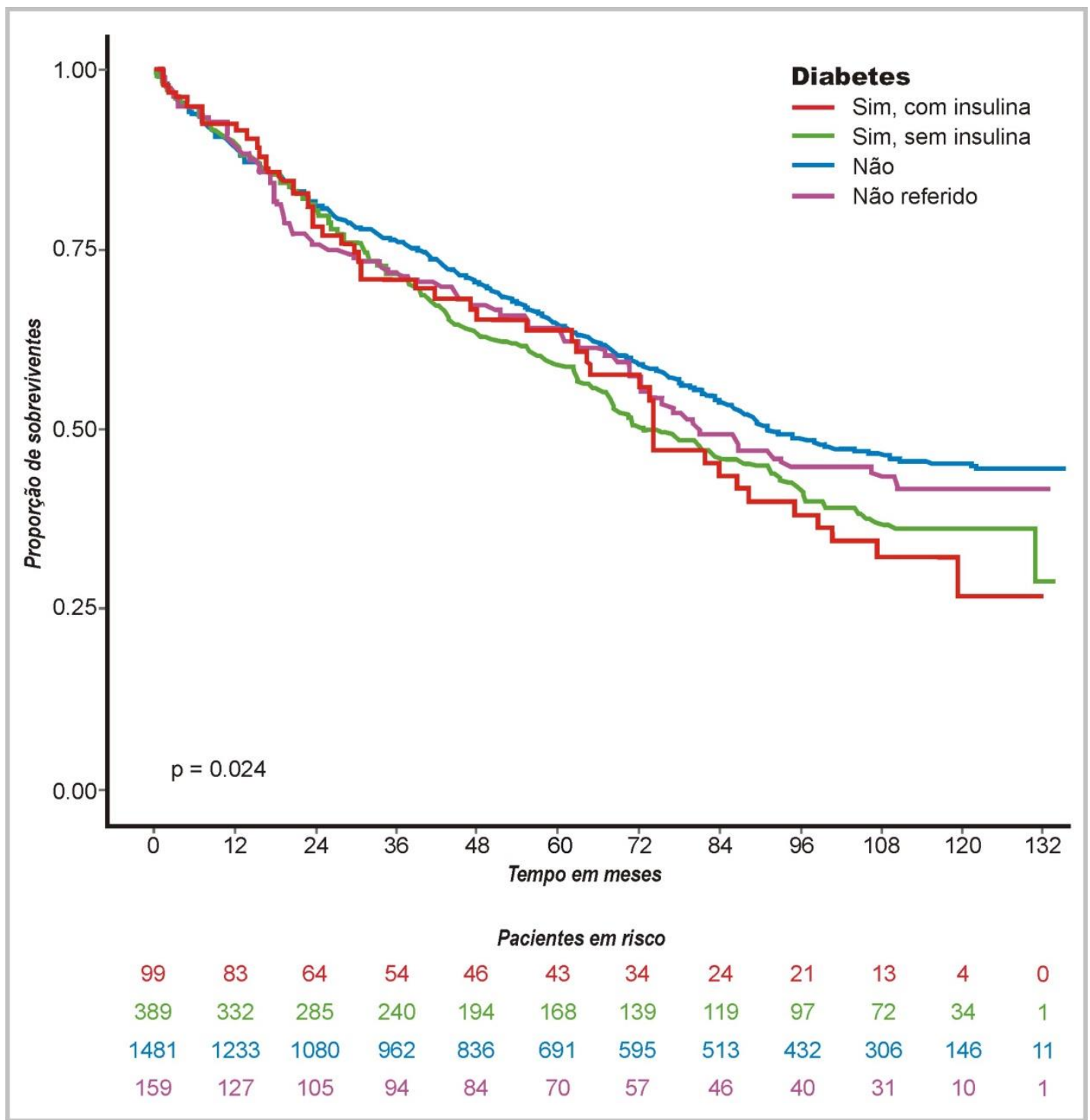

Figura 20 - Probabilidade de sobrevida estimada (Kaplan-Meier) para os 2.128 pacientes de acordo com o antecedente de diabetes melito. Os números sob o eixo das abscissas indicam o número de pacientes em risco no decorrer do tempo de observação decorrido da consulta inicial até a última informação obtida ou data do óbito. 


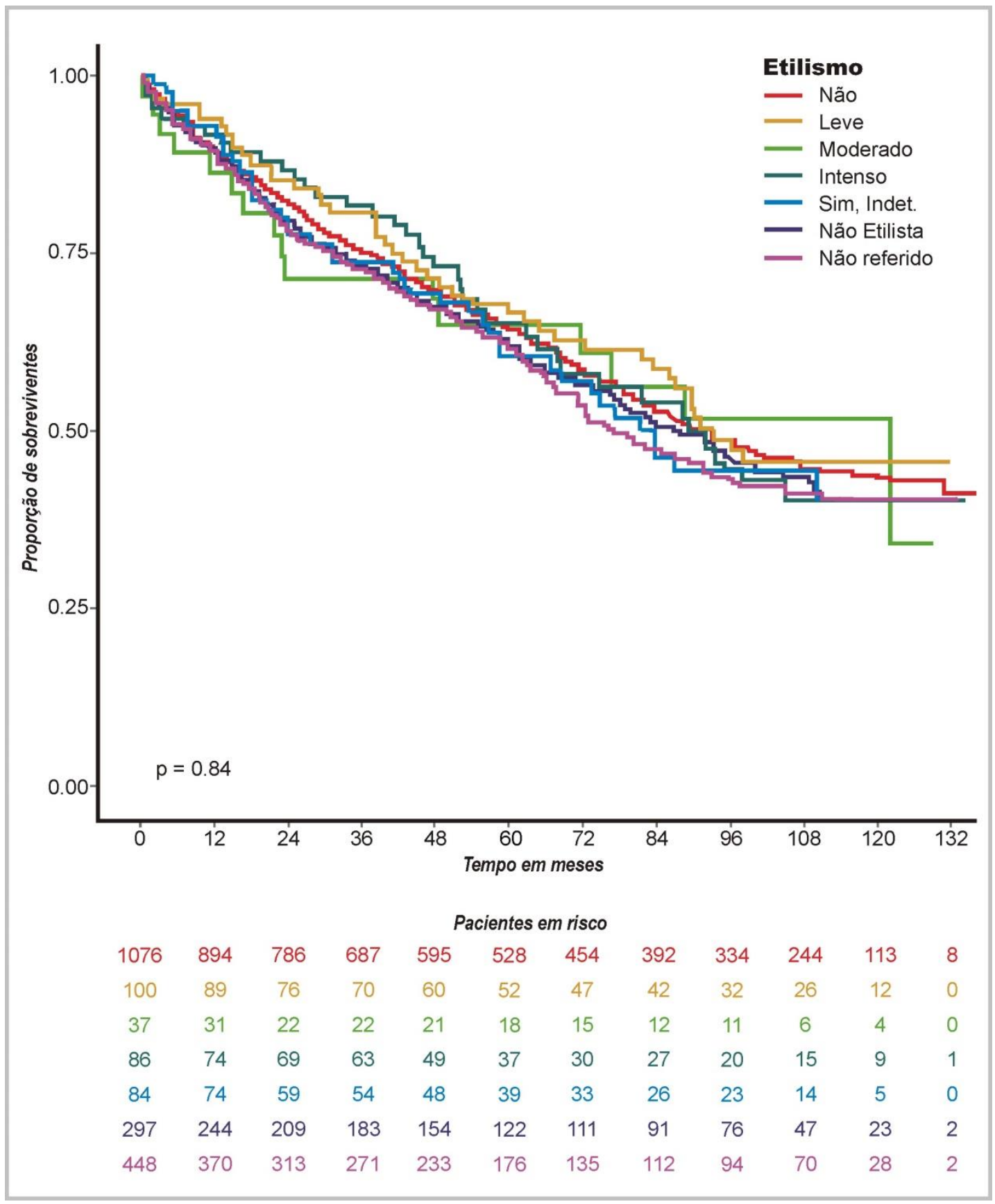

Figura 21 - Probabilidade de sobrevida estimada (Kaplan-Meier) dos 2.128 pacientes de acordo com o antecedente de etilismo. Os números sob o eixo das abscissas indicam o número de pacientes em risco no decorrer do tempo de observação a partir da consulta inicial até a última informação obtida ou data do óbito. 


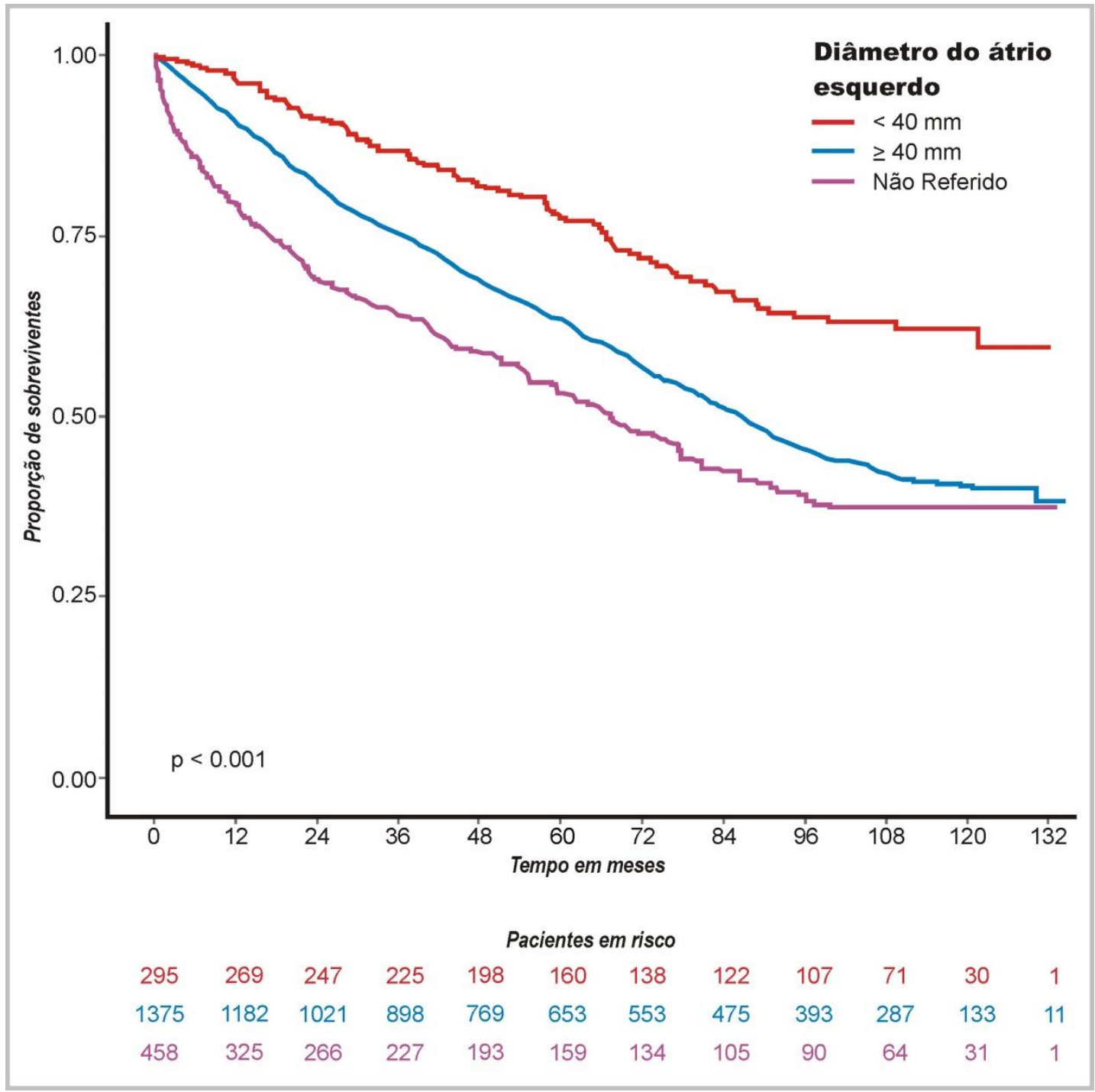

Figura 22 - Probabilidade de sobrevida estimada (Kaplan-Meier) dos 2.128 pacientes de acordo com o diâmetro do átrio esquerdo no ecocardiograma. Os números sob o eixo das abscissas indicam o número de pacientes em risco no decorrer do tempo de observação a partir da consulta inicial até a última informação obtida ou data do óbito. 


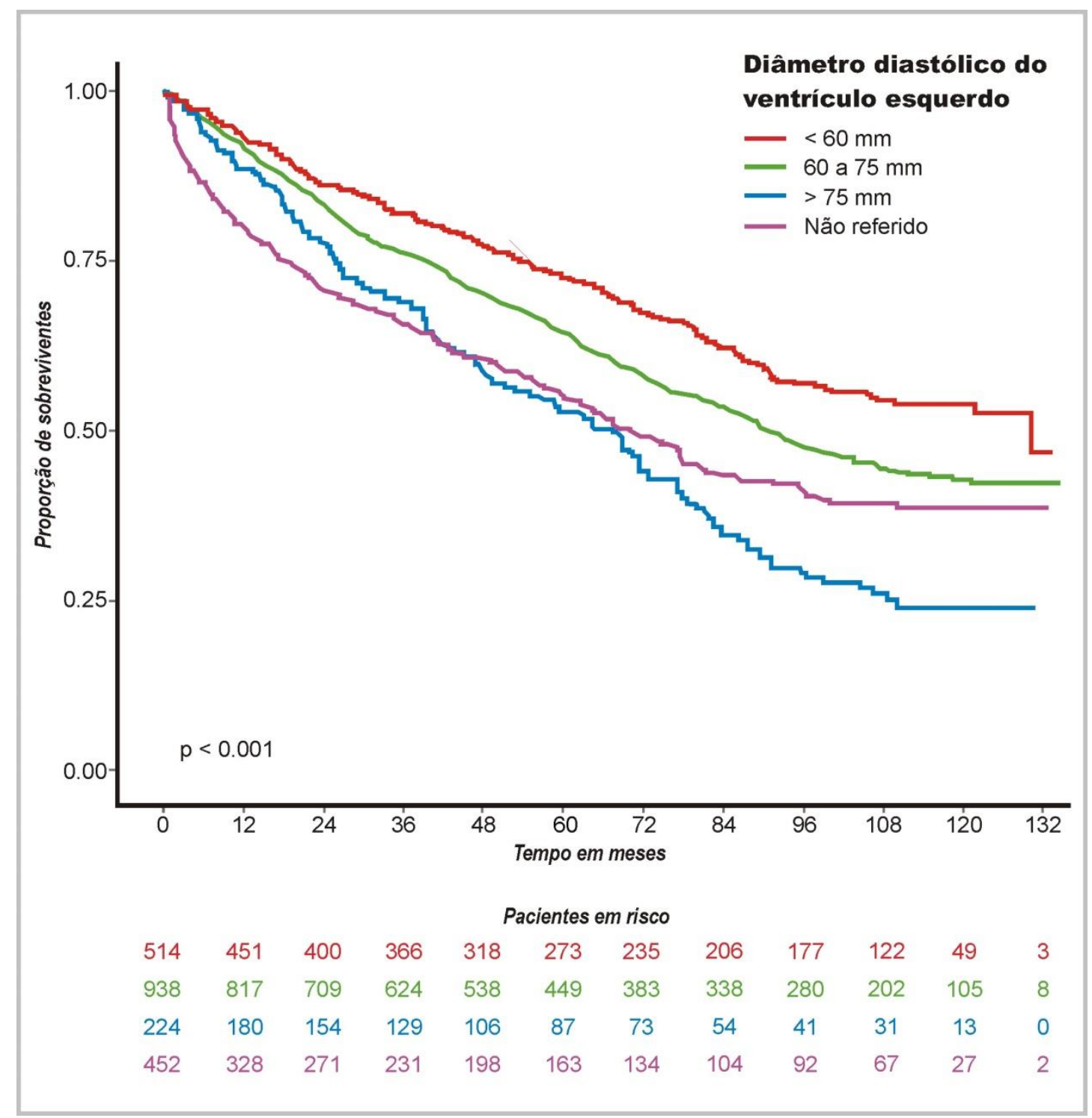

Figura 23 - Probabilidade da sobrevida estimada (Kaplan-Meier) dos 2.128 pacientes de acordo com o diâmetro diastólico do ventrículo esquerdo no ecocardiograma. Os números sob o eixo das abscissas indicam o número de pacientes em risco no decorrer do tempo de observação a partir da consulta inicial até a última informação obtida ou data do óbito. 


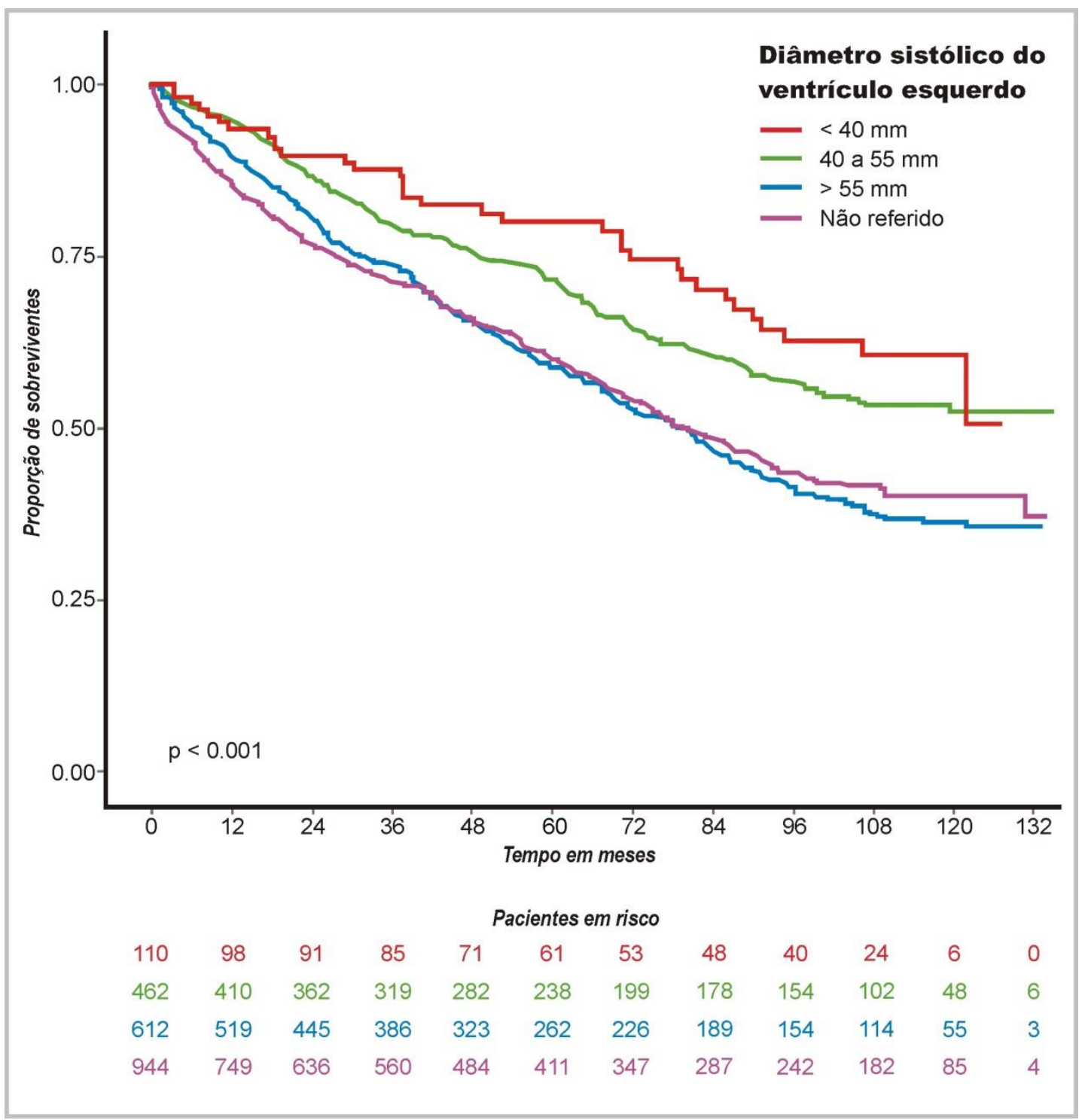

Figura 24 - Probabilidade de sobrevida estimada (Kaplan-Meier) dos 2.128 pacientes de acordo com o diâmetro sistólico do ventrículo esquerdo no ecocardiograma. Os números sob o eixo das abscissas indicam o número de pacientes em risco no decorrer do tempo de observação a partir da consulta inicial até a última informação obtida ou data do óbito. 


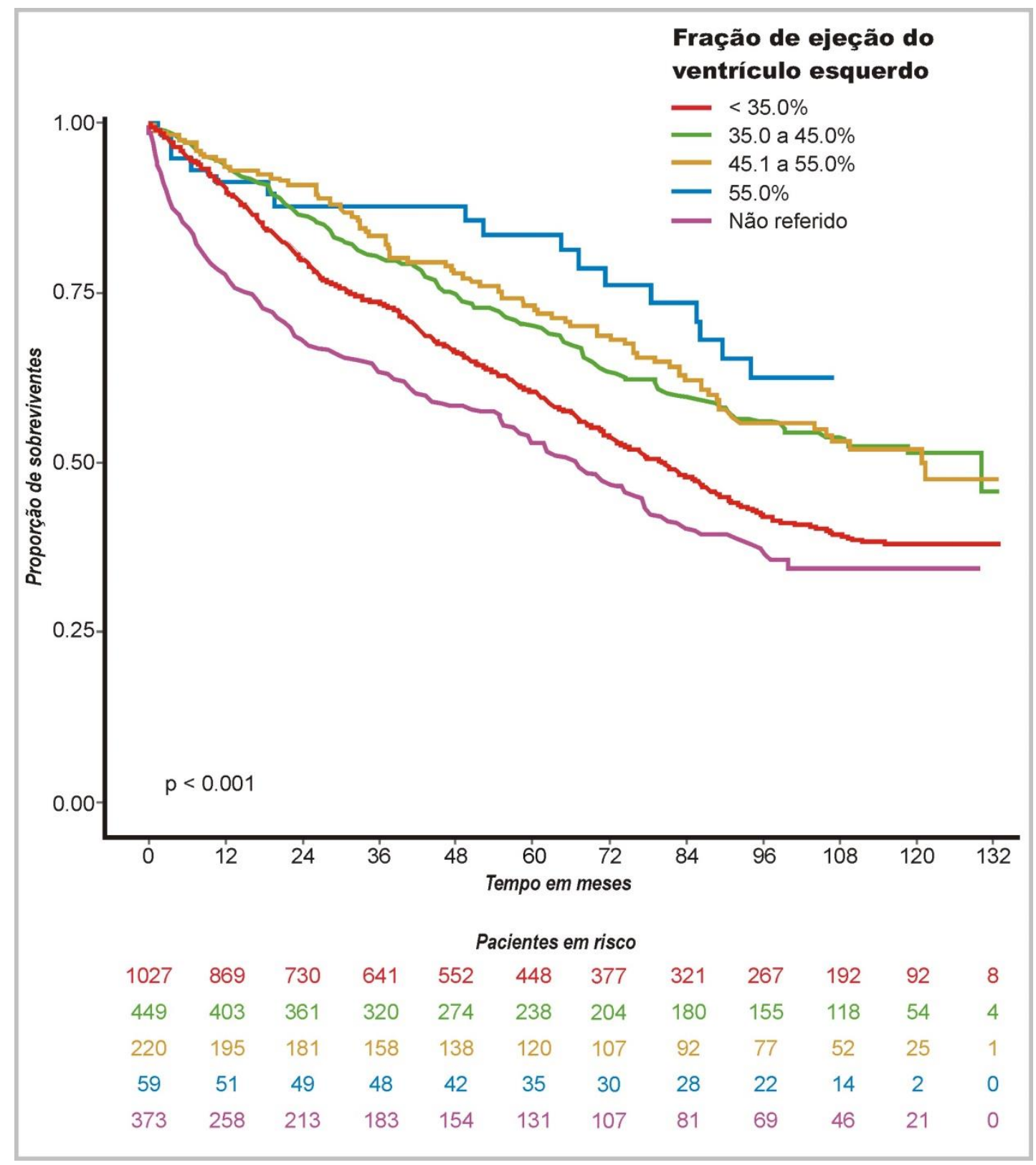

Figura 25 - Probabilidade de sobrevida estimada (Kaplan-Meier) dos 2.128 pacientes de acordo com a fração de ejeção do ventrículo esquerdo no ecocardiograma. Os números sob o eixo das abscissas indicam o número de pacientes em risco no decorrer do tempo de observação a partir da consulta inicial até a última informação obtida ou data do óbito. 


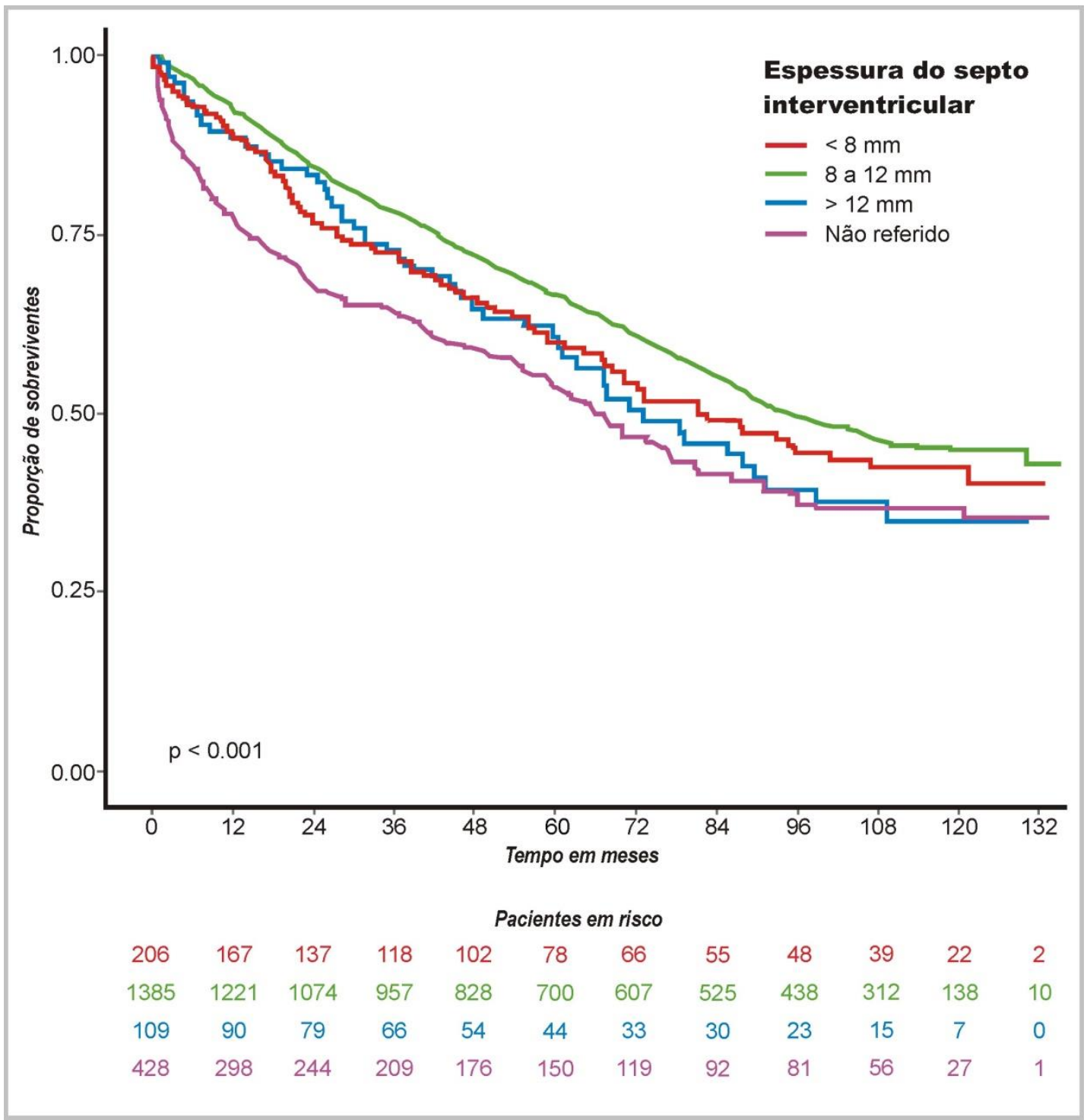

Figura 26 - Probabilidade de sobrevida estimada (Kaplan-Meier) dos 2.128 pacientes de acordo com a espessura diastólica do septo interventricular no ecocardiograma. Os números sob o eixo das abscissas indicam o número de pacientes em risco no decorrer do tempo de observação a partir da consulta inicial até a última informação obtida ou data do óbito. 


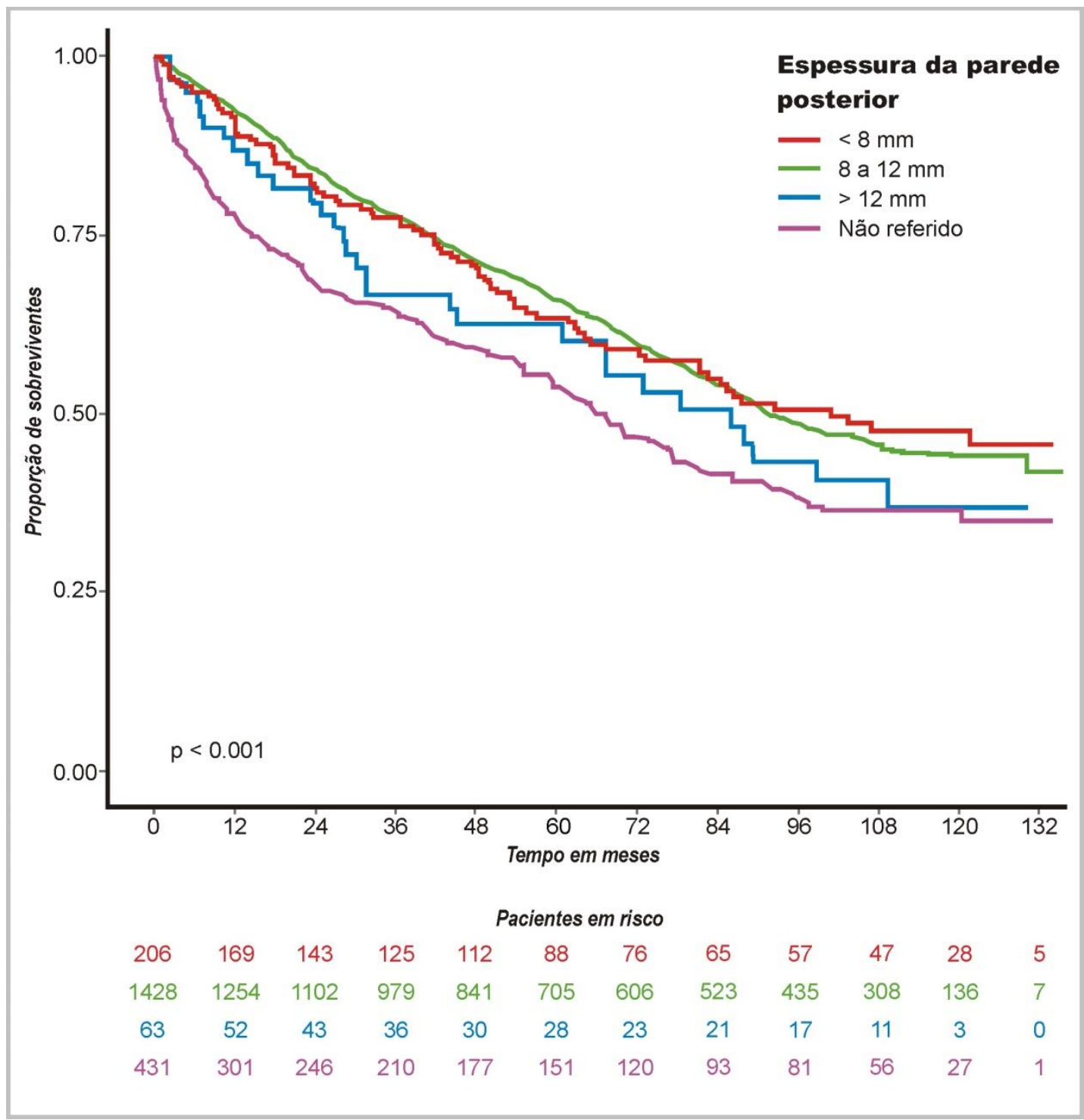

Figura 27 - Probabilidade de sobrevida estimada (Kaplan-Meier) dos 2.128 pacientes de acordo com a espessura diastólica da parede posterior do ventrículo esquerdo no ecocardiograma. Os números sob o eixo das abcissas indicam o número de pacientes em risco no decorrer do tempo de observação a partir da consulta inicial até a última informação obtida ou data do óbito. 


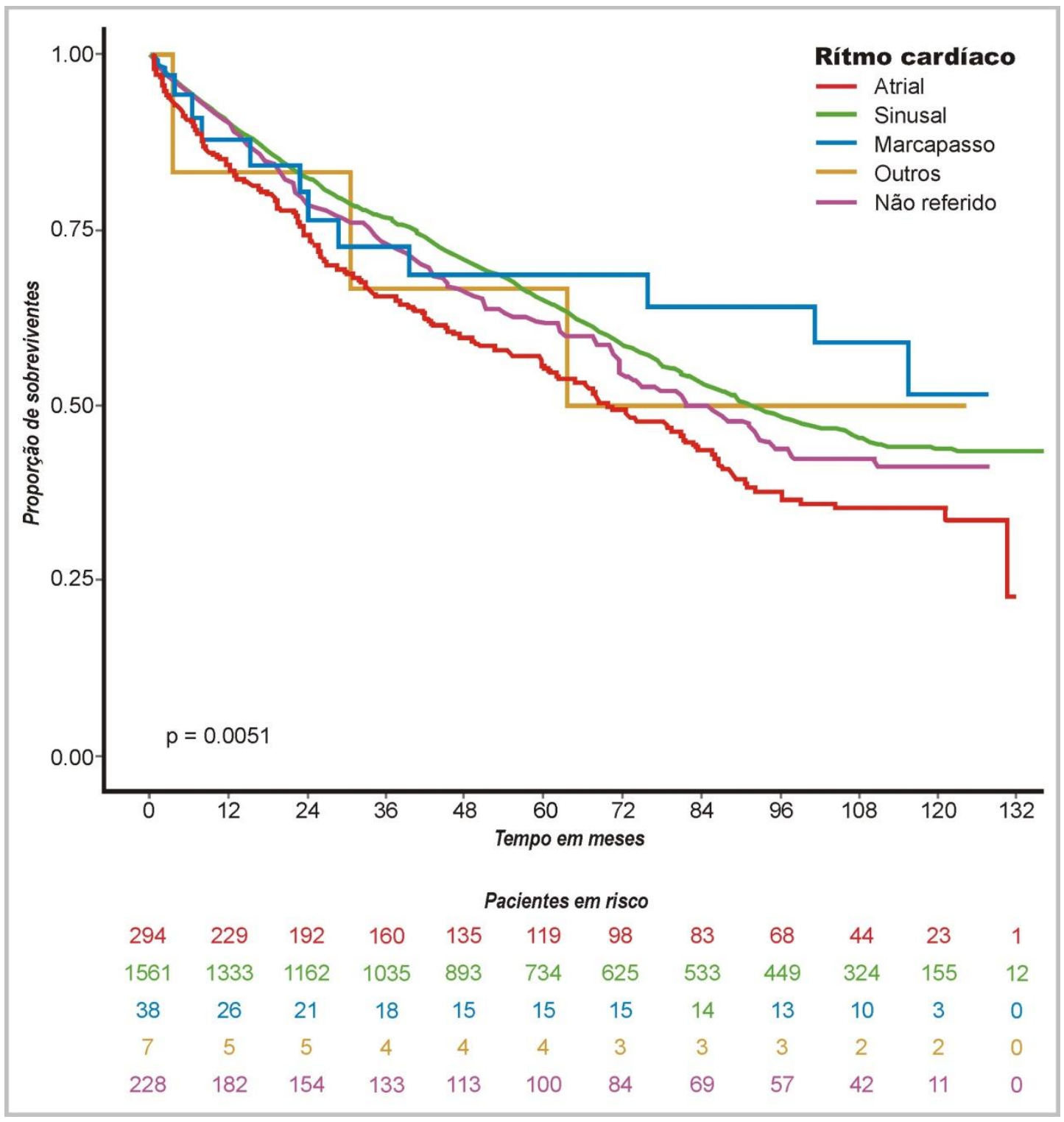

Figura 28 - Probabilidade de sobrevida estimada (Kaplan-Meier) dos 2.128 pacientes de acordo com o rítmo cardíaco. Os números sob o eixo das abscissas indicam o número de pacientes em risco no decorrer do tempo de observação a partir da consulta inicial até a última informação obtida ou data do óbito. 


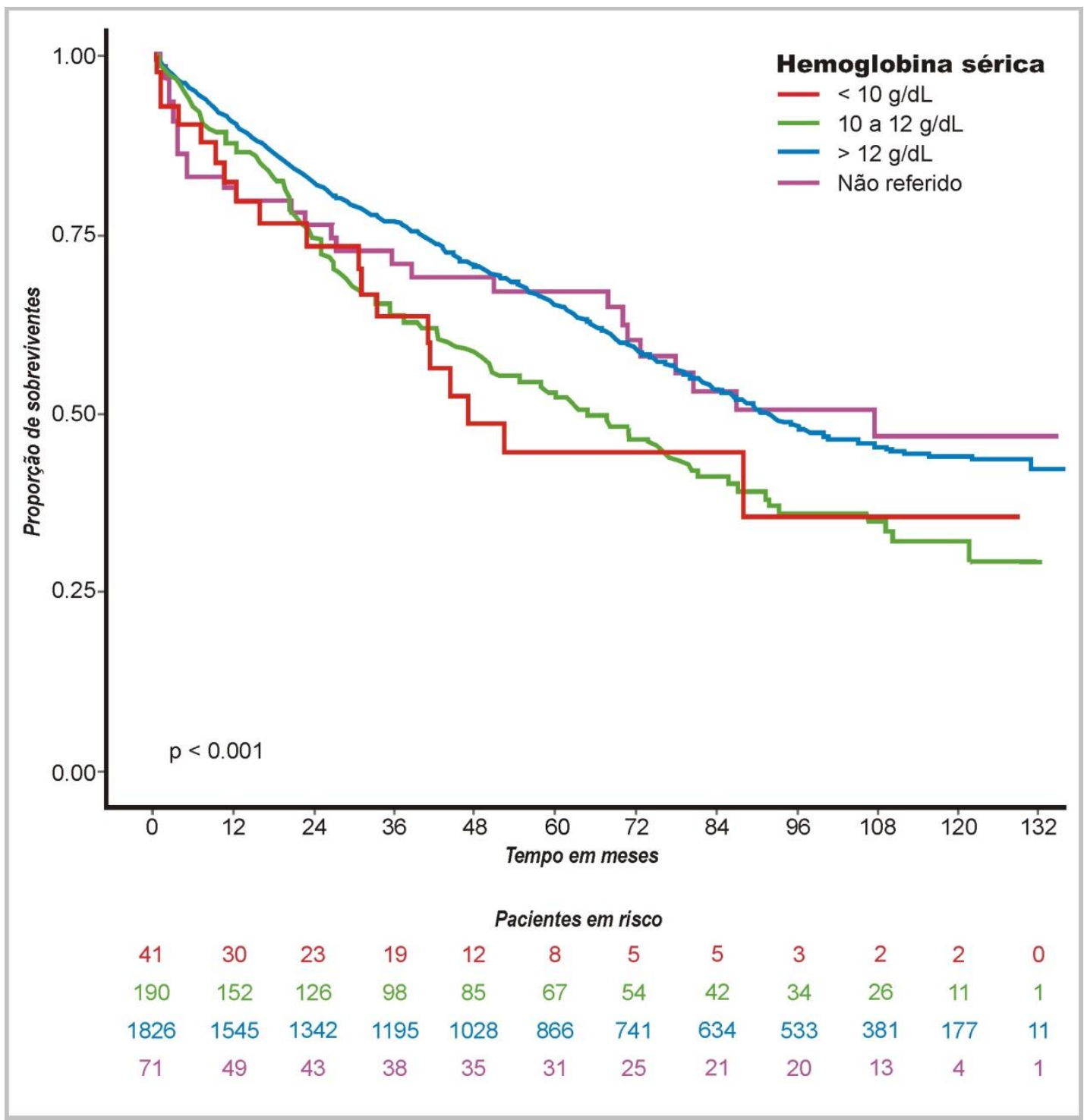

Figura 29 - Probabilidade de sobrevida estimada (Kaplan-Meier) dos 2.128 pacientes de acordo com a taxa de hemoglobina. Os números sob o eixo das abscissas indicam o número de pacientes em risco no decorrer do tempo de observação a partir da consulta inicial até a última informação obtida ou data do óbito 


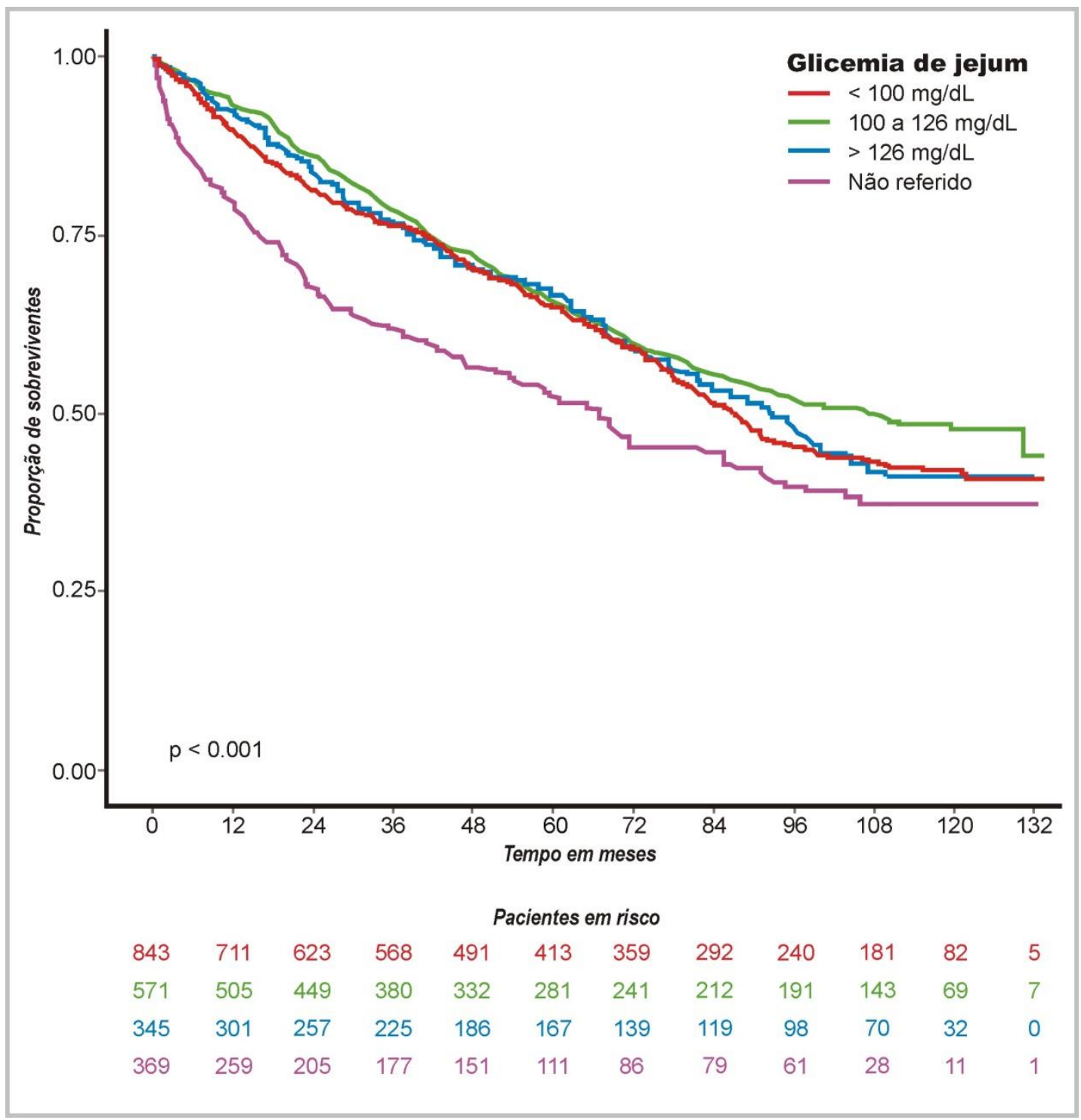

Figura 30 - Probabilidade de sobrevida estimada (Kaplan-Meier) dos 2.128 pacientes de acordo com a glicemia de jejum. Os números sob o eixo das abscissas indicam o número de pacientes em risco no decorrer do tempo de observação a partir da consulta inicial até a última informação obtida ou data do óbito 


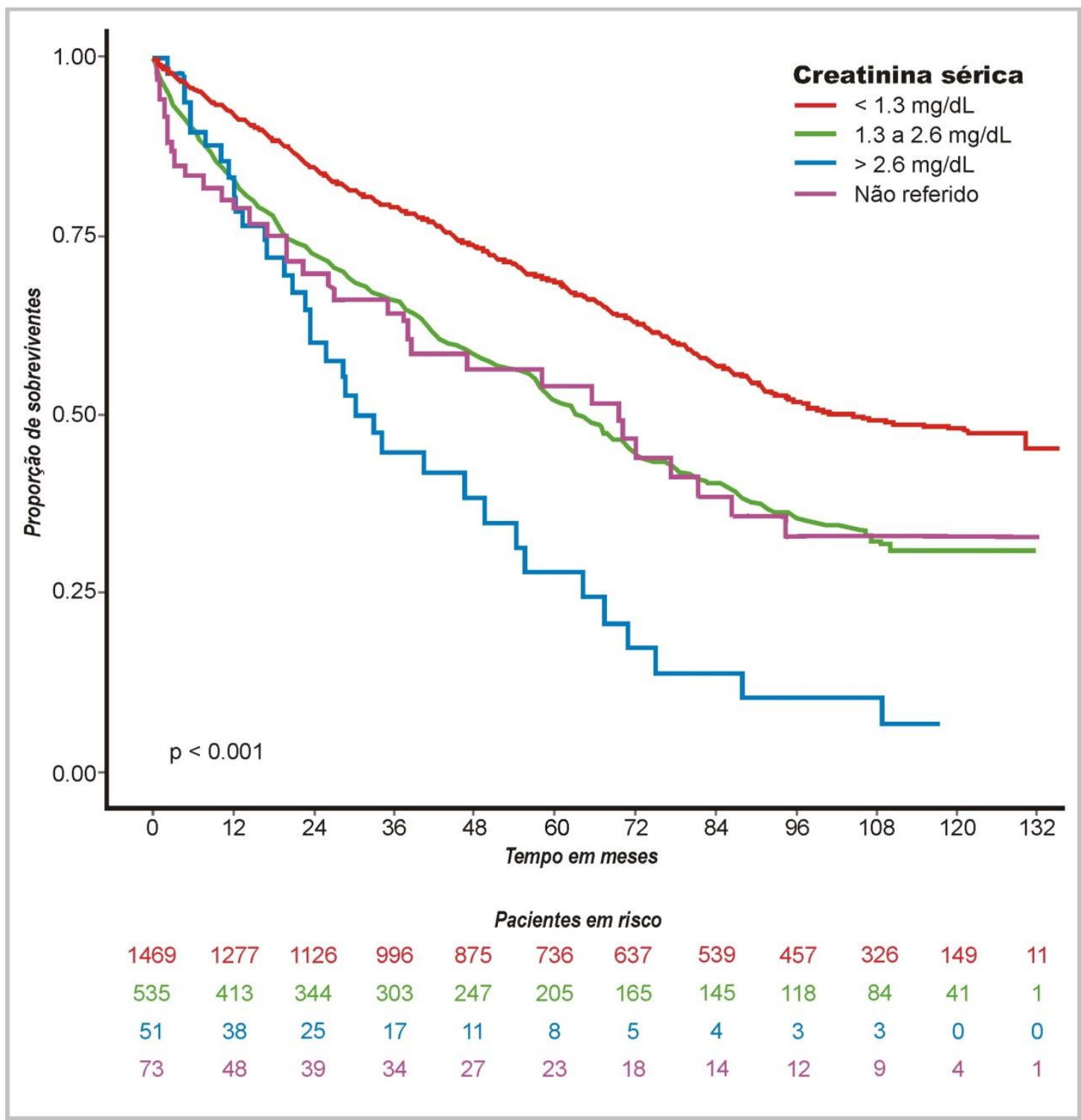

Figura 31 - Probabilidade de sobrevida estimada (Kaplan-Meier) dos 2.128 pacientes de acordo com a taxa de creatinina. Os números sob o eixo das abscissas indicam o número de pacientes em risco no decorrer do tempo de observação a partir da consulta inicial até a última informação obtida ou data do óbito. 


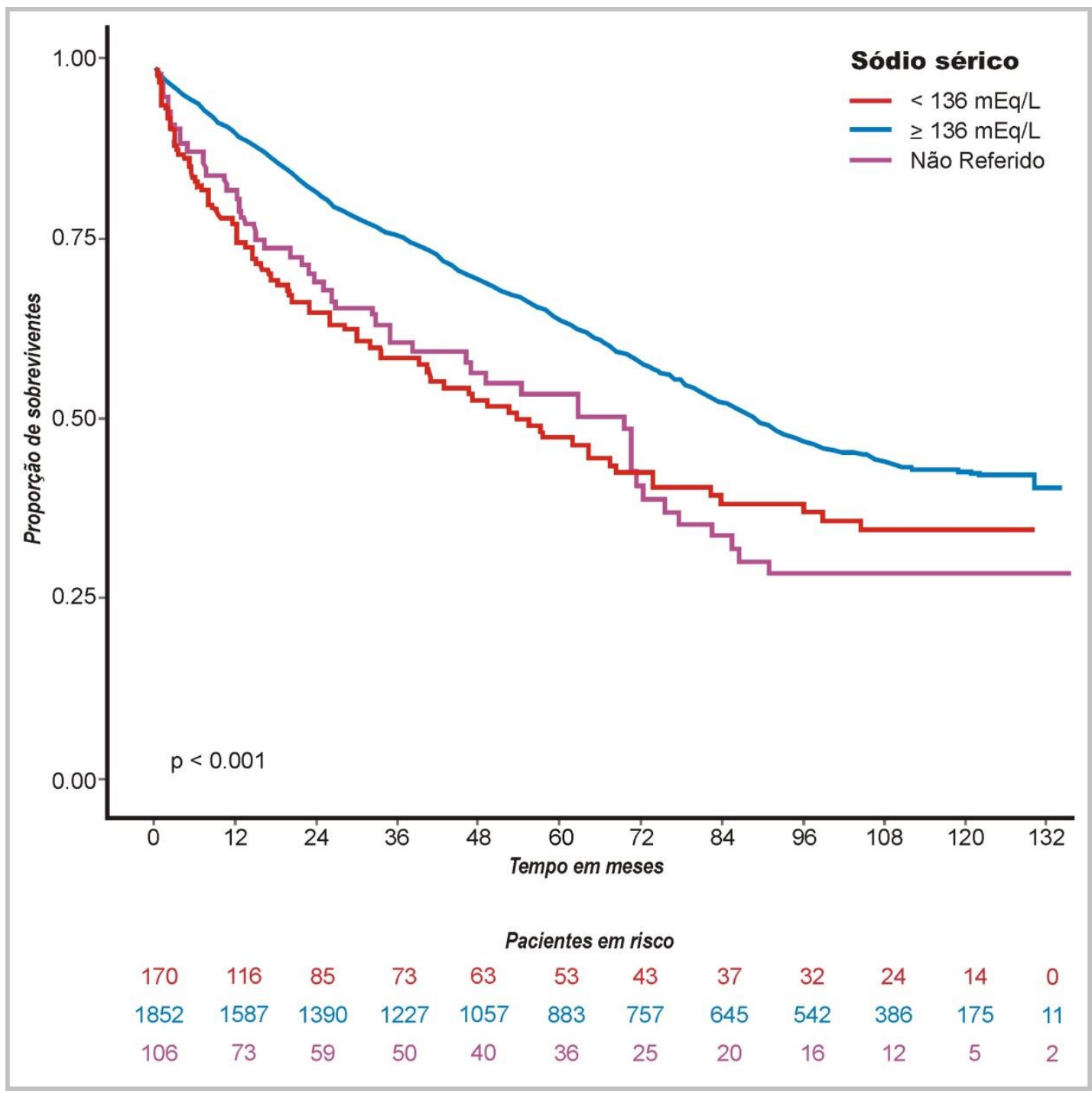

Figura 32 - Probabilidade de sobrevida estimada (Kaplan-Meier) dos 2.128 pacientes de acordo com a taxa de sódio sérico. Os números sob o eixo das abscissas indicam o número de pacientes em risco no decorrer do tempo de observação a partir da consulta inicial até a última informação obtida ou data do óbito. 


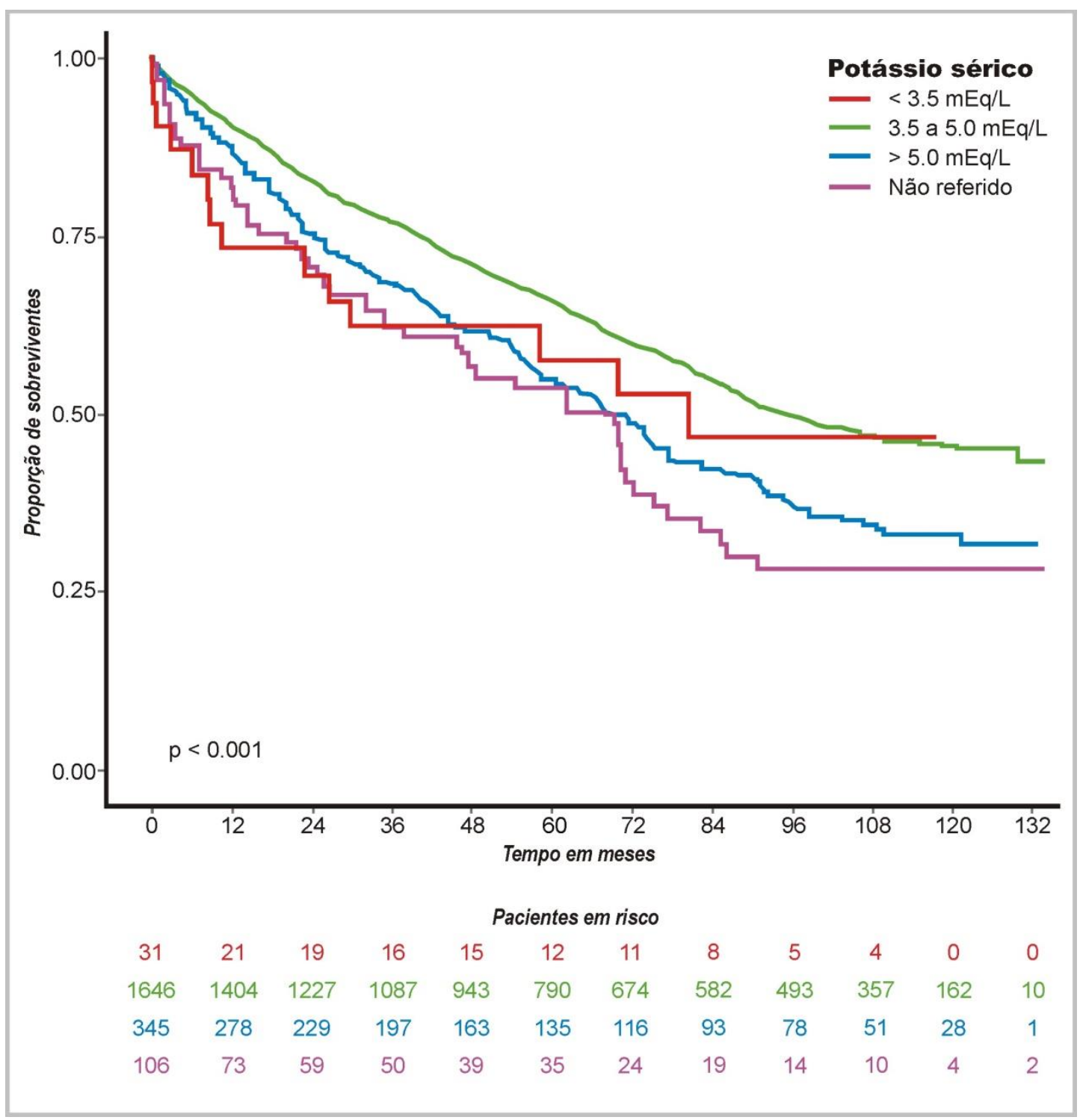

Figura 33 - Probabilidade de sobrevida estimada (Kaplan-Meier) dos 2.128 pacientes de acordo com a taxa de potássio sérico. Os números sob o eixo das abscissas indicam o número de pacientes em risco no decorrer do tempo de observação a partir da consulta inicial até a última informação obtida ou data do óbito. 


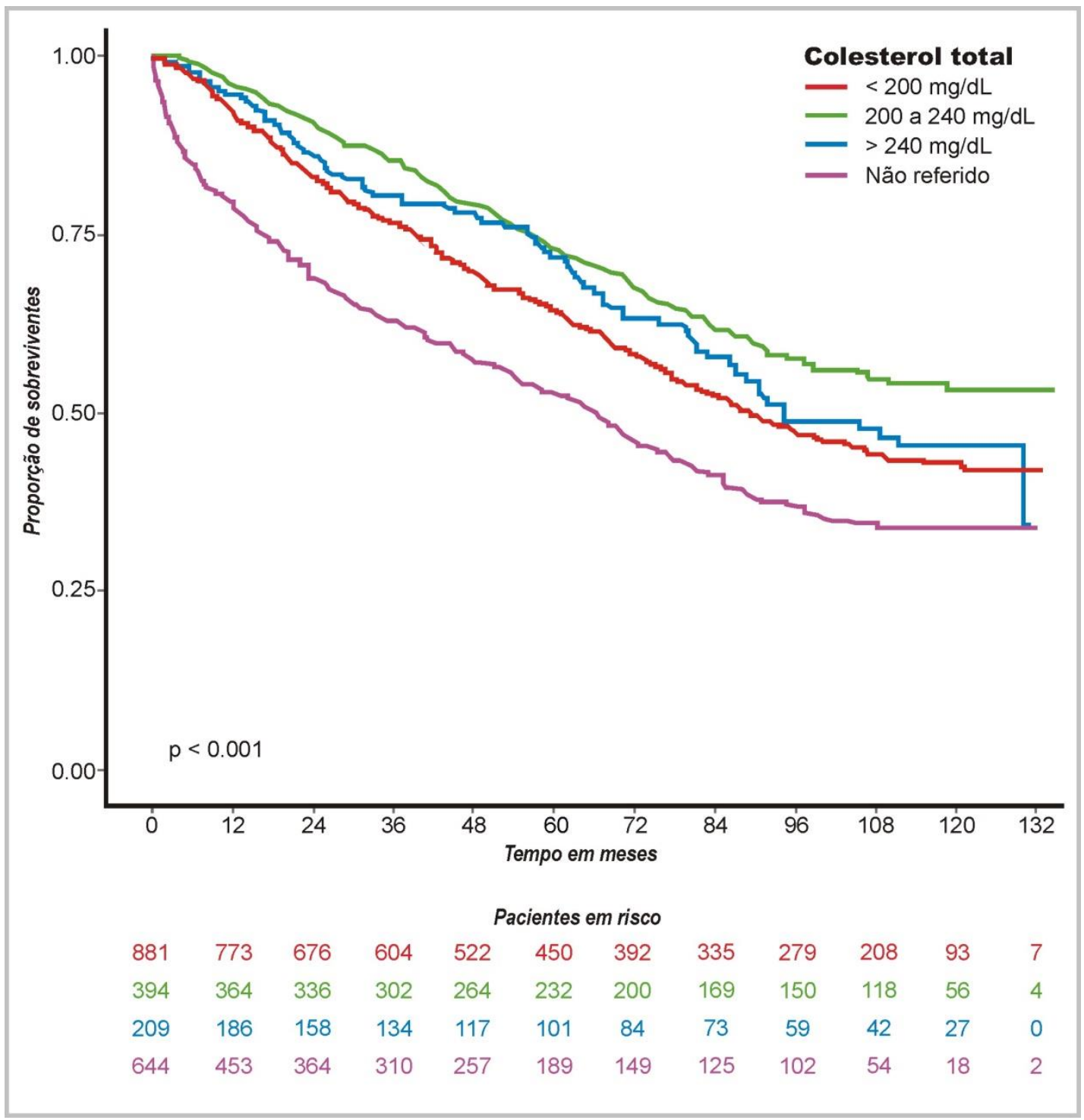

Figura 34 - Probabilidade de sobrevida estimada (Kaplan-Meier) dos 2.128 pacientes de acordo com a taxa de colesterol total. Os números sob o eixo das abscissas indicam o número de pacientes em risco no decorrer do tempo de observação a partir da consulta inicial até a última informação obtida ou data do óbito. 


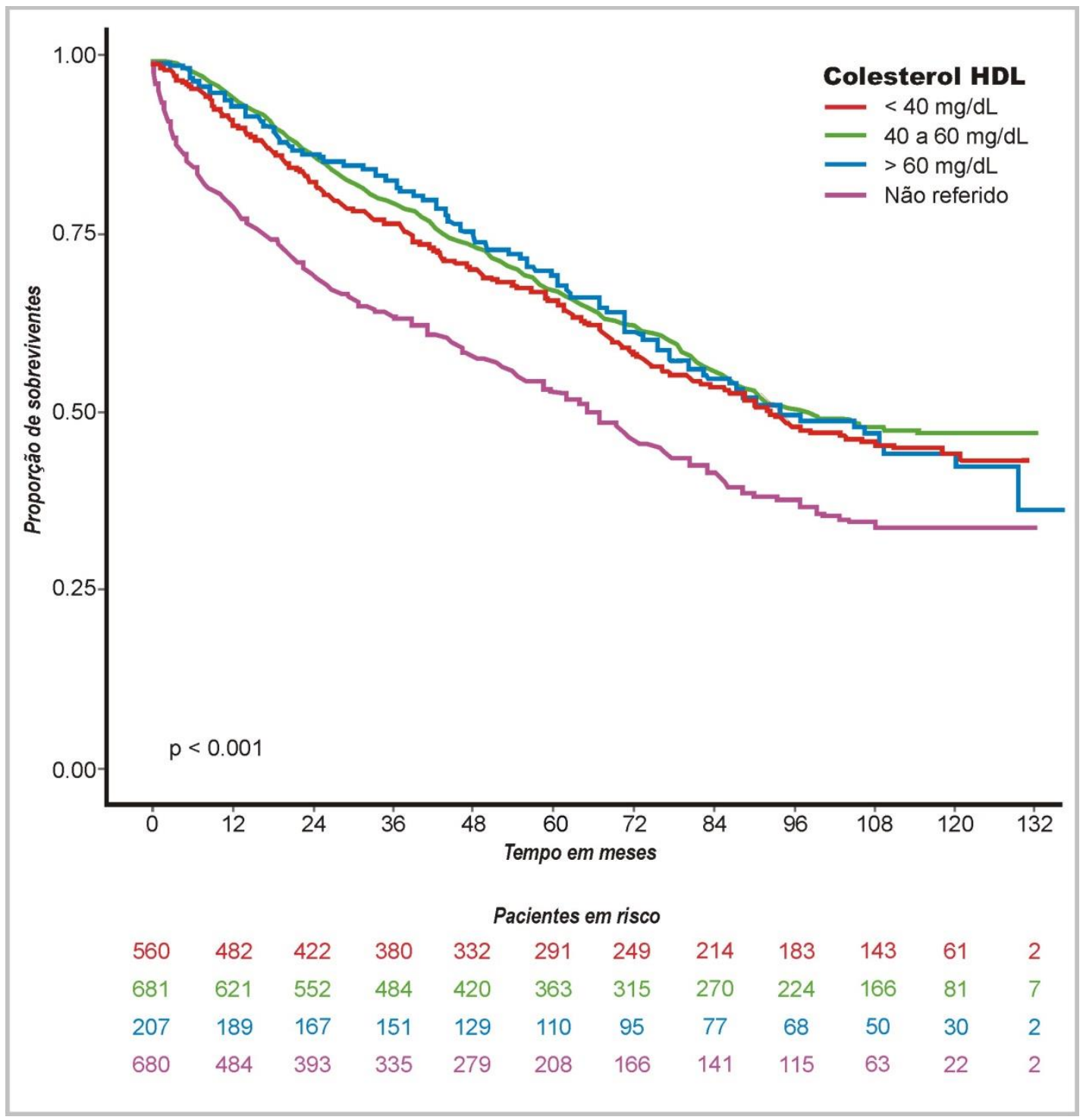

Figura 35 - Probabilidade de sobrevida estimada (Kaplan-Meier) dos 2.128 pacientes de acordo com a taxa de HDL-colesterol. Os números sob o eixo das abscissas indicam o número de pacientes em risco no decorrer do tempo de observação a partir da consulta inicial até a última informação obtida ou data do óbito. 


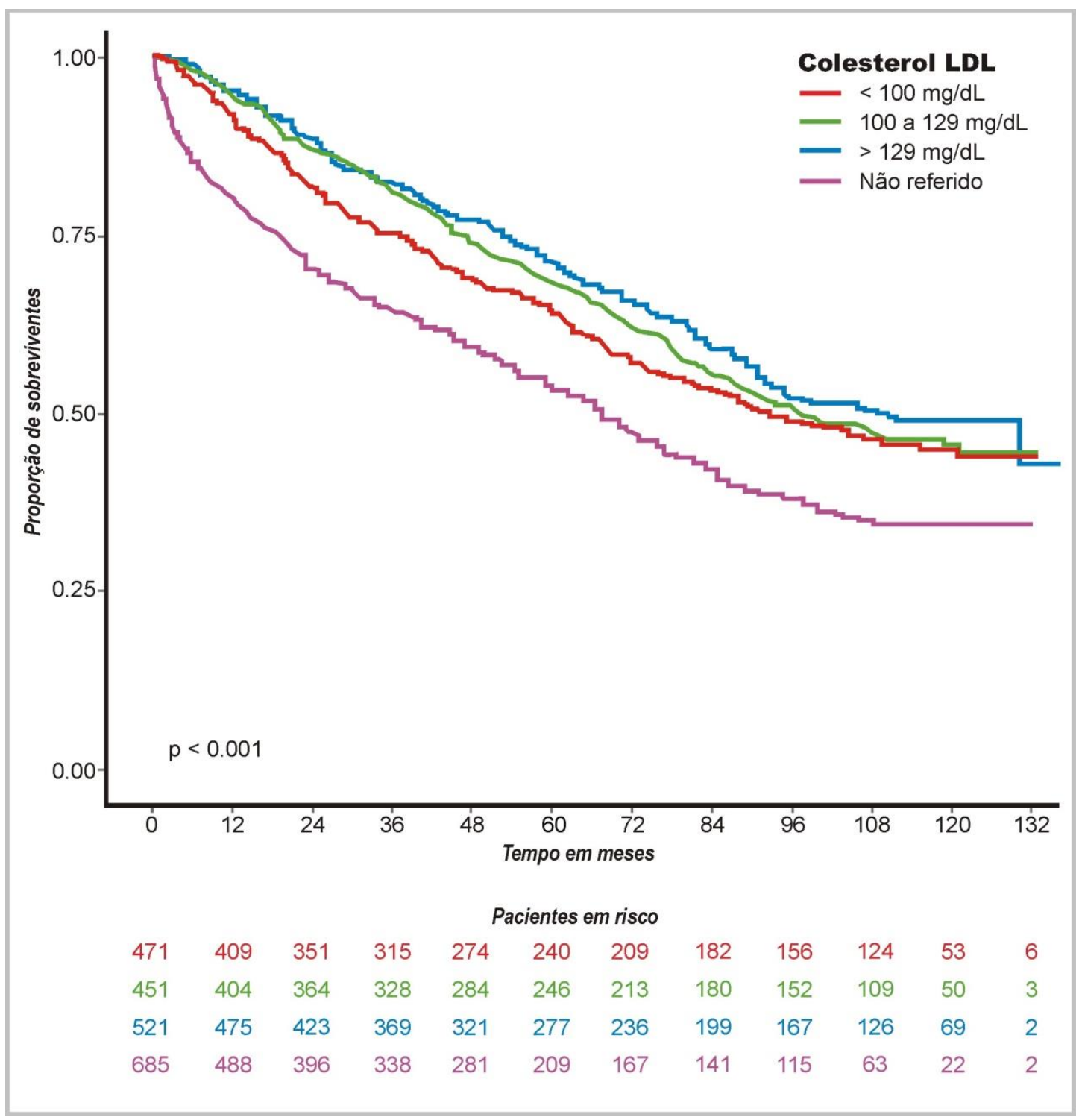

Figura 36 - Probabilidade de sobrevida estimada (Kaplan-Meier) dos 2.128 pacientes de acordo com a taxa de LDL-colesterol. Os números sob o eixo das abscissas indicam o número de pacientes em risco no decorrer do tempo de observação a partir da consulta inicial até a última informação obtida ou data do óbito. 


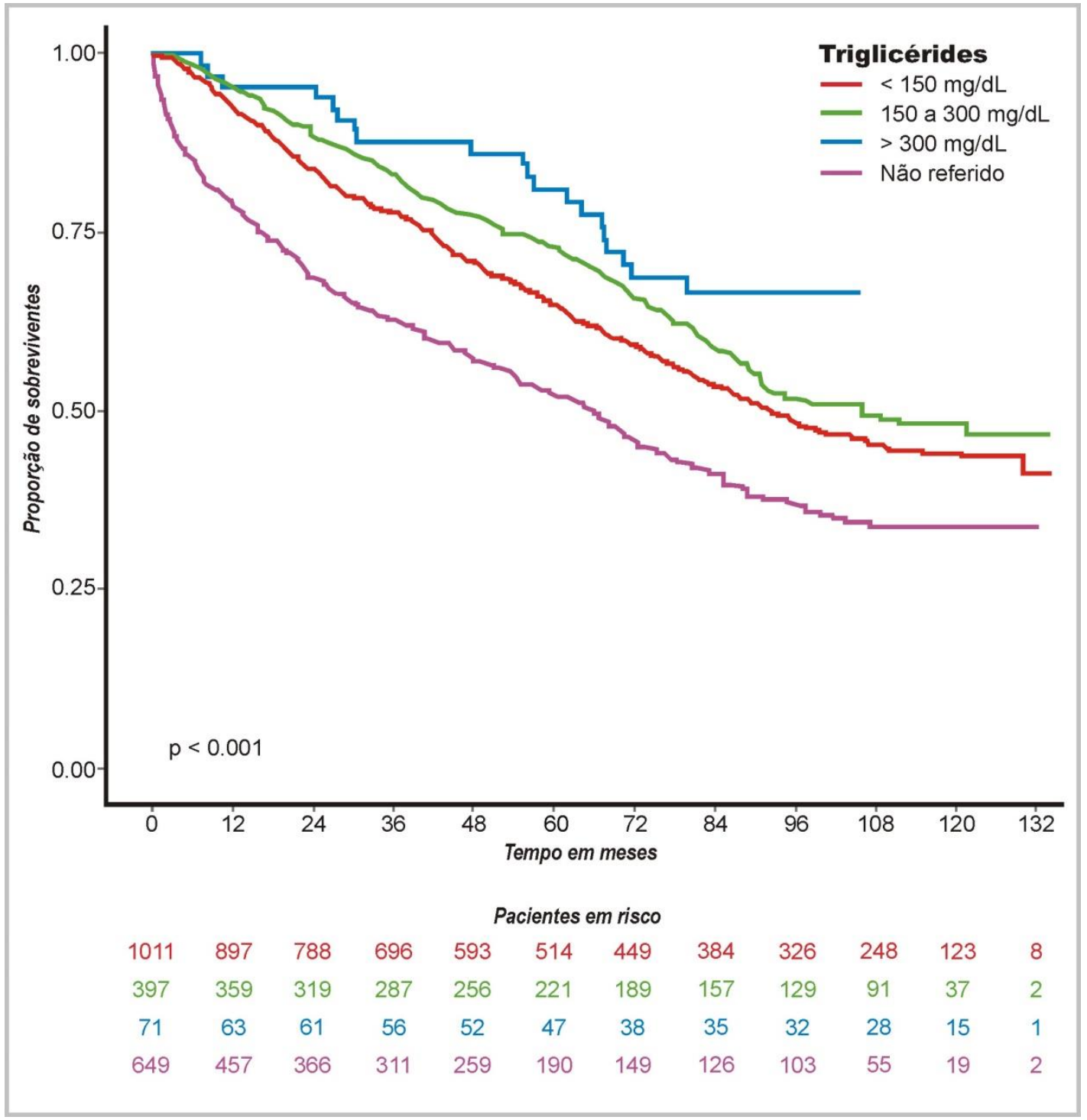

Figura 37 - Probabilidade de sobrevida estimada (Kaplan-Meier) dos 2.128 pacientes de acordo com a taxa de triglicérides. Os números sob o eixo das abscissas indicam o número de pacientes em risco no decorrer do tempo de observação a partir da consulta inicial até a última informação obtida ou data do óbito. 


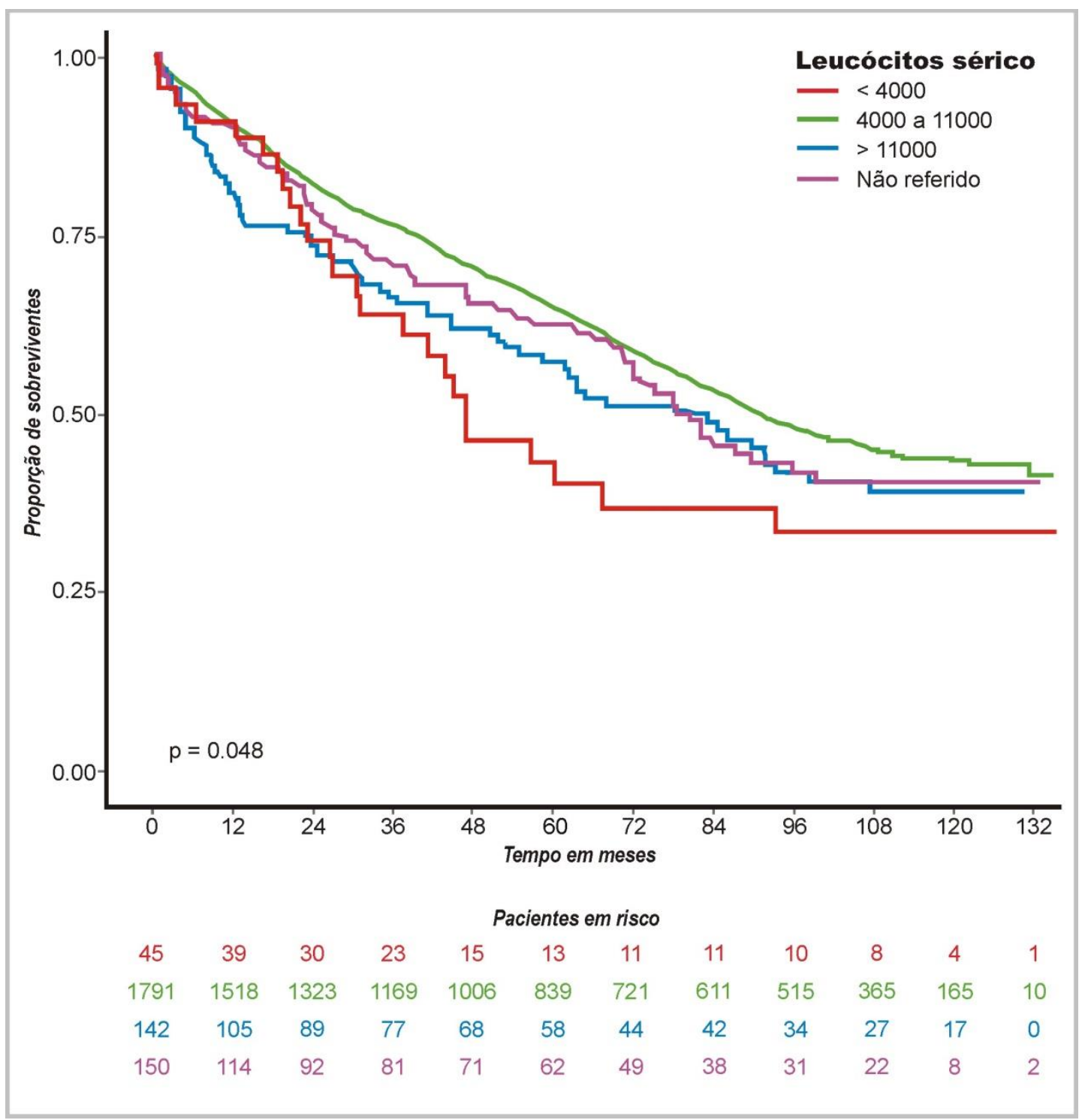

Figura 38 - Probabilidade de sobrevida estimada (Kaplan-Meier) dos 2.128 pacientes de acordo com a taxa de leucócitos. Os números sob o eixo das abscissas indicam o número de pacientes em risco no decorrer do tempo de observação a partir da consulta inicial até a última informação obtida ou data do óbito. 


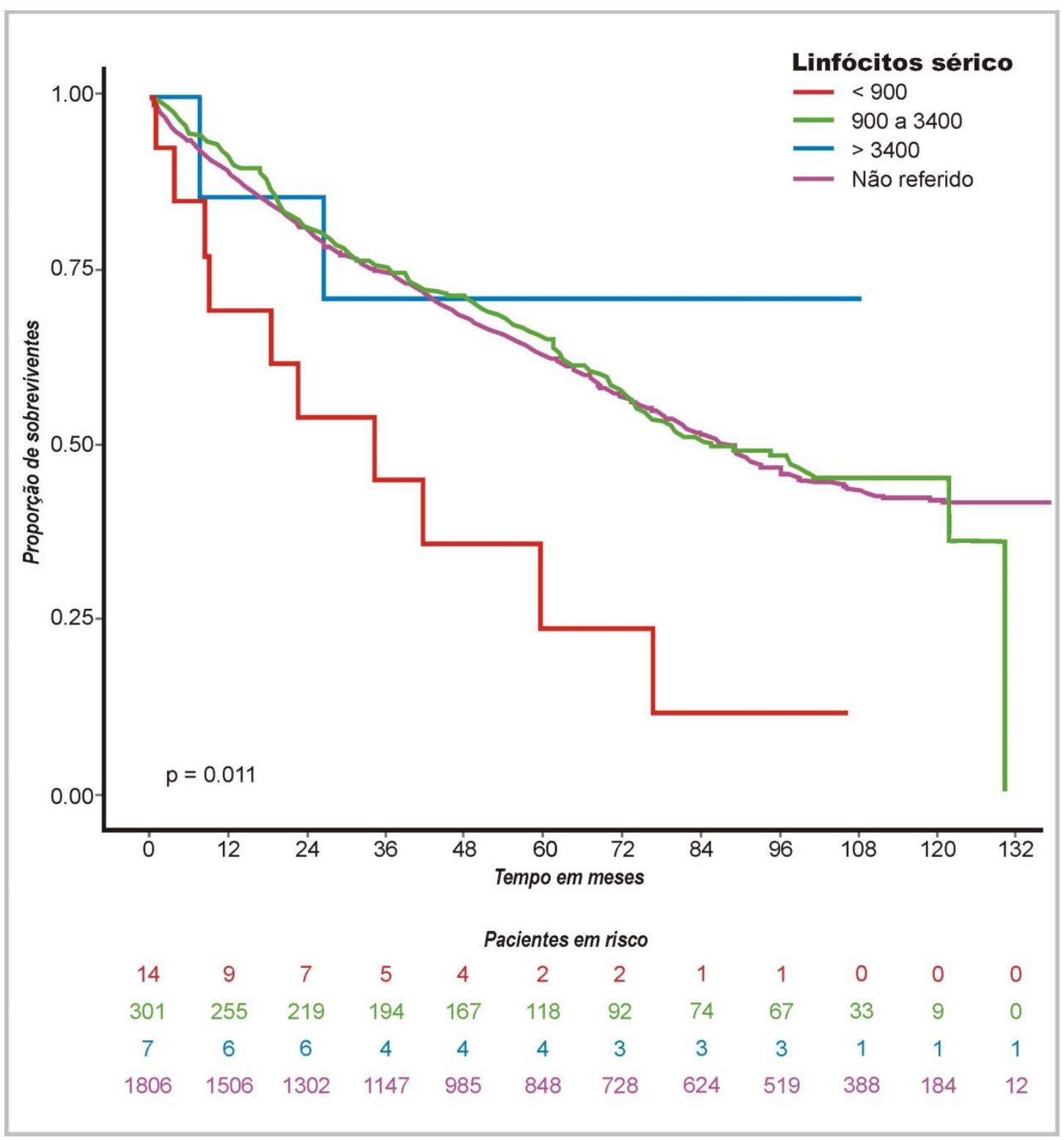

Figura 39 - Probabilidade de sobrevida estimada (Kaplan-Meier) dos 2.128 pacientes de acordo com a taxa de linfócitos. Os números sob o eixo das abscissas indicam o número de pacientes em risco no decorrer do tempo de observação a partir da consulta inicial até a última informação obtida ou data do óbito. 


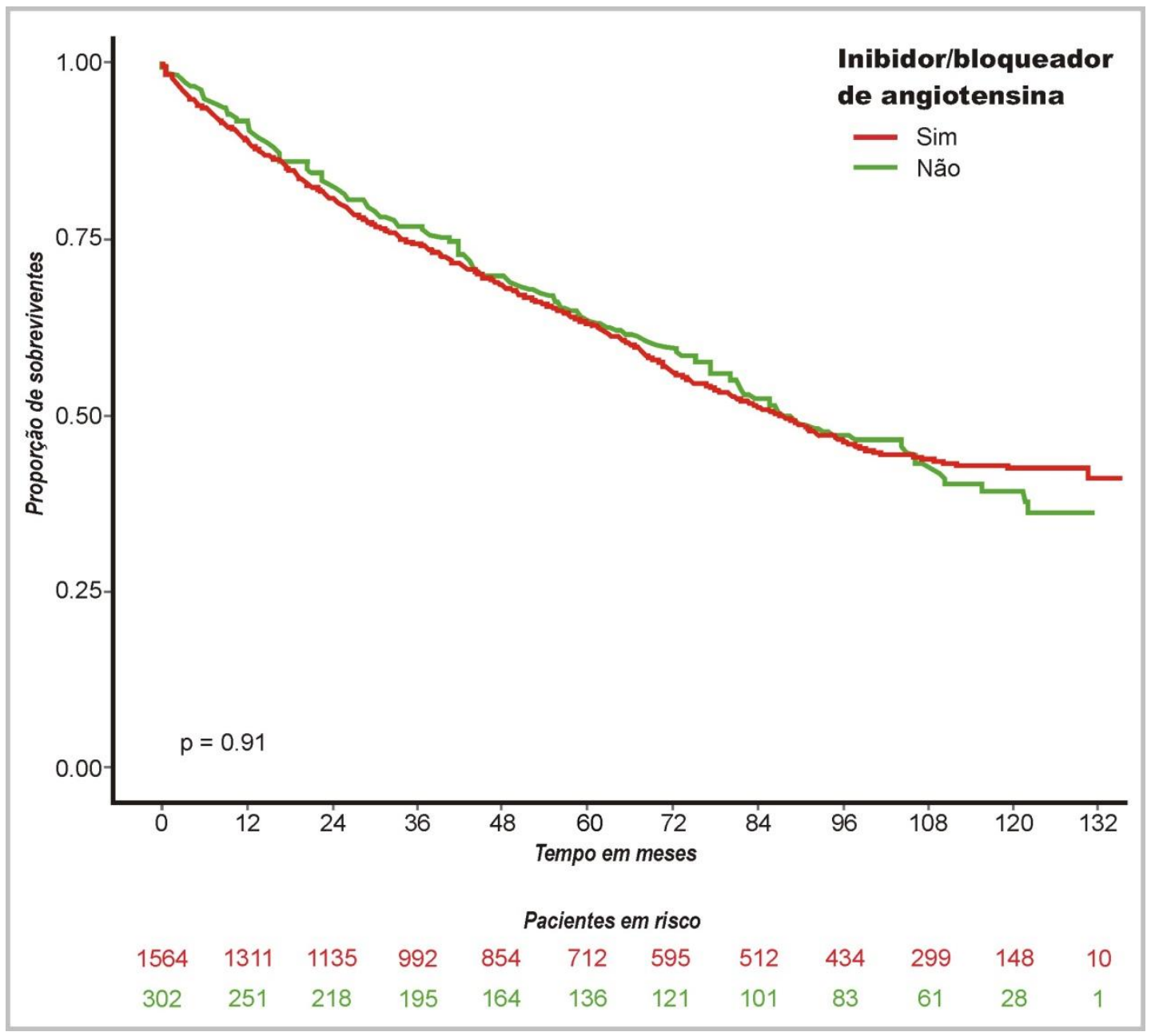

Figura 40 - Probabilidade de sobrevida estimada (Kaplan-Meier) dos 2.128 pacientes quanto ao uso de inibidor de enzima conversora da angiotensina (captopril, enalapril) ou de bloqueador dos receptores da angiotensina II (losartana) na consulta inicial. Os números sob o eixo das abscissas indicam o número de pacientes em risco no decorrer do tempo de observação a partir da consulta inicial até a última informação obtida ou data do óbito. 


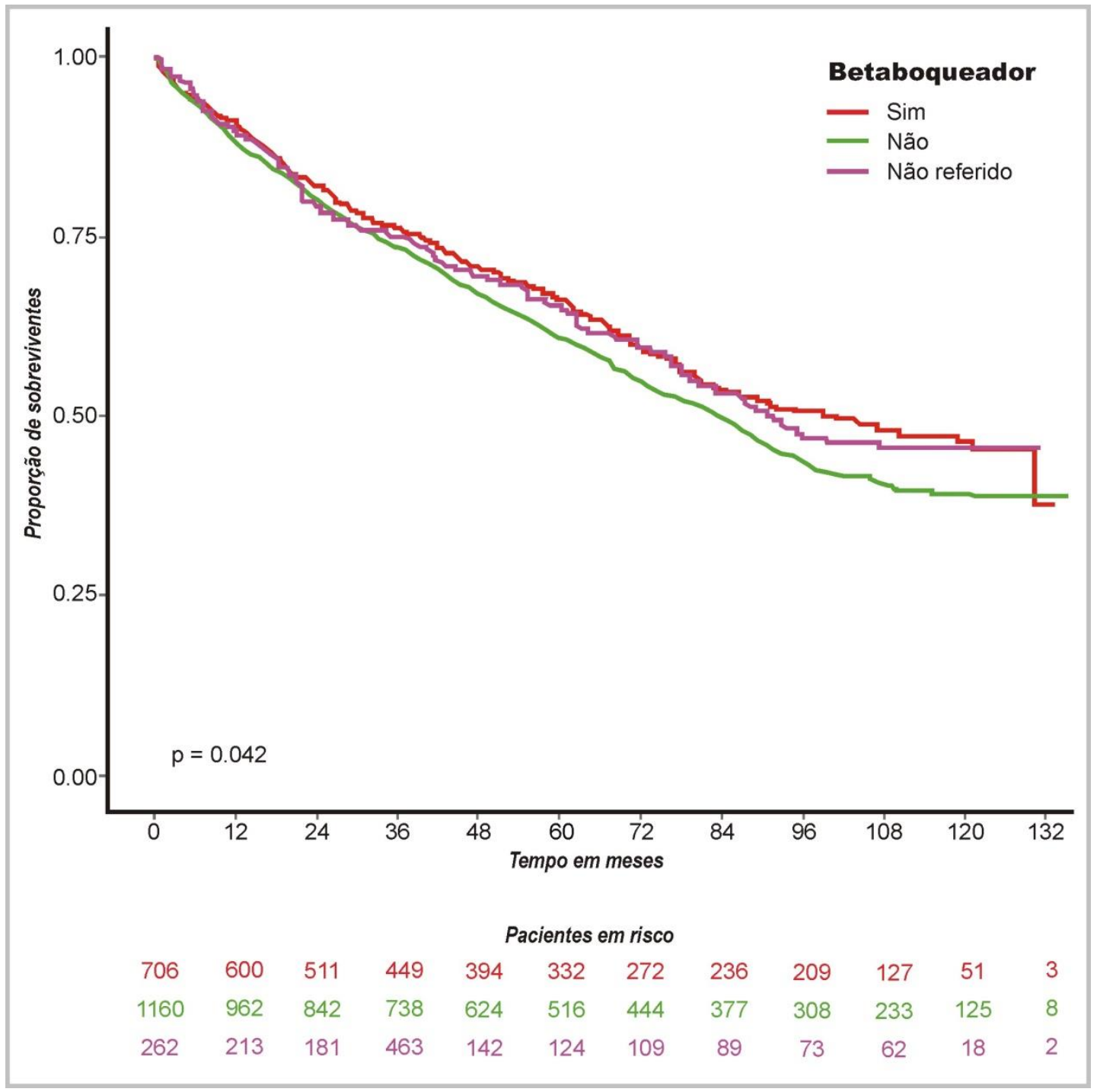

Figura 41 - Probabilidade de sobrevida estimada (Kaplan-Meier) dos 2.128 pacientes quanto ao uso de beta-bloqueadores na consulta inicial. Os números sob o eixo das abscissas indicam o número de pacientes em risco no decorrer do tempo de observação a partir da consulta inicial até a última informação obtida ou data do óbito. 


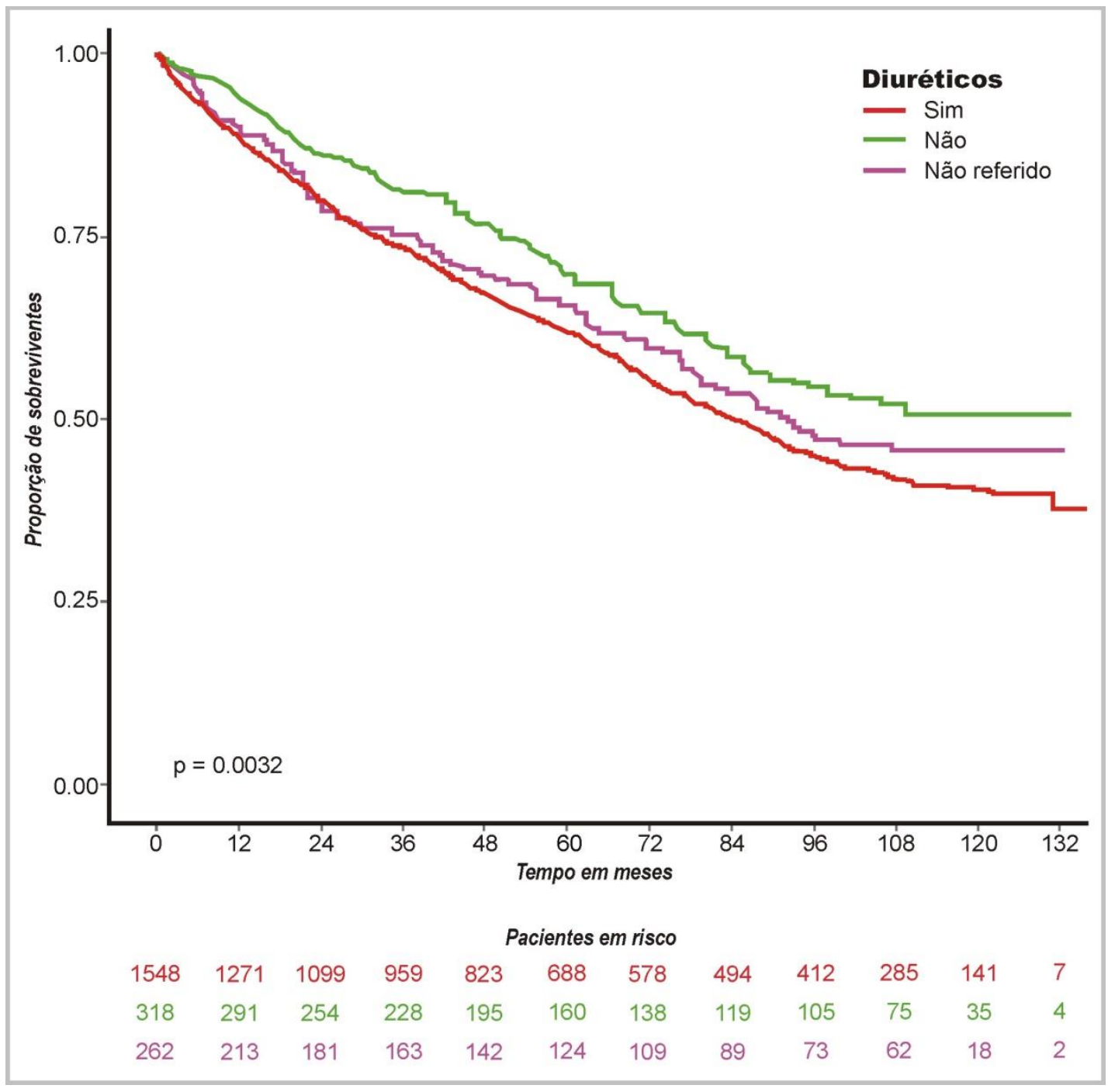

Figura 42 - Probabilidade de sobrevida estimada (Kaplan-Meier) dos 2.128 pacientes quanto ao uso de diuréticos (furosemida, hidroclorotiazida) na consulta inicial. Os números sob o eixo das abscissas indicam o número de pacientes em risco no decorrer do tempo de observação a partir da consulta inicial até a última informação obtida ou data do óbito. 


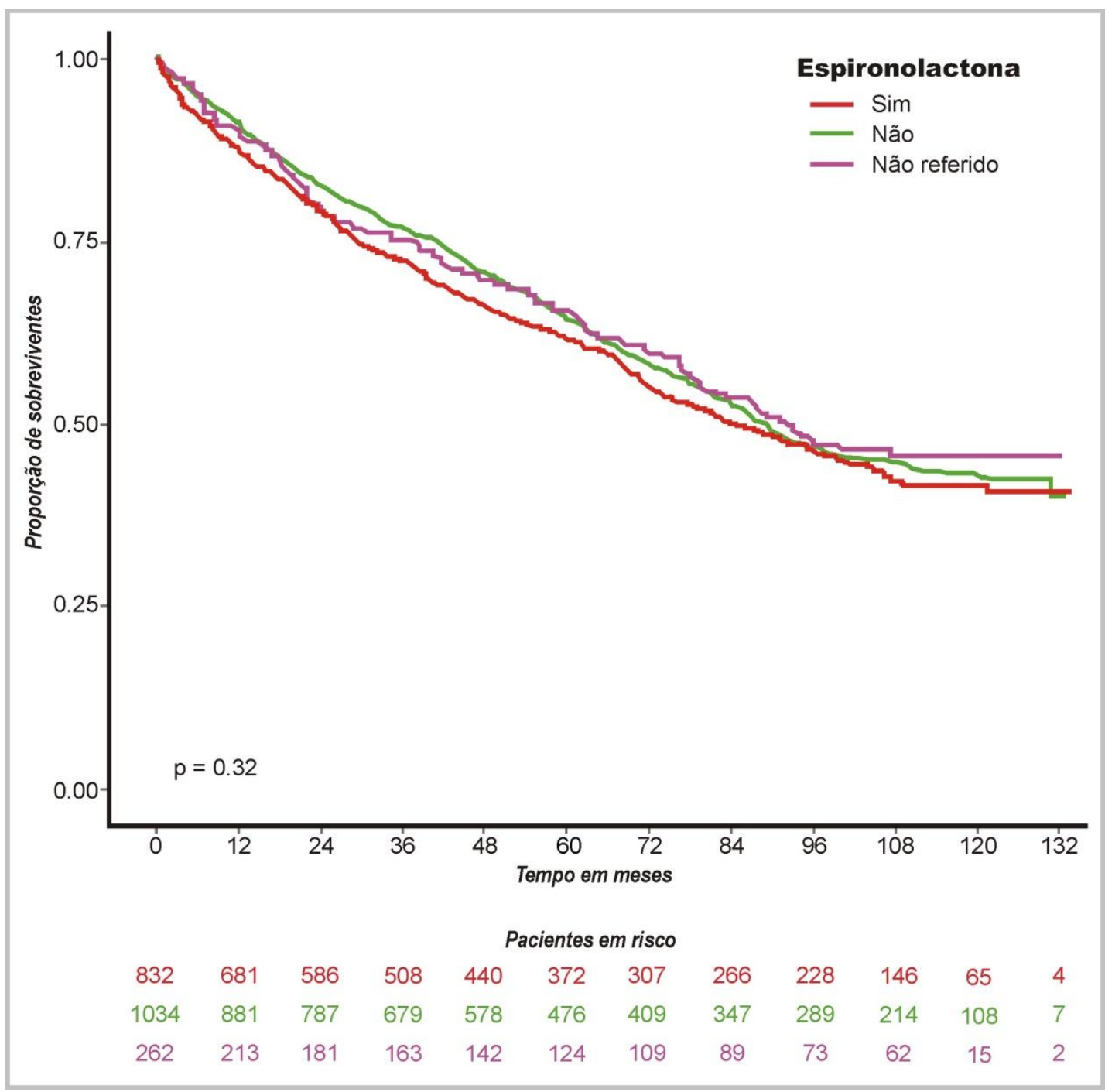

Figura 43 - Probabilidade de sobrevida estimada (Kaplan-Meier) dos 2.128 pacientes quanto ao uso de espironolactona na consulta inicial. Os números sob o eixo das abscissas indicam o número de pacientes em risco no decorrer do tempo de observação a partir da consulta inicial até a última informação obtida ou data do óbito. 


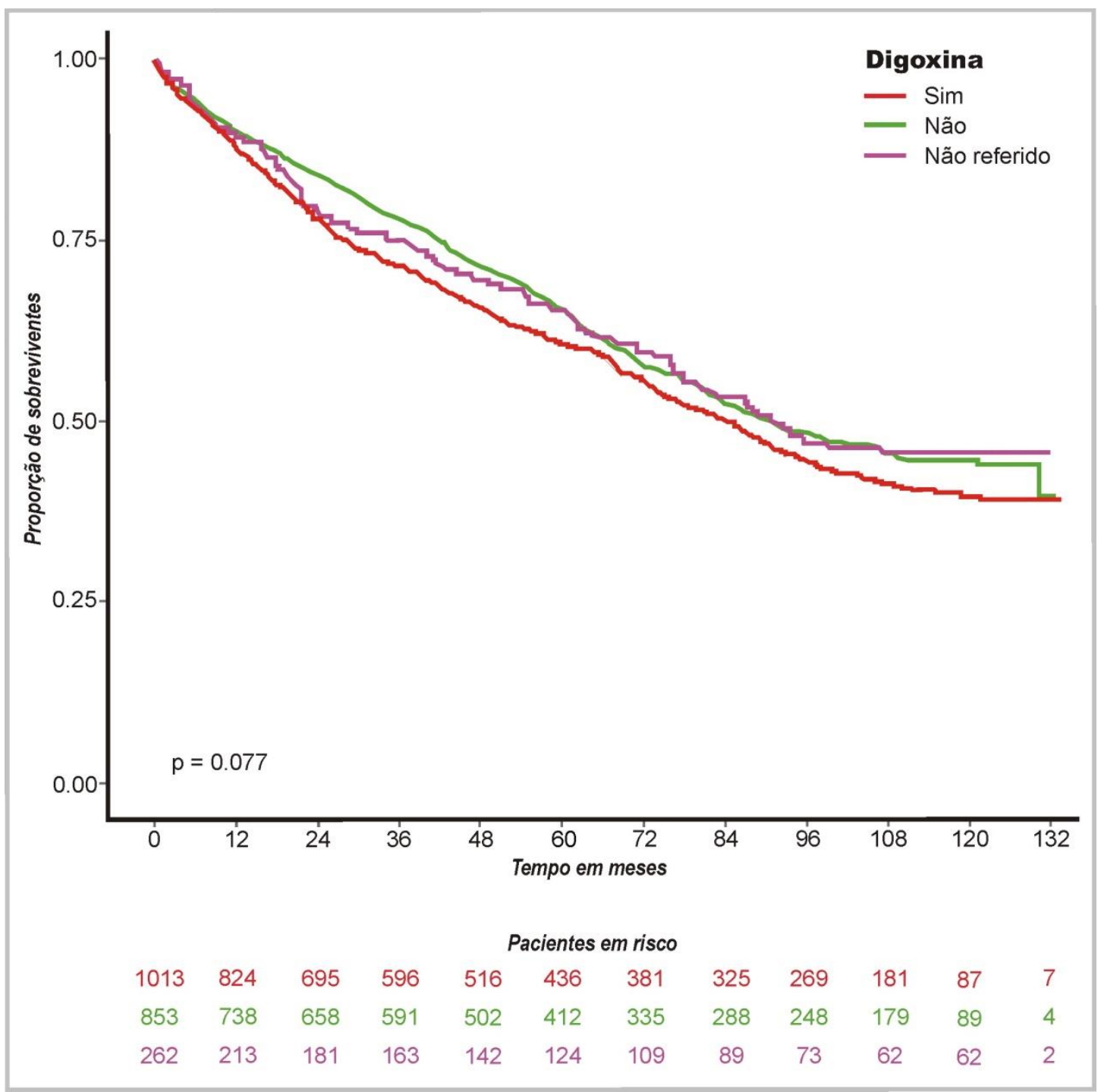

Figura 44 - Probabilidade de sobrevida estimada (Kaplan-Meier) dos 2.128 pacientes quanto ao uso de digoxina na consulta inicial. Os números sob o eixo das abscissas indicam o número de pacientes em risco no decorrer do tempo de observação a partir da consulta inicial até a última informação obtida ou data do óbito. 


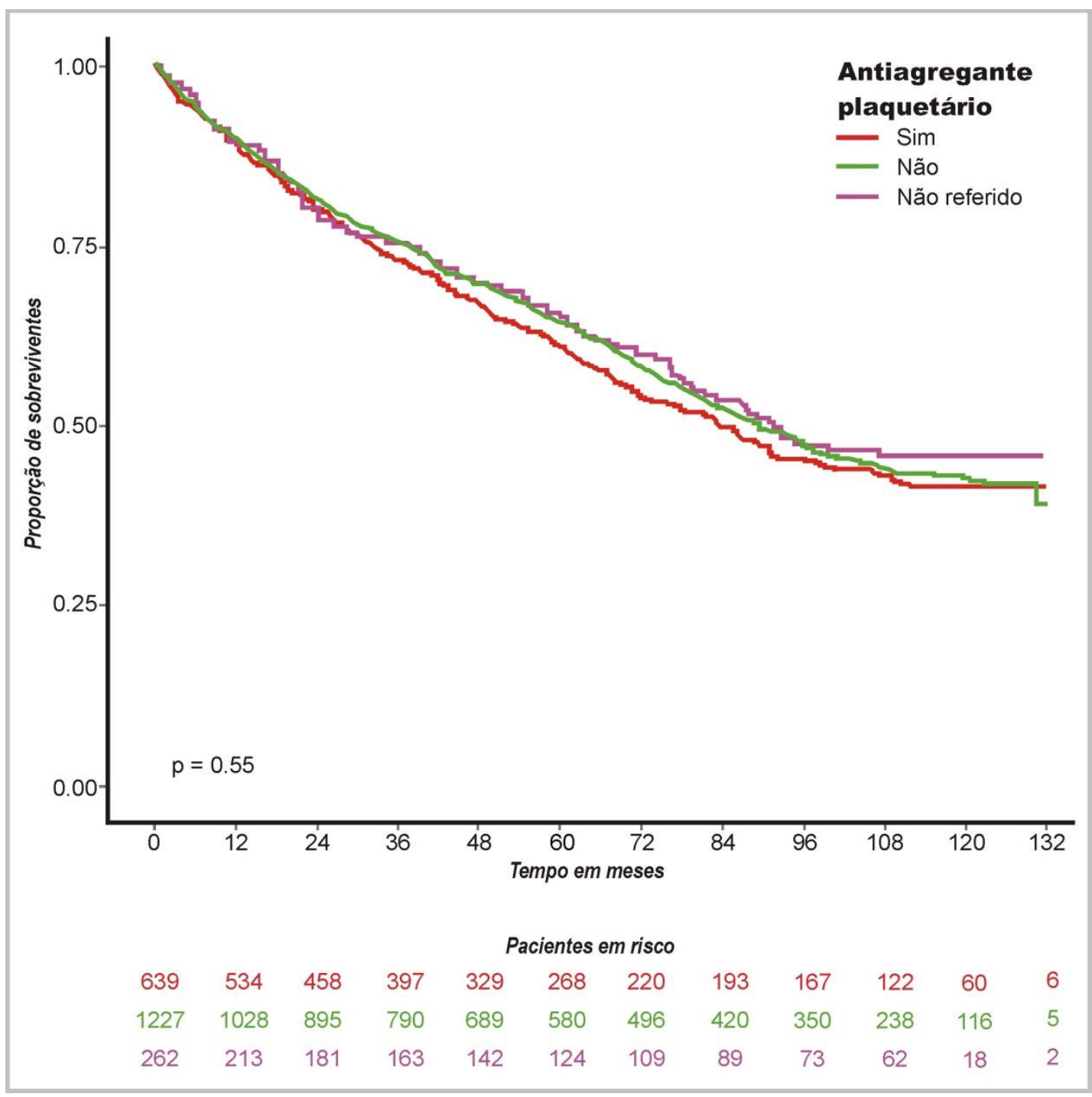

Figura 45 - Probabilidade de sobrevida estimada (Kaplan-Meier) dos 2.128 pacientes quanto ao uso de antiagregante plaquetário (ácido acetilsalićlico) na consulta inicial. Os números sob o eixo das abscissas indicam o número de pacientes em risco no decorrer do tempo de observação a partir da consulta inicial até a última informação obtida ou data do óbito. 


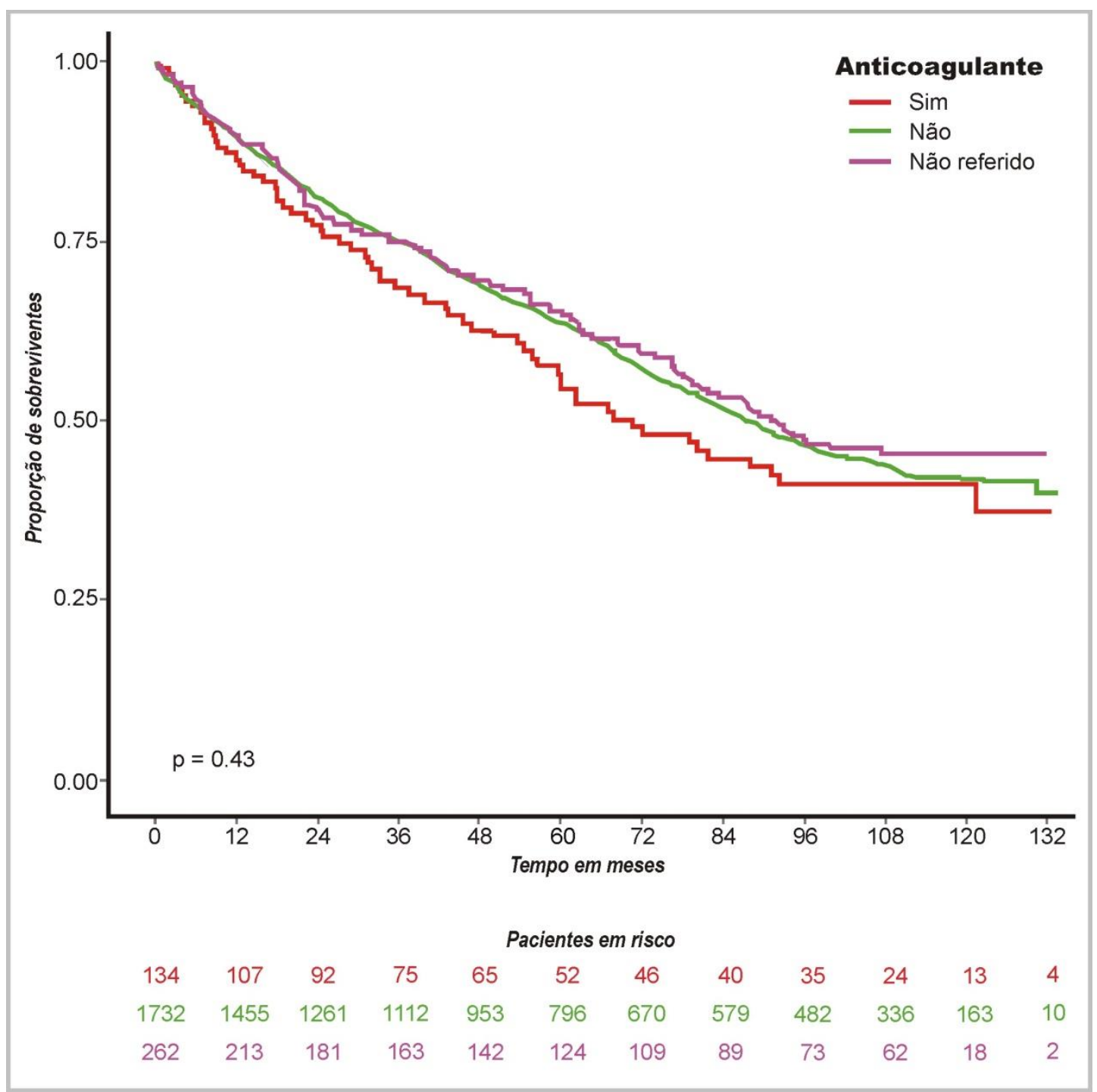

Figura 46 - Probabilidade de sobrevida estimada (Kaplan-Meier) dos 2.128 pacientes quanto ao uso de anticoagulante oral (varfarina) na consulta inicial. Os números sob o eixo das abscissas indicam o número de pacientes em risco no decorrer do tempo de observação a partir da consulta inicial até a última informação obtida ou data do óbito. 


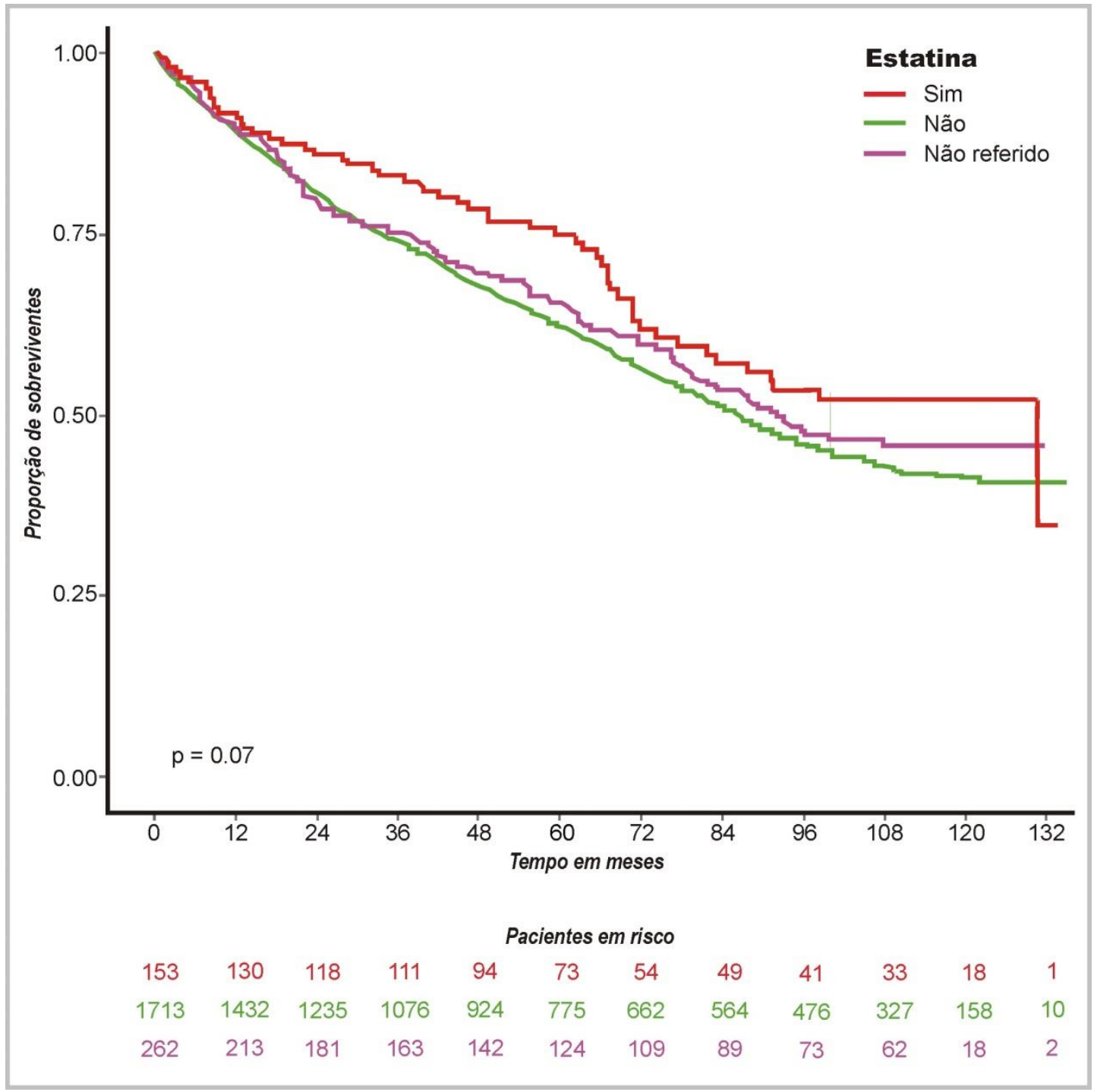

Figura 47 - Probabilidade de sobrevida estimada (Kaplan-Meier) dos 2.128 pacientes quanto ao uso de estatina (sinvastatina) na consulta inicial. Os números sob o eixo das abscissas indicam o número de pacientes em risco no decorrer do tempo de observação a partir da consulta inicial até a última informação obtida ou data do óbito. 


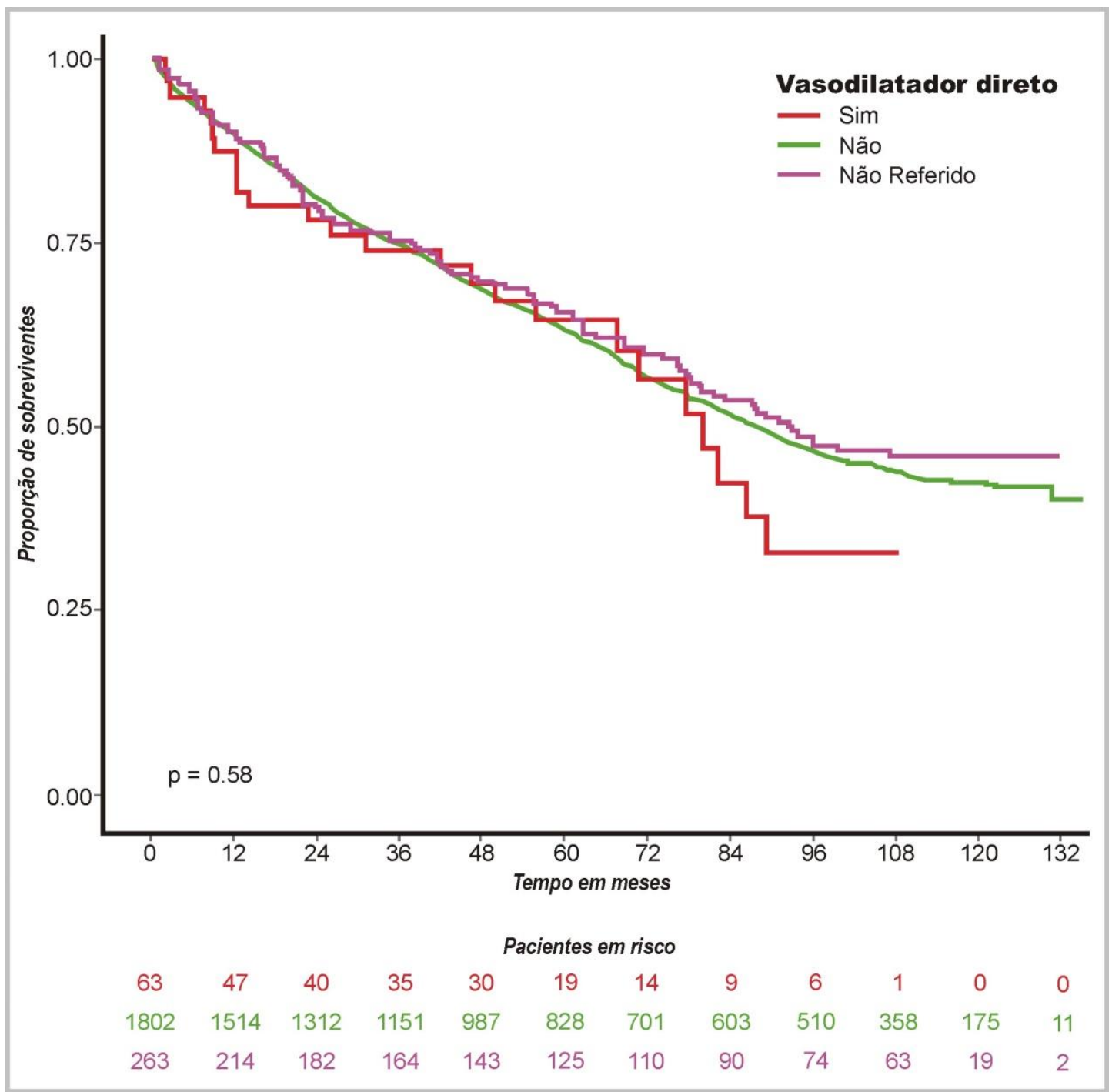

Figura 48 - Probabilidade de sobrevida estimada (Kaplan-Meier) dos 2.128 pacientes quanto ao uso de vasodilatador (hidralazina e mononitrato de isossorbida) na consulta inicial. Os números sob o eixo das abscissas indicam o número de pacientes em risco no decorrer do tempo de observação a partir da consulta inicial até a última informação obtida ou data do óbito. 


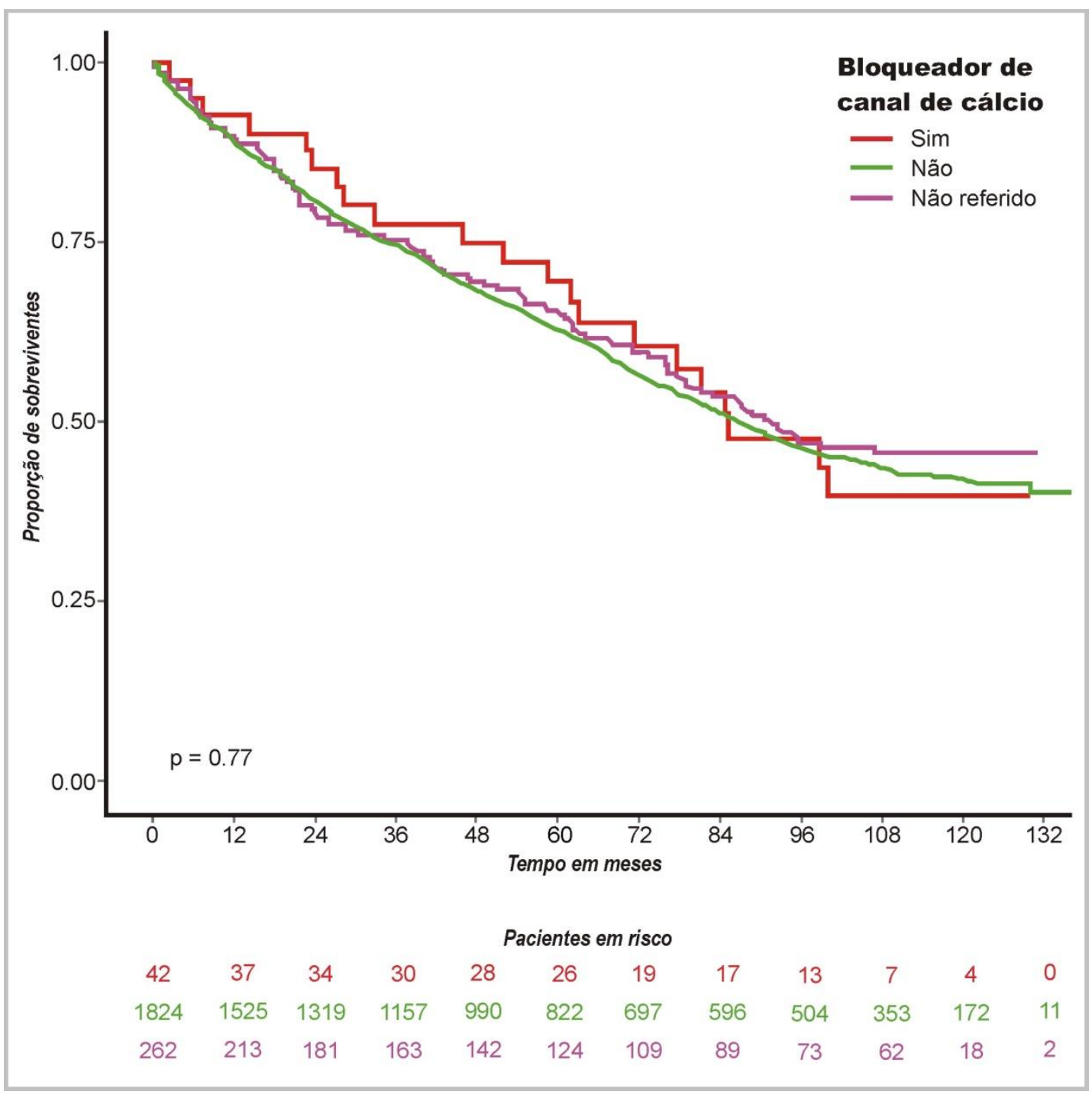

Figura 49 - Probabilidade de sobrevida estimada (Kaplan-Meier) dos 2.148 pacientes quanto ao uso de bloqueador dos canais de cálcio (anlodipina) na consulta inicial. Os números sob o eixo das abscissas indicam o número de pacientes em risco no decorrer do tempo de observação a partir da consulta inicial até a última informação obtida ou data do óbito. 


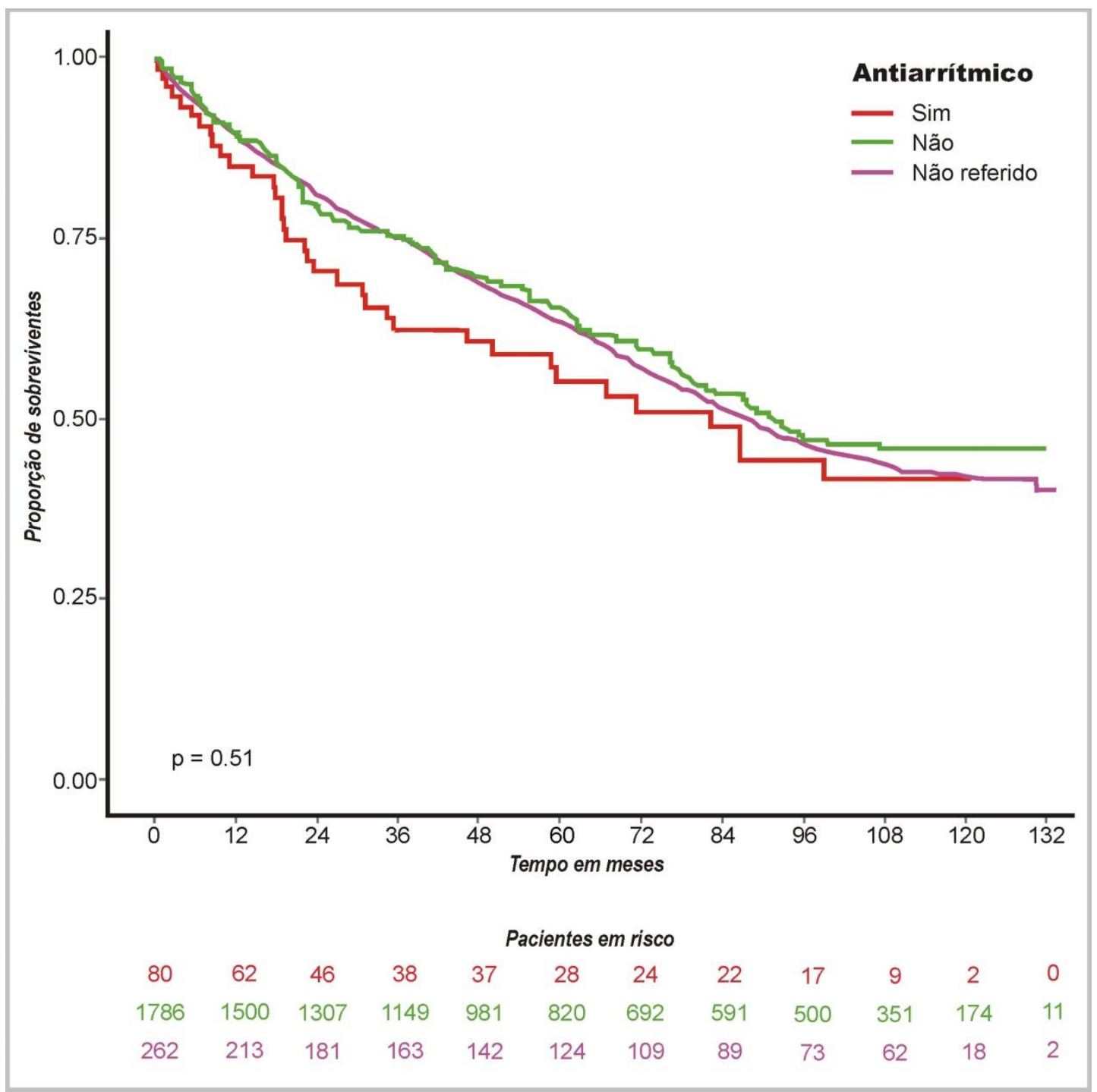

Figura 50 - Probabilidade de sobrevida estimada (Kaplan-Meier) dos 2.128 pacientes quanto ao uso de antiarrítmico (amiodarona) na consulta inicial. Os números sob o eixo das abscissas indicam o número de pacientes em risco no decorrer do tempo de observação a partir da consulta inicial até a última informação obtida ou data do óbito. 


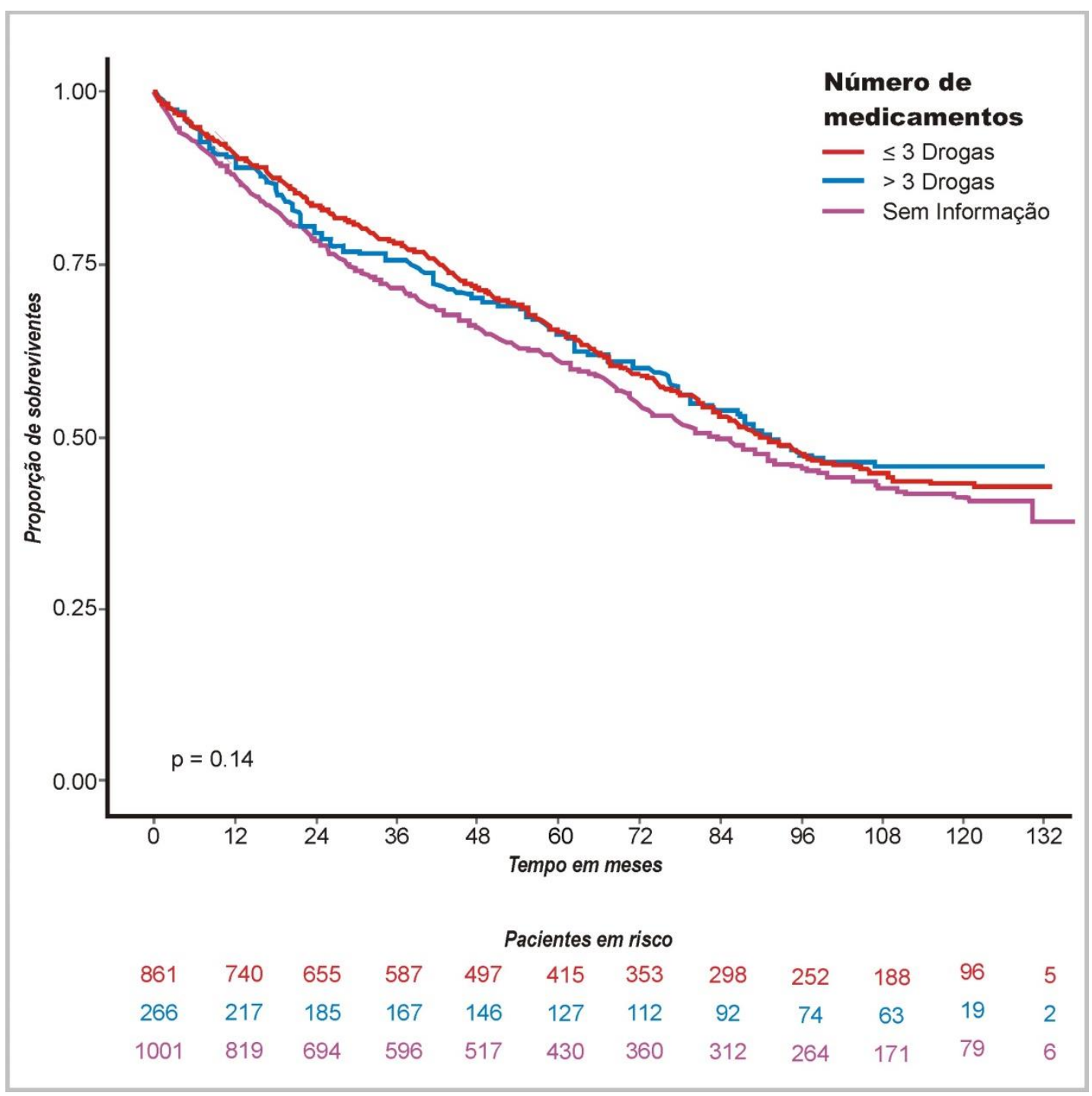

Figura 51 - Probabilidade de sobrevida estimada (Kaplan-Meier) dos 2.128 pacientes quanto ao número de medicamentos em uso na consulta inicial. Os números sob o eixo das abscissas indicam o número de pacientes em risco no decorrer do tempo de observação a partir da consulta inicial até a última informação obtida ou data do óbito. 
Tabela 1 - Características demográficas e clínicas (2.128 pacientes)

\begin{tabular}{|c|c|c|c|c|}
\hline Variáveis & $\mathrm{n}(\%)$ & Mediana & $\begin{array}{c}\text { Sobrevida } \\
\text { em } 5 \text { anos (\%) }\end{array}$ & Valor-p ${ }^{\mp}$ \\
\hline Idade (anos) & & 58 & & $<0,001$ \\
\hline$\leq 40$ & $200(9)$ & & 65 & \\
\hline $41-65$ & $1325(62)$ & & 69 & \\
\hline$>65$ & $603(28)$ & & 51 & \\
\hline Sexo & & & & 0,025 \\
\hline Masculino & $1362(64)$ & & 61 & \\
\hline Feminino & $766(36)$ & & 67 & \\
\hline Grupo étnico & & & & 0,27 \\
\hline Branca & $343(16)$ & & 62 & \\
\hline Não-branca & $131(6)$ & & 59 & \\
\hline Dado faltante & $1654(78)$ & & 65 & \\
\hline Peso (kg) & & 69,4 & & $<0,001$ \\
\hline$<63$ & $594(28)$ & & 57 & \\
\hline $63,1-74,9$ & $562(26)$ & & 63 & \\
\hline$\geq 75$ & $614(29)$ & & 73 & \\
\hline Dado faltante & $358(17)$ & & 58 & \\
\hline Altura (cm) & & 163 & & 0,048 \\
\hline$<159$ & $569(27)$ & & 64 & \\
\hline $159-166$ & $546(26)$ & & 65 & \\
\hline$>167$ & $628(30)$ & & 65 & \\
\hline Dado faltante & $385(18)$ & & 57 & \\
\hline Índice de massa corporal $\left(\mathrm{kg} / \mathrm{m}^{2}\right)^{\S}$ & & 26 & & $<0,001$ \\
\hline$<25$ & $660(31)$ & & 56 & \\
\hline $25-30$ & $697(33)$ & & 69 & \\
\hline$>30$ & $378(18)$ & & 59 & \\
\hline Dado faltante & $393(18)$ & & 74 & \\
\hline Pressão arterial sistólica $(\mathrm{mm} \mathrm{Hg})$ & & 130 & & $<0,001$ \\
\hline$<100$ & $94(4)$ & & 38 & \\
\hline $100-130$ & $927(44)$ & & 60 & \\
\hline$>130$ & $980(46)$ & & 57 & \\
\hline Dado faltante & $127(6)$ & & 69 & \\
\hline
\end{tabular}


Tabela 1 - Características demográficas e clínicas (2.128 pacientes)

\begin{tabular}{|c|c|c|c|c|c|}
\hline Variáveis & & $n(\%)$ & Mediana & $\begin{array}{c}\text { Sobrevida } \\
\text { em } 5 \text { anos (\%) }\end{array}$ & Valor-p ${ }^{\mp}$ \\
\hline Pressão arterial diastólica (mm Hg) & & & 90 & & $<0.001$ \\
\hline$<80$ & & $447(21)$ & & 51 & \\
\hline $80-90$ & & $905(43)$ & & 66 & \\
\hline$>90$ & & $646(30)$ & & 73 & \\
\hline Dado faltante & & $130(6)$ & & 57 & \\
\hline Frequência cardíaca (batimentos/min) & & & 80 & & 0,62 \\
\hline$<60$ & & $68(3)$ & & 57 & \\
\hline $60-100$ & & $1586(75)$ & & 63 & \\
\hline$>100$ & & $144(7)$ & & 62 & \\
\hline Dado faltante & & $330(16)$ & & 60 & \\
\hline Duração dos sintomas (meses) & & & 11,9 & & 0,68 \\
\hline$<12$ & & $261(12)$ & & 60 & \\
\hline$\geq 12$ & & $247(12)$ & & 59 & \\
\hline Dado faltante & & $1620(76)$ & & 63 & \\
\hline \multicolumn{6}{|l|}{ História médica } \\
\hline Hipertensão arterial & & $1538(72)$ & & 65 & 0,049 \\
\hline Normotenso & & $492(23)$ & & 56 & \\
\hline Dado faltante & & $98(5)$ & & 65 & \\
\hline \multirow[t]{4}{*}{ Consumo de álcool } & Leve & $100(5)$ & & 69 & 0,84 \\
\hline & Moderado & $37(2)$ & & 65 & \\
\hline & Intenso & $86(4)$ & & & \\
\hline & Indeterminado & $84(4)$ & & 69 & \\
\hline Ex-etilista & & $297(14)$ & & & \\
\hline Não etilista & & $1076(51)$ & & 62 & \\
\hline Dado faltante & & $448(21)$ & & & \\
\hline \multirow[t]{3}{*}{ Fumante } & $\leq 20$ cigarros & $111(5)$ & & 60 & 0,74 \\
\hline & $>20$ cigarros & $104(5)$ & & & \\
\hline & Indeterminado & $190(9)$ & & 62 & \\
\hline Ex-fumante & & $626(29)$ & & 65 & \\
\hline Não fumante & & $859(40)$ & & 64 & \\
\hline Dado faltante & & $238(11)$ & & & \\
\hline
\end{tabular}


Tabela 1 - Características demográficas e clínicas (2.128 pacientes)

\begin{tabular}{|c|c|c|c|c|}
\hline Variáveis & $\mathrm{n}(\%)$ & Mediana & $\begin{array}{c}\text { Sobrevida } \\
\text { em } 5 \text { anos (\%) }\end{array}$ & Valor-p ${ }^{\mp}$ \\
\hline Diabetes mellitus & & & & 0,024 \\
\hline Insulino dependente & $99(5)$ & & 64 & \\
\hline Não insulino dependente & $389(18)$ & & 59 & \\
\hline Não diabético & $1481(70)$ & & 65 & \\
\hline Dado faltante & $159(7)$ & & 64 & \\
\hline Etiologia da Insuficiência Cardíaca & & & & 0,001 \\
\hline Cardiomiopatia da Doença de Chagas & $333(16)$ & & 50 & \\
\hline Cardiomiopatia hipertensiva & $920(43)$ & & 71 & \\
\hline Cardiomiopatia isquêmica & $523(25)$ & & 55 & \\
\hline Cardiomiopatia dilatada & $206(10)$ & & 69 & \\
\hline Cardiomiopatia alcoólica & $146(7)$ & & 66 & \\
\hline Classe funcional NYHA & & & & 0,001 \\
\hline 1 & $300(14)$ & & 72 & \\
\hline II & $805(38)$ & & 64 & \\
\hline III & $575(27)$ & & 56 & \\
\hline IV & $302(14)$ & & 50 & \\
\hline Dado faltante & $146(7)$ & & 59 & \\
\hline Ritmo cardíaco no eletrocardiograma & & & & 0,0051 \\
\hline Fibrilação atrial & 294(14) & & 56 & \\
\hline Ritmo sinusal & $1561(73)$ & & 65 & \\
\hline Ritmo de marca-passo & $38(2)$ & & 68 & \\
\hline Outro & $7(0)$ & & 66 & \\
\hline Dado faltante & $228(11)$ & & 62 & \\
\hline Espessura do septo interventricular (mm) & & 9 & & $<0,001$ \\
\hline$<8$ & 206(10) & & 57 & \\
\hline $8-12$ & $1385(65)$ & & 68 & \\
\hline$>12$ & $109(5)$ & & 63 & \\
\hline Dado faltante & $428(20)$ & & 54 & \\
\hline Espessura da parede posterior do ventrículo esquerdo (mm) & & 9 & & $<0,001$ \\
\hline$<8$ & 206(10) & & 63 & \\
\hline $8-12$ & 1428(67) & & 66 & \\
\hline $\begin{array}{l}>12 \\
\text { Dado faltante }\end{array}$ & $\begin{array}{c}63(3) \\
431(20)\end{array}$ & & $\begin{array}{l}54 \\
62\end{array}$ & \\
\hline
\end{tabular}


Tabela 1 - Características demográficas e clínicas (2.128 pacientes)

\begin{tabular}{|c|c|c|c|c|}
\hline Variáveis & $n(\%)$ & Mediana & $\begin{array}{c}\text { Sobrevida } \\
\text { em } 5 \text { anos (\%) }\end{array}$ & Valor-p ${ }^{\mp}$ \\
\hline Diâmetro diastólico do ventrículo esquerdo (mm) & & 64 & & $<0,001$ \\
\hline$<60$ & $514(24)$ & & 74 & \\
\hline $60-75$ & $938(44)$ & & 65 & \\
\hline$>75$ & $224(11)$ & & 56 & \\
\hline Dado faltante & $452(21)$ & & 53 & \\
\hline Diâmetro sistólico do ventrículo esquerdo (mm) & & 56 & & $<0,001$ \\
\hline$<40$ & $110(5)$ & & 79 & \\
\hline $40-55$ & $462(22)$ & & 72 & \\
\hline$>55$ & $612(29)$ & & 59 & \\
\hline Dado faltante & $944(44)$ & & 60 & \\
\hline Fração de ejeção do ventrículo esquerdo (\%) & & 31 & & $<0,001$ \\
\hline$<35$ & $1027(48)$ & & 60 & \\
\hline $35-45$ & $449(21)$ & & 69 & \\
\hline $45-55$ & $220(10)$ & & 72 & \\
\hline$>55$ & $59(3)$ & & 82 & \\
\hline Dado faltante & $373(18)$ & & 53 & \\
\hline Diâmetro do átrio esquerdo (mm) & & 46 & & $<0,001$ \\
\hline$<40$ & $295(14)$ & & 78 & \\
\hline$\geq 40$ & $1375(65)$ & & 63 & \\
\hline Dado faltante & $458(22)$ & & 53 & \\
\hline Creatinina sérica (mg/dL) & & 1,1 & & $<0,001$ \\
\hline$<1.3$ & $1469(69)$ & & 68 & \\
\hline $1.3-2.6$ & $535(25)$ & & 51 & \\
\hline$>2.6$ & $51(2)$ & & 28 & \\
\hline Dado faltante & $73(3)$ & & 53 & \\
\hline Sódio sérico (mEq/L) & & 139 & & $<0,001$ \\
\hline$<136$ & $170(8)$ & & 49 & \\
\hline$\geq 136$ & $1852(87)$ & & 66 & \\
\hline Dado faltante & $106(5)$ & & 54 & \\
\hline
\end{tabular}


Tabela 1 - Características demográficas e clínicas (2.128 pacientes)

\begin{tabular}{|c|c|c|c|c|}
\hline Variáveis & $n(\%)$ & Mediana & $\begin{array}{c}\text { Sobrevida } \\
\text { em } 5 \text { anos (\%) }\end{array}$ & Valor-p ${ }^{\mp}$ \\
\hline Potássio sérico (mEq/L) & & 4,6 & & $<0,001$ \\
\hline$<3.5$ & $31(1)$ & & 60 & \\
\hline $3.5-5.0$ & $1646(77)$ & & 66 & \\
\hline$>5.0$ & $345(16)$ & & 54 & \\
\hline Dado faltante & $106(5)$ & & 53 & \\
\hline Hemoglobina (g/dL) & & 14,2 & & $<0,001$ \\
\hline$<10$ & $41(2)$ & & 43 & \\
\hline $10-12$ & $190(9)$ & & 53 & \\
\hline$>12$ & 1826(86) & & 65 & \\
\hline Dado faltante & $71(3)$ & & 66 & \\
\hline Leucócitos $\left(\mathrm{mm}^{3}\right)$ & & 7300 & & 0,048 \\
\hline$<4000$ & $45(2)$ & & 33 & \\
\hline $4000-11000$ & $1791(84)$ & & 63 & \\
\hline$>11000$ & $142(7)$ & & 56 & \\
\hline Dado faltante & $150(7)$ & & 62 & \\
\hline Linfócitos $\left(\mathrm{mm}^{3}\right)$ & & 1919 & & 0,011 \\
\hline$<900$ & $14(1)$ & & 34 & \\
\hline $900-3400$ & $301(14)$ & & 65 & \\
\hline$>3400$ & $7(0)$ & & 71 & \\
\hline Dado faltante & $1806(85)$ & & 62 & \\
\hline Colesterol total $(\mathrm{mg} / \mathrm{dL})$ & & 188 & & $<0,001$ \\
\hline$<200$ & $881(41)$ & & 65 & \\
\hline $200-240$ & $394(19)$ & & 75 & \\
\hline$>240$ & $209(10)$ & & 74 & \\
\hline Dado faltante & $644(30)$ & & 53 & \\
\hline Triglicérides (mg/dL) & & 112 & & $<0,001$ \\
\hline$<150$ & $1011(48)$ & & 65 & \\
\hline $150-300$ & $397(19)$ & & 74 & \\
\hline$>300$ & $71(3)$ & & 80 & \\
\hline Dado faltante & $649(30)$ & & 53 & \\
\hline
\end{tabular}


Tabela 1 - Características demográficas e clínicas (2.128 pacientes)

\begin{tabular}{|c|c|c|c|c|c|}
\hline Variáveis & & $n(\%)$ & Mediana & $\begin{array}{c}\text { Sobrevida } \\
\text { em } 5 \text { anos (\%) }\end{array}$ & Valor-p ${ }^{\mp}$ \\
\hline HDL - colesterol $(\mathrm{mg} / \mathrm{dL})^{\mathrm{H}}$ & & & 43 & & $<0,001$ \\
\hline$<40$ & & $560(26)$ & & 68 & \\
\hline $40-60$ & & $681(32)$ & & 71 & \\
\hline$>60$ & & $207(10)$ & & 54 & \\
\hline Dado faltante & & $680(32)$ & & 69 & \\
\hline LDL- colesterol $(\mathrm{mg} / \mathrm{dL})^{\mathrm{H}}$ & & & 116 & & $<0,001$ \\
\hline$<100$ & & $471(22)$ & & 60 & \\
\hline $100-129$ & & $451(21)$ & & 68 & \\
\hline$>129$ & & $521(24)$ & & 53 & \\
\hline Dado faltante & & $685(32)$ & & 72 & \\
\hline Glicose de jejum (mg/dL) & & & 100 & & $<0,001$ \\
\hline$<100$ & & $843(40)$ & & 65 & \\
\hline $100-126$ & & $571(27)$ & & 66 & \\
\hline$>126$ & & $345(16)$ & & 68 & \\
\hline Dado faltante & & $369(17)$ & & 53 & \\
\hline \multirow{4}{*}{$\mathrm{IECA} / \mathrm{BRA}^{\epsilon}$ (captopril, enalapril, losartana) } & Com medicação & $1564(73)$ & & 62 & 0,91 \\
\hline & Sem medicação & $302(14)$ & & 62 & \\
\hline & Dado faltante & $262(12)$ & & & \\
\hline & com medicação & $1548(73)$ & & 62 & 0,0032 \\
\hline \multirow[t]{3}{*}{ Diuréticos (hidroclorotiazida e furosemida) } & sem medicação & $318(15)$ & & 71 & \\
\hline & Dado faltante & $262(12)$ & & 66 & \\
\hline & Com medicação & $832(39)$ & & 60 & 0,32 \\
\hline \multirow[t]{4}{*}{ Antagonista do receptor da aldosterona (espironolactona) } & Sem medicação & $1034(49)$ & & 63 & \\
\hline & Dado faltante & $262(12)$ & & 65 & \\
\hline & com medicação & $1013(48)$ & & 62 & 0,077 \\
\hline & sem medicação & $853(40)$ & & 66 & \\
\hline \multirow[t]{3}{*}{ Digital (digoxina) } & Dado faltante & $262(12)$ & & 65 & \\
\hline & Com medicação & $134(6)$ & & 56 & 0,43 \\
\hline & Sem medicação & $1732(81)$ & & 63 & \\
\hline Anticoagulante oral (varfarina) & Dado faltante & $262(12)$ & & 65 & \\
\hline
\end{tabular}


Tabela 1 - Características demográficas e clínicas (2.128 pacientes)

\begin{tabular}{|c|c|c|c|c|c|}
\hline Variáveis & $\mathrm{n}(\%)$ & Mediana & $\begin{array}{c}\text { Sobrevida } \\
\text { em } 5 \text { anos } \\
(\%)\end{array}$ & Valor-p ${ }^{\mp}$ & Variáveis \\
\hline \multirow[t]{4}{*}{ Antiagregante plaquetário (aspirina) } & com medicação & $639(30)$ & & 60 & 0,55 \\
\hline & sem medicação & $1227(58)$ & & 63 & \\
\hline & Dado faltante & $262(12)$ & & 65 & \\
\hline & Com medicação & $153(7)$ & & 75 & 0,07 \\
\hline \multirow{3}{*}{ Estatina (sinvastatina) } & Sem medicação & $1712(80)$ & & 60 & \\
\hline & Dado faltante & $262(12)$ & & 63 & \\
\hline & com medicação & $42(2)$ & & 69 & 0,77 \\
\hline \multirow[t]{3}{*}{ Bloqueador dos canais de cálcio (anlodipina) } & sem medicação & $1824(86)$ & & 60 & \\
\hline & Dado faltante & 262(12) & & 62 & \\
\hline & Com medicação & $63(3)$ & & 63 & 0,58 \\
\hline \multirow[t]{2}{*}{ Vasodilator direto (hidralazina, mononitrato de isossorbida) } & Sem medicação & $1802(85)$ & & 62 & \\
\hline & Dado faltante & 263(12) & & 62 & \\
\hline \multirow[t]{5}{*}{ Bloqueador adrenérgico (carvedilol, metoprolol, atenolol, propanolol) } & com medicação & 706(33) & & 66 & 0,042 \\
\hline & sem medicação & $1160(55)$ & & 60 & \\
\hline & Dado faltante & 262(12) & & 65 & \\
\hline & Com medicação & $80(4)$ & & 54 & 0,51 \\
\hline & Sem medicação & $1786(84)$ & & 62 & \\
\hline Antiarrítmico (amiodarona) & Dado faltante & $262(12)$ & & 65 & \\
\hline \multicolumn{6}{|l|}{ Número de medicamentos em uso $\Phi$} \\
\hline & 1 & $118(6)$ & & & \\
\hline & 2 & $272(13)$ & & & \\
\hline & 3 & $471(22)$ & & & \\
\hline & 4 & 496(23) & & & \\
\hline & 5 & $349(16)$ & & & \\
\hline & 6 & $127(6)$ & & & \\
\hline & 7 & $26(1)$ & & & \\
\hline & 8 & $2(0)$ & & & \\
\hline & 9 & $1(0)$ & & & \\
\hline & Dado faltante & $266(12)$ & & & \\
\hline
\end{tabular}


Tabela 1 - Características demográficas e clínicas (2.128 pacientes)

\begin{tabular}{|c|c|c|c|c|c|}
\hline Variáveis & $n(\%)$ & Mediana & $\begin{array}{c}\text { Sobrevida } \\
\text { em } 5 \text { anos } \\
(\%)\end{array}$ & Valor-p $\mathrm{p}^{\mp}$ & Variáveis \\
\hline \multirow[t]{4}{*}{ Número de drogas agrupadas em uso $\zeta$} & & & & & 0,14 \\
\hline & $\leq 3$ & $861(40)$ & & 65 & \\
\hline & $>3$ & $1001(47)$ & & 65 & \\
\hline & Dado faltante & $266(12)$ & & 60 & \\
\hline
\end{tabular}

I Classe funcional da New York Heart Association (NYHA): I- nenhuma limitação; II- limitação a moderados esforços; III- limitação a esforços habituais; IV- limitação em repouso;

H HDL- colesterol ou fração lipoproteica de alta densidade do colesterol; LDL- colesterol ou fração lipoproteica de baixa densidade do colesterol;

$€$ IECA - inibidores da enzima de conversão da angiotensina; BRA - bloqueadores dos receptores da angiotensina I;

$\Phi$ Número de medicações em uso pelo paciente e respectivas porcentagens;

$\zeta$ Número de medicações agrupadas em uso pelo paciente e respectivas porcentagens;

$\mp$ Valor-p (log rank). 
Tabela 2 - Variáveis estudas quanto à probabilidade de sobrevida (etapa 1)

\begin{tabular}{|c|c|c|c|}
\hline Variável & Valor-p & $\begin{array}{c}\text { Valores disponíveis } \\
\mathrm{n}\end{array}$ & $\begin{array}{c}\text { Dados } \\
\text { omissos } \\
(\%)\end{array}$ \\
\hline Idade $^{* *}$ & $p<0,001$ & 2.128 & - \\
\hline Etnia & $p=0,789$ & 474 & 78 \\
\hline Sexo & $p<0,001$ & 2.128 & - \\
\hline Índice de massa corpórea & $p<0,001$ & 1.735 & 19 \\
\hline Pressão Arterial Sistólica & $p<0,001$ & 2.001 & 6 \\
\hline Pressão Arterial Diastólica & $p<0,001$ & 1.998 & 6 \\
\hline Frequência Cardíaca & $p=0,446$ & 1.798 & 16 \\
\hline Etiologia da Insuficiência Cardíaca & $p<0,001$ & 2.128 & - \\
\hline Classe Funcional & $p<0,001$ & 1.982 & 7 \\
\hline Hipertensão Arterial & $p<0,001$ & 2.030 & 5 \\
\hline Etilismo & $p=0,602$ & 1.680 & 21 \\
\hline Tabagismo & $p=0,117$ & 1.890 & 11 \\
\hline Diabetes & $p=0,135$ & 1.969 & 7 \\
\hline Ritmo cardíaco & $p=0,105$ & 1.893 & 11 \\
\hline Espessura do septo interventricular & $p=0,083$ & 1.332 & 37 \\
\hline $\begin{array}{l}\text { Espessura da parede posterior do } \\
\text { ventrículo esquerdo }\end{array}$ & $p=0,477$ & 1.258 & 41 \\
\hline $\begin{array}{l}\text { Diâmetro diastólico do ventrículo } \\
\text { esquerdo }\end{array}$ & $p<0,001$ & 1.676 & 21 \\
\hline $\begin{array}{l}\text { Diâmetro sistólico do ventrículo } \\
\text { esquerdo }\end{array}$ & $p<0,001$ & 1.184 & 44 \\
\hline $\begin{array}{l}\text { Fração de ejeção do ventrículo } \\
\text { esquerdo }\end{array}$ & $\mathrm{p}<0,001$ & 1.755 & 18 \\
\hline Diâmetro do átrio esquerdo & $\mathrm{p}<0,001$ & 1.670 & 22 \\
\hline Sódio sérico & $\mathrm{p}<0,001$ & 2.022 & 5 \\
\hline Potássio sérico & $p=0,002$ & 2.022 & 5 \\
\hline Hemoglobina sérica & $p=0,008$ & 2.057 & 3 \\
\hline Taxa de leucócitos & $p=0,018$ & 1.978 & 7 \\
\hline Taxa de linfócitos & $p=0,037$ & 322 & 85 \\
\hline Colesterol total & $p=0,001$ & 1.484 & 30 \\
\hline Triglicérides & $p=0,015$ & 1.479 & 30 \\
\hline HDL - colesterol & $p=0,280$ & 1.448 & 32 \\
\hline LDL - colesterol & $p=0,119$ & 1.443 & 32 \\
\hline Glicemia de jejum & $p=0,051$ & 1.759 & 17 \\
\hline Creatinina sérica & $p<0,001$ & 2.055 & 3 \\
\hline Número de medicamentos em uso & $p=0,134$ & 1.864 & 12 \\
\hline Início dos sintomas & $p=0,564$ & 510 & 76 \\
\hline
\end{tabular}

*valor - $p$ foi resultante do teste da razão de verossimilhanças para cada uma das variáveis; os valores - $p$ inferiores a 10\% tornaram a característica correspondente elegível para inclusão na na segunda etapa do modelo; ** número de informações disponíveis para cada variável ${ }^{* \star \star}$ a variável idade mostrou-se significante $(p<0,001)$ e foi incluída em todos os ajustes do modelo por ser a sobrevida a resposta do modelo de Cox. Em negrito estão as variáveis selecionadas para a etapa 2 do modelo de Cox. 
Tabela 3 - Uso de tratamento medicamentoso

\begin{tabular}{lccc}
\hline & \multicolumn{2}{c}{ Medicamento em uso } & \\
\cline { 2 - 3 } \multicolumn{1}{c}{ Grupo } & Sim & Não & $\begin{array}{c}\text { Sem } \\
\text { informação } \\
\mathrm{n}(\%)\end{array}$ \\
\hline IECA / BRA & $\mathrm{n}(\%)$ & $\mathrm{n}(\%)$ & $262(12)$ \\
Diuréticos & $1.564(73)$ & $302(14)$ & $262(12)$ \\
Espironolactona & $1.548(73)$ & $318(15)$ & $262(12)$ \\
Digoxina & $832(39)$ & $1.034(49)$ & $262(12)$ \\
Anticoagulante oral & $1.013(48)$ & $853(40)$ & $262(12)$ \\
Antiagregante plaquetário & $134(6)$ & $1.732(81)$ & $262(12)$ \\
Estatina & $639(30)$ & $1.227(58)$ & $262(12)$ \\
Bloqueador dos canais de & $153(7)$ & $1.713(80)$ & $262(12)$ \\
cálcio & $42(2)$ & $1.824(86)$ & $263(12)$ \\
Vasodilatador direto & $63(3)$ & $1.802(85)$ & $262(12)$ \\
Bloqueador alfa-adrenérgico & $706(33)$ & $1.160(55)$ & $262(12)$ \\
ou beta-adrenérgico & $80(4)$ & $1.786(84)$ & \\
Antiarrítmico & & & \\
\hline
\end{tabular}

IECA: inibidores da enzima conversora da angiotensina (captopril, enalapril);

BRA: bloqueadores dos receptores da angiotensina II (losartana);

Diuréticos: hidroclorotiazida ou furosemida;

Espironolactona: diurético poupador de potássio e antagonista do receptor da aldosterona;

Anticoagulante oral: varfarina;

Antiagregante plaquetário: ácido acetilsalicílico;

Estatina: sinvastatina;

Bloqueador dos canais de cálcio: anlodipina

Vasodilatdor direto: hidralazina e mononitrato diisossorbida;

Bloqueadores: alfa adrenérgico (carvedilol) e beta-adrenérgico (metoprolol, atenolol e propranolol);

Antiarritmico: amiodarona 
Tabela 4 - Número de medicamentos em uso

Número de medicamentos em uso pelos pacientes - $\mathrm{n}(\%)$

\begin{tabular}{cccccccccc}
\hline $\begin{array}{c}1 \\
\mathrm{n}(\%)\end{array}$ & $\mathrm{n}(\%)$ & $\mathrm{n}(\%)$ & $\mathrm{n}(\%)$ & $\mathrm{n}(\%)$ & $\mathrm{n}(\%)$ & $\mathrm{n}(\%)$ & $\mathrm{n}(\%)$ & $\mathrm{n}(\%)$ & $\begin{array}{c}\text { Sem } \\
\mathrm{n}(\%)\end{array}$ \\
\hline $118(6)$ & $272(13)$ & $471(22)$ & $496(23)$ & $349(16)$ & $\begin{array}{c}127 \\
(6)\end{array}$ & $26(1)$ & $2(0)$ & $1(0)$ & $266(12)$ \\
\hline * númação
\end{tabular}

* número de medicamentos em uso pelo paciente entre os diferentes grupos de medicações.

Tabela 5 - Variáveis retiradas do modelo de Cox (etapa 2)

\begin{tabular}{|c|c|}
\hline Variável & Valor-p \\
\hline Hipertensão arterial sistêmica & 0,790 \\
\hline Hemoglobina & 0,789 \\
\hline Glicemia de jejum & 0,751 \\
\hline $\begin{array}{l}\text { Fração de ejeção do ventrículo } \\
\text { esquerdo }\end{array}$ & 0,702 \\
\hline Frequência cardíaca & 0,568 \\
\hline Sexo & 0,434 \\
\hline Sódio sérico & 0,428 \\
\hline Leucócitos sérico & 0,165 \\
\hline Triglicérides sérico & 0,144 \\
\hline $\begin{array}{l}\text { Diâmetro sistólico do ventrículo } \\
\text { esquerdo }\end{array}$ & 0,111 \\
\hline Linfócitos sérico & 0,082 \\
\hline
\end{tabular}


Tabela 6 - Reavaliação das variáveis inicialmente excluídas da etapa 2 do modelo de Cox (etapa 3)

\begin{tabular}{lc}
\hline \multicolumn{1}{c}{ Variável } & Valor-p \\
\hline Etnia & 0,650 \\
Frequência cardíaca & 0,489 \\
Etilismo & 0,702 \\
Tabagismo & 0,536 \\
Diabetes melito & 0,034 \\
Espessura da parede posterior do & 0,546 \\
ventrículo esquerdo & 0,137 \\
Ritmo cardíaco & 0,710 \\
HDL - colesterol & 1,000 \\
LDL- colesterol & 0,696 \\
Número de medicamentos em uso & 0,784 \\
Início dos sintomas &
\end{tabular}

${ }^{*} \mathrm{HDL}$-colesterol ou lipoproteína de alta densidade;

**LDL-colesterol ou lipoproteína de baixa densidade;

Resultado do teste da razão de verossimilhança para todas as variáveis. Excluídas no primeiro ajuste do modelo (etapa 1) e reavaliação da importância de cada uma das variáveis após reintroduzi- las no modelo em conjunto com as variáveis do segundo ajuste do modelo (etapa 2);

$\S$ Diabetes melito foi a única variável que permaneceu para o modelo final.

Tabelas 7 - Variáveis do modelo final de Cox selecionadas para a rede neural

\begin{tabular}{lc}
\hline \multicolumn{1}{c}{ Variável } & Valor- $\mathrm{p}^{* *}$ \\
\hline Idade (anos) & $<0.001$ \\
Índice de massa corpórea $\left(\mathrm{kg} / \mathrm{m}^{2}\right)$ & $<0.001$ \\
Pressão arterial diastólica $(\mathrm{mmHg})$ & $<0.001$ \\
Etiologia da insuficiência cardíaca * & $<0.001$ \\
Classe funcional $(\mathrm{NYHA})^{\Delta}$ & $<0.001$ \\
Espessura do septo interventricular $(\mathrm{mm})$ & 0.037 \\
Diâmetro diastólico do ventrículo esquerdo $(\mathrm{mm})$ & $<0.001$ \\
Diâmetro do átrio esquerdo $(\mathrm{mm})$ & 0.025 \\
Potássio sérico $(\mathrm{mEq} / \mathrm{L})$ & 0.015 \\
Colesterol total $(\mathrm{mg} / \mathrm{dL})$ & $<0.001$ \\
Creatinina $(\mathrm{mg} / \mathrm{dL})$ & $<0.001$ \\
Diabetes melito & 0.034 \\
\hline "elog
\end{tabular}

\footnotetext{
* etiologias da insuficiência cardíaca: hipertensiva, isquêmica, dilatada, alcoólica e Doença de Chagas;

$\Delta$ classe funcional segundo a New York Heart Association:

** valor - $p$ do teste de razão de verossimilhança do ajuste final do modelo de Cox
} 
Tabela 8 - Valores de referência para as variáveis com dados faltantes

\begin{tabular}{lccc}
\hline \multicolumn{1}{c}{ Variável } & $\begin{array}{c}\text { Estratégia } \\
1^{*}\end{array}$ & $\begin{array}{c}\text { Estratégia } \\
2^{* \star}\end{array}$ & $\begin{array}{c}\text { Estratégia } \\
3^{* * *}\end{array}$ \\
\hline Índice de massa corpórea $\left(\mathrm{kg} / \mathrm{m}^{2}\right)$ & 25 & 25 & 26 \\
Pressão arterial diastólica $(\mathrm{mm} \mathrm{Hg})$ & 80 & 80 & 90 \\
Espessura diastólica do septo & 8 & 8 & 9 \\
intraventricular (mm) & & & \\
Diâmetro diastólico do ventrículo & 60 & 60 & 64 \\
esquerdo (mm) & 40 & 40 & 46 \\
Diâmetro do átrio esquerdo $(\mathrm{mm})$ & 3,5 & 3,5 & 4,6 \\
Potássio sérico $(\mathrm{mEq} / \mathrm{L})$ & 160 & 200 & 188 \\
Colesterol total $(\mathrm{mg} / \mathrm{dL})$ & 0,9 & 1,3 & 1,1 \\
Creatinina (mg/dL) & & & \\
\hline
\end{tabular}

Pré-requisito para o aprendizado da rede neural: estratégias para a imputação de valores nas informações faltantes;

* valores de referência da normalidade;

** valores superiores da normalidade para as variáveis colesterol total e creatinina sérica;

*** valores de referência da mediana. 
Tabela 9 - Testes para definição do modelo da rede neural (A) (fase 1)

\begin{tabular}{|c|c|c|c|c|c|c|c|c|}
\hline \multirow[b]{2}{*}{$\begin{array}{l}\text { Tempo de sobrevida } \\
\text { observado (anos) }\end{array}$} & \multirow[b]{2}{*}{$\begin{array}{c}\text { Teste da rede } \\
\text { neural }^{*}\end{array}$} & \multirow[b]{2}{*}{$\begin{array}{c}\text { Estratégia } \\
\text { para dado } \\
\text { faltante }\end{array}$} & \multirow[b]{2}{*}{$\begin{array}{c}\text { Critério para aprendizado - } \\
\text { treinamento da rede ou } \\
\text { limitador }\end{array}$} & \multicolumn{2}{|c|}{ Tamanho da amostra } & \multirow[b]{2}{*}{$\begin{array}{l}\text { Função de transferência ou } \\
\text { função de ativação }\end{array}$} & \multirow[b]{2}{*}{$\begin{array}{c}\text { Data inicial para } \\
\text { estimar a sobrevida } \\
\end{array}$} & \multirow[b]{2}{*}{$\begin{array}{c}\text { Erro de previsão da } \\
\text { sobrevida pela rede } \\
\text { neural (\%) } \\
\end{array}$} \\
\hline & & & & $\begin{array}{l}\text { Aprendizado } \\
\text { (TAA) }\end{array}$ & $\begin{array}{c}\text { Previsão } \\
\text { (TAP) }\end{array}$ & & & \\
\hline sem limite & 1 & 1 & & 417 & 968 & Zero Based Log Sigmoid & data da consulta & 525,35 \\
\hline sem limite & 2 & 2 & & 417 & 968 & Zero Based Log Sigmoid & data da consulta & 526,18 \\
\hline sem limite & 3 & 1 & & 417 & 968 & Tangente Hiperbólica & data da consulta & 707,31 \\
\hline sem limite & 4 & 1 & Teste RN 1 ** & 118 & 240 & Zero Based Log Sigmoid & $\begin{array}{l}\text { data do início dos } \\
\text { sintomas }\end{array}$ & 201,00 \\
\hline sem limite & 5 & 1 & Cardiopatia dilatada & 36 & 70 & Zero Based Log Sigmoid & data da consulta & 1002,75 \\
\hline sem limite & 6 & 1 & Cardiopatia hipertensiva & 168 & 379 & Zero Based Log Sigmoid & data da consulta & 885,00 \\
\hline sem limite & 7 & 1 & Cardiopatia alcoólica & 28 & 57 & Zero Based Log Sigmoid & data da consulta & 814,29 \\
\hline sem limite & 8 & 1 & Cardiopatia isquemica & 106 & 263 & Zero Based Log Sigmoid & data da consulta & 361,09 \\
\hline sem limite & 9 & 1 & Cardiopatia doença Chagas & 8 & 188 & Zero Based Log Sigmoid & data da consulta & 400,44 \\
\hline sem limite & 10 & 1 & sexo & 417 & 968 & Zero Based Log Sigmoid & data da consulta & 578,36 \\
\hline sem limite & 11 & 1 & sexo e $\mathrm{FE}^{\wedge} 25 \%$ & 417 & 968 & Zero Based Log Sigmoid & data da consulta & 735,44 \\
\hline sem limite & 12 & 1 & sexo e $\mathrm{FE}^{\wedge} 55 \%$ & 417 & 968 & Zero Based Log Sigmoid & data da consulta & 1023,08 \\
\hline $2<$ sobrevida $<6$ & 13 & 1 & & 200 & 402 & Zero Based Log Sigmoid & data da consulta & 31,99 \\
\hline $2<$ sobrevida $<6$ & 14 & 1 & 22 a 52 anos & 121 & 206 & Zero Based Log Sigmoid & data da consulta & 880,00 \\
\hline $1<$ sobrevida $<6$ & 15 & 1 & 22 a 52 anos & 83 & 162 & Zero Based Log Sigmoid & data da consulta & 51,85 \\
\hline $1<$ sobrevida $<6$ & 16 & 1 & $1,3<\mathrm{Cr}^{\Phi}<2,6$ & 72 & 184 & Zero Based Log Sigmoid & data da consulta & 62,00 \\
\hline $1<$ sobrevida $<6$ & 17 & 1 & $200<\mathrm{TC}^{\boldsymbol{\Psi}}<239$ & 61 & 245 & Zero Based Log Sigmoid & data da consulta & 70,68 \\
\hline $1<$ sobrevida $<6$ & 18 & 1 & $60<\operatorname{DDVE}^{\varepsilon}<75$ & 160 & 374 & Zero Based Log Sigmoid & data da consulta & 63,60 \\
\hline $1<$ sobrevida $<6$ & 19 & 1 & $200<T C^{\Psi}<239$ e $60<D^{2} E^{\varepsilon}<75$ & 163 & 34 & Zero Based Log Sigmoid & data da consulta & 52,84 \\
\hline
\end{tabular}


Tabela 9 - Testes para definição do modelo da rede neural (A) (fase 1)

\begin{tabular}{|c|c|c|c|c|c|c|c|c|}
\hline \multirow[b]{2}{*}{$\begin{array}{c}\text { Tempo de sobrevida } \\
\text { observado (anos) }\end{array}$} & \multirow[b]{2}{*}{$\begin{array}{c}\begin{array}{c}\text { Teste da rede } \\
\text { neural }^{*}\end{array} \\
\end{array}$} & \multirow[b]{2}{*}{$\begin{array}{c}\text { Estratégia } \\
\text { para dado } \\
\text { faltante }\end{array}$} & \multirow[b]{2}{*}{$\begin{array}{c}\text { Critério para aprendizado- } \\
\text { treinamento da rede ou } \\
\text { limitador } \\
\end{array}$} & \multicolumn{2}{|c|}{ Tamanho da amostra } & \multirow[b]{2}{*}{$\begin{array}{l}\text { Função de transferência ou } \\
\text { função de ativação }\end{array}$} & \multirow[b]{2}{*}{$\begin{array}{c}\text { Data inicial para } \\
\text { estimar a sobrevida }\end{array}$} & \multirow[b]{2}{*}{$\begin{array}{c}\text { Erro de previsão da } \\
\text { sobrevida pela rede neural } \\
(\%)\end{array}$} \\
\hline & & & & $\begin{array}{c}\text { Aprendizado } \\
\text { (TAA) }\end{array}$ & $\begin{array}{c}\text { Previsão } \\
\text { (TAP) }\end{array}$ & & & \\
\hline $2<$ sobrevida $<6$ & 20 & 1 & & 50 & 98 & Zero Based Log Sigmoid & $\begin{array}{l}\text { data do início dos } \\
\text { sintomas }\end{array}$ & 22,60 \\
\hline $2<$ sobrevida $<6$ & 21 & 1 & & 200 & 402 & Tangente Hiperbólica & data da consulta & 48,01 \\
\hline $2<$ sobrevida $<6$ & 22 & 1 & & 50 & 98 & Tangente Hiperbólica & $\begin{array}{l}\text { data do início dos } \\
\text { sintomas }\end{array}$ & 20,54 \\
\hline $0<$ sobrevida $<2$ & 23 & 1 & & 118 & 383 & Tangente Hiperbólica & data da consulta & 422,44 \\
\hline sobrevida $>6$ & 24 & 1 & & 101 & 186 & Tangente Hiperbólica & data da consulta & 12,77 \\
\hline $0<$ sobrevida $<2$ & 25 & 1 & & 118 & 383 & Zero Based Log Sigmoid & data da consulta & 527,25 \\
\hline sobrevida $>6$ & 26 & 1 & & 101 & 186 & Zero Based Log Sigmoid & data da consulta & 11,37 \\
\hline $0<$ sobrevida $<2$ & 27 & 1 & & 22 & 47 & Tangente Hiperbólica & $\begin{array}{l}\text { data do início dos } \\
\text { sintomas }\end{array}$ & 35,29 \\
\hline sobrevida $>6$ & 28 & 1 & & 46 & 93 & Tangente Hiperbólica & $\begin{array}{l}\text { data do início dos } \\
\text { sintomas }\end{array}$ & 30,29 \\
\hline $0<$ sobrevida $<2$ & 29 & 1 & & 22 & 47 & Zero Based Log Sigmoid & $\begin{array}{l}\text { data do início dos } \\
\text { sintomas }\end{array}$ & 33,81 \\
\hline sobrevida $>6$ & 30 & 1 & & 46 & 93 & Zero Based Log Sigmoid & $\begin{array}{l}\text { data do início dos } \\
\text { sintomas }\end{array}$ & 24,13 \\
\hline $1,5<$ sobrevida $<8,5$ & 31 & 1 & & 317 & 632 & Zero Based Log Sigmoid & data da consulta & 74,78 \\
\hline sobrevida $>2$ & 32 & 1 & & 298 & 584 & Zero Based Log Sigmoid & data da consulta & 56,60 \\
\hline
\end{tabular}

* número sequencial do teste realizado pela rede neural; ${ }^{* *}$ teste inicial da rede neural (teste RN 1) utilizado como referência para o teste atual;

$\delta \quad$ data inicial disponivel para a rede neural estimar a sobrevida

TAA tamanho da amostra de aprendizado da rede neural; TAP tamanho da amostra de previsão da rede neural;

$\lambda \quad$ valor de referência para a fração de ejeção do ventrículo esquerdo (capacidade funcional) ao ecocardiograma;

$\Phi \quad$ valores de referência para a dosagem da creatinina sérica; $\Psi$ valores de referência para a dosagem sérica do colesterol total;

$\varepsilon \quad$ valores de referência para o diâmetro diastólico do ventrículo esquerdo ao ecocardiograma. 
Tabela 9.1 - Testes para definição do modelo da rede neural (B) (fase 1)

\begin{tabular}{|c|c|c|c|c|c|c|c|c|}
\hline \multirow[b]{2}{*}{$\begin{array}{c}\text { Tempo de } \\
\text { sobrevida } \\
\text { observado (anos) } \\
\end{array}$} & \multirow[b]{2}{*}{$\begin{array}{c}\text { Teste } \\
\text { da rede } \\
\text { neural* }^{*}\end{array}$} & \multirow[b]{2}{*}{$\begin{array}{l}\text { Estratégia } \\
\text { para dado } \\
\text { faltante } \\
\end{array}$} & \multirow[b]{2}{*}{$\begin{array}{l}\text { Critério para } \\
\text { aprendizado/treinamento da } \\
\text { rede ou limitador }\end{array}$} & \multicolumn{2}{|c|}{ Tamanho da amostra } & \multirow[b]{2}{*}{$\begin{array}{l}\text { Função de transferência ou } \\
\text { função de ativação }\end{array}$} & \multirow[b]{2}{*}{$\begin{array}{c}\text { Data inicial para } \\
\text { estimar a sobrevida } \\
\end{array}$} & \multirow[b]{2}{*}{$\begin{array}{c}\text { Erro de previsão da } \\
\text { sobrevida pela rede } \\
\text { neural (\%) } \\
\end{array}$} \\
\hline & & & & $\begin{array}{l}\text { Aprendizado } \\
\text { (TAA) }\end{array}$ & $\begin{array}{c}\text { Previsão } \\
\text { (TAP) }\end{array}$ & & & \\
\hline sem limite & 33 & 3 & $30.000^{\top} ; 0,0001^{\zeta} ;$ Teste RN $1^{* *}$ & 417 & 968 & Zero Based Log Sigmoid & data da consulta & 525,35 \\
\hline sem limite & 34 & 1 & $20.000^{\top} ;$ Teste RN $1^{\text {** }}$ & 417 & 968 & Zero Based Log Sigmoid & data da consulta & 551,41 \\
\hline sem limite & 35 & 1 & $10.000^{\top}$; Teste RN 1 ** & 417 & 968 & Zero Based Log Sigmoid & data da consulta & 542,41 \\
\hline sem limite & 36 & 1 & $0,0010^{\zeta} ;$ Teste RN $1^{\text {** }}$ & 417 & 968 & Zero Based Log Sigmoid & data da consulta & 694,27 \\
\hline sem limite & 37 & 1 & $0,0020^{\zeta} ;$ Teste RN 1 ** & 417 & 968 & Zero Based Log Sigmoid & data da consulta & 704,79 \\
\hline $2<$ sobrevida $<6$ & 38 & 1 & Cardiopatia dilatada & 18 & 38 & Zero Based Log Sigmoid & data da consulta & 26,67 \\
\hline $2<$ sobrevida $<6$ & 39 & 1 & Cardiopatia hipertensiva & 80 & 161 & Zero Based Log Sigmoid & data da consulta & 29,48 \\
\hline $2<$ sobrevida $<6$ & 40 & 1 & Cardiopatia alcoólica & 18 & 29 & Zero Based Log Sigmoid & data da consulta & 29,52 \\
\hline $2<$ sobrevida $<6$ & 41 & 1 & Cardiopatia isquemica & 48 & 101 & Zero Based Log Sigmoid & data da consulta & 27,05 \\
\hline $2<$ sobrevida $<6$ & 42 & 1 & $\begin{array}{c}\text { Cardiopatia da doença de } \\
\text { Chagas }\end{array}$ & 37 & 73 & Zero Based Log Sigmoid & data da consulta & 21,91 \\
\hline
\end{tabular}

* número sequencial do teste realizado pela rede neural; ** teste inicial da rede neural (teste RN 1) utilizado como referência para o teste atual;

$\delta \quad$ data inicial disponível para a rede neural estimar a sobrevida;

TAA tamanho da amostra de aprendizado da rede neural; TAP tamanho da amostra de previsão da rede neural;

T número de ciclos máximos ou iterações estipuladas para o aprendizado-treinamento da rede neural:

$\zeta \quad$ erro delta estipulado para o aprendizado-treinamento da rede neural. 
Tabela 10 - Comparação das redes neurais categorizadas pelo tempo de sobrevida observado: seleção dos melhores modelos de rede neural

\begin{tabular}{|c|c|c|c|c|c|}
\hline \multirow[b]{2}{*}{$\begin{array}{c}\text { Teste da } \\
\text { rede } \\
\text { neural }\end{array}$} & \multicolumn{2}{|c|}{ Número da amostra } & \multirow[b]{2}{*}{$\begin{array}{c}\text { Função de } \\
\text { transferência ou } \\
\text { de ativação }\end{array}$} & \multirow[b]{2}{*}{$\begin{array}{c}\text { Tempo disponível } \\
\text { para estimar a } \\
\text { sobrevida }\end{array}$} & \multirow{2}{*}{$\begin{array}{c}\text { Erro de } \\
\text { previsão da } \\
\text { rede } \\
\text { neural } \\
(\%)\end{array}$} \\
\hline & $\begin{array}{l}\text { Aprendizado/ } \\
\text { Treinamento }^{\star \star}\end{array}$ & Previsão & & & \\
\hline 23 & 118 & 383 & Tangente Hiperbólica & data da consulta & 422,44 \\
\hline 25 & 118 & 383 & $\begin{array}{l}\text { Zero Based Log } \\
\quad \text { Sigmoid }\end{array}$ & data da consulta & 527,25 \\
\hline 27 & 22 & 47 & Tangente Hiperbólica & $\begin{array}{l}\text { data do início dos } \\
\text { sintomas }\end{array}$ & 35,29 \\
\hline 29 & 22 & 47 & $\begin{array}{l}\text { Zero Based Log } \\
\text { Sigmoid }\end{array}$ & $\begin{array}{l}\text { data do início dos } \\
\text { sintomas }\end{array}$ & 33,81 \\
\hline
\end{tabular}

** tempo de seguimento ou tempo de sobrevida observado inferior a 2 anos.

\begin{tabular}{|c|c|c|c|c|c|}
\hline \multirow{2}{*}{$\begin{array}{c}\text { Teste da } \\
\text { rede } \\
\text { neural }\end{array}$} & \multicolumn{2}{|c|}{ Número da amostra } & \multirow[b]{2}{*}{$\begin{array}{c}\text { Função de } \\
\text { transferência ou } \\
\text { de ativação }\end{array}$} & \multirow[b]{2}{*}{$\begin{array}{c}\text { Tempo disponível } \\
\text { para estimar a } \\
\text { sobrevida }\end{array}$} & \multirow{2}{*}{$\begin{array}{c}\text { Erro de } \\
\text { previsão da } \\
\text { rede } \\
\text { neural } \\
(\%)\end{array}$} \\
\hline & $\begin{array}{l}\text { Aprendizado/ } \\
\text { Treinamento }\end{array}$ & Previsão & & & \\
\hline 13 & 200 & 402 & $\begin{array}{l}\text { Zero Based Log } \\
\text { Sigmoid }\end{array}$ & data da consulta & 31,99 \\
\hline 21 & 200 & 402 & Tangente Hiperbólica & data da consulta & 48,01 \\
\hline 20 & 50 & 98 & $\begin{array}{l}\text { Zero Based Log } \\
\text { Sigmoid }\end{array}$ & $\begin{array}{l}\text { data do início dos } \\
\text { sintomas }\end{array}$ & 22,60 \\
\hline 22 & 50 & 98 & Tangente Hiperbólica & $\begin{array}{l}\text { data do início dos } \\
\text { sintomas }\end{array}$ & 20,54 \\
\hline
\end{tabular}

** tempo de seguimento ou tempo de sobrevida observado entre 2 e 6 anos

\begin{tabular}{ccccccc}
\hline \multirow{2}{*}{$\begin{array}{c}\text { Teste } \\
\text { da rede } \\
\text { neural }\end{array}$} & $\begin{array}{c}\text { Número da amostra } \\
\text { Treinamento }\end{array}$ & Previsão & & $\begin{array}{c}\text { Função de } \\
\text { transferência ou } \\
\text { de ativação }\end{array}$ & $\begin{array}{c}\text { Tempo disponível } \\
\text { para estimar a } \\
\text { sobrevida }\end{array}$ & $\begin{array}{c}\text { Erro de } \\
\text { previsão da } \\
\text { rede } \\
\text { neural } \\
(\%)\end{array}$ \\
\hline 24 & 101 & 186 & Tangente Hiperbólica & data da consulta & 12,77 \\
\hline 26 & 101 & 186 & $\begin{array}{c}\text { Zero Based Log } \\
\text { Sigmoid }\end{array}$ & data da consulta & 11,37 \\
\hline 28 & 46 & 93 & Tangente Hiperbólica & $\begin{array}{c}\text { data do início dos } \\
\text { sintomas }\end{array}$ & 30,29 \\
\hline 30 & 46 & 93 & Zero Based Log & $\begin{array}{c}\text { data do início dos } \\
\text { sintomas }\end{array}$ & 24,13 \\
\hline
\end{tabular}

** tempo de seguimento ou tempo de sobrevida observado superior a 6 anos.

* em todos os testes das redes neurais foram utilizados valores normais para o dado faltante 
Tabela 11 - Modelos de redes neurais para previsão da sobrevida nos pacientes vivos até 2012 (fase 2)

\begin{tabular}{|c|c|c|c|c|c|c|c|c|c|}
\hline \multicolumn{6}{|c|}{$\begin{array}{l}\text { Aprendizado da rede neural } \\
\text { (pacientes falecidos até 2012) }\end{array}$} & \multicolumn{4}{|c|}{$\begin{array}{l}\text { Previsão de sobrevida } \\
\text { da rede neural } \\
\text { (pacientes vivos até 2012) }\end{array}$} \\
\hline $\begin{array}{l}\text { Modelo } \\
\text { de rede } \\
\text { neural }\end{array}$ & $\underset{*}{\text { TAA }}$ & $\begin{array}{l}\text { Erro } \\
\text { real da } \\
\text { rede } \\
\text { neural } \\
(\%)\end{array}$ & $\begin{array}{l}\text { Sobrevida } \\
\text { (tempo } \\
\text { decorrido) }\end{array}$ & $\begin{array}{l}\text { Função } \\
\text { de } \\
\text { transferência }\end{array}$ & $\begin{array}{c}\text { Tempo de } \\
\text { sobrevida } \\
\text { observado } \\
\text { (anos) }\end{array}$ & $\begin{array}{c}\text { Previsão } \\
\text { da rede } \\
\text { neural } \\
(\text { PREV) }\end{array}$ & $\underset{* *}{\mathrm{TAP}}$ & $\begin{array}{l}\text { Sobrevida } \\
\text { hipotética }\end{array}$ & $\begin{array}{c}\text { Erro } \\
\text { hipotético } \\
\text { da rede } \\
\text { neural } \\
(\%)\end{array}$ \\
\hline 13 & 200 & 31,99 & $(\text { DO-DPC })^{\varphi}$ & $\begin{array}{l}\text { zero based } \\
\text { log sigmoid }\end{array}$ & $2 \mathrm{a} 6$ & PREV01 & 300 & $\begin{array}{l}\text { (DUR- }^{-} \\
\text {DPC) }\end{array}$ & 38,47 \\
\hline 20 & 50 & 22,60 & $(\mathrm{DO}-\mathrm{DIS})^{\varsigma}$ & $\begin{array}{l}\text { zero based } \\
\text { log sigmoid }\end{array}$ & 2 a 6 & PREV02 & 51 & (DUR్-DIS) & 39,33 \\
\hline 22 & 50 & 20,54 & $(\mathrm{DO}-\mathrm{DIS})^{\varsigma}$ & $\begin{array}{l}\text { tangente } \\
\text { hiperbólica }\end{array}$ & 2 a 6 & PREV03 & 51 & (DUR_-DIS) & 33,23 \\
\hline 24 & 101 & 12,77 & $(\mathrm{DO}-\mathrm{DPC})^{\boldsymbol{\Psi}}$ & $\begin{array}{l}\text { tangente } \\
\text { hiperbólica }\end{array}$ & $\begin{array}{c}\text { superior a } \\
6\end{array}$ & PREV04 & 636 & $\begin{array}{l}\text { (DUR- } \\
\text { DPC) }\end{array}$ & 20,71 \\
\hline 26 & 101 & 11,37 & $(\mathrm{DO}-\mathrm{DPC})^{\boldsymbol{\Psi}}$ & $\begin{array}{l}\text { zero based } \\
\text { log sigmoid }\end{array}$ & $\begin{array}{c}\text { superior a } \\
6\end{array}$ & PREV05 & 636 & $\begin{array}{l}\text { (DUR- }^{\Phi} \\
\text { DPC) }\end{array}$ & 21,50 \\
\hline 27 & 22 & 35,29 & $(\mathrm{DO}-\mathrm{DIS})^{\varsigma}$ & $\begin{array}{l}\text { tangente } \\
\text { hiperbólica }\end{array}$ & 0 a 2 & PREV06 & 24 & (DUR్-DIS) & 63,72 \\
\hline 29 & 22 & 33,81 & $(\mathrm{DO}-\mathrm{DIS})^{\zeta}$ & $\begin{array}{l}\text { zero based } \\
\text { log sigmoid }\end{array}$ & 0 a 2 & PREV07 & 24 & (DUR-DIS) & 85,47 \\
\hline 28 & 46 & 30,29 & $(\mathrm{DO}-\mathrm{DIS})^{\zeta}$ & $\begin{array}{l}\text { tangente } \\
\text { hiperbólica }\end{array}$ & $\begin{array}{c}\text { superior a } \\
6\end{array}$ & PREV08 & 199 & (DUR్-DIS) & 43,23 \\
\hline 30 & 46 & 24,13 & $(\mathrm{DO}-\mathrm{DIS})^{\zeta}$ & $\begin{array}{l}\text { zero based } \\
\text { log sigmoid }\end{array}$ & $\begin{array}{c}\text { superior a } \\
6\end{array}$ & PREV09 & 199 & (DUR-DIS) & 48,67 \\
\hline
\end{tabular}

*TAA: tamanho da amostra para aprendizado da rede neural;

${ }^{* *}$ TAP: tamanho da amostra para a previsão da rede neural;

$\lambda$ PREV: modelo de previsão da rede neural para os pacientes vivos associado ao modelo de aprendizado da rede neural com os pacientes falecidos até 2012;

$\Phi$ : tempo decorrido calculado pela diferença entre a data da última revisão ou do último contato com o paciente e o dado disponível (data da primeira consulta ou data do início dos sintomas);

$\Psi$ : tempo decorrido calculado pela diferença entre a data do óbito do paciente e a data da primeira consulta; $\zeta$ : tempo decorrido calculado pela diferença entre a data do óbito do paciente e a data do início dos sintomas. 
Tabela 12 - Modelos de redes neurais comparáveis: erro hipotético de previsão da rede versus erro real observado (fase 3)

\begin{tabular}{ccccc}
\hline $\begin{array}{c}\text { Modelo } \\
\text { de rede } \\
\text { neural * }\end{array}$ & $\begin{array}{c}\text { Previsão da } \\
\text { rede neural } \\
\text { (PREV) }{ }^{\wedge}\end{array}$ & $\begin{array}{c}\text { Número de } \\
\text { pacientes } \\
\text { para } \\
\text { comparação }\end{array}$ & $\begin{array}{c}\text { Erro de previsão } \\
\text { hipotético de } \\
\text { sobrevida pela rede } \\
\text { neural } \\
\text { (vivos até 2012) } \\
(\%)\end{array}$ & $\begin{array}{c}\text { Erro de previsão da } \\
\text { sobrevida pela rede } \\
\text { neural real } \\
\text { (falecidos em 2013) } \\
(\%)\end{array}$ \\
\hline 13 & PREV 01 & 19 & 35,62 & \\
20 & PREV 02 & 2 & 11,55 & 47,55 \\
22 & PREV 03 & 2 & 40,95 & 40,37 \\
24 & PREV04 & 36 & 21,20 & 56,14 \\
26 & PREV 05 & 36 & 18,48 & 18,80 \\
* corresponde ao modelo de rede utilizada no aprendizado com os melhores resultados na \\
previsão da sobrevida;
\end{tabular}


Tabela 13 - Modelo de rede neural 13 individual e comparável: erro hipotético de previsão da rede versus erro real observado (fase 3)

Para modelo RN 13 (aprendizado falecidos até 2012) e PREV01 (previsão vivos até 2012)

\begin{tabular}{ccccc}
\hline $\begin{array}{c}\text { Modelo } \\
\text { de rede } \\
\text { neural }\end{array}$ & $\begin{array}{c}\text { Tamanho da } \\
\text { amostra de } \\
\text { aprendizado }\end{array}$ & $\begin{array}{c}\text { Sobrevida } \\
\text { (tempo } \\
\text { decorrido) }\end{array}$ & $\begin{array}{c}\text { Função de } \\
\text { transferência } \\
\text { ou ativação }\end{array}$ & $\begin{array}{c}\text { Tempo de sobrevida } \\
\text { observado } \\
\text { (anos) }\end{array}$ \\
\hline 13 & 200 & (DO-DPC) $^{\Psi}$ & $\begin{array}{c}\text { zero based } \\
\text { log sigmoid }\end{array}$ & 2 a 6 \\
\hline
\end{tabular}

$\delta$ : modelo de rede neural utilizada no aprendizado da rede;

$\Psi$ : tempo decorrido, calculado pela diferença entre a data do óbito do paciente e a data da primeira consulta.

\begin{tabular}{|c|c|c|c|c|c|}
\hline $\begin{array}{l}\text { Número } \\
\text { do caso }\end{array}$ & $\begin{array}{l}\text { Sobrevida } \\
\text { calculada - } \\
\text { VIVO (DUR- } \\
\text { DPC) }\end{array}$ & $\begin{array}{l}\text { Sobrevida hipotética } \\
\text { da rede neural } \\
\text { PREV 01 } \\
\text { (vivos em 2012) } \\
\text { (em dias) }\end{array}$ & $\begin{array}{c}\text { Erro de previsão } \\
\text { hipotético da rede } \\
\text { neural } \\
\text { (vivos em 2012) } \\
(\%)\end{array}$ & $\begin{array}{c}\text { Sobrevida real } \\
\text { (falecidos em } \\
2013 \text { ) } \\
\text { (em dias) }\end{array}$ & $\begin{array}{c}\text { Erro de } \\
\text { previsão da } \\
\text { rede neural } \\
\text { comparado } \\
\text { com erro real } \\
\text { (falecidos em } \\
2013) \\
(\%) \\
\end{array}$ \\
\hline 127 & 1.330 & 1.258 & 5,43 & 3.769 & 66,63 \\
\hline 180 & 1.434 & 1.797 & 25,35 & 3.526 & 49,02 \\
\hline 407 & 1.302 & 1.716 & 31,79 & 3.490 & 50,83 \\
\hline 675 & 2.063 & 1.795 & 12,99 & 3.630 & 50,55 \\
\hline 878 & 1.736 & 1.261 & 27,34 & 3.509 & 64,05 \\
\hline 1.086 & 859 & 1.265 & 47,22 & 3.429 & 63,12 \\
\hline 1.194 & 1.218 & 1.798 & 47,60 & 3.532 & 49,10 \\
\hline 1.341 & 1.172 & 1.794 & 53,06 & 3.297 & 45,59 \\
\hline 1.685 & 1.061 & 1.803 & 69,94 & 3.259 & 44,68 \\
\hline 2.204 & 950 & 1.795 & 88,99 & 2.971 & 39,57 \\
\hline 2.669 & 1.997 & 1.761 & 11,82 & 2.477 & 28,91 \\
\hline 2.962 & 1.357 & 1.427 & 5,29 & 2.659 & 46,35 \\
\hline 3.687 & 1.886 & 1.255 & 33,45 & 2.499 & 50,17 \\
\hline 3.837 & 1.834 & 1.221 & 33,41 & 2.451 & 23,96 \\
\hline 3.838 & 1.603 & 1.792 & 11,77 & 2.356 & 32,04 \\
\hline 3.855 & 1.108 & 1.794 & 61,94 & 2.640 & 77,89 \\
\hline 3.862 & 1.726 & 548 & 68,25 & 2.479 & 27,80 \\
\hline 3.892 & 1.745 & 1.720 & 1,44 & 2.382 & 45,47 \\
\hline 3.997 & 1.013 & 1.255 & 39,80 & 2.302 & 47,66 \\
\hline
\end{tabular}

Ф: tempo decorrido, calculado pela diferença entre a data da última revisão ou último contato com o paciente e a data da primeira consulta;

$\lambda$ PREV: modelo de previsão da rede neural para os pacientes vivos associado ao modelo de aprendizado da rede neural com os pacientes falecidos em 2012;

*: média e desvio-padrão (DP) das porcentagens do erro hipotético de previsão da rede neural para os pacientes vivos até 2012;

**: média e desvio-padrão (DP) das porcentagens do erro relativo da rede comparada com a porcentagem do erro real dos pacientes que faleceram em 2013. 
Tabela 14 - Modelo de rede neural 20 individual e comparável: erro hipotético de previsão da rede versus erro real observado (fase 3)

Para modelo RN 20 (aprendizado falecidos até 2012) e PREV02 (previsão vivos até 2012)

\begin{tabular}{ccccc}
\hline $\begin{array}{c}\text { Modelo } \\
\text { de rede } \\
\text { neural }\end{array}$ & $\begin{array}{c}\text { Tamanho da } \\
\text { amostra de } \\
\text { aprendizado }\end{array}$ & $\begin{array}{c}\text { Sobrevida } \\
\text { (tempo } \\
\text { decorrido) }\end{array}$ & $\begin{array}{c}\text { Função de } \\
\text { transferência } \\
\text { ou ativação }\end{array}$ & $\begin{array}{c}\text { Tempo de sobrevida } \\
\text { observado } \\
\text { (anos) }\end{array}$ \\
\hline 20 & 50 & (DO-DIS) $^{\Psi}$ & $\begin{array}{c}\text { zero based } \\
\text { log sigmoid }\end{array}$ & 2 a 6 \\
\hline
\end{tabular}

ঠ: modelo de rede neural utilizada no aprendizado da rede;

$\Psi$ : tempo decorrido, calculado pela diferença entre a data do óbito do paciente e a data do início dos sintomas.

\begin{tabular}{|c|c|c|c|c|c|}
\hline $\begin{array}{l}\text { Número } \\
\text { do } \\
\text { caso }\end{array}$ & $\begin{array}{c}\text { Sobrevida } \\
\text { calculada - } \\
\text { VIVO } \\
\text { (DUR-DPC) }\end{array}$ & $\begin{array}{c}\text { Sobrevida } \\
\text { hipotética da } \\
\text { rede neural } \\
\text { PREV } 02^{\wedge} \\
\text { (vivos até 2012) } \\
\text { (em dias) }\end{array}$ & $\begin{array}{c}\text { Erro de previsão } \\
\text { hipotético da rede } \\
\text { neural } \\
\text { (vivos até 2012) } \\
\text { (\%) }\end{array}$ & $\begin{array}{c}\text { Sobrevida } \\
\text { real } \\
\text { (falecidos em } \\
\text { 2013) }\end{array}$ & $\begin{array}{l}\text { Erro de previsão } \\
\text { da rede neural } \\
\text { comparado com } \\
\text { erro real } \\
\text { (falecidos em } \\
2013) \\
(\%)\end{array}$ \\
\hline 2.962 & 1.720 & 1.329 & 23,10 & 2.659 & 50,02 \\
\hline \multirow[t]{2}{*}{3.997} & 2.008 & 1.595 & 6,80 & 2.302 & 30,72 \\
\hline & & & 11,55 DP $12,49^{*}$ & & $\begin{array}{c}40,37 \text { DP } \\
13,65^{\star *}\end{array}$ \\
\hline
\end{tabular}

Ф: tempo decorrido, calculado pela diferença entre a data da última revisão ou último contato com o paciente e a data da primeira consulta;

$\lambda$ PREV: modelo de previsão da rede neural para os pacientes vivos associado ao modelo de aprendizado da rede neural com os pacientes falecidos em 2012.

*: média e desvio-padrão (DP) das porcentagens do erro hipotético de previsão da rede neural para os pacientes vivos até 2012;

**: média e desvio-padrão (DP) das porcentagens do erro hipotético de previsão da rede comparada com a porcentagem do erro real de sobrevida dos pacientes que faleceram em 2013. 
Tabela 15- Modelo de rede neural 22 individual e comparável: erro hipotético de previsão da rede versus erro real observado (fase 3)

Para modelo RN 22 (aprendizado falecidos até 2012) e PREV03 (previsão vivos até 2012)

\begin{tabular}{ccccc}
\hline $\begin{array}{c}\text { Modelo } \\
\text { de rede } \\
\text { neural }\end{array}$ & $\begin{array}{c}\text { Tamanho da } \\
\text { amostra de } \\
\text { aprendizado }\end{array}$ & $\begin{array}{c}\text { Sobrevida } \\
\text { (tempo } \\
\text { decorrido) }\end{array}$ & $\begin{array}{c}\text { Função de } \\
\text { transferência } \\
\text { ou ativação }\end{array}$ & $\begin{array}{c}\text { Tempo de sobrevida } \\
\text { observado } \\
\text { (anos) }\end{array}$ \\
\hline 22 & 50 & (DO- DIS) $^{\Psi}$ & $\begin{array}{c}\text { tangente } \\
\text { hiperbólica }\end{array}$ & 2 a 6 \\
\hline
\end{tabular}

ঠ: modelo de rede neural utilizada no aprendizado da rede;

$\Psi$ : tempo decorrido, calculado pela diferença entre a data do óbito do paciente e a data do início dos sintomas.

\begin{tabular}{|c|c|c|c|c|c|}
\hline $\begin{array}{l}\text { Número } \\
\text { do } \\
\text { caso }\end{array}$ & $\begin{array}{l}\text { Sobrevida } \\
\text { calculada - } \\
\text { VIVO } \\
\text { (DUR-DPC) }^{\Phi}\end{array}$ & $\begin{array}{c}\text { Sobrevida } \\
\text { hipotética da rede } \\
\text { neural } \\
\text { PREV 03 } \\
{ }^{\wedge} \\
\text { (vivos até 2012) } \\
\text { (em dias) }\end{array}$ & $\begin{array}{c}\text { Erro de previsão } \\
\text { hipotético da rede } \\
\text { neural } \\
\text { (vivos em 2012) } \\
(\%)\end{array}$ & $\begin{array}{c}\text { Sobrevida real } \\
\text { (falecidos em } \\
2013 \text { ) } \\
\text { (em dias) }\end{array}$ & $\begin{array}{l}\text { Erro de previsão } \\
\text { da rede neural } \\
\text { comparado com } \\
\text { erro real } \\
\text { (falecidos em } \\
2013) \\
(\%)\end{array}$ \\
\hline 2.962 & 1.720 & 1.166 & 32,20 & 2.659 & 56,15 \\
\hline \multirow[t]{2}{*}{3.997} & 2.008 & 1.010 & 49,70 & 2.302 & 56,14 \\
\hline & & & 40,95 DP $12,37^{\star}$ & & 56,14 DP $0,01^{\star \star}$ \\
\hline
\end{tabular}

Ф: tempo decorrido, calculado pela diferença entre a data da última revisão ou último contato com o paciente e a data da primeira consulta;

$\lambda$ PREV: modelo de previsão da rede neural para os pacientes vivos associado ao modelo de aprendizado da rede neural com os pacientes falecidos em 2012;

*: média e desvio-padrão (DP) das porcentagens do erro hipotético de previsão da rede neural para os pacientes vivos até 2012;

**: média e desvio-padrão (DP) das porcentagens do erro de previsão da rede comparada com a porcentagem do erro real dos pacientes que faleceram em 2013. 
Tabela 16 - Modelo de rede neural 24 individual e comparável: erro hipotético de previsão da rede versus erro real observado (fase 3 )

Para modelo RN 24 (aprendizado falecidos em 2012) e PREV04 (previsão vivos em 2012)

\begin{tabular}{ccccc}
$\begin{array}{l}\text { Modelo } \\
\text { de rede } \\
\text { neural }\end{array}$ & $\begin{array}{c}\text { Tamanho da } \\
\text { amostra de } \\
\text { aprendizado }\end{array}$ & $\begin{array}{c}\text { Sobrevida } \\
\text { (tempo } \\
\text { decorrido) }\end{array}$ & $\begin{array}{c}\text { Função de } \\
\text { transferência } \\
\text { ou ativação }\end{array}$ & $\begin{array}{c}\text { Tempo de sobrevida } \\
\text { observado } \\
\text { (anos) }\end{array}$ \\
\hline 24 & 101 & (DO-DPC) $^{\mathbf{W}}$ & $\begin{array}{c}\text { tangente } \\
\text { hiperbólica }\end{array}$ & superior a 6 anos \\
\hline
\end{tabular}

$\bar{\delta}$ : modelo de rede neural utilizada no aprendizado da rede;

$\Psi$ : tempo decorrido, calculado pela diferença entre a data do óbito do paciente e a data da primeira consulta.

\begin{tabular}{|c|c|c|c|c|c|}
\hline $\begin{array}{l}\text { Número do } \\
\text { caso }\end{array}$ & $\begin{array}{c}\text { Sobrevida calculada } \\
\text { VIVO (DUR-DPC) } \\
\text { (em dias) }\end{array}$ & $\begin{array}{c}\text { Sobrevida hipotética da } \\
\text { rede neural } \\
\text { PREV 04 } \\
\text { (vivos em 2012) }^{\wedge} \\
\text { (em dias) }\end{array}$ & $\begin{array}{l}\text { Erro hipotético da } \\
\text { rede neural } \\
\text { (vivos até 2012) } \\
(\%)\end{array}$ & $\begin{array}{c}\text { Sobrevida real } \\
\text { (falecidos em 2013) } \\
\text { (em dias) }\end{array}$ & $\begin{array}{c}\text { Erro da rede neural } \\
\text { comparado com } \\
\text { erro real (falecidos } \\
\text { em 2013) } \\
(\%)\end{array}$ \\
\hline 115 & 3.558 & 3.495 & 1,76 & 3.586 & 2,52 \\
\hline 156 & 3.552 & 3.239 & 8,82 & 3.630 & 10,77 \\
\hline 157 & 3.615 & 3.548 & 1,84 & 3.705 & 2,59 \\
\hline 267 & 3.437 & 2.302 & 33,03 & 3.755 & 38,7 \\
\hline 442 & 2.496 & 2.445 & 2,06 & 3.573 & 31,57 \\
\hline 475 & 3.681 & 3.527 & 4,18 & 3.700 & 4,66 \\
\hline 702 & 3.281 & 2.756 & 16,00 & 3.544 & 22,23 \\
\hline 848 & 3.362 & 2.628 & 21,83 & 3.474 & 24,35 \\
\hline 949 & 3.108 & 3.309 & 6,46 & 3.339 & 0,9 \\
\hline 1.015 & 3.410 & 2.166 & 36,48 & 3.449 & 37,19 \\
\hline 1.166 & 2.931 & 3.399 & 15,97 & 3.423 & 0,69 \\
\hline 1.269 & 2.693 & 3.183 & 18,20 & 3.461 & 8,02 \\
\hline 1.272 & 3.277 & 3.482 & 6,27 & 3.343 & 4,17 \\
\hline 1.408 & 3.346 & 2.435 & 27,21 & 3.427 & 28,93 \\
\hline 1.453 & 3.281 & 3.232 & 1,51 & 3.473 & 6,9 \\
\hline 1.460 & 3.285 & 4.047 & 23,19 & 3.330 & 21,52 \\
\hline 1.477 & 3.480 & 2.236 & 35,74 & 3.485 & 35,83 \\
\hline 1.490 & 2.902 & 3.332 & 14,80 & 3.244 & 2,69 \\
\hline 1.511 & 2.612 & 3.052 & 16,85 & 3.423 & 10,83 \\
\hline 1.513 & 2.589 & 3.239 & 25,10 & 3.399 & 4,71 \\
\hline 1.525 & 3.425 & 2.702 & 21,10 & 3.429 & 21,18 \\
\hline 1.538 & 2.963 & 4.069 & 37,34 & 3.312 & 22,86 \\
\hline 1.686 & 3.059 & 3.821 & 24,92 & 3.284 & 16,35 \\
\hline 1.754 & 3.214 & 2.612 & 18,73 & 3.284 & 20,45 \\
\hline 2.083 & 2.938 & 2.264 & 22,93 & 2.964 & 23,6 \\
\hline 2.477 & 2.828 & 4.067 & 43,81 & 2.973 & 36,47 \\
\hline 2.481 & 2.467 & 4.062 & 64,64 & 2.780 & 46,1 \\
\hline 2.526 & 2.559 & 3.548 & 38,65 & 2.799 & 26,76 \\
\hline 2.612 & 2.626 & 3.485 & 32,71 & 2.894 & 20,41 \\
\hline 2.621 & 2.534 & 2.224 & 12,24 & 2.802 & 20,63 \\
\hline 2.641 & 2.915 & 3.548 & 21,71 & 2.934 & 20,91 \\
\hline 2.714 & 2.737 & 3.486 & 27,38 & 2.810 & 24,07 \\
\hline 2.789 & 2.726 & 3.442 & 26,28 & 2.753 & 25,04 \\
\hline 2.815 & 2.938 & 3.016 & 2,64 & 2.943 & 2,46 \\
\hline $\begin{array}{l}2.871 \\
3.475\end{array}$ & $\begin{array}{l}2.884 \\
2.514\end{array}$ & $\begin{array}{l}2.237 \\
3.231\end{array}$ & $\begin{array}{l}22,42 \\
28,52\end{array}$ & $\begin{array}{l}2.904 \\
2.547\end{array}$ & $\begin{array}{l}22,95 \\
26,85\end{array}$ \\
\hline 3.475 & & & $\begin{array}{c}21,20 \\
\text { DP } 13,96^{*}\end{array}$ & & $\begin{array}{c}18,80 \\
\text { DP } 12,39^{\star *}\end{array}$ \\
\hline
\end{tabular}

$\Phi$ : tempo decorrido, calculado pela diferença entre a data da última revisão ou último contato com o paciente e a data da rimeira consulta; $\lambda$ PREV: modelo de previsão da rede neural para os pacientes vivos associado ao modelo de aprendizado da rede neural; *: média e desvio-padrão (DP) das porcentagens do erro hipotético de previsão da rede neural ara os pacientes vivos até 2012; **: média desvio-padrão (DP) das porcentagens do erro da rede comparada com a porcentagem do erro real dos pacientes que faleceram em 2013. 
Tabela 17 - Modelo de rede neural 26 individual e comparável: erro hipotético de previsão da rede versus erro real observado (fase 3)

Para modelo RN 26 (aprendizado óbito em 2012) e PREV05 (previsão vivos em 2012)

\begin{tabular}{ccccc}
\hline $\begin{array}{c}\text { Modelo } \\
\text { de rede }\end{array}$ & Tamanho da & Sobrevida & Função de & Tempo de sobrevida \\
neural & amo & (tempo & transferência & observado \\
& aprendizado & decorrido) & ou ativação & (anos)
\end{tabular}

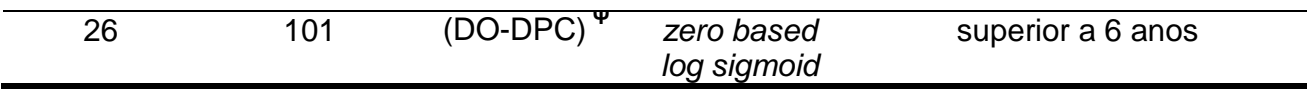

\begin{tabular}{|c|c|c|c|c|c|}
\hline $\begin{array}{l}\text { Número } \\
\text { do } \\
\text { caso }\end{array}$ & $\begin{array}{c}\text { Sobrevida } \\
\text { calculada - VIVO } \\
\text { (DUR-DPC) } \Phi\end{array}$ & $\begin{array}{c}\text { Sobrevida hipotética da } \\
\text { rede neural PREV } 05^{\wedge} \\
\text { (vivos em 2012) (em } \\
\text { dias) } \\
\end{array}$ & $\begin{array}{c}\text { Erro hipotético de } \\
\text { previsão da rede neural } \\
\text { (vivos até 2012) (\%) }\end{array}$ & 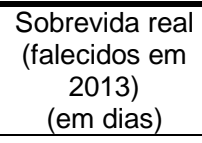 & $\begin{array}{c}\text { Erro da rede neural } \\
\text { comparado com erro } \\
\text { real (óbito em 2013) } \\
(\%) \\
\end{array}$ \\
\hline 115 & 3.558 & 3.902 & 9,66 & 3.586 & 8,81 \\
\hline 156 & 3.552 & 2.656 & 25,22 & 3.630 & 26,82 \\
\hline 157 & 3.615 & 3.408 & 5,73 & 3.705 & 8,02 \\
\hline 267 & 3.437 & 2.655 & 22,75 & 3.755 & 29,29 \\
\hline 442 & 2.496 & 2.514 & 0,74 & 3.573 & 29,63 \\
\hline 475 & 3.681 & 2.694 & 26,81 & 3.700 & 27,18 \\
\hline 702 & 3.281 & 2.841 & 13,4 & 3.544 & 19,83 \\
\hline 848 & 3.362 & 3.307 & 1,63 & 3.474 & 4,80 \\
\hline 949 & 3.108 & 2.318 & 25,41 & 3.339 & 30,57 \\
\hline 1.015 & 3.410 & 2.189 & 35,8 & 3.449 & 36,53 \\
\hline 1.166 & 2.931 & 4.085 & 39,37 & 3.423 & 19,34 \\
\hline 1.269 & 2.693 & 2.367 & 12,21 & 3.461 & 31,62 \\
\hline 1.272 & 3.277 & 2.669 & 18,54 & 3.343 & 20,15 \\
\hline 1.408 & 3.346 & 3.006 & 10,15 & 3.427 & 12,28 \\
\hline 1.453 & 3.281 & 2.430 & 25,95 & 3.473 & 30,04 \\
\hline 1.460 & 3.285 & 4.095 & 24,65 & 3.330 & 22,97 \\
\hline 1.477 & 3.480 & 2.147 & 38,32 & 3.485 & 38,41 \\
\hline 1.490 & 2.902 & 2.571 & 11,42 & 3.244 & 20,76 \\
\hline 1.511 & 2.612 & 2.241 & 14,19 & 3.423 & 34,52 \\
\hline 1.513 & 2.589 & 3.044 & 17,57 & 3.399 & 10,44 \\
\hline 1.525 & 3.425 & 2.770 & 19,13 & 3.429 & 19,22 \\
\hline 1.538 & 2.963 & 3.743 & 26,31 & 3.312 & 13,00 \\
\hline 1.686 & 3.059 & 2.747 & 10,21 & 3.284 & 16,36 \\
\hline 1.754 & 3.214 & 2.590 & 19,40 & 3.284 & 21,12 \\
\hline 2.083 & 2.938 & 2.805 & 4,52 & 2.964 & 5,36 \\
\hline 2.477 & 2.828 & 3.974 & 40,52 & 2.973 & 33,66 \\
\hline 2.481 & 2.467 & 4.055 & 64,39 & 2.780 & 45,88 \\
\hline 2.526 & 2.559 & 3.027 & 18,28 & 2.799 & 8,13 \\
\hline 2.612 & 2.626 & 2.090 & 20,43 & 2.894 & 27,79 \\
\hline 2.621 & 2.534 & 2.947 & 16,29 & 2.802 & 5,17 \\
\hline 2.641 & 2.915 & 2.247 & 22,93 & 2.934 & 23,43 \\
\hline 2.714 & 2.737 & 2.488 & 9,08 & 2.810 & 11,44 \\
\hline 2.789 & 2.726 & 2.727 & 0,03 & 2.753 & 0,95 \\
\hline
\end{tabular}




\begin{tabular}{cccccc}
\hline $\begin{array}{c}\text { Número } \\
\text { do } \\
\text { caso }\end{array}$ & $\begin{array}{c}\text { Sobrevida } \\
\text { calculada - VIVO } \\
\text { (DUR-DPC) } \Phi\end{array}$ & $\begin{array}{c}\text { Sobrevida hipotética da } \\
\text { rede neural PREV 05 } \\
\text { (vivos em 2012) }(\mathrm{em} \\
\text { dias) }\end{array}$ & $\begin{array}{c}\text { Erro hipotético de } \\
\text { previsão da rede neural } \\
\text { (vivos até 2012) }(\%)\end{array}$ & $\begin{array}{c}\text { Sobrevida real } \\
\text { (falecidos em } \\
\text { 2013) } \\
\text { (em dias) }\end{array}$ & $\begin{array}{c}\text { Erro da rede neural } \\
\text { comparado com erro } \\
\text { real (óbito em 2013) } \\
(\%)\end{array}$ \\
\hline \multirow{2}{*}{2.871} & 2.884 & 2.831 & 1,83 & 2.904 & 2,51 \\
3.475 & 2.514 & 2.432 & 3,27 & 2.547 & 4,52 \\
\hline
\end{tabular}

$\delta$ : modelo de rede neural utilizada no aprendizado da rede;

$\Psi$ : tempo decorrido, calculado pela diferença entre a data do óbito do paciente e a data da primeira consulta.

*: média e desvio-padrão (DP) das porcentagens do erro hipotético de previsão da rede neural para os pacientes

vivos até 2012;

**: média e desvio-padrão (DP) das porcentagens do erro da rede comparada com a porcentagem do erro real

dos pacientes que faleceram em 2013;

$\Phi$ : tempo decorrido, calculado pela diferença entre a data da última revisão ou último contato com o paciente $e$

a data da primeira consulta;

$\lambda$ PREV: modelo de previsão da rede neural para os pacientes vivos associado ao modelo de aprendizado da

rede neural com os pacientes falecidos em 2012. 
Tabela 18 - Reensaio da rede neural com pacientes que vieram a falecer em 2013 (Reensaio 1): fase 4

\begin{tabular}{|c|c|c|c|c|c|}
\hline \multicolumn{3}{|c|}{$\begin{array}{l}\text { Modelo de rede neural } 24 \\
\text { (falecidos até 2012) }\end{array}$} & \multicolumn{3}{|c|}{$\begin{array}{c}\text { Modelo de rede neural } 24 \\
\text { REENSAIO } 1 \text { (falecidos em 2013) }\end{array}$} \\
\hline $\begin{array}{c}\text { Tamanho } \\
\text { da amostra } \\
\text { de } \\
\text { aprendizado } \\
(\text { TAA })^{*}\end{array}$ & $\begin{array}{c}\text { Tamanho da } \\
\text { amostra de } \\
\text { previsão } \\
(\mathrm{TAP})^{\S}\end{array}$ & $\begin{array}{c}\text { Erro de } \\
\text { previsão da } \\
\text { rede neural } \\
(\%)\end{array}$ & $\begin{array}{l}\text { Tamanho da } \\
\text { amostra de } \\
\text { aprendizado } \\
\text { da rede } \\
(\text { TAA })^{* *}\end{array}$ & $\begin{array}{c}\text { Tamanho da } \\
\text { amostra de } \\
\text { previsão } \\
(\text { TAP })^{\epsilon}\end{array}$ & $\begin{array}{l}\text { Erro de } \\
\text { previsão } \\
\text { da } \\
\text { rede neural } \\
(\%)\end{array}$ \\
\hline 101 & 186 & 12,77 & 145 & 269 & 13,76 \\
\hline
\end{tabular}

*: corresponde aos pacientes mortos em 2012 sem dados faltantes;

**: corresponde ao somatório dos pacientes falecidos até 2012 e os pacientes que vieram a falecer em 2013 sem dados faltantes;

$\S$ : corresponde ao total de óbitos até 2012;

$€$ : corresponde ao somatório do total de óbitos até 2012 e o total de pacientes que vieram a falecer em 2013.

\begin{tabular}{ccc|ccc}
\hline \multicolumn{3}{c|}{$\begin{array}{c}\text { Modelo de rede neural 26 } \\
\text { (falecidos até 2012) }\end{array}$} & \multicolumn{3}{c}{ Modelo de rede neural 26 } \\
REENSAIO 1 (falecidos em 2013)
\end{tabular}

*: corresponde aos pacientes mortos em 2012 sem dados faltantes;

**: corresponde ao somatório dos pacientes falecidos até 2012 e os pacientes que vieram a falecer em 2013 sem dados faltantes;

$\S$ : corresponde ao total de óbitos até 2012;

$€$ : corresponde ao somatório do total de óbitos até 2012 e o total de pacientes que vieram a falecer em 2013. 
Tabela 19 - Reensaio da rede neural com pacientes que vieram a falecer em 2014 (Reensaio 2): fase 4

\begin{tabular}{|c|c|c|c|c|c|c|c|c|}
\hline \multicolumn{2}{|c|}{$\begin{array}{c}\text { Modelo de rede neural 24 } \\
\text { (falecidos até 2012) }\end{array}$} & \multicolumn{2}{|c|}{$\begin{array}{c}\text { Modelo de rede neural 24 } \\
\text { Reensaio1 (falecidos em } \\
\text { 2013) }\end{array}$} & \multicolumn{3}{|c|}{$\begin{array}{c}\text { Modelo de rede neural 24 } \\
\text { Reensaio 2 (falecidos em } \\
\text { 2014) }\end{array}$} \\
\hline TAA $^{*}$ & $\begin{array}{c}\text { TAP } \\
\S\end{array}$ & $\begin{array}{c}\text { Erro de } \\
\text { previsão de } \\
\text { sobrevida da } \\
\text { rede neural } \\
(\%)\end{array}$ & TAA $^{* *}$ & TA $^{\epsilon}$ & $\begin{array}{c}\text { Erro de } \\
\text { previsão } \\
\text { real da rede } \\
\text { neural (\%) }\end{array}$ & TAA $^{* * *}$ & TAP & $\begin{array}{c}\text { Erro de } \\
\text { previsão } \\
\text { de sobrevida } \\
\text { da rede } \\
\text { neural } \\
(\%)\end{array}$ \\
\hline 101 & 186 & 145 & 269 & 13,76 & 175 & 319 & 17,33 \\
\hline
\end{tabular}

*: corresponde aos pacientes falecidos em 2012 sem dados faltantes;

**: corresponde ao somatório dos pacientes falecidos até 2012 e os pacientes que vieram a falecer em 2013 sem dados faltantes;

${ }^{* * *}$ : corresponde ao somatório dos pacientes falecidos em 2013 e os pacientes que vieram a falecer em 2014 sem dados faltantes;

$\S$ : corresponde ao total de óbitos até 2012;

$€$ : corresponde à somatória do total de óbitos até 2012 e o total de pacientes que vieram a falecer 2013;

$£$ : corresponde ao somatório do total de óbitos 2013 e o total de pacientes que vieram a falecer em 2014.

\begin{tabular}{|c|c|c|c|c|c|c|c|c|}
\hline \multicolumn{3}{|c|}{$\begin{array}{l}\text { Modelo de rede neural } 26 \\
\text { (falecidos até 2012) }\end{array}$} & \multicolumn{3}{|c|}{$\begin{array}{c}\text { Modelo de rede neural } 26 \\
\text { Reensaio1 (falecidos em 2013) }\end{array}$} & \multicolumn{3}{|c|}{$\begin{array}{c}\text { Modelo de rede neural } 26 \\
\text { Reensaio } 2 \text { (falecidos em 2014) }\end{array}$} \\
\hline TAA $^{*}$ & $\mathrm{TAP}^{\S}$ & $\begin{array}{l}\text { Erro de } \\
\text { previsão de } \\
\text { sobrevida da } \\
\text { rede neural } \\
(\%)\end{array}$ & $\mathrm{TAA}^{* *}$ & TAP $^{\epsilon}$ & $\begin{array}{c}\text { Erro de } \\
\text { previsão real } \\
\text { da rede } \\
\text { neural (\%) }\end{array}$ & $\mathrm{TAA}^{* \star *}$ & $\mathrm{TAP}^{\varepsilon}$ & $\begin{array}{c}\text { Erro de } \\
\text { previsão } \\
\text { de sobrevida da } \\
\text { rede neural } \\
(\%)\end{array}$ \\
\hline 101 & 186 & 11,37 & 145 & 269 & 12,30 & 175 & 319 & 14,88 \\
\hline
\end{tabular}

*: corresponde aos pacientes mortos em 2012 sem dados faltantes;

**: corresponde ao somatório dos pacientes falecidos em 2012 e os pacientes que vieram a falecer em 2013 sem dados faltantes;

***: corresponde ao somatório dos pacientes falecidos em 2013 e os pacientes que vieram a falecer em 2014 sem dados faltantes;

$\S$ : corresponde ao total de óbitos até 2012;

$€$ : corresponde ao somatório do total de óbitos até 2012 e o total de pacientes que vieram a falecer em 2013;

$£$ : corresponde ao somatório do total de óbitos até 2013 e o total de pacientes que vieram a falecer em 2014. 
Tabela 20 - Comparação da previsão de sobrevida entre o modelo inicial da rede neural 24 e reensaio 1: fase 4

\begin{tabular}{|c|c|c|c|c|c|}
\hline \multirow[b]{2}{*}{$\begin{array}{l}\text { Número } \\
\text { do caso }\end{array}$} & \multirow[b]{2}{*}{$\begin{array}{l}\text { Sobrevida real } \\
\text { (em dias) }\end{array}$} & \multicolumn{2}{|c|}{$\begin{array}{c}\text { PREV 04 } \\
\text { (vivos em 2012) }\end{array}$} & \multicolumn{2}{|c|}{$\begin{array}{l}\text { REENSAIO } 1 \text { do modelo de rede neural } 24 \\
\text { (falecidos em 2013) }\end{array}$} \\
\hline & & $\begin{array}{l}\text { Sobrevida da } \\
\text { rede neural (em } \\
\text { dias) }\end{array}$ & $\begin{array}{l}\text { Erro de previsão } \\
\text { hipotético da rede } \\
\text { neural } \\
(\%) \\
\end{array}$ & $\begin{array}{l}\text { Sobrevida da rede } \\
\text { neural } \\
\text { (em dias) }\end{array}$ & $\begin{array}{l}\text { Erro de previsão real rede } \\
\text { neural (\%) }\end{array}$ \\
\hline 115 & 3.586 & 3.495 & 1,76 & 3.709 & 3,44 \\
\hline 156 & 3.630 & 3.239 & 8,82 & 3.041 & 16,23 \\
\hline 157 & 3.705 & 3.548 & 1,84 & 3.469 & 6,37 \\
\hline 267 & 3.755 & 2.302 & 33,03 & 3.549 & 5,49 \\
\hline 442 & 3.573 & 2.445 & 2,06 & 3.568 & 0,13 \\
\hline 475 & 3.700 & 3.527 & 4,18 & 3.370 & 8,92 \\
\hline 702 & 3.544 & 2.756 & 16 & 3.727 & 5,15 \\
\hline 848 & 3.474 & 2.628 & 21,83 & 3.547 & 2,11 \\
\hline 949 & 3.339 & 3.309 & 6,46 & 3.505 & 4,96 \\
\hline 1.015 & 3.449 & 2.166 & 36,48 & 3.637 & 5,44 \\
\hline 1.166 & 3.423 & 3.399 & 15,97 & 3.555 & 3,86 \\
\hline 1.269 & 3.461 & 3.183 & 18,2 & 3.378 & 2,40 \\
\hline 1.272 & 3.343 & 3.482 & 6,27 & 3.286 & 1,71 \\
\hline 1.408 & 3.427 & 2.435 & 27,21 & 3.403 & 0,70 \\
\hline 1.453 & 3.473 & 3.232 & 1,51 & 3.458 & 0,44 \\
\hline 1.460 & 3.330 & 4.047 & 23,19 & 4.024 & 20,83 \\
\hline 1.477 & 3.485 & 2.236 & 35,74 & 3.498 & 0,38 \\
\hline 1.490 & 3.244 & 3.332 & 14,8 & 3.511 & 8,23 \\
\hline 1.511 & 3.423 & 3.052 & 16,85 & 3.225 & 5,79 \\
\hline 1.513 & 3.399 & 3.239 & 25,1 & 3.564 & 4,84 \\
\hline 1.525 & 3.429 & 2.702 & 21,1 & 3.527 & 2,84 \\
\hline 1.538 & 3.312 & 4.069 & 37,34 & 3.422 & 3,32 \\
\hline 1.686 & 3.284 & 3.821 & 24,92 & 3.304 & 0,60 \\
\hline 1.754 & 3.284 & 2.612 & 18,73 & 3.324 & 1,20 \\
\hline 2.083 & 2.964 & 2.264 & 22,93 & 2.501 & 15,64 \\
\hline 2.477 & 2.973 & 4.067 & 43,81 & 3.026 & 1,55 \\
\hline 2.481 & 2.780 & 4.062 & 64,64 & 2.827 & 1,69 \\
\hline 2.526 & 2.799 & 3.548 & 38,65 & 3.264 & 16,60 \\
\hline 2.612 & 2.894 & 3.485 & 32,71 & 3.989 & 37,84 \\
\hline 2.621 & 2.802 & 2.224 & 12,24 & 2.545 & 9,17 \\
\hline 2.641 & 2.934 & 3.548 & 21,71 & 2.659 & 9,37 \\
\hline 2.714 & 2.810 & 3.486 & 27,38 & 2.329 & 17,12 \\
\hline 2.789 & 2.753 & 3.442 & 26,28 & 2.490 & 9,55 \\
\hline 2.815 & 2.943 & 3.016 & 2,64 & 3.200 & 8,73 \\
\hline 2.871 & 2.904 & 2.237 & 22,42 & 3.558 & 22,53 \\
\hline \multirow[t]{2}{*}{3.475} & 2.547 & 3.231 & 28,52 & 3.568 & 40,08 \\
\hline & & & 21,20 DP $13,96^{*}$ & & $\begin{array}{c}8,48 \\
\text { DP } 9,61^{\star \star}\end{array}$ \\
\hline
\end{tabular}


Tabela 21 - Comparação da previsão da sobrevida entre o modelo inicial da rede neural 26 e reensaio 1: fase 4

\begin{tabular}{|c|c|c|c|c|c|}
\hline \multirow[b]{2}{*}{$\begin{array}{l}\text { Número } \\
\text { do caso }\end{array}$} & \multirow[b]{2}{*}{$\begin{array}{l}\text { Sobrevida real } \\
\text { (em dias) }\end{array}$} & \multicolumn{2}{|c|}{$\begin{array}{c}\text { PREV 05 } \\
\text { (vivos até 2012) }\end{array}$} & \multicolumn{2}{|c|}{$\begin{array}{l}\text { REENSAIO } 1 \text { do modelo de rede neural } 26 \text { (óbitos } \\
2013 \text { ) }\end{array}$} \\
\hline & & $\begin{array}{l}\text { Sobrevida da } \\
\text { rede neural (em } \\
\text { dias) }\end{array}$ & $\begin{array}{c}\text { Erro de previsão } \\
\text { hipotético da rede } \\
\text { neural } \\
(\%) \\
\end{array}$ & $\begin{array}{c}\text { Sobrevida da rede } \\
\text { neural } \\
\text { (em dias) }\end{array}$ & $\begin{array}{l}\text { Sobrevida da rede neural } \\
\text { (\%) }\end{array}$ \\
\hline 115 & 3.586 & 3.902 & 9,66 & 3.520 & 1,84 \\
\hline 156 & 3.630 & 2.656 & 25,22 & 2.618 & 27,87 \\
\hline 157 & 3.705 & 3.408 & 5,73 & 3.568 & 3,71 \\
\hline 267 & 3.755 & 2.655 & 22,75 & 3.787 & 0,84 \\
\hline 442 & 3.573 & 2.514 & 0,74 & 3.326 & 6,91 \\
\hline 475 & 3.700 & 2.694 & 26,81 & 2.654 & 28,27 \\
\hline 702 & 3.544 & 2.841 & 13,40 & 3.400 & 4,06 \\
\hline 848 & 3.474 & 3.307 & 1,63 & 3.467 & 0,20 \\
\hline 949 & 3.339 & 2.318 & 25,41 & 3.418 & 2,36 \\
\hline 1.015 & 3.449 & 2.189 & 35,80 & 3.621 & 4,99 \\
\hline 1.166 & 3.423 & 4.085 & 39,37 & 2.635 & 23,03 \\
\hline 1.269 & 3.461 & 2.367 & 12,21 & 2.628 & 24,05 \\
\hline 1.272 & 3.343 & 2.669 & 18,54 & 2.688 & 19,60 \\
\hline 1.408 & 3.427 & 3.006 & 10,15 & 3.269 & 4,60 \\
\hline 1.453 & 3.473 & 2.430 & 25,95 & 2.596 & 25,24 \\
\hline 1.460 & 3.330 & 4.095 & 24,65 & 2.653 & 20,33 \\
\hline 1.477 & 3.485 & 2.147 & 38,32 & 3.408 & 2,21 \\
\hline 1.490 & 3.244 & 2.571 & 11,42 & 2.711 & 16,42 \\
\hline 1.511 & 3.423 & 2.241 & 14,19 & 2.617 & 23,54 \\
\hline 1.513 & 3.399 & 3.044 & 17,57 & 3.340 & 1,75 \\
\hline 1.525 & 3.429 & 2.770 & 19,13 & 3.093 & 9,79 \\
\hline 1.538 & 3.312 & 3.743 & 26,31 & 2.651 & 19,95 \\
\hline 1.686 & 3.284 & 2.747 & 10,21 & 2.665 & 18,86 \\
\hline 1.754 & 3.284 & 2.590 & 19,40 & 2.798 & 14,80 \\
\hline 2.083 & 2.964 & 2.805 & 4,52 & 2.695 & 9,06 \\
\hline 2.477 & 2.973 & 3.974 & 40,52 & 2.622 & 11,82 \\
\hline 2.481 & 2.780 & 4.055 & 64,39 & 2.873 & 3,34 \\
\hline 2.526 & 2.799 & 3.027 & 18,28 & 2.627 & 6,14 \\
\hline 2.612 & 2.894 & 2.090 & 20,43 & 3.243 & 12,04 \\
\hline 2.621 & 2.802 & 2.947 & 16,29 & 2.645 & 5,62 \\
\hline 2.641 & 2.934 & 2.247 & 22,93 & 2.654 & 9,54 \\
\hline 2.714 & 2.810 & 2.488 & 9,08 & 2.943 & 4,74 \\
\hline 2.789 & 2.753 & 2.727 & 0,03 & 2.567 & 6,77 \\
\hline 2.815 & 2.943 & 2.663 & 9,35 & 2.620 & 10,96 \\
\hline 2.871 & 2.904 & 2.831 & 1,83 & 2.550 & 12,19 \\
\hline \multirow[t]{2}{*}{3.475} & 2.547 & 2.432 & 3,27 & 2.731 & 7,24 \\
\hline & & & 18,48 DP $14,10^{\star}$ & & $\begin{array}{c}11,24 \\
\text { DP } 8,51^{\star *}\end{array}$ \\
\hline
\end{tabular}


Tabela 22 - Comparação da previsão da sobrevida entre o modelo inicial da rede neural 24, reensaio 1 e reensaio 2: fase 5

\begin{tabular}{|c|c|c|c|c|c|c|c|}
\hline \multirow[b]{2}{*}{$\begin{array}{l}\text { Número } \\
\text { do } \\
\text { caso }\end{array}$} & \multirow[b]{2}{*}{$\begin{array}{l}\text { Sobrevida real } \\
\text { (em dias) }\end{array}$} & \multicolumn{2}{|c|}{$\begin{array}{c}\text { PREV 04 } \\
\text { (vivos até 2012) }\end{array}$} & \multicolumn{2}{|c|}{$\begin{array}{l}\text { REENSAIO } 1 \text { do modelo de } \\
\text { rede neural } 24 \text { (aprendizado } \\
2013 \text { ) }\end{array}$} & \multicolumn{2}{|c|}{$\begin{array}{l}\text { REENSAIO } 2 \text { do modelo de } \\
\text { rede neural } 24 \\
\text { (aprendizado } 2013 \text { e 2014) }\end{array}$} \\
\hline & & $\begin{array}{l}\text { Sobrevida } \\
\text { da rede } \\
\text { neural } \\
\text { (em dias) }\end{array}$ & $\begin{array}{c}\text { Erro } \\
\text { hipotético da } \\
\text { rede neural } \\
(\%)\end{array}$ & $\begin{array}{l}\text { Sobrevida da } \\
\text { rede neural } \\
\text { (em dias) }\end{array}$ & $\begin{array}{c}\text { Erro real da } \\
\text { rede neural (\%) }\end{array}$ & $\begin{array}{l}\text { Sobrevida da } \\
\text { rede neural } \\
\text { (em dias) }\end{array}$ & $\begin{array}{l}\text { Erro real da } \\
\text { rede neural } \\
\qquad(\%)\end{array}$ \\
\hline 115 & 3.586 & 3.495 & 1,76 & 3.709 & 3,44 & 3.241 & 9,63 \\
\hline 156 & 3.630 & 3.239 & 8,82 & 3.041 & 16,23 & 2.523 & 30,49 \\
\hline 157 & 3.705 & 3.548 & 1,84 & 3.469 & 6,37 & 3.513 & 5,18 \\
\hline 267 & 3.755 & 2.302 & 33,03 & 3.549 & 5,49 & 3.513 & 6,44 \\
\hline 442 & 3.573 & 2.445 & 2,06 & 3.568 & 0,13 & 2.523 & 29,38 \\
\hline 475 & 3.700 & 3.527 & 4,18 & 3.370 & 8,92 & 3.442 & 6,98 \\
\hline 702 & 3.544 & 2.756 & 16 & 3.727 & 5,15 & 2.968 & 16,25 \\
\hline 848 & 3.474 & 2.628 & 21,83 & 3.547 & 2,11 & 3.616 & 4,08 \\
\hline 949 & 3.339 & 3.309 & 6,46 & 3.505 & 4,96 & 3.513 & 5,21 \\
\hline 1.015 & 3.449 & 2.166 & 36,48 & 3.637 & 5,44 & 3.508 & 1,71 \\
\hline 1.166 & 3.423 & 3.399 & 15,97 & 3.555 & 3,86 & 3.363 & 1,75 \\
\hline 1.269 & 3.461 & 3.183 & 18,2 & 3.378 & 2,40 & 3.628 & 4,83 \\
\hline 1.272 & 3.343 & 3.482 & 6,27 & 3.286 & 1,71 & 2.867 & 14,24 \\
\hline 1.408 & 3.427 & 2.435 & 27,21 & 3.403 & 0,70 & 3.184 & 7,10 \\
\hline 1.453 & 3.473 & 3.232 & 1,51 & 3.458 & 0,44 & 3.572 & 2,84 \\
\hline 1.460 & 3.330 & 4.047 & 23,19 & 4.024 & 20,83 & 3.058 & 8,17 \\
\hline 1.477 & 3.485 & 2.236 & 35,74 & 3.498 & 0,38 & 3.513 & 0,81 \\
\hline 1.490 & 3.244 & 3.332 & 14,8 & 3.511 & 8,23 & 3.370 & 3,88 \\
\hline 1.511 & 3.423 & 3.052 & 16,85 & 3.225 & 5,79 & 3.096 & 9,55 \\
\hline 1.513 & 3.399 & 3.239 & 25,1 & 3.564 & 4,84 & 3.130 & 7,91 \\
\hline 1.525 & 3.429 & 2.702 & 21,1 & 3.527 & 2,84 & 3.518 & 2,61 \\
\hline 1.538 & 3.312 & 4.069 & 37,34 & 3.422 & 3,32 & 3.347 & 1,06 \\
\hline 1.686 & 3.284 & 3.821 & 24,92 & 3.304 & 0,60 & 3.141 & 4,35 \\
\hline 1.754 & 3.284 & 2.612 & 18,73 & 3.324 & 1,20 & 3.014 & 8,22 \\
\hline 2.083 & 2.964 & 2.264 & 22,93 & 2.501 & 15,64 & 3.157 & 6,52 \\
\hline 2.477 & 2.973 & 4.067 & 43,81 & 3.026 & 1,55 & 2.404 & 19,13 \\
\hline 2.481 & 2.780 & 4.062 & 64,64 & 2.827 & 1,69 & 2.697 & 3,00 \\
\hline 2.526 & 2.799 & 3.548 & 38,65 & 3.264 & 16,60 & 2.524 & 9,83 \\
\hline 2.612 & 2.894 & 3.485 & 32,71 & 3.989 & 37,84 & 3.183 & 9,99 \\
\hline 2.621 & 2.802 & 2.224 & 12,24 & 2.545 & 9,17 & 3.447 & 23,03 \\
\hline 2.641 & 2.934 & 3.548 & 21,71 & 2.659 & 9,37 & 3.334 & 13,65 \\
\hline 2.714 & 2.810 & 3.486 & 27,38 & 2.329 & 17,12 & 2.523 & 10,20 \\
\hline 2.789 & 2.753 & 3.442 & 26,28 & 2.490 & 9,55 & 2.404 & 12,67 \\
\hline 2.815 & 2.943 & 3.016 & 2,64 & 3.200 & 8,73 & 2.208 & 24,97 \\
\hline 2.871 & 2.904 & 2.237 & 22,42 & 3.558 & 22,53 & 2.871 & 1,13 \\
\hline \multirow[t]{3}{*}{3.475} & 2.547 & 3.231 & 28,52 & 3.568 & 40,08 & 2.524 & 0,92 \\
\hline & & & 21,20 & & 8,48 & & 9,10 \\
\hline & & & DP $13,96^{\star}$ & & DP $9,61^{\star \star}$ & & DP $7,87^{\star \star \star}$ \\
\hline
\end{tabular}

* média e desvio-padrão (DP) das porcentagens do erro hipotético de previsão da rede inicial; ** média e desvio-padrão das porcentagens (DP) do erro hipotético de previsão da rede neural para os pacientes do reensaio 1 (óbitos incorporados até 2013); ${ }^{* \star *}$ média e desvio-padrão (DP) do erro hipotético de previsão da rede neural para os pacientes do reensaio 2. (óbitos incorporados até 2014); $\lambda$ PREV: modelo de previsão da rede neural para os pacientes vivos associado ao modelo de aprendizado da rede. 
Tabela 23 - Comparação da previsão da sobrevida entre o modelo inicial da rede neural 26, o reensaio 1 e o reensaio 2: fase 5

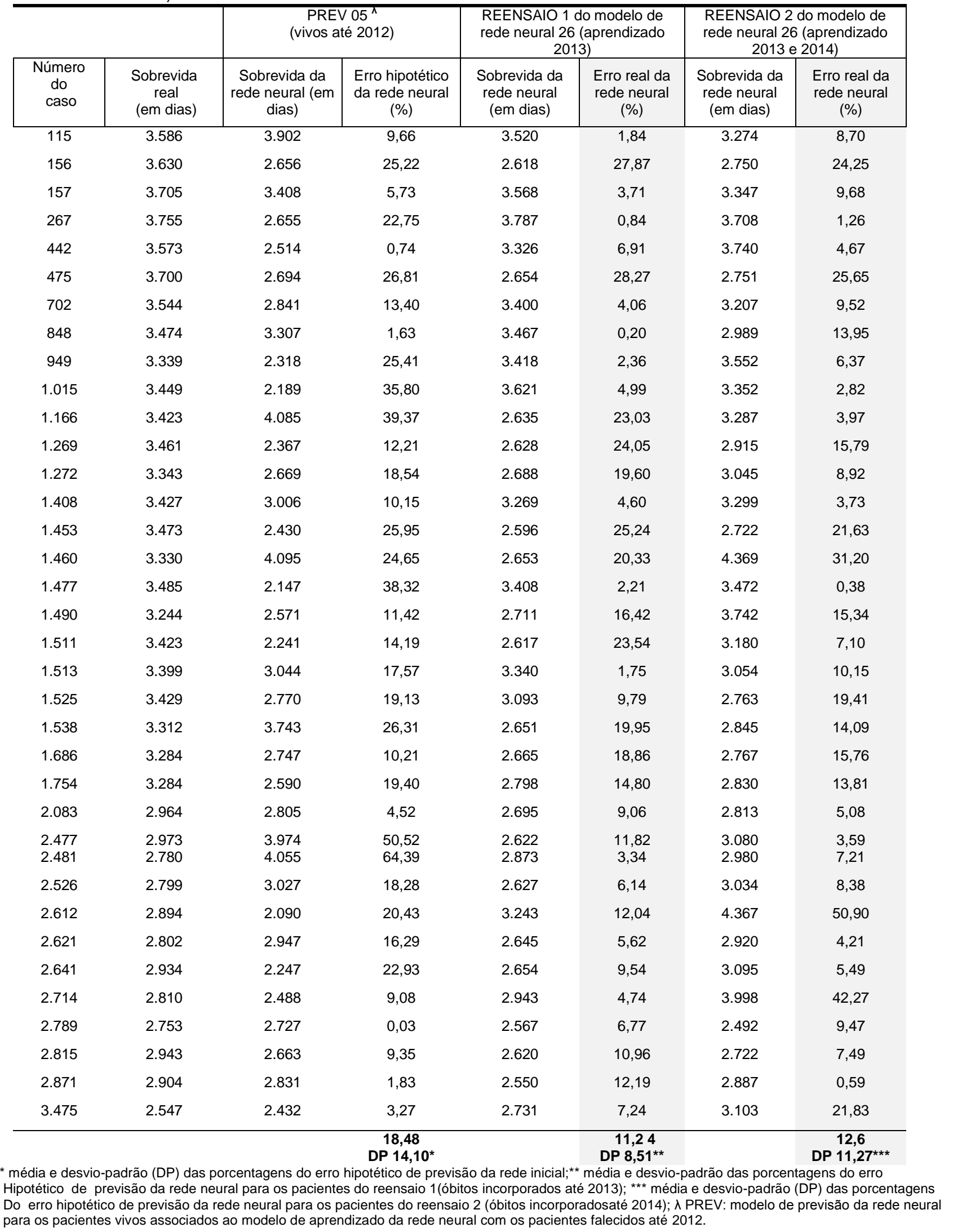


Tabela 24 - Sensibilidade, especificidade, acurácia, valor preditivo positivo e valor preditivo negativo dos melhores modelos de rede neural

\begin{tabular}{|c|c|c|c|c|c|c|c|c|c|c|c|c|c|c|}
\hline \multirow[b]{2}{*}{$\begin{array}{l}\text { Critério para o modelo de rede neural } \\
\text { (RN) }\end{array}$} & \multirow[b]{2}{*}{\begin{tabular}{|l} 
Intervalo \\
de corte \\
(dias)
\end{tabular}} & \multicolumn{5}{|c|}{ Pacientes com óbitos confirmados até 2012 * } & \multicolumn{5}{|c|}{ Pacientes com óbitos não confirmados até 2012 ** } & \multirow[b]{2}{*}{$\begin{array}{l}\text { Acurácia } \\
\text { da rede } \\
\text { neural } \\
\text { ई }\end{array}$} & \multirow[b]{2}{*}{\begin{tabular}{|l|} 
Valor \\
Preditivo \\
Positivo \\
(VPP) $^{\pi}$
\end{tabular}} & \multirow[b]{2}{*}{$\begin{array}{l}\text { Valor } \\
\text { Preditivo } \\
\text { Negativo } \\
\text { (VPN) }^{\varphi}\end{array}$} \\
\hline & & $\begin{array}{l}\text { Modelo } \\
\text { da } \\
\text { rede } \\
\text { neural }\end{array}$ & \begin{tabular}{|l|} 
Total \\
de \\
óbitos
\end{tabular} & \begin{tabular}{|l|} 
Verdadeiro \\
Positivo \\
(VP)
\end{tabular} & \begin{tabular}{|l|} 
Falso \\
Negativo \\
(FN)
\end{tabular} & \begin{tabular}{|l|} 
Sensibilidade \\
da rede \\
neural $^{\zeta}$
\end{tabular} & \begin{tabular}{|l|} 
Modelo \\
de \\
Previsão \\
da RN \\
(Prev) \\
\end{tabular} & \begin{tabular}{|l|} 
Total \\
de \\
pacientes \\
"vivos" \\
$\star \star \star \star$
\end{tabular} & \begin{tabular}{|l} 
Verdadeiro \\
Negativo \\
(VN)
\end{tabular} & \begin{tabular}{|l|} 
Falso \\
Positivo \\
(FP)
\end{tabular} & $\begin{array}{l}\text { Especificidade } \\
\text { da rede neural } \\
\end{array}$ & & & \\
\hline sobrevida de 2 a 6 anos / Log Sig / DO-DPC & 730 (2 anos) & RN13 & 402 & 338 & 64 & $84,1 \%$ & PREV01 & 300 & 226 & 74 & $75,3 \%$ & $80,3 \%$ & $82,0 \%$ & $77,9 \%$ \\
\hline sobrevida de 2 a 6 anos / Log Sig / DO-DPC & 365 (1 ano) & RN13 & 402 & 226 & 176 & $56,2 \%$ & PREV01 & 300 & 139 & 161 & $46,3 \%$ & $52,0 \%$ & $58,4 \%$ & $44,1 \%$ \\
\hline sobrevida de 2 a 6 anos / Log Sig / DO-DIS & 730 (2 anos) & RN20 & 98 & 88 & 10 & $89,8 \%$ & PREV02 & 51 & 39 & 12 & $76,5 \%$ & $85,2 \%$ & $88,0 \%$ & $79,6 \%$ \\
\hline sobrevida de 2 a 6 anos / Log Sig / DO-DIS & 365 & RN20 & 98 & 71 & 27 & $72,4 \%$ & PREV02 & 51 & 23 & 28 & $45,1 \%$ & $63,1 \%$ & $71,7 \%$ & $46,0 \%$ \\
\hline sobrevida de 2 a 6 anos / Tag h / DO-DIS & 730 (2 anos) & RN22 & 98 & 88 & 10 & $89,8 \%$ & PREV03 & 51 & 37 & 14 & $72,5 \%$ & $83,9 \%$ & $86,3 \%$ & $78,7 \%$ \\
\hline sobrevida de 2 a 6 anos / Tag h / DO-DIS & 365 (1 ano) & RN22 & 98 & 75 & 23 & $76,5 \%$ & PREV03 & 51 & 22 & 29 & $43,1 \%$ & $65,1 \%$ & $72,1 \%$ & $48,9 \%$ \\
\hline sobrevida inferior a 2 anos / Tag h / DO-DIS & $\begin{array}{c}180(6 \\
\text { meses) }\end{array}$ & RN27 & 47 & 33 & 14 & $70,2 \%$ & PREV06 & 24 & 9 & 15 & $37,5 \%$ & $59,2 \%$ & $68,8 \%$ & $39,1 \%$ \\
\hline sobrevida inferior a 2 anos / Tag h / DO-DIS & 365 (1 ano) & RN27 & 47 & 41 & 6 & $87,2 \%$ & PREV06 & 24 & 16 & 8 & $66,7 \%$ & $80,3 \%$ & $83,7 \%$ & $72,7 \%$ \\
\hline sobrevida inferior a 2 anos / Log Sig / DO-DIS & $\begin{array}{l}180(6 \\
\text { meses) }\end{array}$ & RN29 & 47 & 33 & 14 & $70,2 \%$ & PREV07 & 24 & 7 & 17 & $29,2 \%$ & $56,3 \%$ & $66,0 \%$ & $33,3 \%$ \\
\hline sobrevida inferior a 2 anos / Log Sig / DO-DIS & 365 (1 ano) & RN29 & 47 & 41 & 6 & $87,2 \%$ & PREV07 & 24 & 15 & 9 & $62,5 \%$ & $78,9 \%$ & $82,0 \%$ & $71,4 \%$ \\
\hline sobrevida superior a 6 anos / Tag h / DO-DPC & 730 (2 anos) & RN24 & 186 & 135 & 51 & $72,6 \%$ & PREV04 & 636 & 355 & 281 & $55,8 \%$ & $59,6 \%$ & $32,5 \%$ & $87,4 \%$ \\
\hline sobrevida superior a 6 anos / Tag h / DO-DPC & $\begin{array}{c}1095(3 \\
\text { anos) }\end{array}$ & RN24 & 186 & 173 & 13 & $93,0 \%$ & PREV04 & 636 & 493 & 143 & $77,5 \%$ & $81,0 \%$ & $54,7 \%$ & $97,4 \%$ \\
\hline sobrevida superior 6 anos / Log Sig / DO-DPC & 730 (2 anos) & RN26 & 186 & 135 & 51 & $72,6 \%$ & PREV05 & 636 & 348 & 288 & $54,7 \%$ & $58,8 \%$ & $31,9 \%$ & $87,2 \%$ \\
\hline sobrevida superior 6 anos / Log Sig / DO-DPC & $\begin{array}{c}1095(3 \\
\text { anos) }\end{array}$ & RN26 & 186 & 173 & 13 & $93,0 \%$ & PREV05 & 636 & 486 & 150 & $76,4 \%$ & $80,2 \%$ & $53,6 \%$ & $97,4 \%$ \\
\hline sobrevida superior 6 anos / Tag h / DO-DIS & 730 (2 anos) & RN28 & 93 & 63 & 30 & $67,7 \%$ & PREV08 & 199 & 60 & 139 & $30,2 \%$ & $42,1 \%$ & $31,2 \%$ & $66,7 \%$ \\
\hline sobrevida superior 6 anos / Log Sig / DO-DIS & 730 (2 anos) & RN30 & 93 & 63 & 30 & $67,7 \%$ & PREV09 & 199 & 51 & 148 & $25,6 \%$ & $39,0 \%$ & $29,9 \%$ & $63,0 \%$ \\
\hline
\end{tabular}


Tabela 25 - Avaliação dos melhores modelos de rede neural com o emprego da função de perda

\begin{tabular}{|c|c|c|c|c|}
\hline Características do modelo de rede neural & $\begin{array}{l}\text { Modelo de } \\
\text { rede neural } \\
(\mathrm{RN})\end{array}$ & $\begin{array}{l}\text { Tamanho da } \\
\text { amostra (TAP) }\end{array}$ & $\begin{array}{l}\text { Erro médio } \\
\text { estimado com a } \\
\text { função de perda } \\
\text { (dias) }\end{array}$ & $\begin{array}{l}\text { Erro médio } \\
\text { estimado com a } \\
\text { função de perda } \\
\text { quadrática } \\
\text { (dias) }\end{array}$ \\
\hline sobrevida de 2 a 6 anos ; Log Sig ${ }^{\S}$ (DO - DPC) & RN13 & 402 & 389,31 & 254536,84 \\
\hline sobrevida de 2 a 6 anos; Log Sig ${ }^{\S}$; (DO - DIS) & RN20 & 98 & 259,06 & 181761,35 \\
\hline sobrevida de 2 a 6 anos; Tag hip ${ }^{\S}$; (DO - DIS) & RN22 & 98 & 231,61 & 180813,08 \\
\hline sobrevida superior a 6 anos; Tag hip ${ }^{\S}$; (DO - DPC) & RN24 & 186 & 332,55 & 272775,89 \\
\hline sobrevida superior a 6 anos ; Log $\operatorname{Sig}^{\S}$; (DO - DPC) & RN26 & 186 & 293,88 & 3340,04 \\
\hline sobrevida inferior a 2 anos; Tag hip ${ }^{\S}$; (DO - DIS) & RN28 & 47 & 133,07 & 55988,47 \\
\hline sobrevida inferior a 2 anos ; Log Sig $\$$; (DO - DIS) & RN30 & 47 & 126,95 & 52233,39 \\
\hline
\end{tabular}

§ função de ativação ou transferência tangente hiperbólica (Tag hip) ou zero based log sigmoid (Log Sig): função matemática aplicada a cada uma das variáveis de entrada da rede neural, com seus respectivos pesos sinápticos ajustáveis pelo algoritmo de aprendizado (backpropagation), cuja somatória resulta na resposta da rede neural;

DO: data do óbito; DPC: data da consulta inicial; DIS: data do início dos sintomas;

$\varphi$ TAP: tamanho da amostra de treinamento ou previsão;

I Função de perda absoluta = somatória (|sobrevida real-sobrevida estimada|) de cada paciente / número de pacientes. 


\section{Referências Bibliográficas}


Aaronson KD, Schwartz JS, Chen TM, Wong KI, Goin JE, Mancini DM. Development and prospective validation of a clinical index to predict survival in ambulatory patients referred for cardiac transplant evaluation. Circulation. 1997 Jun; 95(12):2660-7.

Abdul-Rahim AH, Maclsaac RL, Jhund P, Petrie MC, Lees KR, McMurray JJV, On behalf the VICCTA-Heart Failure Collaborators. Efficacy and safety of digoxin in patients with heart failure and reduced ejection fraction according to diabetes status: An analysis of the Digitalis Investigation Group (DIG) trial. Int J Cardiol. 2016 Feb;209:310-316. doi:10.1016/j.jjcard.2016.02.074.

Abebe TB, Gebreyohannes EA, Bhagavathula AS, Tefera YG, Abegaz TM. Anemia in severe heart failure patients: does it predict prognosis? BMC Cardiovasc Disord. 2017 Sep;17(1):248. doi:10.1186/s12872-017-0680-5.

Abraham WT, Fonarow GC, Albert NM, Stough WG, Gheorghiade M, Greenberg BH, et al. OPTIMIZE-HF Investigators and Coordinators. Predictors of in-hospital mortality in patients hospitalized for heart failure: insights from the Organized Program to Initiate Lifesaving Treatment in Hospitalized Patients with Heart Failure (OPTIMIZEHF). J Am Coll Cardiol. 2008 Jul;52(5):347-56. doi: 0.1016/j.jacc.2008.04.028.

Acanfora D, Gheorghiade M, Trojano L, Furgi G, Pasini E, Picone C, et al. Relative lymphocyte count: a prognostic indicator of mortality in elderly patients with congestive heart failure. Am Heart J. 2001 Jul; 142(1):167-73. PMID:11431674.

Addetia K, Michel C, Holcroft CA, Sheppard R, Rudski LG. Early improvement in serial echocardiographic studies in heart failure patients predicts long term survival-a pilot study. J Card Fail. 2015 Jun;21(6):470-8. doi: 10.1016/ j.cardfail. 2015.04.002.

Afsarmanesh N, Horwich TB, Fonarow GC. Total cholesterol levels and mortality risk in nonischemic systolic heart failure. Am Heart J. 2006 Dec;152(6):1077-83. doi:10. 1016/j.ahj.2006.06.015.

Ahmed FE. Artificial neural networks for diagnosis and survival prediction in colon cancer. Mol Cancer. 2005 Aug;4:29. doi:10.1186/1476-4598-4-29.

Ahmed A, Rich MW, Love TE, Lloyd-Jones DM, Aban IB, Colucci WS, et al. Digoxin and reduction in mortality and hospitalization in heart failure: a comprehensive post hoc analysis of the DIG trial. Eur Heart J. 2006a Jan; 27(2):178-86. doi:10.1093/eurheartj/ehi687.

Ahmed A, Aronow WS, Fleg JL. Predictors of mortality and hospitalization in women with heart failure in the Digitalis Investigation Group trial. Am J Ther. 2006 b Jul-Ago; 13(4): 325-31. PMID:16858168.

Ahmed A, Zannad F, Love TE, Tallaj J, Gheorghiade M, Ekundayo OJ, Pitt B. A propensity-matched study of the association of low serum potassium levels and mortality in chronic heart failure. Eur Heart J. 2007 Jun;28 (11):1334-43. doi:10. 1093/eurheartj/ehm091. 
Alla F, Briançon S, Juillière Y, Mertes PM, Villemot JP, Zannad F. Differential clinical prognostic classifications in dilated and ischemic advanced heart failure: the EPICAL study. Am Heart J. 2000 May;139(5):895-904. doi:10.1016/S0002-8703(00)90023-1.

Albuquerque DC, Neto JD, Bacal F, Rohde LE, Bernardez-Pereira S, Berwanger O, et al. Investigadores Estudo BREATHE. I Brazilian registry of heart failure - Clinical aspects, care quality and hospitalization outcomes. Arq Bras Cardiol. 2015 Jun;104(6):433-42. Erratum in: Correction. [Arq Bras Cardiol. 2015]. doi: 10. 5935 / abc. 20150031 .

Ambrósio PE. Redes neurais artificiais no apoio ao diagnóstico diferencial de lesões intersticiais pulmonares [dissertação]. Ribeirão Preto: Universidade de São Paulo, Faculdade de Filosofia Ciências e Letras; 2002. Disponível em: www.teses.usp.br/teses/disponiveis/59/59135/tde-26102002-155559/Dissertacao.pdf

Anand I, McMurray JJ, Whitmore J, Warren M, Pham A, McCamish MA, et al. Anemia and its relationship to clinical outcome in heart failure. Circulation. 2004 Jul;110(2):149-54. doi:10.1161/01.CIR.0000134279.79571.73.

Anand IS, Kuskowski MA, Rector TS, Florea VG, Glazer RD, Hester A, et al. Anemia and change in hemoglobin over time related to mortality and morbidity in patients with chronic heart failure: results from Val-HeFT. Circulation. 2005 Aug;112(8):11217. doi:10.1161/ CIRCULATIONAHA.104.512988.

Anand IS. Anemia and chronic heart failure implications and treatment options. $\mathrm{J} A m$ Coll Cardiol. 2008 Aug;52(7):501-11. doi:10.1016/j.jacc.2008.04.044.

Anker SD, Ponikowski P, Varney S, Chua TP, Clark AL, Webb-Peploe KM, et al. Wasting as independent risk factor for mortality in chronic heart failure. Lancet.1997 Apr;349(9058):1050-3. doi: 10. 1016/S0140-6736(96)07015-8.

Anker SD, Negassa A, Coats AJ, Afzal R, Poole-Wilson PA, Cohn JN, et al. Prognostic importance of weight loss in chronic heart failure and the effect of treatment with angiotensin - converting - enzyme inhibitors: an observational study. Lancet. 2003 Mar;361(9363):1077-83. doi:10.1016/S0140-6736(03)12892-9.

Assunção F. Estratégias para tratamento de variáveis com dados faltantes durante o desenvolvimento de modelos preditivos [mestrado]. São Paulo: Universidade de São Paulo, Instituto de Matemática e Estatística; 2012. doi:10.11606/D.71.2010.tde21062010-100432. Recuperado em 2017-01-18, de www.teses.usp.br.

Astion ML, Wilding $\mathrm{P}$. The application of backpropagation neural networks to problems in pathology and laboratory medicine. Arch Pathol Lab Med.1992 Oct; 116(10):995-1001. PMID:1417451.

Barker WH, Mullooly JP, Getchell W. Changing incidence and survival for heart failure in a well-defined older population, 1970-1974 and 1990-1994. Circulation. 2006 Fev;113(6):799-805. doi:10.1161/CIRCULATIONAHA.104.492133. 
Bartosch-Härlid A, Andersson B, Aho U, Nilsson J, Andersson R. Artificial neural networks in pancreatic disease. Br J Surg. 2008 Jul;95(7):817-26. doi:10.1002/ bjs. 6239.

Baxt WG. Use of an artificial neural network for the diagnosis of myocardial infarction. Ann Intern Med. 1991 Jan;115(11):843-8. PMID: 1952470. Erratum in: Ann Intern Med 1992;116(1):94. doi:10.7326/0003-4819-115-11-843.

Baxt WG. Application of artificial neural networks to clinical medicine. Lancet. 1995 Oct; 346(8983):1135-8. PMID: 7475607.

Baxt WG, Skora J. Prospective validation of artificial neural network trained to identify acute myocardial infarction. Lancet. 1996 Jan;347(8993):12-5. PMID: 8531540.

Bestetti RB, Dalbo CM, Freitas OC, Teno LA, Castilho OT, Oliveira JS. Noninvasive predictors of mortality for patients with Chagas' heart disease: a multivariate stepwise logistic regression study. Cardiology. 1994 Nov;84(4-5):261-7. doi:10.1159/0001 76409.

Bestetti RB, Muccillo G. Clinical course of Chagas'heart disease: a comparison with dilated cardiomyopathy. Int J Cardiol. 1997 Jul;60(2):187-93. PIMD: 9226290.

Bestetti RB, Otaviano AP, Cardinalli-Neto, Rocha BF, Theodoropoulos TA, Cordeiro JA. Effects of B-Blockers on outcome of patients with Chagas' cardiomyopathy with chronic heart failure. Int J Cardiol. 2011 Sep;115:205-208. doi:10.1016/j.ijcard. 2010.05.033.

Bestetti RB, Daniel RAF. The treatment of chronic heart failure secondary to Chagas cardiomyopathy in the contemporary era. International Cardiovascular Forum Journal. 2016;vol:7:19-25. doi:10.17987/icfj.v7i0.217.

Bielecka-Dabrowa A, Mikhailidis DP, Jones L, Rysz J, Aronow WS, Banach M. The meaning of hypokalemia in heart failure. Int J Cardiol. 2012 Jun;158(1): 12-7. doi: 10. 1016/j.ijcard.2011.06.121.

Bocchi EA, Cruz F, Guimarães G, Pinho Moreira LF, Issa VS, Ayub-Ferreira SM, et al. Long-term prospective, randomized, controlled study using repetitive education at six-month intervals and monitoring for adherence in heart failure outpatients: the REMADHE trial. Circ Heart Fail. 2008 Jul;1(2):115-124. doi: 10.1161/CIRCHEARTFAILURE.107.744870.

Bocchi EA, Marcondes-Braga FG, Ayub-Ferreira SM, Rohde LE, Oliveira WA, Almeida DR, et al. Sociedade Brasileira de Cardiologia. III Diretriz Brasileira de Insuficiência Cardíaca Crônica. Arq Bras Cardiol. 2009;93 (1supl.1):1-71. doi:10.1590/S0066-782X2009002000001. 
Bocchi EA, Marcondes-Braga FG, Bacal F, Ferraz AS, Albuquerque D, Rodrigues D, et al. Sociedade Brasileira de Cardiologia. Atualização da Diretriz Brasileira de Insuficiência Cardíaca Crônica-2012. Arq Bras Cardiol. 2012 Jan; 98(1 supl. 1):133.

Bocchi EA, Arias A, Verdejo H, Diez M, Gómez E, Castro P. Interamerican Society of Cardiology. The reality of heart failure in Latin America. J Am Coll Cardiol. 2013 Sep;62(11):949-58. doi:10.1016/j.jacc.2013.06.013.

Bocchi EA, Bestetti RB, Scanavacca MI, Neto EC, Issa VS. Chronic Chagas heart disease management. From etiology to cardiomyopathy treatment. J Am Coll Cardiol. 2017 Sep;70(12):1510-24. doi:10.1016/j.jacc.2017.08.004.

Böhm M, Swedberg K, Komajda M, Borer JS, Ford I, Dubost-Brama A, et al. SHIFT Investigators. Heart rate as a risk factor in chronic heart failure (SHIFT): the association between heart rate and outcomes in a randomised placebo -controlled trial. Lancet. 2010 Sep;376(9744): 886-94. doi:10.1016/S0140-6736(10) 61259-7.

Braunwald E. Biomarkers in heart failure. N Engl J Med. 2008 May; 358(20): 214859. doi:10.1056/NEJMra0800239.

Burnett H, Earley A, Voors AA, Senni M, McMurray JJ, Deschaseaux C, et al. Thirty years of evidence on the efficacy of drug treatments for chronic heart failure with reduced ejection fraction: a network meta-analysis. Circ Heart Fail. 2017 Jan;10 (1).pii: e003529. doi: 10.1161/CIRCHEARTFAILURE.116.003529.

Buskard T, Stevenson M, Frize M, Solven F. Estimation of ventilation, length of stay, and mortality using artificial neural networks. Conf Proc Electrical and Computer Engineering. 1994, Canada, September 25-28, 1994. IEEEXplore. 2002; doi: 10.1109/CCECE.1994.405854.

Bustamante-Teixeira MT, Faerstein E, Latorre MR. Técnica de análise de sobrevida. Cad. Saúde Pública. 2002 May-Jun, Rio de Janeiro,18(3):579-594. doi:10.1590/S 0102-311X2002000300008.

Carlo $\mathrm{CH}$, Cardoso JN, Ochia ME, Oliveira Junior MT, Ramires JA, Pereira-Barretto AC. Temporal variation in the prognosis and treatment of advanced heart failure before and after 2000. Arq Bras Cardiol. 2014 May;102(5):495-504. PMID: 24759950.

Castro LN. Análise e síntese de estratégias de aprendizado para redes neurais artificiais [dissertação]. Campinas: Universidade Estadual de Campinas, Faculdade de Engenharia Elétrica e de Computação; 1998. Disponível em: $\mathrm{ftp}: / / \mathrm{ftp} . d c a . f e e . u n i c a m p . b r / p u b / d o c s / v o n z u b e n / t h e s e s /$ Inunes_mest/indice.pdf 
Castro FCC, de Castro MC. Redes Neurais Artificiais. Pontifícia Universidade Católica do Rio Grande do Sul. Capítulo 2, Processos de aprendizado [citado 10 Nov 2016]; p.1-23. Disponível em: www.politecnica. pucrs.br/ decastro/ pdf / RNA_C2.pdf

Charach G, Grosskopf I, Roth A, Afek A, Wexler D, Sheps D, et al. Usefulness of total lymphocyte count as predictor of outcome in patients with chronic heart failure. Am J Cardiol. 2011 May; 107 (9): 1353-6. doi:10.1016/j.amjcard.2010.12.049.

Chizzola PR, Mansur AJ, da Luz PL, Bellotti G. Compliance with pharmacological treatment in outpatients from a Brazilian cardiology referral center. Sao Paulo Med J. 1996 Sep-Oct;114(5):1259-64. doi:10.1590/S1516-31801996000500004.

Christ M, Klima T, Grimm W, Mueller HH, Maisch B. Prognostic significance of serum cholesterol levels in patients with idiopathic dilated cardiomyopathy. Eur Heart J. 2006 Mar;27(6):691-9. doi:10.1093/eurheartj/ehi195.

Cintron G, Jonhson G, Francis G, Cobb F, Cohn JN. Prognostic significance of serial changes in left ventricular ejection fraction in patients with congestive heart failure. The V-HeFT VA Cooperative Studies Group. Circulation. 1993 Jun;87(6Suppl):VI1723. PMID: 8500235.

Cohn JN, Archibald DG, Ziesche S, Franciosa JA, Harston WE, Tristani FE et al. Effect of vasodilator therapy on mortality in chronic congestive heart failure. Results of a Veterans Administration Cooperative Study. N Engl J Med. 1986 Jun;314 (24): 1547-52. doi:10.1056/NEJM198606123142404.

Cohn JN, Archibald DG, Francis GS, Ziesche S, Franciosa JA, Harston WE. et al Veterans Administration Cooperative Study on Vasodilator Therapy of Heart Failure: Influence of prerandomization variables on the reduction of mortality by treatment with hydralazine and isosorbide dinitrate. Circulation. 1987 May;75(5 Pt 2):IV49-54. PMID: 3552302.

Cohn JN, Rector TS. Prognosis of congestive heart failure and predictors of mortality. Am J Cardiol. 1988 Jul;62(2):25A-30A. doi: 10.1016/ S0002-9149(88) 80081-X.

Cox DR. Regression Models and Life-Tables. J R Stat Soc Series B Stat Methodol. Vol. 34, No. 2. (1972), p.187-220.

Cowie MR, Wood DA, Coats AJ, Thompson SG, Suresh V, Poole-Wilson PA, et al. Survival of patients with a new diagnosis of heart failure: a population based study. Heart. 2000 May;83(5):505-10. doi:10.1136/heart. 83.5.505.

Cross SS, Harrison RF, Kennedy RL. Introduction to neural networks. Lancet. 1995 Oct;346(8982):1075-9. PMID:7564791. 
Das A, Ben-Menachem T, Farooq FT, Cooper GS, Chak A, Sivak MV Jr, et al. Artificial neural network as a predictive instrument in patients with acute nonvariceal upper gastrointestinal hemorrhage. Gastroenterology. 2008 Jan;134 (1):65-74. doi:10.1053/j.gastro.2007.10.037.

Damman K, Valente MA, Voors AA, O'Connor CM, van Veldhuisen DJ, Hillege HL. Renal impairment, worsening renal function, and outcome in patients with heart failure: an updated meta-analysis. Eur Heart J. 2014 Fev;35(7):455-69. doi: 10.1093/ eurheartj/eht386.

Davos CH, Doehner W, Rauchhaus M, Cicoira M, Francis DP, Coats AJ, et al. Body mass and survival in patients with chronic heart failure without cachexia: The importance of obesity. J Cardiac Fail. 2003 Fev;9(1):29-35. doi:10. 1054/ jcaf.2003.4.

Diaz A, Bourassa MG, Guertin MC, Tardif JC. Long-term prognostic value of resting heart rate in patients with suspected or proven coronary artery disease. Eur Heart J. 2005 Mar;26(10):967-74. doi:10.1093/eurheartj/ehi190.

Doehner W. Critical appraisal of the obesity paradox in cardiovascular disease: how to manage patients with overweight in heart failure? Heart Fail Rev. 2014 Sep; 19(5):637-44. doi:10.1007/s10741-014-9425-z.

Dries DL, Exner DV, Domanski MJ, Greenberg B, Stevenson LW. The prognostic implications of renal insufficiency in asymptomatic and symptomatic patients with left ventricular systolic dysfunction. J Am Coll Cardiol. 2000 Mar;35(3):681-9. doi:10. 1016/S0735-1097(99)00608-7.

Ennett CM, Frize M, Walker CR. Influence of missing values on artificial neural network performance. Stud Health Technol Inform. 2001;84(Pt 1):449-53. doi: 10. 3233/978-1-60750-928-8-449.

Ennett CM, Frize M, Charette E. Improvement and automation of artificial neural networks to estimate medical outcomes. Med Eng Phys. 2004 May;26(4):321-328. doi:10.1016/j.medengphy.2003.09.005.

Ennett CM, Frize M, Wlaker R. Imputation of missing values by integrating neural networks and case-based reasoning. Conf Proc IEEE Eng Med Biol Soc. 2008;2008:4337-41. Proferida na 30th Annual International IEEE EMBS Conference Vancouver, British Columbia, Canada, August 20-24, 2008. doi:10.1109/ IEMBS. 2008.4650170.

Espinosa R, Carrasco HA, Belandria F, Fuenmayor AM, Molina C, González R, et al. Life expectancy analysis in patients with Chagas' disease: prognosis after one decade (1973-1983). Int J Cardiol. 1985 May;8(1):45-56. PMID: 3997291.

Ezekowitz JA, McAlister FA, Armstrong PW. Anaemia is common in heart failiure and is associated with poor outcomes: insights from a cohort of 12065 patients with newonset heart failure. Circulation. 2003 Jan;107(2):223-225. doi:10.1161/ 01. CIR00 00 0526 22.51963.FC. 
Fogel DB, Wasson EC 3rd, Boughton EM. Evolving neural networks for detecting breast câncer. Cancer Lett. 1995 Sep;96(1):49-53. PMID: 7553607.

Fonarow GC, Adams KF Jr, Abraham WT, Yancy CW, Boscardin WJ; ADHERE Scientific Advisory Committee, Study Group, and Investigators. Risk stratification for in-hospital mortality in acutely decompensated heart failure: classification and regression tree analysis. JAMA. 2005 Feb;293(5):572-80. doi: 10.1001/ jama. 293.5.572.

Fonarow GC, Srikanthan P, Costanzo MR, Cintron GB, Lopatin M; ADHERE Scientific Advisory Committee and Investigators. An obesity paradox in acute heart failure: analysis of body mass index and inhospital mortality for 108,927 patients in the Acute Decompensated Heart Failure National Registry. Am Heart J. 2007a Jan;153(1):74-81. doi:10.1016/j.ahj.2006.09.007.

Fonarow GC, Heywood JT, Heidenreich PA, Lopatin M, Yancy CW; ADHERE Scientific Advisory Committee and Investigators. Temporal trends in clinical characteristics, treatments, and outcomes for heart failure hospitalizations, 2002 to 2004: findings from Acute Decompensated Heart Failure National Registry (ADHERE). Am Heart J. 2007b Jun;153(6):1021-8. doi:10.1016/j.ahj.2007.03.012.

Franke J, Zugck C, Hochadel M, Hack A, Frankenstein L, Zhao JD, et al. Etiologyspecific assessment of predictors of long-term survival in chronic systolic heart failure. Int J Cardiol Heart Vasc. 2015 Feb;7:61-68. doi:10.1016/j.ijcha. 2015. 01.015.e Collection 2015 Jun 1.

Freitas HFG. Prognóstico em portadores de insuficiência cardíaca encaminhados para avaliação de tratamento cirúrgico [tese]. São Paulo: Universidade de São Paulo, Faculdade de Medicina; 2002. doi:10.11606 / T.5.2002.tde-19082014-100741. Disponível em: http:// www.teses.usp.br.

Freitas HFG, Chizzola PR, Paes AT, Lima AC, Mansur AJ. Risk stratification in a Brazilian hospital - based cohort of 1220 outpatients with heart failure: role of Chagas'heart disease. Int J Cardiol. 2005 Jul;102(2):239-47. doi:10.1016/j.ijcard. 2004. 05.025.

Freitas HFG, Barbosa EA, Rosa FHFP, Lima ACP, Mansur AJ. Association of HDL cholesterol and triglycerides with mortality in patients with heart failure. Braz J Med Biol Res. 2009 May;42(5)420-425. doi:10.1590/S0100-879X2009000500004.

Frize M, Ennett CM, Charette E. Automated optimization of neural networks in estimating medical outcomes. Proc $3^{\text {rd }}$ IEEE ITAB-ITIS Conference Information Technology Applications in Biomedicine and International Telemedical Information Society. 2000:168-73.

Frize M, Ennett CM, Stevenson M, Trigg HC. Clinical decision support systems for intensive care units: using artificial neural networks. Med Eng Phys. 2001; 23:217-25. doi.org/10.1016/S1350-4533(01)00041-8. 
Gerber Y, Weston SA, Redfield MM, Chamberlain AM, Manemann SM, Jiang R, et al. A contemporary appraisal of the heart failure epidemic in Olmsted County, Minnesota, 2000 to 2010. JAMA Intern Med. 2015 Jun; 175(6):996-1004. doi:10.1001/jamainternmed.2015.0924.

Gheorghiade M, Filippatos $G$. Reassessing treatment of acute heart failure syndromes: the ADHERE Registry. Eur Heart J Suppl. 2005 Apr;7(suppl B):B13-B19. doi:10.1093/eurheartj/sui008.

Gheorghiade M, Patel K, Filippatos G, Anker SD, van Veldhuisen DJ, Cleland JG, et al. Effect of oral digoxin in high-risk heart failure patients: a pre-specified subgroup analysis of the DIG trial. Eur $J$ Heart Fail. 2013 May;15(5):551-9. doi:10.1093/eurjhf/hft010.

Godoy HL, Silveira JA, Segalla E, Almeida DR. Hospitalization and Mortality rates for heart failure in public hosptitals in São Paulo. Arq Bras Cariol. 2011 Nov;97(5):402-7. doi:10.1590/S0066-782X2011005000096.

Go AS, Yang J, Ackerson LM, Lepper K, Robbins S, Massie BM, et al. Hemoglobin level, chronic kidney disease, and the risks of death and hospitalization in adults with chronic heart failure: the Anaemia in Chronic Heart Failure: Outcomes and Resource Utilization (ANCHOR) Study. Circulation. 2006 Jun;113(23):2713-3. doi:10.1161/CIRCULATIONAHA.105.577577.

Gradman A, Deedwania P, Cody R, Massie B, Packer M, Pitt B,et al. Predictors of total mortality and sudden death in mild to moderate heart failure. Captopril-Digoxin Study Group. J Am Coll Cardiol. 1989 Sep;14:564-570. PMID: 2768707.

Grossi E. How artificial intelligence tools can be used to assess individual patient risk in cardiovascular disease: problems with the current methods. BMC Cardiovasc Disord. 2006 May;6:20. doi:10.1186/1471-2261-6-20.

Guidi G, Pettenati MC, Melillo P, ladanza E. A machine learning system to improve heart failure patient assistance. IEEE $J$ Bioimed Health Inform. 2014 Nov;18(6):1750-6. doi:10.1109/JBHI.2014.2337752.

Guimarães AM, Mathias IM, Dias AH, Ferrari JW, Cazelatto Junior CDO. Modulo de validação cruzada para treinamento de redes neurais artificiais com algoritmos back propagation e resilient propagation. Publ. UEPG Exact Earth Sci., Agr. Sci. Eng., Ponta Grossa. 14 (1): 17-24, abr. 2008. doi: 10.5212/ Publ. Exatas.v. 14i1. 017024. Disponível em: http://dx.doi.org/10.5212/Publ. Exatas.v.14i1.017024.

Haykin S. Neural Networks : A Comprehensive Foundation. Chapter Multilayer preceptrons p.178. New Jersey: Prentice-Hall, Inc; 1999.[cited 2009 ]. Available from: http://cdn.preterhuman.net/.../neuralnetworks. 
Hecht-Nielsen R. Theory of the backpropagation neural network. Proceedings of the international joint conference on neural networks 1, p.593-611, June 1989. doi:10.1016/B978-0-12-741252-8.500108.

Hjalmarson A, Goldstein S, Fagerberg B, Wedel H, Waagstein F, Kjekshus J,et al. Effects of controlled -release metoprolol on total mortality, hospitalizations, and wellbeing in patients with heart failure: the Metoprolol $\mathrm{CR} / \mathrm{XL}$ Randomized Intervention Trial in congestive heart failure (MERIT-HF). MERIT-HF Study Group. JAMA. 2000 Mar; 283 (10): 1295-302. doi: 10.1001/jama.283.10.1295.

Horwich TB, Fonarow GC, Hamilton MA, MacLellan WR, Woo MA, Tillisch JH. The relationship between obesity and mortality in patients with heart failure. J Am Coll Cardiol. 2001 Sep;38(3):789-95. PMID: 11527635.

Horwich TB, Hamilton MA, Maclellan WR, Fonarow GC. Low serum total cholesterol is associated with marked increase in mortality in advanced heart failure. J Card Fail. 2002 Aug;8(4):216-24. PMID: 12397569.

Horwich TB, Hernandez AF, Dai D, Yancy CW, Fonarow GC. Cholesterol levels and in-hospital mortality in patients with acute decompensated heart failure. Am Heart $\mathrm{J}$. 2008 Dec;156(6):1170-6. doi:10.1016/j.ahj.2008.07.004.

Huehnergarth KV, Mozaffarian D, Sullivan MD, Crane BA, Wilkinson CW, Lawler RL, et al. Usefulness of relative lymphocyte count as an independent predictor of death/urgent transplant in heart failure. Am J Cardiol. 2005 Jun;95(12):1492-5. doi:10.1016/j.amjcard.2005.02.022.

Hunt SA, Baker DW, Chin MH, Cinquegrani MP, Feldman AM, Francis GS, et al. ACC/AHA guidelines for the evaluation and management of chronic heart failure in the adult: executive summary: a report of the American College of Cardiology/American Heart Association Task Force on Practice Guidelines (Committee to Revise the 1995 Guidelines for the Evaluation and Management of Heart Failure). J Am Coll Cardiol. 2001 Dec;38(7):2101-13. doi:10.1016/S07351097(01)01683-7.

Hunt SA; American College of Cardiology; American Heart Association Task Force on Practice Guidelines (Writing Committee to Update the 2001 Guidelines for the Evaluation and Management of Heart Failure). ACC/AHA 2005 guideline update for the diagnosis and management of chronic heart failure in the adult: a report of the American College of Cardiology/ American Heart Association Task Force on Practice Guidelines (Writing Committee to Update the 2001 Guidelines for the Evaluation and Management of Heart Failure). J Am Coll Cardiol. 2005 Sep;46(6):e1-82. Erratum in J Am Coll Cardiol. 2006 Apr;47(7):1503-1505. doi:10.1016/j.jacc.2005.08.022.

Hsiao SH, Chiou KR. Left atrial expansion index predicts all-cause mortality and heart failure admissions in dyspnoea. Eur J Heart Fail. 2013 Nov;15(11):1245-52. doi:10.1093/eurjhf/hft087. 
Issa VS, Amaral AF, Cruz FD, Ferreira SM, Guimarães GV, Chizzola PR, et al. Bblocker therapy and mortality of patients with Chagas cardiomyopathy: a sub analysis of the REMADHE prospective trial. Circ Heart Fail. 2010 Jan;3(1):82-88. doi:10.1161/CIRCHEARTFAILURE.109.882035.

James PA, Oparil S, Carter BL, Cushman WC, Dennison-Himmelfarb C, Handler J, et al. 2014 Evidence-based guideline for the management of high blood pressure in adults report from the Panel Members appointed to the eighth joint national committee (JNC 8). JAMA $2014 \quad$ Feb; 311(5):507-520. doi:10.1001/jama.2013.284427.

Kaambwa B, Bryan S, Billingham L. Do the methods used to analyse missing data really matter? An examination of data from an observational study of Intermediate Care patients. BMC Res Notes. 2012 Jun;5:330. doi.10.1186/1756-0500-5-330.

Kajimoto K, Minami Y, Sato N, Takano T. Investigators of the Acute Decompensated Heart Failure Syndromes (ATTEND) registry. Serum sodium concentration, blood urea nitrogen, and outcomes in patients hospitalized for acute decompensated heart failure. Int J Cardiol. 2016 Nov;222:195-201. doi: 10. 1016/j.ijcard.2016.07.255.

Kalantar-Zadeh K, Block G, Horwich T, Fonarow GC. Reverse epidemiology of conventional cardiovascular risk factors in patients with chronic heart failure. $J \mathrm{Am}$ Coll Cardiol. 2004 Apr;43(8):1439-44. doi:10.1016/j.jacc.2003.11.039.

Kang J, Park JJ, Cho YJ, Oh IY, Park HA, Lee SE, et al. Predictors and prognosis value of worsening renal function during admission in HFpEF versus HFrEF: data from the KorAHF. J Am Heart Assoc. 2018 Mar;7(6).pii:e007910. doi:10.1161/JAHA.117.007910.

Kannel WB. Epidemiology and prevention of cardiac failure: Framingham Study insights. Eur Heart J. 1987 Sep;8 Suppl F:23-6. PMID: 3665963. doi:10.1093/ eurheartj/ 8. suppl_F.23.

Kaplan EL, Meier P. Nonparametric estimation from incomplete observations. $J A m$ Stat Assoc. 1958 Jun;53(282):457-481. doi: 10. 2307/2281868.

Kaufman R, Azevedo VMP, Xavier RMA, Geller M, Chaves RBM, Castier MB. Evolution of heart failure-related hospital admissions and mortality rates: a 12-year analysis. Int J Cardiovasc Sci. 2015 Sep;28(4):276-28. doi: 10.5935/23594802.20150040.

Kenchaiah S, Evans JC, Levy D, Wilson PW, Benjamin EJ, Larson MG, et al. Obesity and the risk of heart failure. N Engl J Med. 2002 Aug; 347 (5):305-13. doi:10.1056/NEJMoa020245.

Kenchaiah S, Vasan RS. Heart Failure in Women--Insights from the Framingham Heart Study. Cardiovasc Drugs Ther. 2015 Aug;29(4):377-90. doi: 10.1007/s10557015-6599-0. 
Keogh AM, Baron DW, HickieJB. Prognostic guides in patients with idiopathic or ischemic dilated cardiomyopathy assessed for cardiac transplantation. $A m J$ Cardiol.1990 Apr;65(13):903-8. PMID:2138849.

Khan MG. Cardiac drug therapy. $8^{\text {th }}$ ed., Humana Press; 2015. p.31.[cited 2015]. Available from: http://rudiapt.files.wordpress.com/2017/11/cardiac-drug-therapy-8thed-2015-pdf.

Kjekshus J, Apetrei E, Barrios V, Böhm M, Cleland JGF, Cornel JH, et al. CORONA Group. Rosuvastatin in older patients with systolic heart failure. N Engl J Med. 2007 Nov; 357(22):2248-61. doi:10.1056/NEJMoa0706201.

Klein L, O'Connor CM, Leimberger JD, Gattis-Stough W, Piña IL, Felker GM, et al. OPTIME-CHF Investigators. Lower serum sodium is associated with increased shortterm mortality in hospitalized patients with worsening heart failure: results from the Outcomes of a Prospective Trial of Intravenous Milrinone for Exacerbations of Chronic Heart Failure (OPTIME-CHF) study. Circulation. 2005 May;111(19):2454-60. doi:10.1161/ 01.CIR. 0000165065. 82609. 3D.

Krittanawong $\mathrm{C}$, Zhang $\mathrm{H}$, Wang Z, Aydar M, Kitai T. Artificial intelligence in precision cardiovascular medicine. J Am Coll Cardiol. 2017 May;69(21):2657-2664. doi:10.1016/j.jacc.2017.03.571.

Krumholz HM, Seeman TE, Merrill SS, Mendes de Leon CF, Vaccarino V, Silverman $\mathrm{DI}$, et al. Lack of association between cholesterol and coronary heart disease mortality and morbidity and all-cause mortality in persons older than 70 years. JAMA. 1994 Nov;272(17):1335-40. doi: 10.1001/jama. 1994. 03520170045034.

Kyriakou M, Kiff PF. Prognosis of the comorbid heart failure and anaemia: a systematic review. Clin Trials Regul Sci Cardiol. 2016 Jul; 16:12 -21. doi:10.1016/j.ctrsc.2016.01.008.

Lang RM, Bierig M, Devereux RB, Flachskampf FA, Foster E, Pellikka PA, et al. Recommendations for chamber quantification: a report from the American Society of Echocardiography's guidelines and standards committee and the chamber quantification writing group, developed in conjunction with the European Association of Echocardiography, a branch of the European Society of Cardiology. J Am Soc Echocardiogr. 2005 Dec;18:1440-1463. doi:10.1016/j.ctrsc. 2016.01.008.

Lee DS, Austin PC, Rouleau JL, Liu PP, Naimark D, Tu JV. Predicting mortality among patients hospitalized for heart failure: derivation and validation of a clinical model. JAMA. 2003 Nov;290(19):2581-7.doi:10.1001/jama.290.19.2581.

Lee $\mathrm{WH}$, Packer M. Prognostic importance of serum sodium concentration and its modification by converting-enzyme inhibition in patients with severe chronic heart failure. Circulation. 1986 Fev;73(2):257-67. PMID:3002660. 
Levy WC, Mozaffarian D, Linker DT, Sutradhar SC, Anker SD, Cropp AB, et al. The Seattle Heart Failure Model: prediction of survival in heart failure. Circulation. 2006 Mar;113(11):1424-33. doi: 10.1161/ CIRCULATIONAHA. 105.584102.

Lewis EF, Moye LA, Rouleau JL, Sacks FM, Arnold JM, Warnica JW, et al. CARE Study. Predictors of late development of heart failure in stable survivors of myocardial infarction: the CARE study. J Am Coll Cardiol. 2003 Oct;42(8):1446-53. PMID: 14563590.

Likoff MJ, Chandler SL, Kay HR. Clinical determinants of mortality in chronic congestive heart failure secondary to idiopathic dilated or to ischemic cardiomyopathy. Am J Cardiol. 1987 Mar;59(6):634-8. PMID: 3825904.

Lisboa PJ. A review of evidence of health benefit from artificial neural networks in medical intervention. Neural Netw. 2002 Jan;15(1):11-39. PMID:11958484.

Lisboa PJ, Taktak AFG. The use of an artificial neural network in decision support in cancer: a systematic review. Neural Netw. 2006 May;19(4):408-15. doi:10.1016/j. neunet.2005.10.007.

Little RJ, D'Agostino R, Cohen M, Dickersin K, Emerson SS, Farrar JT, et al. The prevention and treatment of missing data in clinical trials. N Engl J Med. $2012 \mathrm{Oct}$; 367(14): 1355-1360. doi:10.1056/NEJMsr1203730.

Lundin M, Lundin J, Burke HB, Toikkanen S, Pylkkänen L, Joensuu H. Artificial neural networks applied to survival prediction in breast cancer. Oncology. 1999 Nov;57(4):281-6. doi:10.1159/000012061.

Macintyre K, Capewell S, Stewart S, Chalmers JW, Boyd J, Finlayson A, et al. Evidence of improving prognosis in heart failure: trends in case fatality in 66547 patients hospitalized between 1986 and 1995. Circulation. 2000 Sep;102(10):112631. PMID: 10973841.

Mahmood SS, Levy D, Vasan RS, Wang TJ. The Framingham Heart Study and the epidemiology of cardiovascular diseases: a historical perspective. Lancet. 2014 Mar; 383(9921):999-1008. doi: 10.1016/S0140-6736(13)61752-3.

McKee PA, Castelli WP, McNamara PM, Kanel WB. The natural history of congestive heart failure: the Framingham study. N Engl J Med. 1971 Dec; 285 (26): 1441-1446. doi:10.1056/NEJM197112232852601.

McManus DD, Shah SJ, Fabi MR, Rosen A, Whooley MA, Schiller NB. Prognostic value of left ventricular end-systolic volume index as a predictor of heart failure hospitalization in stable coronary artery disease: data from the Heart and Soul Study. J Am Soc Echocardiogr. 2009 Fev;22(2):190-7. doi: 10.1016/j.echo.2008.11.005. 
McMurray JJ, Packer M, Desai AS, Gong J, Lefkowitz MP, Rizkala AR, et al. PARADIGM-HF Investigators and Committees. Angiotensin-neprilysin inhibition versus enalapril in heart failure. $N$ Engl $J$ Med. 2014 Sep ;371(11):993-1004. doi: 10.1056/NEJMoa 1409077.

Mady C, Cardoso RH, Barretto AC, da Luz PL, Bellotti G, Pileggi F. Survival and predictors of survival in patients with congestive heart failure due to Chagas' cardiomyopathy. Circulation. 1994. Dec;90(6):3098-3102. doi: 10.1161/01.CIR.90.6.3098.

Maraldi C, Volpato S, Cesari M, Onder G, Pedone C, Woodman RC, et al. Investigators of the Gruppo Italiano di Farmacoepidemiologia nell'Anziano Study. Anemia, physical disability, and survival in older patients with heart failure. $J$ Card Fail. 2006 Sep;12(7):533-9. doi:10.1016/ j.cardfail. 2006. 05.002.

Marçula M, Cuoco MAR, Yamada ATY, De Paula RS, Uemura,RT, Barretto ACP, Mansur AJ. Comparison of prognostic variables between two cohorts of outpatients with heart failure in the last two decades. Paris European Heart Jo0urnal (Abstract Supplement) (2011);32:459.

Marçula M, de Souza Buto MF, Madaloso BA, Nunes RA, Cuoco MA, de Paula RS, et al. Lymphocyte count and prognosis in patients with heart failure. Int $J$ Cardiol. 2015 Jun;188:60-2. doi: 10. 1016/ j. ijcard. 2015.04.043.

Maron BJ, Towbin JA, Thiene G, Antzelevitch C, Corrado D, Arnett D, et al. American Heart Association; Council on Clinical Cardiology, Heart Failure and Transplantation Committee; Quality of Care and Outcomes Research and Functional Genomics and Translational Biology Interdisciplinary Working Groups; Council on Epidemiology and Prevention. Circulation. 2006 Apr; 113(14):1807-16. doi: 10.1161/ CIRCULATIONAHA. 106.17428.

Merlo M, Pyxaras SA, Pinamonti B, Barbati G, Di Lenarda A, Sinagra G. Prevalence and prognostic significance of left ventricular reverse remodeling in dilated cardiomyopathy receiving tailored medical treatment. $J A m$ Coll Cardiol. 2011Mar;57(13):1468-76. doi:10.1016/j.jacc.2010.11.030.

Miller DD, Brown EW. Artificial intelligence in medical practice: The question to the answer? Am J Med. 2018 Fev;131(2):129-133. doi: 10.1016/j.amjmed.2017.10. 035

Milo-Cotter O, Cotter G, Weatherley BD, Adams KF, Kaluski E, Uriel N, et al. Hyponatraemia in acute heart failure is a marker of increased mortality but not when associated with hyperglycaemia. Eur J Heart Fail. 2008 Jan;10(2):196-200. doi:10.1016/j.ejheart.2008.01.008.

Moutinho MA, Colucci FA, Alcoforado V, Tavares LR, Rachid MB, Rosa ML, et al. Heart failure with preserved ejection fraction and systolic dysfunction in the community. Arq Bras Cardiol. 2008 Fev;90 (2):132-7. doi:10.1590/S0066782X2008000200011. 
Myers J, de Souza CR, Borghi-Silva A, Guazzi M, Chase P, Bensimhon D,et al. A neural network approach to predicting outcomes in heart failure using cardiopulmonary exercise testing. Int $J$ Cardiol. 2014 Feb;171(2):265-9. doi: 10.1016/j.ijcard. 2013. 12.031.

Nadruz W Jr, Gioli-Pereira L, Bernardez-Pereira S, Marcondes-Braga FG, Fernandes-Silva MM, Silvestre OM, et al. Temporal trends in the contribution of Chagas cardiomyopathy to mortality among patients with heart failure. Heart. 2018 Sep;104(18):1522-1528. doi: 10.1136/heartjnl-2017-312869.

Neuro XL. Predictor OLSOFT Software Development. Available from: http:// www.NeuroXL.com; adquirido em 2011-3-14.

New York Heart Association. Criteria Committee, New York Heart Association, Inc. Diseases of the Heart and Blood Vessels. Nomenclature and Criteria for diagnosis, 6th ed. Boston: Little, Brown and Co. 1964, p.114. [cited 1964]. Available from: http://www.heart.org/en/health-topics/heart-failure/what-is-heart-failure/classes-ofheart-failure

Nieminen MS, Harjola VP, Hochadel M, Drexler H, Komajda M, Brutsaert D, et al. Gender related diferences in patients presenting with acute heart failure. Results from Euro Heart Failure Survey II. Eur J Heart Fail. 2008 Feb;10(2):140-8. doi:10. 1016/j.ejheart. 2007.12.012.

Nunes LN, Klück MM, Fachel JMG. Uso da imputação múltipla de dados faltantes: uma simulação utilizando dados epidemiológicos. Cad Saúde Pública, Rio de Janeiro, 2009;25(2):268-278. [citado18 jan 2017]. Disponível em: http://dx.doi.org/10. 1590/SO102-311X2009000200005.

Nunes LN. Métodos de imputação de dados aplicados na área da saúde [dissertação]. Rio Grande do Sul: Universidade Federal do Rio Grande do Sul, Instituto de Epidemiologia; 2011. [citado 01 jan 2018]. Disponível em: http://hdl.handle.net/10183/11422.

Nunes MC, Rocha MO, Ribeiro AL, Colosimo EA, Rezende RA, Carmo GA, et al. Right ventricular dysfunction is an independent predictor of survival in patients with dilated chronic Chagas' cardiomyopathy. Int J Cardiol. 2008 Jul; 127 (3):372-9. doi:10.1016/j.ijcard.2007.06.012.

Nunes MC, Dones W, Morillo CA, Encina JJ, Ribeiro AL; Council on Chagas Disease of the Interamerican Society of Cardiology. Chagas disease: an overview of clinical and epidemiological aspects. J Am Coll Cardiol. 2013 Aug ;62 (9):767-76. doi: 10. 1016/j.jacc.2013.05.046.

Ogava MH. Redes neurais em análise de sobrevivência: uma aplicação na área de relacionamento com clientes [dissertação]. São Paulo: Universidade de São Paulo. Instituto de Matemática e Estatística; 2007. doi:10.11606/ D.45. 2007.tde-26082007225003. 
Ogulata SN, Sahin C, Erol R. Neural network-bases computer-aided diagnosis in classification of primary generalized epilepsy by EEG signals. J Med Syst. 2009 Apr;33(2):107-12. PMID: 19397095.

Okoshi MP, Capalbo RV, Romeiro FG, Okoshi K. Cardiac Cachexia: perspectives for prevention and treatment. Arq Bras Cardiol. 2017 Jan; 108(1):74-80. doi: 10.5935/ abc.20160142.

Oliveira JW, Valência DM, Medeiros PG, Marçula M. Risk-adjusted monitoring of time to event in the presence of long-term survivors. Biom J. 2016 Nov; 58(6):1485-1505. doi:10.1002/ bimj. 201500094.

Ortiz J, Ghefter CGM, Silva CE, Sabbatini RME. One-year mortality prognosis in heart failure: a neural network approach based on echocardiographic data. J Am Coll Cardiol. 1995a Dec;26(7):1586-93. doi:10.1016/0735-1097(95)00385-1.

Ortiz J, Sabbatini RME, Ghefter CGM, Silva CES. Uso de redes neurais artificiais na avaliação da sobrevida na insuficiência cardíaca. Arq Bras Cardiol. 1995b Jan;64(1):87-90. PMID: 7669018.

Packer M, Coats AJ, Fowler MB, Katus H, Mohacsi P, Rouleau JL, et al. Carvedilol prospective randomized cumulative survival study group. N Engl J Med. 2001 May;344(22):1651-8. doi: 10.1056/NEJM200105313442201.

Paes TA. Uso de modelos com fração de cura na análise de dados de sobrevivência com omissão nas covariáveis [tese]. São Paulo: Universidade de São Paulo, Instituto de Matemática e Estatística; 2007. doi:10.11606 / T.45. 2007.tde-22072007-134749.

Palazzuoli A, Lombardi C, Ruocco G, Padeletti M, Nuti R, Metra M, et al. Chronic kidney disease and worsening renal function in acute heart failure: different phenotypes with similar prognostic impact? Eur Heart J Acute Cardiovasc Care. 2016 Dec;5(8):534-548. doi:10.1177/2048872615589511.

Papik K, Molnar B, Schaefer R, Dombovarl Z, Tulassay Z, Feher J. Application of neural networks in medicine - a review. Med Sci Monit. 1998;4(3):538-546. [cited 1997 dec 30]. Available from: http://pdfs.semanticscholar.org/.../2da18cb0287042e27ded932f9.

Pereira Barretto AC , Nobre MRC, Wajngarten M, Canesin MF, Ballas D, Serro-Azul JB. Heart failure in a large tertiary hospital of São Paulo. Arq Bras Cardiol. 1998 Jul;71(1):15-20. doi:10.1590/S0066-782X1998000700004.

Pereira Barretto AC, Nobre MRC, Lancarotte I, Scipioni AR, Ramires JAF. Do cardiologists at a University Hospital adopt the guidelines for the treatment of heart failure? Arq Bras Cardiol. 2001 Jul;77(1):30-60. PMID:11500745. 
Peto $\mathrm{R}$, Peto J. Asymptotically efficient rank invariant test procedures. J $R$ Stat Soc Ser A.1972;135(2):185-207.

Pfeffer MA, Swedberg K, Granger CB, Held P, McMurray JJ, Michelson EL, et al. CHARM Investigators and Committees. Effects of candesartan on mortality and morbidity in patients with chronic heart failure: the CHARM-Overall programme. Lancet. 2003 Sep; 362(9386):759-66. PMID:13678868.

Pimentel $R$, Couto $M$, Laszczyńska $O$, Friões $F$, Bettencourt $P$, Azevedo $A$. Prognostic value of worsening renal function in outpatients with chronic heart failure. Eur J Intern Med. 2014 Sep;25(7):662-8. doi:10.1016/j.ejim.2014.06.002.

Pitt B, Zannad F, Remme WJ, Cody R, Castaigne A, Perez A, et al. The effect of spironolactone on morbidity and mortality in patients with severe heart failure. $N$ Engl J Med. 1999 Sep;341:709-17. doi: 10.1056/NEJM199909023411001.

Pitt B, Remme WJ, Zannad F, Neaton J, Martinez F, Roniker B, et al. Eplerenone, a selective aldosterone blocker, in patients with left ventricular dysfunction after myocardial infarction. $N$ Engl $J$ Med. 2003 May;348:1309-21. doi: 10.1056/NEJMmMoa030207.

Pocock SJ, Wang D, Pfeffer MA, Yusuf S, McMurray JJ, Swedberg KB, et al. Predictors of mortality and morbidity in patients with chronic heart failure. Eur Heart $J$. 2006 Jan;27(1):65-75. doi:10.1093/eurheartj/ehi555.

Ponikowski P, Voors AA, Anker SD, Bueno H, Cleland JGF, Coats AJS, et al. 2016 ESC Guidelines for the diagnosis and treatment of acute and chronic heart failure The Task Force for the diagnosis and treatment of acute and chronic heart failure of the European Society of Cardiology (ESC) Developed with the special contribution of the Heart Failure Association (HFA) of the ESC. Eur J Heart Fail. 2016 Jul;18:891975. doi:10.1002/ejhf.592. [cited 2016 jul 14]. Available from: http://eurheartj. oxford journals.org. doi:10. 1093/ eur heartj /ehw128.

Poole-Wilson PA, Uretsky BF, Thygesen K, Cleland JG, Massie BM, Rydén L; Atlas Study Group. Assessment of treatment with lisinopril and survival. Mode of death in heart failure: findings from the ATLAS trial. Heart. 2003 Jan;89(1):42-8. PMID:12482789.

Rassi AJr, Rassi A, Little WC, Xavier SS, Rassi SG, Rassi AG, et al. Development and validation of a risk score for predicting death in Chagas' heart disease. $N$ Engl $J$ Med. 2006 Aug; 355(8):799-808. doi:10.1056/NEJMoa053241.

Rassi AJr, Rassi A, Rassi SG. Predictors of mortality in chronic Chagas disease: a systematic review of observational studies. Circulation. 2007 Mar; 115(9):1101-8. doi:10.1161/CIRCULATIONAHA.106.627265.

Rassi AJr, Rassi A, Marin-Neto. Chagas disease. Lancet. 2010 Apr;375:1388-402. doi:10.1016/S0140-6736(10)60061-X. 
Rauchhaus M, Clark AL, Doehner W, Davos C, Bolger A, Sharma R, et al. The relationship between cholesterol and survival in patients with chronic heart failure. $J$ Am Coll Cardiol. 2003 Dec;42(11):1933-40. PMID:14662255.

Remme WJ, Swedberg K; Task force for the diagnosis and treatment of chronic heart failure, European Society of Cardiology. Guidelines for the diagnosis and treatment of chronic heart failure. Eur Heart J. 2001 Sep;22(17):1527-60. doi: 10. 1053/ euhj.2001.2783. Erratum in: Eur Heart J 2001;22(23):2217-8.

Rohde LE, Clausell N, Ribeiro JP, Goldraich L, Netto R, William Dec G, et al. Health outcomes in decompensated congestive heart failure: a comparison of tertiary hospitals in Brazil and United States. Int J Cardiol. 2005 Jun;102(1):71-7. doi:10.1016/j.ijcard.2004.04.006.

Roger VL, Weston SA, Redfield MM, Hellermann-Homan JP, Killian J, Yawn BP, et al. Trends in heart failure incidence and survival in a community-based population. JAMA. 2004Jul;292(3):344-50. doi:10.1001/jama.292.3.344.

Roger VL. Epidemiology of heart failure. Circ Res. 2013 Aug;113(6):646-59. doi: 10.1161/CIRCRESAHA.113.300268.

Rossignol P, Ménard J, Fay R, Gustafsson F, Pitt B, Zannad F. Eplerenone survival benefits in heart failure patients post-myocardial infarction are independent from its diuretic and potassium-sparing effects. Insights from an EPHESUS (Eplerenone Post-Acute Myocardial Infarction Heart Failure Efficacy and Survival Study) substudy. J Am Coll Cardiol. 2011 Nov;58(19):1958-66. doi: 10.1016/j.jacc.2011.04.049.

Sacks CA, Jarcho JA, Curfman GD. Paradigm shifts in heart-failure therapy-a timeline. N Engl J Med. 2014 Sep;371(11):989-91. doi: 10.1056/ NEJMp 1410241.

Sanchez ECM. Controle por aprendizado acelerado e neuro-fuzzi de sistemas servohidráulicos de alta frequência [dissertação]. Rio de Janeiro: Pontifícia Universidade Católica do Rio de Janeiro, Engenharia Mecânica; 2009. Certificado Digital no0721406/CA. Disponível em: www2.dbd.puc-rio.br/pergamum/tesesabertas/ 0721406_09_cap_03.pdf.

Santos TM. Avaliação do desempenho de modelos preditivos no contexto de análise de sobrevivência [dissertação]. São Paulo: Universidade de São Paulo. doi: 10.11606/D.45.2013.tde-03092013-111337. [citado 2017 jan 11].Disponível em: http://www.teses.usp.br.

Scott R. Artificial intelligence: its use in medical diagnosis. J Nucl Med . 1993 Mar;34(3):510-4. PMID:8441047.

Senni M, Tribouilloy CM, Rodeheffer RJ, Jacobsen SJ, Evans JM, Bailey KR, et al. Congestive heart failure in the community: trends in incidence and survival in a 10year period. Arch Intern Med. 1999 Jan;159(1):29-34. PMID: 9892327. 
Senni M, Redfield MM. Heart failure with preserved systolic function. A different natural history? J Am Coll Cardiol. 2001 Nov;38(5):1277-82. PMID:11691495.

Senni M, Santilli G, Parrella P, De Maria R, Alari G, Berzuini C, et al. A novel prognostic index to determine the impact of cardiac conditions and co-morbidities on one-year outcome in patients with heart failure. Am J Cardiol. 2006 Oct;98(8):107682. doi:10.1016/ j.amjcard. 2006.05.031.

Shah KS, Xu H, Matsouaka RA, Bhatt DL, Heidenreich PA, Hernandez AF, et al. Heart failure with preserved, borderline, and reduced ejection fraction: 5-year outcomes. J Am Coll Cardiol. 2017Nov;70 (20):2476-2486. doi:10.1016/j.jacc.2017.08.074.

Silva LA, Hernandez EDM, Rangayyan MR. Classification of breast masses using a committee machine of artificial neural networks. J Eletron Imaging. 2008 Jan-Fev;17 (1):1-10. Biblioteca Digital da Produção Intelectual - BDPI, Universidade de São Paulo. [cited 18 mar 2008]. Available from: http://producao. usp.br/handle/BDPI/14703.

Silva CP, Bacal F, Pires PV, Mangini S, Issa VS, Moreira SF, et al. Heart failure profile at the beta blockers. Arq Bras. Cardiol. 2007 Apr;88:475-9. doi:10.1590/S0066 - 782X20070004000 018.

Silverberg DS, Wexler D, Blum M, Keren G, Sheps D, Leibovitch E, et al. The use of subcutaneous erythropoietin and intravenous iron for the treatment of the anemia of severe, resistant congestive heart failure improves cardiac and renal function and functional cardiac class, and markedly reduces hospitalizations. J Am Coll Cardiol. 2000 Jun;35(7):1737-44. PMID:10841219.

Sinha RK, Aggarwal Y, Das BN. Backpropagation artificial neural network detects change in electro-encephalogram power spectra of syncopic patients. J Med Syst. 2007 Feb;31(1):63-8. PubMed PMID:17283923.

Steinberg BA, Fang JC. Long-term outcomes of acute heart failure: Where are we now? J Am Coll Cardiol. 2017 Nov;70(20):2487-2489. doi: 10.1016 /j.jacc. 2017.08.075.

Swedberg K, Cleland J, Dargie H, Drexler H, Follath F, Komajda M, et al. Task Force for the diagnosis and treatment of chronic heart failure of the european society of cardiology. Eur Heart J. 2005 Mai;26(11):1115-40. doi: 10.1093/ eurheartj/ ehi204.

Swedberg K, Komajda M, Böhm M, Borer JS, Ford I, Dubost-Brama A, et al. SHIFT Investigators. Ivabradine and outcomes in chronic heart failure (SHIFT): a randomised placebo-controlled study. Lancet. 2010 Sep;376(9744):875-85. doi: 10.1016/S0140-6736(10)61198-1. Erratum in Lancet. 2010;376(9757):1988. Lajnscak, M [corrected to Lainscak, M]; Rabanedo, I Roldan [corrected to Rabadán, I Roldan]; Leva, M [corrected to leva, M]. 
Tang YD, Katz SD. The prevalence of anemia in chronic heart failure and its impact on the clinical outcomes. Heart Fail Rev. 2008 Dec;13(4):387-92. doi: 10. 1007/s 10741-008-9089-7.

Theodoropoulos TA, Bestetti RB, Otaviano AP, Cordeiro JA, Rodrigues VC, Silva AC. Predictors of all-cause mortality in chronic Chagas' heart disease in the current era of heartfailure therapy. Int J Cardiol. 2008 Aug;128(1):22-9. doi: 10.1016/j.ijcard. 2007.11. 057.

Tourassi GD, Floyd CE, Sostman HD, Coleman RE. Artificial neural network for diagnosis of acute pulmonary embolism: effect of case and observer selection. Radiology. 1995 Mar;194(3):889-93. doi:10.1148/radiology.194.3.7862997.

Uthamalingam S, Patvardhan EA, Subramanian S, Ahmed W, Martin W, Daley M, et al. Utility of the neutrophil to lymphocyte ratio in predicting long- term outcomes in acute decompensated heart failure. Am J Cardiol. 2011 Fev; 107 (3): 433-8. doi:10. 1016/j.amjcard.2010.09.039.

Vardeny $\mathrm{O}$, Wu DH, Desai A, Rossignol P, Zannad F, Pitt B, et al. RALES Investigators. Influence of baseline and worsening renal function on efficacy of spironolactone in patients with severe heart failure: insights from RALES (Randomized Aldactone Evaluation Study). J Am Coll Cardiol. 2012 Nov;60(20):2082-9. doi:10.1016/j.jacc.2012.07.048.

Vasan RS, Larson MG, Leip EP, Evans JC, O'Donnell CJ, Kannel WB, et al. Impact of high-normal blood pressure on the risk of cardiovascular disease. N Engl J Med. 2001 Nov;345(18):1291-7. doi:10.1056/NEJMoa003417.

Veloso LG, de Oliveira MT Jr, Munhoz RT, Morgado PC, Ramires JA, Barretto AC. Nutritional repercussion in advanced heart failure and its value in prognostic assessment. Arq Bras Cardiol. 2005 Jun;84(6):480-5. doi:/S0066-782X2005000 600009 .

Volpato S, Zuliani G, Guralnik JM, Palmieri E, Fellin R. The inverse association between age and cholesterol level among older patients: the role of poor health status. Gerontology. 2001a Jan-Fev;47(1):36-45. doi: 10.1159/000052768.

Volpato S, Leveille SG, Corti MC, Harris TB, Guralnik JM. The value of serum albumin and high-density lipoprotein cholesterol in defining mortality risk in older persons with low serum cholesterol. J Am Geriatr Soc. 2001b Sep;49(9):1142-7. PMID:11559371.

Von Zubben FJ, Attux RRF. Perceptron de múltiplas camadas. IA353-Profs. Fernando J. Von Zuben \& Romis R.F.Attux. DCA/FEEC/Unicamp \& DECOM/ FEEC/Unicamp.Tópico 5. [citado 2001]. Disponível em: ftp://ftp.dca.fee.unicamp.br/pub/docs/vonzuben/ia.353_1s07/topico5_07.pdf. 
Waikar SS, Mount DB, Curhan GC. Mortality after hospitalization with mild, moderate, and severe hyponatremia. Am J Med. 2009 Sep;122(9):857-65. doi: 10.1016/j. amjmed. 2009.01.027.

Ware JH, Harrihgton D, Hunter DJ, D’Agostino Sr. Missing data. N Engl J Med. 2012 Oct;367(14):1353-1354. PIMC: 3771340.

Wilding P, Morgan MA, Grygotis AE, Shoffner MA, Rosato EF. Application of backpropagation neural networks to diagnosis of breast and ovarian cancer. Cancer Lett. 1994 Mar 15;77(2-3):145-53. PMID: 8168061.

WHO Expert Committee on Physical Status : the use and Interpretation of Anthropometry (1993: Geneva, Switzerland) \& World Health Organization. (1995). Physical status: the use of and interpretation of anthropometry, report of a WHO expert committee. Geneva: World Health Organization.[cited 1995]. Available from: http://www. who.int/iris/handle/10665/37003.

World Health Organization (WHO). ICD-10 Version: 2010 - International Classification of Diseases. 10 th revision. [cited 2010]. Available from: http:// apps.who.int/ classifications /icd10/browse/2010/en.

Yuan Y. Prediction performance of survival models. [tese]. Canada: University of Waterloo, Ontario, 2008. [cited 2008].Available from:http://uwspace.uwaterloo.ca/bitstream/100 12/3974/1/thesis.pdf.

Zannad F, Garcia AA, Anker SD, Armstrong PW, Calvo G, Cleland JG, et al. Clinical outcome endpoints in heart failure trials: a European Society of Cardiology Heart Failure Association consensus document. Eur J Heart Fail. 2013 Oct;15(10):1082-94. doi:10.1093/eurjhf/hft095.

Zugck C, Krüger C, Kell R, Körber S, Schellberg D, Kübler W, et al. Risk stratification in middle-aged patients with congestive heart failure:prospective comparison of the Heart Failure Survival Score (HFSS) and a simplified two-variable model. Eur J Heart Fail. 2001 Oct;3(5):577-85. PMID: 11595606. 